\title{
Calibration and Test Services
}

\author{
of the National Bureau of Standards
}

United States Department of Commerce

National Bureau of Standards

Miscellaneous Publication 250 


\section{THE NATIONAL BUREAU OF STANDARDS}

\section{Functions and Activities}

The functions of the National Bureau of Standards include the development and maintenance of the national standards of measurement and the provision of means and methods for making measurements consistent with these standards; the determination of physical constants and properties of materials; the development of methods and instruments for testing materials, devices, and structures; advisory services to government agencies on scientific and technical problems; invention and development of devices to serve special needs of the Government; and the development of standard practices, codes, and specifications, including assistance to industry, business, and consumers in the development and acceptance of commercial standards and simplified trade practice recommendations. The work includes basic and applied research, development, engineering, instrumentation, testing, evaluation, calibration services, and various consultation and information services. Research projects are also performed for other government agencies when the work relates to and supplements the basic program of the Bureau or when the Bureau's unique competence is required. The scope of activities is suggested by the listing of divisions and sections on the inside of the back cover.

\section{Publications}

The results of the Bureau's research are published either in the Bureau's own series of publications or in the journals of professional and scientific societies. The Bureau itself publishes three periodicals available from the Government Printing Office: The Journal of Research, published in four separate sections, presents complete scientific and technical papers; the Technical News Bulletin presents summary and preliminary reports on work in progress; and Central Radio Propagation Laboratory Ionospheric Predictions provides data for determining the best frequencies to use for radio communications throughout the world. There are also seven series of nonperiodical publications: Monographs, Applied Mathematics Series, Handbooks, Miscellaneous Publications, Technical Notes, Commercial Standards, and Simplified Practice Recommendations.

A complete listing of the Bureau's publications can be found in National Bureau of Standards Circular 460, Publications of the National Bureau of Standards, 1901 to June 1947 (\$1.25), and the Supplement to National Bureau of Standards Circular 460, July 1947 to June 1957 (\$1.50), and Miscellaneous Publication 240, July 1957 to June 1960 (includes Titles of Papers Published in Outside Journals 1950 to 1959) (\$2.25); available from the Superintendent of Documents, Government Printing Office, Washington, D.C., 20402. 
UNITED STATES DEPARTMENT OF COMMERCE • Luther H. Hodges, Secretary NATIONAL BUREAU OF STANDARDS • A. V. Astin, Director

\title{
Calibration and Test Services of the National Bureau of Standards
}

\author{
[Reprinted from the Federal Register \\ July 26, 1963-Vol. 28, No. 145, Part II, \\ and November 7, 1963-Vol. 28, No. 218.]
}

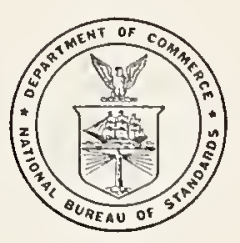

National Bureau of Standards Miscellaneous Publication 250 
Library of Congress Catalog Card Number: 63-60099 


\section{Contents}

Introduction

Part 200-Policy and general information concerning calibrations and tests

Part 201-Electricity

Resistance measurements

201.101 Precision standard resistors

201.102 Precision resistance apparatus

201.103 Multi-megohm resistors_-_-_._._._._._.

Inductance and capacitance measurements

201.104 Standard inductors

201.105 Standard capacitors

Electrochemistry

201.201 Standard cells

Electrical instruments

201.301 Standard resistors for current measurements_._._._._._._._. 12

201.302 Volt boxes (fixed ratio voltage dividers) 13

201.303 A-c-d-c instruments and thermal converters____._._. 15

201.304 A-c-d-c wattmeters, single phase

201.305 Watthour meters

201.306 Current transformers

201.307 Current transformer comparators (testing sets)

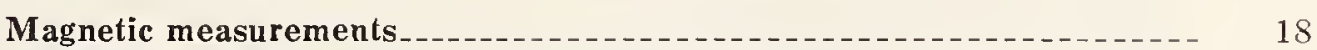

201.401 General magnetic measurements; normal induction and hys-

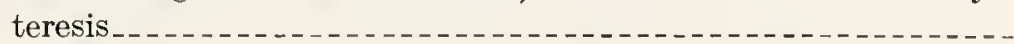

201.402 Magnetic materials; alternating-current permeability and core

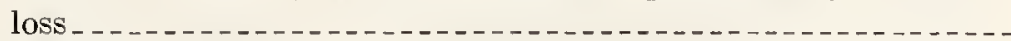

201.403 Magnetic testing apparatus; mutual inductors, search coils, and

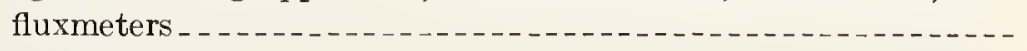

Dielectric measurements

201.500 Dielectric constant, power factor

Voltage ratio and high-voltage measurements_._. 20

201.601 Voltage dividers

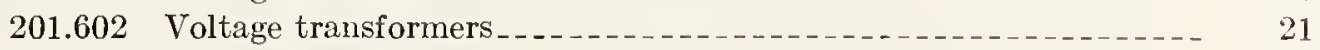

201.603 Voltage transformer comparators

201.604 Kilovoltmeters $\ldots \ldots \ldots$

High-frequency region.-.

201.810 Rf, rf-d-c voltmeters, and thermal converters in the frequency range of $30 \mathrm{kc} / \mathrm{s}$ to $1000 \mathrm{Mc} / \mathrm{s}$; from 0.2 to $300 \mathrm{v}$

201.811 Rf voltmeters and signal cources in the frequency range of $30 \mathrm{kc} / \mathrm{s}$ to $1000 \mathrm{Mc} / \mathrm{s}$; from $1 \mu \mathrm{v}$ to $0.1 \mathrm{v}$

201.820 Rf calorimeters, $30 \mathrm{kc} / \mathrm{s}$ to $400 \mathrm{Mc} / \mathrm{s}$

201.830 Immittance, $30 \mathrm{kc} / \mathrm{s}$ to $1 \mathrm{Gc} / \mathrm{s}$

201.840 Dissipative fixed coaxial attenuators

201.841 Dissipative variable coaxial attenuators

201.842 Waveguide below cutoff (piston) attenuators

201.843 Coaxial fixed directional couplers

201.844 Coaxial variable directional couplers

201.850 Field strength measurements, $30 \mathrm{c} / \mathrm{s}$ to $1000 \mathrm{Mc} / \mathrm{s} \ldots$

Microwave region

201.910 Continuous, low-level power messurement of waveguide bolometer units and bolometer-coupler units

201.911 Continuous low-level power measurement of waveguide dry calorimeters 
Part 201-Electricity-Continued

Microwave region-Continued

201.920 Reflection coefficient magnitude measurement on waveguide reflectors (mismatches)

201.930 Frequency measurement on cavity wavemeters___________._. 34

201.940 Attenuation difference measurements on variable attenuators____ 34

201.941 Insertion loss measurements on fixed attenuators _-_.__________ 36

201.950 Effective noise temperature measurements on noise sourees_._._. 36

Part 202-Metrology

Photometry and colorimetry

202.181 Lamp standards of candlepower. 38

202.182 Photometrie instruments and aceessories_._._._._._._._._._._. 40

202.183 Miseellaneous photometric measurements and tests____________ 40

202.184 Rating of incandescent eleetrie lamps___________________ 41

202.185 Spectrophotometrie standards__._._._._._._._. 41

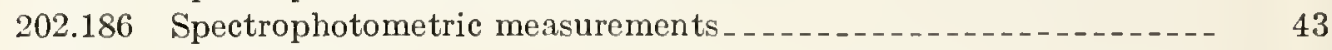

202.187 Colorimetry____._._._.

202.188 Reflectometry

202.189 Opaeimetry _._....... 46

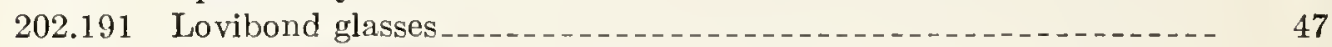

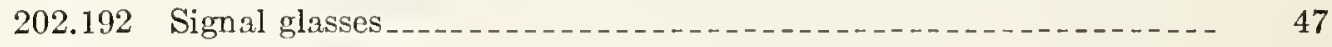

202.193 Haze standards__._._._._._._.

202.194 Radiometry _._.

Refractometry

202.201 Optical instruments___._.

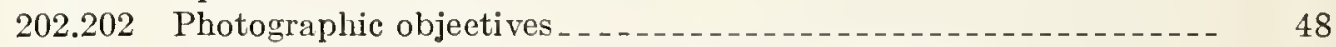

202.203 Optical components, speetaele lenses, goggle lenses, ete_____._. 51

202.204 Refraetometrie instruments _..._.

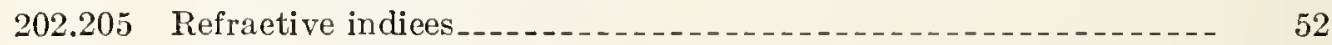

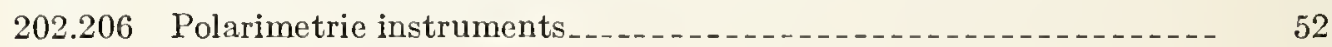

Photographic research

202.311 Photography (step table density, residual thiosulfate concentration, etc.)

Length.

202.401 Referenee line standards of length

202.402 Working line standards of length

202.403 Commercial line standards of length

202.404 Steel tapes_._._._._.

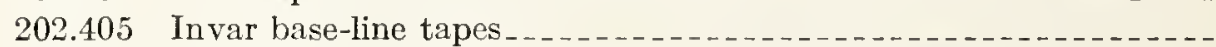

202.406 Surveyors' measuring instruments (other than tapes)

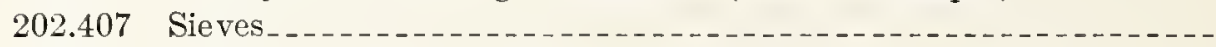

202.408 Haemaeytometers

202.409 Areas and area-measuring instruments_._._._._._._..........

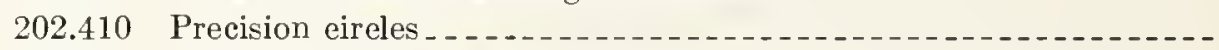

202.411 Linear thermal expansion of solids

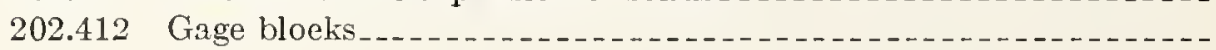

Engineering metrology

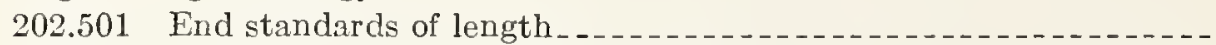

202.502 Plain eylindrieal plug and ring gages _........................

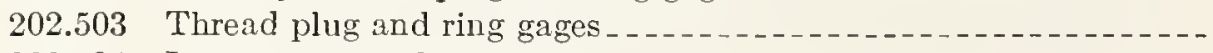

202.504 Instruments and eomponents

202.505 Optical reference planes

Angle blocks

Polygons _.

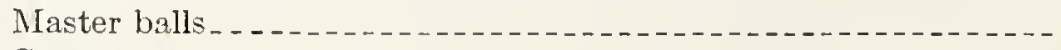


Part 202-Metrology-Continued Pago

Mass and volume

202.611 Reference standards of mass

202.612 Large mass standards .

202.613 Calibration of mass elements of pressure gage testing apparatus _- $\quad 72$

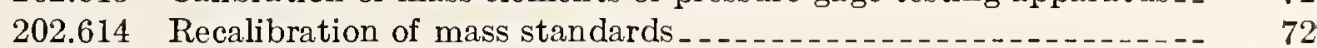

202.615 Glass volumetric apparatus

202.616 Metal volumetric apparatus

202.617 Hydrometers._._._._._._.

202.618 Density determination of solids and liquids _............... 76

Part 203-Heat

Temperature physics

203.101 Laboratory thermometers

203.102 Thermocouples, thermocouple materials, and pyrometer indica-

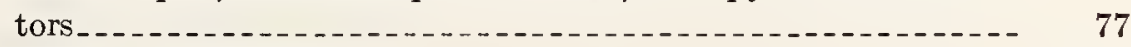

203.103 Resistance thermometers

203.104 Clinical thermometers

203.105 Optical pyrometers and ribbon filament lamps_..._._._. 80

Part 204-Radiation physics

Radioactivity

204.201 Calibration of gamma-emitting radioactive samples_._-_._-_._- 81

204.202 Calibration of alpha-emission rate of sources_._-_._-_._-_._. 82

204.203 Calibration of beta-emitting radioactive samples............ 82

Radiological equipment-gamma-ray sources _.

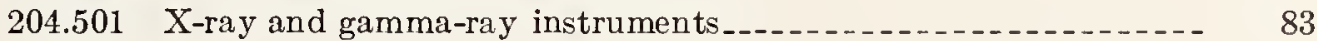

204.502 Gamma-ray sources......... 85

Neutron physics

204.701 Neutron sources

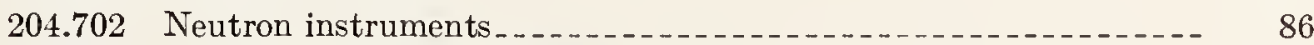

204.703 Neutron irradiation of foils

Part 205-Analytical and inorganic chemistry

Pure substances.

205.101 Measurement of physical properties of primary reference fuels used for octane number determination _................. 87

Part 206-Mechanics

Vibration

206.001 Vibration pickups_._. 87

Sound

206.101 Acoustic measurements_._. 89

Pressure and vacuum

206.201 Pressure measurements

Fluid mechanics._._.

206.301 Aerod ynamical measurements _._._._._._._._._._._._. 91

206.302 Fluid meters, including gas-measuring instruments_____._._._. 91

Engineering mechanics

206.401 Hardness tests..._.

206.402 Calibration of load cells with remote reading electrical indicators - $\quad 92$

206.403 Special mechanical tests of devices, materials, and structures.... 93

206.404 Calibration of proving rings_._._._._._._. 94

206.405 Calibration of elastic force-measuring devices_._._._. 
Electrodeposition

208.601 Standard thickness samples of electroplated coatings

Part 210 -Building research

Fire resistance

210.201 Fire resistance tests of building components____._.

Thermal conductivity _._.

210.601 Thermal conductivity

Part 215-Physical chemistry

Organic chemistry

215.301 Synthesis of $\mathrm{C}^{14}$ labeled sugars and related products_._._._. $\ldots . .998$

215.302 Synthesis of tritium-labeled carbohydrates_._._._._._._._._. 98

Index

Publications and order form 


\section{Calibration and Test Services of the National Bureau of Standards}

\section{Introduction}

To promote accuracy and uniformity in physical measurements, the National Bureau of Standards provides calibration and testing services for a wide variety of standards and instruments. These services, together with the fees for their perfomance, are listed in the following sections of this publication. However, calibration and testing are but one aspect of NBS service to science and industry; a brief résumé of some of the other services is presented below:

Standard Materials. NBS prepares and sells nearly 600 different standard materials whose chemical composition or physical properties have carefully been determined. These materials are used for standardizing solutions in volumetric analysis, for checking methods of analysis and evaluating their accuracy, and for calibrating spectrometers, calorimeters, $p \mathrm{H}$ meters, and other instruments. Among the standard materials offered by the Bureau are steels of certified composition, metals of known freezing temperature for use in thermometry, color standards, and radionuclides of known emission rate. A complete listing of the standard materials is available in NBS Misc. Publ. 241, available from the Superintendent of Documents, U.S. Government Printing Office, Washington, D.C., 20402, for 30 cents.

Standard Radio Broadcast Services. The Bureau broadcasts standard time and frequency signals from radio stations WWV (Beltsville, Md.) and WWVH (Maui, Hawaii). These broadcasts, made on $2.5,5,10,15,20$, and $25 \mathrm{Mc} / \mathrm{s}$ from $\mathrm{WWV}$, and 5,10 , and $15 \mathrm{Mc} / \mathrm{s}$ from WWVH, provide standard radio and audio frequencies, time signals and standard time intervals, standard musical pitch, radio propagation forecasts, and alerts concerning outstanding geophysical events. To improve the accuracy of long-distance coverage, low-frequency stations WWVL $(20 \mathrm{kc} / \mathrm{s})$ and WWVB $(60 \mathrm{kc} / \mathrm{s})$ have been established in Colorado. Single copies of NBS Misc. Publ. 236, Standard frequencies and time signals from NBS stations WWV and WWVH, which describes these radio broadcasts, can be obtained by writing to the Office of Technical Information, NBS, Washington, D.C., 20234.

Noте: If you wish to be placed on a mailing list to receive periodic listings of changes in fee schedules, please fill out and mail the post card inserted after p. 103.

The sections that follow are reprinted from the Federal Register of July 26, 1963, and amended November 7, 1963. As services are initiated or discontinued, or fees are changed, further announcements will appear in the Federal Register, and major changes will be noted in the Standards and Calibration column of the NBS Technical News Bulletin. 


\section{Code of Federal Regulations}

\section{Title 15-Commerce and Foreign Trade}

(Reprinted from the "Federal Register" July 26, 1963-Vol. 28, No. 145, Part II, and November 7, 1963-Vol. 28, No. 218.)

\section{Part 200-General ${ }^{1}$}

\subsection{Tests ${ }^{2}$ performed by the National Bureau of Standards.}

a. Statutory functions: The National Bureau of Standards has been assigned the following functions (15 U.S.C. 271-282):

(1) The custody, maintenance, and development of the national standards of measurement together with the provision of calibration services related to these standards.

(2) The determination of physical constants and properties of materials.

(3) The development of methods for testing materials, mechanisms, and structures and the testing of materials, supplies, and equipment.

(4) Cooperation in the establishment of standard practices, incorporated in codes and specifications.

(5) Advisory services to government agencies on scientific and technical problems.

(6) Invention and development of devices to serve special needs of the government.

The testing activities stem from the functions in subparagraphs (1), (3), and (4) of this paragrapl. This schedule of fees lists the services that are available to the public.

b. Testing policy: (1) The Bureau's principal emphasis is on those calibrations and other tests requiring such accuracy as can be obtained only by direct comparison with NBS standards. The public is urged to obtain secondary standardization services from qualified sources other than the Bureau. Except in unusual circumstances, calibrations and other tests are performed for the users of the equipment rather than for suppliers. Tests that the Bureau undertakes are restricted to the following:

(i) Tests involving comparison of standards or instruments with NBS standards.

(ii) Tests of devices or materials to determine compliance with specifications or claims, only if the device or material is critical in national scientific or technical operations, and if suitable testing facilities are not available elsewhere.

(iii) Referee tests, to which paragraph (i) above does not apply, where private laboratories are unable to agree on the method of measurement, the results of tests, or the interpretation of these results, provided that the importance of the case justifies the test and that all parties agree in advance in writing to accept and abide by the findings of the Bureau.

(iv) Cooperative tests with national or international standardizing organizations to develop standards or specifications of mutual interest.

(2) Tests of the following types are not made for private organizations or individuals:

(i) Tests of devices and materials regularly performed by commercial laboratories. (A Directory of Testing Laboratories, Commercial and Institutional, is available from the American Society for Testing and Materials, 1916 Race Street, Philadelphia, Pa. 19103)

(ii) Tests of secret processes, or of inadequately described materials, devices, or processes.

(iii) Tests whose objective is public relations, advertising, or sales promotion.

(3) Requests for calibration of any equipment may be declined if, in the Bureau's opinion the equipment is not suitable for use as a plant or laboratory standard. The Bureau reserves the right to decline any request for testing, temporarily or permanently, if the tests would interfere with other activities deemed by the Director to be of greater importance.

1 Chapter I1-National Bureau of Standards, Department of Commerce, Subchapter A-Test Fee Schedules.

Pursuant to authority contained in 15 U.S.C. 275 a the following rerision, effective upon publication in the Federal Register, supersedes in its entirety Subchapter A, Chapter I1, Title 15 of the Code of Federal Regulations previously issued.

Authority: $\$ \$ 200.1$ and 200.2 issued under sec. 9,31 Stat. 1450, as amended; 15 U.S.C. 277 . Interpret or apply sec. 7 , 70 Stat. 959 ; 15 U.S.C. $275 \mathrm{a}$. "Tests" as used herein includes calibrations. 
c. Request for tests: (1) Except for specific tests listed in the fee schedule a preliminary letter, stating clearly the tests desired, should be sent to the National Bureau of Standards, Washington, D.C., 20234, or to the National Bureau of Standards, Boulder, Colo., 80310, as appropriate, prior to any shipment, to determine if and when and at which laboratory the Bureau can undertake the test. In general, the purpose of the test and the manner in which the results are to be used should be stated. A formal purchase order for the test should be sent prior to or at the time of shipment.

(2) A test number will be assigned by the Bureau to each item or group of items accepted, and this test number should be referred to in all subsequent communications. If the apparatus submitted has been previously calibrated by the Bureau, reference should be made in the letter or order to this test number.

(3) Acceptance of such orders does not imply acceptance of any provisions set forth in the purchase order contrary to the policy, practice, or regulations of the National Bureau of Standards or the U.S. Government. (A statement to the effect that the National Bureau of Standards is an agency of the U.S. Government should satisfy other Government agencies with regard to compliance with Government regulations and executive orders.)

d. Packing, shipping, and insurance: (1) Equipment sent to the Bureau must be properly packed by the applicant to minimize likelihood of damage in shipment and handling. Suggestions on packing and shipping are made in some sections of the fee schedule. In every case, the applicant should consider the nature of the equipment, pack it accordingly, and clearly label shipments containing fragile instruments or materials, glass, etc. The use of "security express" should be considered in shipping delicate instruments.

(2) Shipping charges both to and from the Bureau must be assumed by the applicant. It is generally impractical for the Bureau to prepay shipping charges and add this cost to the billing invoice. Return shipments are made by the Bureau in accordance with its judgment of the best method of shipping unless specific instructions are received. Such instructions should be clearly shown on the purchase order for the test. The Bureau cannot guarantee that instructions printed obscurely on the order will be followed. Parcel post shipments generally will be returned prepaid by the Bureau.

(3) When a test number has been assigned prior to shipment to the Bureau this number should be clearly marked on the shipping container. When a test number has not been assigned, an invoice, copy of the purchase order, or letter should be enclosed in the shipment to insure proper identification. The original purchase order should be forwarded to the Bureau.

(4) The risk of loss or damage, either in shipment or in testing, must be assumed by the applicant. Any arrangements for insurance covering such risk must be made by the applicant, except that the Bureau will, in other than parcel post shipments, request the carrier to provide insurance coverage for a specified amount for return shipment if this is specified by the applicant on the face of the purchasc order. If transit insurance is carried by the applicant this should be stated on the face of the purchase order, and in any case the purchase order should show the value of the equipment.

e. Identification: The data reported in the Bureau's tests pertain only to the individual item or piece of apparatus tested. It is therefore essential that this piece be identified uniquely by an appropriate number or symbol. In most cases, the manufacturer's name and serial numbers are used When such a number is lacking, the applicant should provide an alternative identifying mark. If none is found, the Bureau may apply an appropriate one, usually the Bureau's test number, for which an additional charge may be made.

f. Condition of apparatus: All apparatus submitted for test must be in good operating condition. Repairs and adjustments should be attended to by the applicant prior to shipment. Apparatus not in good condition cannot be tested, nor can the Bureau undertake the repair or adjustment of any equipment, except by special arrangement. If it is evident that equipment has been abused or has not received proper care, a test ordinarily will not be conducted. If 
defects are found at the Bureau after a test has begun, this fact will be reported, the test may be terminated and a report issued summarizing such information as has been found, and a fec charged in accordance with the amount of work done.

g. Priority and time of test: (1) In general, tests are undertaken in the order in which the requests are received, provided that the proper arrangements have been made and the information necessary for test performance has been received by the time the test is scheduled to start. When it is desired that apparatus be out of normal service for a minimum time, arrangements may in some cases be made in advance for the setting of a specific date for the test; in such cases shipment can then be made in accordance with this date.

(2) The time for the completion of tests depends on a number of factors. Some tests require considerable time in themselves, as is indicated in the fee schedules. The condition of submitted equipment, the test load in the Bureau's laboratories, and emergency work for the Government are other factors that enter into consideration. Time estimates made by the Bureau are therefore tentative.

h. Witnessing of tests: The Bureau welcomes scientists and engineers who may wish to visit its laboratories and discuss test methods. However, visitors ordinarily will not be permittcd to witness the actual carrying out of highly precise measurements because their presence introduces distraction that may lead to errors or delays. This policy may be waired in those cases where the visitor can be of service in setting up apparatus of a new or unusual nature, in the case of referee tests, or in other cases in which the legal validity of the result may require the presence of duly authorized witncsses.

i. Report of test: Results of calibrations and other tests are issued as reports entitled "National Bureau of Standards Report of Calibration" or "National Bureau of Standards Report of Test," as appropriate. The report form used carries no special significance. Whenever formal certification is required by law, or to meet special conditions adjudged by the National Bureau of Standards to warrant it, a letter will be provided certifying that the particular item was received and calibrated or tested, and identifying the Report containing the results.

j. Use of test results: (1) The results of tests are pertinent only to the particular device or specimen tested and their application to other items of the same lot or type may not be warranted and therefore is not authorized by the National Bureau of Standards. However, the Bureau may declare that an entire lot of nominally identical items does or does not meet stated requirements for acceptance on the basis of tests on a sample of instruments or objects drawn from the lot in accordance with an approved sampling procedure.

(2) The National Bureau of Standards does not "approve," "recommend," or "endorse" any proprietary product or material as a class or group, and results reported by the Bureau shall not be used in advertising or sales promotion, or to indicate either explicitly or implicitly endorsement of the product or material by the National Bureau of Standards.

k. Fees: (1) In accordance with 15 U.S.C. 271-282, fees are charged for all tests made for the public.

(2) This fee schedule is published subject to the above-mentioned basic act which authorizes the Secretary of Commerce, from time to time, to make regulations regarding the payment of fees, the limits of tolerance to be obtained in standards submitted for verification, and related matters.

1. Billing charges: 'The minimum billing charge for' any test request accepted by the Bureau is $\$ 5.00$, unless otherwise indicated in a particular fee schedule. If apparatus is returned without testing a minimum charge of $\$ 5.00$ may be made to cover handling. Fees for tests include the cost of preparation of an original report. Copies of reports ordinarily are not issued to other than the recipient of the original, and are not issued unless the applicant has shown a 
technical need for them. Copies of reports requested subsequent to the date of tests will be supplied at a cost of $\$ 1.00$ each. All checks should be made payable to NBS, Department of Commerce.

200.2 Location of Laboratories. The calibrations listed in Parts 201 (low-frequency), $202,203,204,205,206,208,210$, and 215 of this subchapter are performed in the laboratories of the National Bureau of Standards at Washington, D.C., 20234. Many of the calibrations listed in Part 201 can also be performed at the NBS Boulder Laboratories, although in some cases only over limited ranges. Calibrations listed in Part 201 (high-frequency) are performed by the Radio Standards Laboratory of the National Bureau of Standards at Boulder, Colo., 80310. In general, electrical calibrations at frequencies higher than $30 \mathrm{kc} / \mathrm{s}$ are made at Boulder and those at lower frequencies are made either at Washington or at Boulder. Inquiries concerning calibrations (giving full details of ranges, frequencies, burdens, etc.) and shipment of apparatus should be directed in accordance with the foregoing. If apparatus is to be calibrated at both high and low frequencies, arrangements should be initiated with the Boulder Laboratories. The cost of shipping the apparatus between laboratories will be billed to the applicant.

\section{Part 201-Electricity}

The calibration service covered by this part includes the determinations of the corrections for standard electrical and electronic measuring apparatus and their range-extending auxiliaries used at power and audio frcquencies (up to $30 \mathrm{kc} / \mathrm{s}$ ), high frequencies $(30 \mathrm{kc} / \mathrm{s}$ to 300 $\mathrm{Mc} / \mathrm{s}$ ), and microwave frequencies (above $300 \mathrm{Mc} / \mathrm{s}$ ).

The Bureau does not test, except occasionally for other agencies of the Federal Government, electrical devices or supplies not directly related to the field of measurement. Tests of power transformers, motors, gencrators, relays, wiring, appliances, etc., should not be requested.

\section{Resistance Measurements}

Precision Wire-Wound Resistance Standards and Apparatus

Sec.

201.100 General

201.101 Precision standard resistors

201.102 Precision resistance apparatus

\section{Resistance Standards Other Than Wire-Wound}

201.103 Multi-megohm resistors

\section{Inductance and Capacitance Measurements}

201.104 Standard inductors

201.105 Standard capacitors; tests with alternating current

Electrochemistry

201.201 Standard cells

\section{Electrical Instruments}

201.300 General

201.301 Standard resistors for current measurements

201.302 Volt boxes (fixed-ratio voltage dividers)

201.303 A-c-d-c instruments and thermal converters

201.304 A-c-d-c wattmeters, single phase

201.305 Watthour meters 
201.307 Current transformer comparators (testing sets)

201.400 General

\section{Magnetic Mcasurements}

201.401 General magnetic measurements; normal induction and hysteresis

201.402 Magnetic materials; alternating-current permeability and core loss

201.403 Magnetic testing apparatus; mutual inductors, search coils, and fluxmeters

201.500 Dielectric constant, dissipation factor

Diclectric Measurements

201.601 Voltage dividers

Voltage Ratio and High-Voltage Mcasurements

201.602 Voltage transformers

201.603 Voltage transformer comparators

201.604 Kilovoltmeters

201.800 General

\section{High-Frequency Region}

$201.810 \mathrm{Rf}, \mathrm{r} f-\mathrm{d}-\mathrm{c}$ voltmeters, and thermal converters in the frequency range of $30 \mathrm{kc} / \mathrm{s}$ to $1000 \mathrm{Mc} / \mathrm{s}$; from 0.2 to $300 \mathrm{v}$

$201.811 \mathrm{Rf}$ voltmeters and signal sources in the frequency range of $30 \mathrm{kc} / \mathrm{s}$ to $1000 \mathrm{Mc} / \mathrm{s}$; from $1 \mu v$ to $0.1 \mathrm{v}$

$201.820 \mathrm{Rf}$ calorimeters, $30 \mathrm{kc} / \mathrm{s}$ to $400 \mathrm{Mc} / \mathrm{s}$

201.830 Immittance, $30 \mathrm{kc} / \mathrm{s}$ to $1 \mathrm{Gc} / \mathrm{s}$

201.840 Dissipative fixed coaxial attenuators

201.841 Dissipative variable coaxial attenuators

201.842 Waveguide below-cutoff (piston) attenuators

201.843 Coaxial fixed directional couplers

201.844 Coaxial variable directional couplers

201.850 Ficld strength measurements, $30 \mathrm{c} / \mathrm{s}$ to $1000 \mathrm{Mc} / \mathrm{s}$

201.900 Gencral

\section{Microwave Region}

201.910 Continuous, low-level power measurement of waveguide bolometer units and bolometer-coupler units

201.911 Continuous low-level power measurement of waveguide dry calorimeters

201.920 Reflection coefficient magnitude measurement on waveguide reflectors (mismatches)

201.930 Frequency measurement on cavity wavemeters

201.940 Attenuation difference measurements on variable attenuators

201.941 Insertion loss measurcments on fixed attenuators

201.950 Effective noise temperature measurements on noise sources

\section{Resistance Measurements \\ Involving Precision Wire-Wound Resistors}

201.100 General. In general, 201.101 and 201.102 apply only to apparatus embodying the following essential features:

(a) The resistance material should have a low temperature coefficient, should not change its resistance appreciably with time, and for low-valued coils should have a small thermoelectric power against copper.

(b) All wire standard resistors and the more important section of resistance apparatus for use in d-c circuits should be wound on metal or ceramic supports, preferably in a single layer. Electrical connections to the resistance material should be brazed in all cases in which the total resistance is less than $1,000 \mathrm{ohms}$. The resistance material should be protected against oxidation and other chemical action and should be annealed or aged by baking after winding.

(c) Precision standard resistors should be so adjusted as to give an accuracy of at least 
0.02 percent without corrections. Precision resistance apparatus should be adjusted within 0.05 percent of nominal value.

(d) Because comparatively rapid changes in resistance take place in new apparatus, it is not advisable to calibrate new or repaired apparatus until at least two months after the resistors have been annealed and adjusted. Precision apparatus known to be new will be held in the laboratory (in the absence of other instructions) for at least a month, when the measurements will be repeated to determine the drift in value, if any. No extra charge is made for these later measurements. Occasionally during the course of calibration it is discovered that the standard or instrument under observation is defective and in need of repair. In such instances the item in question will be rejected and a fee equal to the published fee, in whole or in part, will be assessed commensurate with the effort expended before the calibration was halted.

(e) Unless otherwise stated, the tests listed are generally made using a direct current of such magnitude as to cause only a negligible heating of the resistance material. Calibrations of standard resistors, bridges, and decade resistors consist of determinations of the resistance of the standards or of the resistance of the elements of the bridges or similar apparatus from which values corresponding to all possible readings can be computed. Measurements of potentiometers consist of determinations from which the ratios of the resistances corresponding to all possible readings can be computed. Precision standard resistors are ordinarily measured at a temperature of $25^{\circ} \mathrm{C}$, while resistance apparatus is measured at room temperatures, usually from 22 to $25^{\circ} \mathrm{C}$.

(f) The Bureau does not calibrate portable self-contained test equipment having relatively low accuracy such as portable potentiometers, resistance test sets, and double-bridge ohmmeters. The accuracy of these devices is such that a complete detailed determination of corrections is not economically feasible. Apparatus of this type may be spot-checked by measuring known voltages or resistances with them. Adequate calibration services of this type can be obtained from a number of commercial testing laboratories.

201.101 Precision standard resistors. Standards of $10 \mathrm{ohms}$ and less of the precision type provided with amalgamated current terminals and designed for oil immersion must be of the four-terminal type, that is, must have both current and potential terminals. The resistance of standards having nominal values in the range $0.0001 \mathrm{ohm}$ to $100,000 \mathrm{ohms}$ will usually be given to the nearest 0.0001 percent in terms of the calibrating unit (the legal unit) maintained by the Bureau with a group of 1-ohm standard resistors. Each report of calibration will state the accuracy of the reported value at the time of calibration. This accuracy will vary from 0.0001 percent for 'Thomas-type 1-ohm standards to 0.002 percent for resistors of nominal value $0.001 \mathrm{ohm}$. Additional information regarding standard resistors may be found on the back of the report of calibration.

\begin{tabular}{|c|c|}
\hline Item & Description \\
\hline $201.101 a$ & $\begin{array}{l}\text { Determination of resistance in oil bath at } 25{ }^{\circ} \mathrm{C} \text {. For all standards } \\
\text { having resistances in the range } 0.0001 \text { to } 100,000 \mathrm{ohms} \text {, inclusive, } \\
\text { provided they are adjusted within } 0.05 \text { percent of a nominal value } \\
\text { which is itself a decimal multiple (or submultiple) of } 1 \mathrm{ohm}\end{array}$ \\
\hline $201.101 b$ & $\begin{array}{l}\text { Determination of resistance in oil bath at } 25{ }^{\circ} \mathrm{C} \text {. For odd-valued } \\
\text { standards not falling within the scope of item } 201.101 \mathrm{a}\end{array}$ \\
\hline $201.101 \mathrm{c}$ & $\begin{array}{l}\text { Measurement of resistance in oil bath at } 20,25 \text {, and } 30{ }^{\circ} \mathrm{C} \text {, and de- } \\
\text { termination of temperature coefficient. Such measurements are } \\
\text { made only when it is shown that the small changes in resistance re- } \\
\text { sulting from necessary variations of the temperature from } 25^{\circ} \mathrm{C} \text { are } \\
\text { of importance }\end{array}$ \\
\hline
\end{tabular}

Fee 


\begin{tabular}{c|c|c}
\hline Item & Description & Fee \\
\hline $201.101 \mathrm{z}$ & $\begin{array}{c}\text { For special calibrations not covered by the above schedule, advance } \\
\text { arrangement must be made. Fees will be charged dependent on the } \\
\text { time involved in maling a calibration. }\end{array}$ & \\
\hline
\end{tabular}

201.102 Precision resistance apparatus. Corrections pertinent to apparatus of suitable quality submitted under this section will ordinarily be reported to a number of significant figures so chosen that normal variation of ambient conditions within the stated bounds of test conditions will not affect the corrections by more than a few units in the last place reported. Calibrations will be made at room temperature, usually 22 to $25^{\circ} \mathrm{C}$.

\begin{tabular}{c|c|}
\hline Item & Description \\
\hline
\end{tabular}

Fee

201.102a Precision decade and plug boxes. For decades not exceeding 10,000 ohms per step.

(1) First point in each box

(2) Each additional point in same resistance box

$\$ 15.00$

5.00

$201.102 b$

Megohm box, 10 sections each 100,000 ohms

145. 00

$201.102 \mathrm{c}$

201.102d-1

Wire-wound 0.1 - to $100-$ megohm boxes with 10 equal sectionscalibration with all sections in parallel

47.00

Precision Wheatstone bridges

201.102d-2

Calorimetric bridges of all kinds

$201.102 \mathrm{e}$

$201.102 f$

$201.102 \mathrm{~g}$

$201.102 \mathrm{~h}$

201.102i-1

Potentiometers, minimum steps $10 \mu \mathrm{v}$ or more

385.00

520. 00

220.00

Potentiometers, minimum steps less than $10 \mu \mathrm{v}$

410.00

Kelvin bridge ratio box

160. 00

Double ratio set for Kelvin bridge, with double set of fixed and variable arms

465. 00

Four-dial precision resistive voltage divider

260. 00

$201.102 \mathrm{i}-2$

Five-dial precision resistive voltage divider

$201.102 \mathrm{i}-3$

Six-dial precision resistive voltage divider or univer'sal ratio set_-

320.00

350. 00

$201.102 \mathrm{z}$

For special tests not covered by the above schedule, advance arrangements must be made. Fees will be charged dependent on the time involved in making the tests. 


\section{Resistance Standards Other Than Wire-Wound}

201.103 Multi-megohm resistance standards-except wire-wound. Measurements made on resistors submitted under this section are accurate to 0.1 percent at the time of test if nominal values are in the range $10^{6}$ to $10^{12} \mathrm{ohms}$; for higher-valued resistors the accuracy is 0.5 percent. In order that the reported results be of significance it is necessary that standards submitted for tests be made of suitable materials processed in such a manner that resistance values do not change rapidly with time. They should be so constructed and treated that the effect of relative humidity is minimized. The resistance of these standards usually depends on the magnitude of the applied voltage; the test voltage should therefore be specified. Each resistor should have an identifying number engraved on or permanently attached to it.

\begin{tabular}{|c|c|c|}
\hline Item & Description & Fee \\
\hline $201.103 a$ & $\begin{array}{l}\text { Determination of resistance of a resistor at one voltage (1.5 to } 250 \mathrm{v}) \\
\text { at room temperature }\left(23{ }^{\circ} \mathrm{C}\right) \text { and humidity (50\% rh or less) when } \\
\text { the resistor has a nominal value between } 10^{6} \text { and } 10^{10} \text { ohms }\end{array}$ & $\$ 25.00$ \\
\hline $201.103 b$ & $\begin{array}{l}\text { Determination of resistance of a resistor at one voltage }(1.5 \text { to } 250 \mathrm{v}) \\
\text { at standard laboratory temperature }\left(23^{\circ} \mathrm{C}\right) \text { and humidity }(50 \% \mathrm{rh} \\
\text { or less) when the resistance is higher than } 10^{10} \mathrm{ohms} \text { but the current } \\
\text { involved is not less than } 10^{-12} \text { amp. }\end{array}$ & 40.00 \\
\hline $201.103 \mathrm{c}$ & $\begin{array}{l}\text { Determination of resistance of a resistor at each voltage }(1.5 \text { to } 250 \mathrm{v}) \\
\text { at standard laboratory temperature }\left(23^{\circ} \mathrm{C}\right) \text { and humidity }(50 \% \mathrm{rh} \\
\text { or less) when the current involved is less than } 10^{-12} \text { amp but not less } \\
\text { than } 10^{-13} \text { amp. }\end{array}$ & 50.00 \\
\hline $201.103 z$ & $\begin{array}{l}\text { For special tests not covered by the above schedule, advance arrange- } \\
\text { ments must be made. Fees will be charged dependent on the time } \\
\text { involved in making the tests. }\end{array}$ & \\
\hline
\end{tabular}

\section{Inductance and Capacitance Measurements}

NoтE: Tests at radiofrequencies are performed at the NBS Boulder Laboratories, Boulder, Colo., 80310.

\subsection{Standard inductors.}

(a) Inductors for use in a-c bridges are ordinarily tested at 100,400,1,000, or 10,000 c/s at a room temperature of $23{ }^{\circ} \mathrm{C}$ and a relative humidity of 50 percent or less. Measurements at $10,000 \mathrm{c} / \mathrm{s}$ are limited to standard inductors of 0.1 henry or less. Most inductors used at $60 \mathrm{c} / \mathrm{s}$ can be tested at $100 \mathrm{c} / \mathrm{s}$ since the variation of inductance with frequency in this range is usually negligible. Purchase orders should state which frequency or frequencies are to be used for calibration purposes. A metal-encased standard is calibrated with the case connected to the "low" terminal of the inductor unless other conditions are specified. Variable inductors used as circuit elements in laboratory setups are low-accuracy devices which do not come within the purview of this schedule and should not be submitted for calibration. Q values are not supplied for inductors calibrated under this schedule. Inductors intended for use as $Q$ standards atradiofrequencies should be referred to the Boulder Laboratories. Mutual inductors used in mag- 
netic testing for calibrating ballistic galvanometers should be calibrated with direct current under item 201.403a.

(b) Accuracy: Inductance values and accuracy statements given in reports of calibration depend upon two factors: (1) the accuracy of the comparison of the client's inductor with the NBS working standards of inductance; (2) the uncertainty in the derivation of the unit of inductance which is embodied in the NBS working standards. In general, inductance values will be given to as many significant figures as are justified at the time of measurement. The accuracy figure given in each report of calibration takes into account factors (1) and (2) stated above and will vary from 0.02 percent to 0.2 percent depending upon the nominal value of the inductor and the frequency of the test current employed.

(c) Inductors can usually be shipped safely express but should be carefully packed to avoid damage to the coil fastenings and terminals.

\begin{tabular}{|c|c|c|}
\hline Item & Description & Fee \\
\hline $201.104 a$ & $\begin{array}{l}\text { Determination of self or mutual inductance of a fixed inductor with non- } \\
\text { magnetic core at one frequency, } 100,400,1,000 \text {, or } 10,000 \mathrm{c} / \mathrm{s}\end{array}$ & $\$ 30.00$ \\
\hline $201.104 b$ & $\begin{array}{l}\text { Determination at an additional frequency } 100,400,1,000 \text {, or } 10,000 \mathrm{c} / \mathrm{s} \\
\text { on an inductor tested under } 201.104 \mathrm{a}_{-}\end{array}$ & 20.00 \\
\hline $201.104 z$ & $\begin{array}{l}\text { For special calibrations not covered by the above schedule, advance } \\
\text { arrangements must be made. Fees will be charged depending upon } \\
\text { the nature of the calibration. }\end{array}$ & \\
\hline
\end{tabular}

\subsection{Standard capacitors.}

(a) Calibrations are ordinarily performed at $65,100,400,1,000$, and $10,000 \mathrm{c} / \mathrm{s}$ with an ambient temperature of about $23^{\circ} \mathrm{C}$ and a relative humidity of 50 percent or less.

(b) The accuracy stated in the report of calibration is determined in part by the accuracy of the NBS measurements and in part by the performance characteristics of the capacitor itself and is sufficiently broad to allow for variations in the stray capacitance at the connectors, variations in temperature of a few degrees Celsius, considerable variation in relative humidity and atmospheric pressure, and frequency deviations of a few percent from the stated test conditions. Over the above frequency range, and in the capacitance range from $0.001 \mathrm{pf}$ to $100 \mu f$, the available accuracy usually lies in the range 0.002 to 0.5 percent.

(c) The capacitance value given is the equivalent parallel capacitance. In general a determination of the equivalent parallel conductance with high accuracy is not feasible; however, for solid dielectric capacitors an approximate value is given without additional charge.

(d) Continuously adjustable ("variable") capacitors are no longer calibrated by the Bureau.

(e) In applying the following schedule to decade capacitance boxes the first entry (201.105a) applies to a determination of the zero capacitance and conductance of the box (all dials set at zero). The second entry applies to the determination of the capacitance and conductance added to the circuit when any one dial is advanced from zero to a specified setting, and at the frequency used in determining zero capacitance. For measurements at additional frequencies the schedule is applied in the same manner, i.e., the higher fee is used for the first point (zero calibration) at the new frequency, and the lower fee applies to additional points at that frequency. 


\begin{tabular}{|c|c|c|}
\hline Item & Description & Fee \\
\hline $201.105 a$ & $\begin{array}{l}\text { Determination of either direct or grounded capacitance of a fixed capaci- } \\
\text { tor or one section of a subdivided capacitor, with alternating current } \\
\text { at one frequency selected from those listed above (201.105) }\end{array}$ & $\$ 35.00$ \\
\hline $201.105 \mathrm{~b}$ & $\begin{array}{l}\text { Determination of either direct or grounded capacitance of each addi- } \\
\text { tional point on the same subdivided capacitor submitted under item } \\
201.105 \mathrm{a}\end{array}$ & 12.00 \\
\hline $201.105 \mathrm{z}$ & $\begin{array}{l}\text { For special calibrations not covered by the above schedule, advance } \\
\text { arrangements must be made. Fees will be charged dependent on } \\
\text { the time involved in making the calibration. }\end{array}$ & \\
\hline
\end{tabular}

\subsection{Standard cells.}

\section{Electrochemistry}

(a) Unsaturated standard cells will be accepted for calibiation by the Bureau only from public utilities and others having operations of such a nature as to require calibrations by the Bureau.

(b) Unsaturated cells normally require about two weeks for a complete calibration. The cells are kept in a thermally insulated cabinet and readings of their emf are taken daily for a period of ten days after the values have become reasonably constant. If the emf continues to fluctuate, or is unusually low, or if the cell shows other abnormal indications, the nature of the failure is stated. Unsaturated cells are not likely to be injured by normal transportation (mail or express), if they are carefully packed. Shipment during very cold weather should be avoided because of the possible hazard from freezing.

(c) Saturated cells should be transported by messenger because they should never be inverted nor tipped more than $45^{\circ}$. In order that the reported values are of the highest accuracy the emfs of saturated cells are measured while they are kept 6 to $S$ weeks in an NBS temperature-controlled oil bath or in their own thermoregulated air bath.

\begin{tabular}{|c|c|c|}
\hline Item & Description & Fee \\
\hline $201.201 \mathrm{a}$ & $\begin{array}{l}\text { Cadmium standard cell (unsaturated type), determination of electro- } \\
\text { motive force with accuracy of } 0.01 \text { percent }\end{array}$ & $\$ 29.00$ \\
\hline $201.201 b$ & $\begin{array}{l}\text { Cadmium standard cell (saturated type), measurement of the first cell } \\
\text { of a group at a fixed temperature of } 28{ }^{\circ} \mathrm{C} \text {, in thermostatically con- } \\
\text { trolled oil bath or at a fixed temperature in a thermoregulated air } \\
\text { bath. }\end{array}$ & $5 S .00$ \\
\hline $201.201 \mathrm{c}$ & Each additional saturated cell of a group & 29.00 \\
\hline $201.201 d$ & $\begin{array}{l}\text { Cadmium standard cell (saturated type), measurement of the first cell } \\
\text { of a group at any temperature between } 20 \text { and } 35{ }^{\circ} \mathrm{C} \text {, except } 28{ }^{\circ} \mathrm{C} \text {, } \\
\text { in a thermostatically controlled oil bath }\end{array}$ & 71.00 \\
\hline
\end{tabular}




\begin{tabular}{c|c|c}
\hline Item & Description & Fee \\
\hline $201.201 \mathrm{e}$ & $\begin{array}{l}\text { Each additional cell of a group (at temperatures between } 20 \text { and } 35^{\circ} \mathrm{C}, \\
\text { except } 28{ }^{\circ} \mathrm{C}, \text { in a thermostatically controlled oil bath) } \ldots\end{array}$ & $\$ 34.00$ \\
$201.201 \mathrm{z}$ & $\begin{array}{l}\text { For special tests not covered by the above schedule, fees will be charged } \\
\text { dependent upon the nature of the test. }\end{array}$ & \\
\hline
\end{tabular}

\subsection{General.}

\section{Electrical Instruments}

(a) Indicating (pointer-and-scale) instruments should be calibrated quite frequently with d-c standards and a-c-d-c transfer instrumcnts, or with stable d-c or a-c sources which are calibrated periodically in this way. Suitable standards and transfer instruments are now readily a vailable commercially. Because of the necessity of frequent tests, a single d-c or a-c calibration of an indicating instrument has little permanent value. Thus in this category the Bureau ordinarily accepts for calibration only rms a-c $-d-c$ instruments and thermal converters of 0.1 percent rated accuracy or better, for a-c-d-c difference tests only.

(b) The Burea u's a-c-d-c difference tests consist of determination of the difference between quantitics (current, voltage, or power) required to give the same response (output) of an instrument or thermal converter on alternating current and on reversed direct current, as evaluated by comparison with an NBS a-c-d-c transfer standard. The alternating quantity, $Q_{a}$, required for a given response of the instrument or converter is then $Q_{a}=Q_{d}(1+S)$ where $Q_{d}$ is the average quantity required for this response on reversed direct current, as determined by $d-c$ standards, and $S$ is the small fractional a-c-d-c difference. Usually NBS a-c-d-c difference tests are made on each range of the instrument or converter. The differences depend on the ratios of the reactances of the components, and increase with frequency, but are small and relatively permanent over the rated frequency range of a well-designed instrument. Therefore, NBS tests are normally made only at the upper rated frequency on each range and at the lower rated frequency on one range. Ordinarily, the tests need not be repeated at intervals of less than five years, and then only if the instrument is to be used over the upper part of its frequency range.

\subsection{Standard resistors for current measurements.}

(a) Calibration: The Bureau normally calibrates only resistors of 0.04 percent accuracy or better. Test results for suitable standard resistors for current measurements are usually reported to an accuracy of 0.01 percent.

(b) Design: A standard resistor for current measurements is a four-terminal resistor, for which the resistance is defined as the ratio of the open-circuit potential difference between the potential terminals to the current through the current terminals. The resistance value will be definite and reproducible only if the current flow pattern at the potential terminals is completely reproduced. This flow pattern should be fixed by resistor design to be independent of the way in which current is introduced at the current terminals and of the location of leads on the potential terminals. In some instances where this has not been done the type and location of connections to the current terminals can be specified adequately to fix the flow pattern at the potential terminals.

(c) High-current resistors: Resistors for high currents (above about 1,000 amp) require considerable power, so that their temperature rise between low and rated current, and the resulting change in resistance, will depend not only on their design, including means provided for dissipating heat, but also on the connecting bus bars and their junctions to the resistor. Bus bars of generous cross section may carry away a significant part of the heat generated in the resistor; inadequate bus bars may actually contribute to the heating of the resistor. In addition, contact resistance at the points of connection to the bus bars, unless carefully minimized, may contribute appreciably to the heating. (Contact resistance of bolted connections 
depends on area of contact, cleanness of surfaces, and pressure.) Resistance determinations made in the laboratory at rated current may therefore be of little value because the working temperature conditions cannot be duplicated. The best experimental procedure to use in such cases is to place the standard in a temperature-controlled enclosure and measure its resistance with a comparatively low test current when it is heated uniformly to temperatures approximating that at which it will operate in service (201.301d and e). From data at two or more elevated temperatures, combined with that at room temperature, a curve can be plotted from which the resistance at the operating temperature can be read, provided this temperature is determined by the user with the resistor under the actual operating conditions.

Changes in resistance may also result from strains in the resistance element produced by mechanical forces incidental to clamping the resistor connections, as well as from inherent internal expansion constraints on resistor parts, or forces from the magnetic field produced by the current.

(d) Test schedule: Resistors when first submitted for test should be tested with about 20 percent of rated current and with full rated current; normally when resubmitted for test, determinations need be made only with 20 percent of rated current; once stability is proved, the resistor need not be recalibrated at intervals of less than two years.

\begin{tabular}{c|c|c}
\hline Item & Description & Fee \\
\hline $201.301 \mathrm{a}-1$ & Initial determination of resistance of a single-range resistor or one range &
\end{tabular}
of a multirange resistor, at 30 percent rated current or less (current rating not to exceed $300 \mathrm{amp}) \ldots \ldots \ldots$

201.301a-2 Same as a-1, except current rating above $300 \mathrm{amp}$ but not to exceed $1,000 \mathrm{amp}_{\ldots} \ldots \ldots$

201.301b Determination of resistance on another range of a multirange resistor, at 30 percent rated current or less (current rating not to exceed 300 amp)

$201.301 \mathrm{c}$

Test according to item 201.301a or 201.301b having been made, for an additional determination at another test current (not to excced 1,000

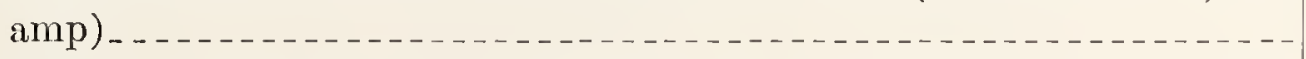

201.301d Additional determination of resistance at temperatures above room temperature at a current not greater than 30 percent rated, for first elevated temperature . . . . . . . . .

201.301e Additional determination of resistance of each additional elevated temperature, at a current not greater than 30 pcrcent rated...........

Twenty determinations of resistances corresponding to 9 plug positions and 11 slider positions of an adjustable low-resistance standard, at 30 $\operatorname{amp}$

For determinations of resistance at currents larger than 1,000 amp and requiring unusual setups or procedures, and for special tests not covered by the above schedule, advance arrangements must be made. Fees for such tests will depend upon the nature of the test.

201.302 Volt boxes (fixed ratio voltage dividers). A volt box is a resistive voltage divider used to extend the range of the voltage measured by a potentiometer. Its ratio for 
any range is obtained by dividing the voltage across its input terminals by the open-circuit voltage across the section to be connected to the potentiometer.

(a) Calibration: The Bureau normally calibrates only volt boxes for which the maker's stated ratio accuracy is 0.04 percent or better. Values of ratio are normally reported to an accuracy of 0.005 percent.

(b) Humidity effects: The insulating structure of a volt box is equivalent to a network of high resistances in parallel with one or more of its wire-wound precision resistance elements. 'Thus, changes in insulation resistance as a result of variations in surface or volume moisture may affect the ratios. Such ratio changes are normally less on low than on high ratios. This effect can be reduced or eliminated by constructions which provide built-in guard electrodes, maintained at appropriate potentials. Another effect of humidity is to produce changes in the values of the precision wire-wound resistors. The magnitude of this effect varies with coil construction and with wire size and coating. Because humidity effects may reach equilibrium only after days (or even weeks), it is recommended that laboratory humidity be held continuously at or below 50 percent.

(c) Ambient temperature and self-heating effects: Changes in ambient temperature should have little effect on ratio if all the resistance elements have the same temperature coefficient. However, self-heating as a result of sustained operation may significantly change the ratios because of unequal temperature rise in the various resistors. The magnitude of this effect depends on construction and coil arrangement, and on the power dissipated. It should (1) be less for low than for high ranges, (2) be greater for volt boxes that require higher current at rated voltage, (3) increase approximately with the square of the applied voltage, and (4) be entirely negligible at 20 percent of rated voltage on all ranges.

(d) Suggested test schedule: Volt boxes should be tested at rated voltage. The first calibration test should also include a test at 20 percent rated voltage on one or more of the higher ranges, which are preferably selected by the Bureau. The equilibrium values at 20 and 100 percent rated voltage may be used to estimate the magnitude of the self-heating effects for the various ranges. 'Tests having once been made at 20 and 100 percent rated roltage, subsequent determinations need be made only at rated voltage, since the self-heating effect should not change with time.

Once stability has been established, a volt box should not require recalibration at intervals less than two years.

\begin{tabular}{|c|c|c|}
\hline Item & Description & Fee \\
\hline $201.302 \mathrm{a}-1$ & $\begin{array}{l}\text { Determination of ratio on one range at rated voltage, not to exceed } \\
1,500 \mathrm{v} \text {, and at a ratio not to exceed } 5,000 / 1\end{array}$ & $\$ 67.00$ \\
\hline $201.302 \mathrm{a}-2$ & Determination as in (1) above except ratio not to exceed $10,000 / 1_{\ldots} \ldots$ & 100.00 \\
\hline $201.302 b_{-} \ldots$ & Determination of ratio at rated voltage on an additional range $\mathrm{e}_{-\ldots}$ & 16.00 \\
\hline $201.302 c_{\ldots-n}$ & Determination at a reduced voltage on a range tested in $201.302 \mathrm{a}$ or $\mathrm{b}$ - & 9.00 \\
\hline $201.302 d_{-} \ldots$ & $\begin{array}{l}\text { Test per range, at rated voltage, of a multirange guarded standard } \\
\text { voltage divider. (Design similar to that described in NBS RP1419.) } \\
\text { Value normally reported to an accuracy of } 0.001 \text { percent }\end{array}$ & 20.00 \\
\hline $201.302 z_{----}$ & $\begin{array}{l}\text { For tests on volt boxes not covered by the above schedule advance } \\
\text { arrangements must be made. Fees will be charged depending upon } \\
\text { the nature of the test. }\end{array}$ & \\
\hline
\end{tabular}


201.303 A-c-d-c instruments and thermal converters $(20$ to $50,000 \mathrm{c} / \mathrm{s}$, up to $50 \mathrm{amp}$ and $600 \mathrm{v}$ ). Ordinarily only rms a-c-d-c instruments or converters of 0.1 percent rated accuracy or better are accepted for test, which consists of a-c-d-c difference determinations by the procedures of items 201.303a to c. See 201.300.

\begin{tabular}{c|c|c}
\hline Item & Description & Fee \\
\hline $201.303 a$ & $\begin{array}{c}\text { Initial determination of a-c-d-c difference of an instrument or converter } \\
\text { at one applied voltage or current, frequency from 20 through } 50,000\end{array}$ &
\end{tabular}
$\mathrm{c} / \mathrm{s}$

$\$ 33.00$

$201.303 \mathrm{~b}$ Each additional determination of a-c-d-c difference of the same instrument, converter, or set of converters, frequency from 20 through $20,000 \mathrm{c} / \mathrm{s}$

201.303c Each additional determination of a-c-d-c difference of the same instrument, converter, or set of converters, frequency from 20,000 through $50,000 \mathrm{c} / \mathrm{s}_{-}$

20.00

201.303z For special tests not covered by the above schedule advance arrangements must be made. Fees will be charged depending upon the nature of the test. For tests at higher voltages see 201.604

201.304 A-c-d-c wattmeters, single phase $(20$ to $2,000 \mathrm{c} / \mathrm{s}$, up to $15 \mathrm{amp}$ and $500 \mathrm{v})$. Ordinarily only single-phase a-c-d-c wattmeters of 0.1 percent rated accuracy or better are accepted for test, which consists of a-c-d-c difference determinations by the procedures of items 201.304a to c. See 201.300. Unless otherwise specified, these tests are made at two scale points at 0.5 power factor on a base range and one scale point at other combinations of ranges, followed by tests at unity power factor at one scale point on one or more ranges, depending upon the results obtained.

\begin{tabular}{|c|c|c|}
\hline Item & Description & Fee \\
\hline $201.304 \mathrm{a}$ & $\begin{array}{l}\text { Determination of the difference between the reading on reversed direct } \\
\text { current and the reading on alternating current at the first scale point } \\
\text { at which this difference is determined, at currents not to exceed } 15 \\
\text { amp. }\end{array}$ & $\$ 44.00$ \\
\hline $201.304 \mathrm{~b}$ & $\begin{array}{l}\text { Determination of this difference at one scale point on an additional } \\
\text { range, frequency, or power factor, at currents not to exceed } 15 \text { amp-- }\end{array}$ & 16.00 \\
\hline $201.304 \mathrm{c}$ & $\begin{array}{l}\text { Determination at each additional scale point with the same combination } \\
\text { of range, frequency, and power factor, at currents not to exceed } 15\end{array}$ & 7.00 \\
\hline $201.304 \mathrm{z}$ & $\begin{array}{l}\text { For frequencies greater than } 70 \mathrm{c} / \mathrm{s} \text { and for special tests not covered by } \\
\text { the above schedule, advance arrangements must be made. Fees will } \\
\text { be charged depending upon the nature of the test. }\end{array}$ & \\
\hline
\end{tabular}

201.305 Watthour meters. Except under unusual circumstances, only portable standard watthour meters (rotating standards) will be accepted for test. Tests consist of 
determinations of the percentage registration of the meter "as received." If meters are to be cleaned and adjusted this must be done before they are submitted for test. 'The Bureau does not undertake the cleaning and adjustment of meters and does not knowingly begin tests on faulty meters. Before tests can be started the test conditions must be completely specified by the user as to current and voltage ranges to be tested, frequency, applied voltage and current, and power factor. A guide listing a limited yet adequate schedule of tests is available at no charge. Test voltages should be chosen from the following values: 1, 2, or 4 times 110, 115, 120, 125 , and $130 \mathrm{v}$. Test current should be chosen from the following values: 1, 10, or 100 times $0.25,0.5,0.75,1,1.25,1.5,2,2.5,3,3.75,4,5,7.5 \mathrm{amp}$ (but not to exceed $100 \mathrm{amp}$ ). Tests at other voltages or currents, or at power factors other than 1.0 and 0.5 current lagging, will be considered as special tests, because rearrangements of cireuits are required (see 201.305z). Unless otherwise specified, test runs on portable standard watthour meters (rotating standards) are of approximately $100 \mathrm{sec}$ duration. The meters are energized for at least 30 min at rated voltage and current on one range before starting the test.

\begin{tabular}{|c|c|c|}
\hline Item & Description & Fee \\
\hline $201.305 \mathrm{a}$ & $\begin{array}{l}\text { Test at } 60 \mathrm{c} / \mathrm{s} \text { on one combination of range, applied voltage, and power } \\
\text { factor, at not more than five current loads }\end{array}$ & $\$ 54.00$ \\
\hline $201.305 b$ & $\begin{array}{l}\text { Additional test on the same or an additional combination of range, } \\
\text { applied eurrent, voltage, and power factor }\end{array}$ & 8.00 \\
\hline $201.305 c$ & $\begin{array}{l}\text { Test of one or two additional meters simultaneously with first, under } \\
\text { the same conditions as } 201.305 \mathrm{a} \text {, per meter }\end{array}$ & 28.00 \\
\hline $201.305 \mathrm{~d}$ & $\begin{array}{l}\text { Test of each additional meter simultaneously with the first, under the } \\
\text { same conditions as } 201.305 \mathrm{~b} \text {, per meter. }\end{array}$ & 4.00 \\
\hline $201.305 z$ & $\begin{array}{l}\text { For special tests not covered by the above sehedule advance arrange- } \\
\text { ments must be made. Fees will be charged depending upon the time } \\
\text { required for the test. }\end{array}$ & \\
\hline
\end{tabular}

\subsection{Gurrent transformers.}

(a) Calibration: The Bureau normally calibrates only eurrent transformers of high quality for use as reference standards. The Bureau may decline requests for tests which are not to be used for establishing or checking a reference standard. If the transformer quality is stated in terms of ASA accuracy classes, calibration will normally be limited to transformers stated to be in the 0.3 percent class for one or more ASA burdens. Bureau equipment is primarily designed for testing current transformers whose rated secondary current is 5 amp. Results obtained at frequencies near $60 \mathrm{c} / \mathrm{s}$ will normally be reported to an accuracy of 0.05 percent in ratio and $1 \mathrm{~min}$ in phase angle. However, in some instances the ratio can be reported to an accuracy of 0.02 percent and the phase angle to $0.5 \mathrm{~min}$.

(b) Test information: Tests cannot be started until information is furnished concerning the following conditions: (1) test frequency, (2) secondary test currents, (3) secondary burdens, (4) ranges to be tested. It is customary to make tests at secondary currents of $0.5,1,2,3,4$, and 5 amp.

(e) Transformer burden: Current transformers should be tested with burdens equivalent to the impedances imposed when the transformer is used as a reference standard. Inclusion of tests at ASA burdens is not recommended. The burdens listed in the American Standard for Instrument Transformers, C-57.13, are for rating purposes only and differ from the instrument burdens imposed on a reference standard. Large errors in measurement can 
result if the values of ratio and phase angle obtained with an ASA burden are used for the transformer when it supplies only an instrument burden.

Preferably the burden should be specified in terms of the measured resistance and inductance, including the leads to connect the instruments to the secondary of the transformer. If this measurement cannot be made conveniently, it will suffice in most cases to state the name of the maker, the type, range, and serial number of each instrument used in the burden, and the length and size of the wire of the leads used in the secondary circuit. Alternatively the burden may be stated in terms of the volt-amperes and power factor of the secondary circuit at the test frequency.

The test equipment regularly used at the Bureau imposes a minimum test burden of about $0.16 \mathrm{ohm}$ with a minimum inductance of about $10 \mu \mathrm{h}$ (if the burden inductance is larger than $10 \mu \mathrm{h}$, the minimum resistance is increased above $0.16 \mathrm{ohm}$ ). Special test equipment and procedures must be used for burdens lower than $0.16 \mathrm{ohm}$, so that advance arrangements must be made and higher fees must be charged. In planning for the tests of a transformer it is therefore desirable to select a low burden, but one larger than this minimum, preferably not less than $0.2 \mathrm{ohm}$. The required total may be made up by incorporating resistance in the leads to the instruments.

(d) Multirange current transformers, in which the same sections of primary windings are used in series and in parallel, usually have phase angles and ratio factors which are equal on the several ranges to within the accuracy needed for almost any measurement purpose. Hence a test at six values of secondary current on one range is nearly always sufficient to determine the characteristics of the transformer. Further tests, often made at 0.5 and 5 secondary amperes on each additional range, merely serve as a safeguard by means of which mistakes in winding may be detected. When the various ranges of a multirange transformer are obtained by taps on either winding, this relation does not necessarily hold, particularly in the case of secondary taps; and tests in addition to the initial six-point test on one range should be made, using two values of secondary current on each of the ranges so obtained. Transformers of some designs, however, show very little difference in ratio factor and phase angle on the various ranges, and the Bureau should be consulted before tests on a large number of ranges are requested.

(e) Demagnetization: Unless otherwise specified, current transformers will be demagnetized before being tested. If it is desired to have a transformer tested as submitted (without demagnetization), this fact should specifically be stated.

(f) Test limitation at frequencies greater than $60 \mathrm{c} / \mathrm{s}$ : At $400 \mathrm{c} / \mathrm{s}$, the maximum current range for which tests are made is about $200 \mathrm{amp}$ and the phase angle values are normally reported to an accuracy of $3 \mathrm{~min}$; at $800 \mathrm{c} / \mathrm{s}$ there is a further reduction in the current range and accuracy. If the burdens at these higher frequencies are specified in terms of volt-amperes and power factor, the frequency for which these values are stated must be clearly indicated so that the proper burden resistance and inductance can be duplicated.

(g) Recalibration: At room temperature the ratio and phase angle under a specified test condition should be repeatable unless the core is magnetized. Once stability has been demonstrated a current transformer should not require recalibration at intervals less than 5 years.

\begin{tabular}{|c|c|c|}
\hline Item & Description & Fee \\
\hline $201.306 \mathrm{a}-1$ & $\begin{array}{l}\text { Determinations of the ratio and phase angle of a current transformer on } \\
\text { one range at one frequency and one burden (not less than } 0.2 \text { ohm re- } \\
\text { sistance) at not more than six values of secondary current, namely, } \\
0.5,1,2,3,4 \text {, and } 5 \text { amp unless otherwise specified; primary current } \\
\text { not to exceed } 500 \text { amp. }\end{array}$ & $\$ 87.00$ \\
\hline
\end{tabular}




\begin{tabular}{|c|c|c|}
\hline Item & Description & Fee \\
\hline $201.306 a-2$ & $\begin{array}{l}\text { Same as a-1 except primary current greater than } 500 \text { amp but not to } \\
\text { cxcecd } 8,000 \text { amp }\end{array}$ & $\$ 115.00$ \\
\hline $201.306 \mathrm{~b}-1$ & $\begin{array}{l}\text { Detcrminations of the ratio and phase angle at one value of seeondary } \\
\text { eurrent on an additional eombination of frcquency, range, and bur- } \\
\text { den (not less than } 0.2 \mathrm{ohm} \text { resistance); primary eurrent not to exceed } \\
500 \mathrm{amp}\end{array}$ & 18.00 \\
\hline $201.306 b-2$ & $\begin{array}{l}\text { Same as b-1 exccpt primary current greater than } 500 \text { amp but not to } \\
\text { exceed } 8,000 \text { amp }\end{array}$ & 26.00 \\
\hline $201.306 \mathrm{c}$ & $\begin{array}{l}\text { Determinations of ratio and phase angle at an additional value of second- } \\
\text { ary current with the same combination of frequeney, range, and bur- } \\
\text { den used in } 201.306 \text { a or b, primary current not to exceed } 8,000 \text { amp_- }\end{array}$ & 9.00 \\
\hline $201.306 z$ & $\begin{array}{l}\text { For tests of eurrent transformers at frequencies other than } 25,50 \text {, or } 60 \\
\text { c/s, or with burdens less than } 0.2 \text { ohm resistanee, or with primary } \\
\text { currents greater than } 8,000 \text { amp, and for special tests not covered by } \\
\text { the above schedule advance arrangements must be made. Fees will } \\
\text { be charged depending upon the nature of the test_. }\end{array}$ & \\
\hline
\end{tabular}

201.307 Current transformer comparators (testing sets).

\begin{tabular}{|c|c|c|}
\hline Item & Description & Fee \\
\hline $201.307 \mathrm{a}$ & $\begin{array}{l}\text { Determination of the values of current ratio and phase angle for settings } \\
\text { of the dials of a current transformer comparator for } 60 \mathrm{e} / \mathrm{s} \text { (not ex- } \\
\text { eeeding } 13 \text { points on ratio dial and } 15 \text { on phase angle dial) }\end{array}$ & $\$ 265.00$ \\
\hline $201.307 \mathrm{~b}$ & $\begin{array}{l}\text { Determination according to } 201.307 \text { a having been made, for } 10 \text { deter- } \\
\text { minations at } 25 \mathrm{c} / \mathrm{s} \text { or for determinations on the seeond range of a } \\
\text { double-range eomparator }\end{array}$ & 40.00 \\
\hline $201.307 \mathrm{z}$ & $\begin{array}{l}\text { For speeial tests not eovered by the above schedule, advance arrange- } \\
\text { ments must be made. Fees will be charged depending upon the } \\
\text { nature of the test.- }\end{array}$ & \\
\hline
\end{tabular}

201.400 General.

\section{Magnetic Measurements}

(a) A general diseussion of magnetie prineiples and methods used in magnetic testing is given in NBS Monograph 47, Basie magnetic quantities and the measurement of the magnetic properties of materials. Priee 30 eents. Available from Superintendent of Doeuments, U.S. Government Printing Offiee, Washington, D.C., 20402. See p. 103 for order blank.

(b) Tests in this field are for the most part made on samples whieh serve as standards to coordinate work in various laboratories and thus seeure uniformity in eommereial testing. For this purpose it is essential that the standard bars be very uniform in their magnetic properties. The Bureau does not normally make routine acceptance tests of magnetic materials unless these speeimens are to be used, at least temporarily, as standards. The standard dimensions of magnetic test specimens are given in 201.401 and 201.402. It is oceasionally 
possible to test specimens of unusual materials or shapes where the services of the Bureau are needed in the development of new test procedures which are likely to be of importance in the industry. In such cases a full understanding of the problem should be developed by correspondence, or preferably by a visit which will permit direct discussion between the engineers concerned and the Bureau staff.

201.401 General magnetic measurements; normal induction and hysteresis. Specimens submitted for test should be of rectangular cross section, width not to exceed 3.0 $\mathrm{cm}\left(1 \frac{1}{3} \mathrm{in}\right.$.); thickness not to exceed $1.0 \mathrm{~cm}\left(\frac{3}{8} \mathrm{in}\right.$.); for magnetizing forces from 0 to 300 or 0 to 5,000 oersteds, length to be not less than $25.4 \mathrm{~cm}$ (10 in.); for magnetizing forces in the range

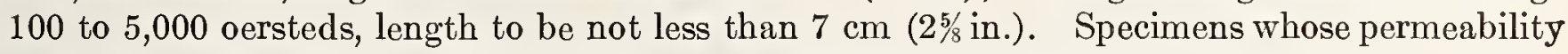
is not greater than 4 may be of circular cross section, diameter not to exceed $1.27 \mathrm{~cm}$ ( $1 / 2$ in.) but in any event cross-sectional area must be not less than $0.2 \mathrm{~cm}^{2}\left(0.031\right.$ in. $\left.^{2}\right)$.

\begin{tabular}{l|c|c}
\hline Item & Description & Fee \\
\hline & &
\end{tabular}

201.401a Determination of data for normal induction curve in the range 0 to 300 oersteds

$\$ 50.00$

201.401b Determination of data for normal induction curve in the range 100 to 5,000 oersteds

50.00

201.401c Determination of data for normal induction curve in the range 0 to 5,000 oersteds...... 900

201.401d Determination of data for demagnetization curve, one value of magnetizing force......

201.401e Same as 201.401d, each additional value of maximum magnetizing force

201.401f Determination of permeability for specimens whose permeability is

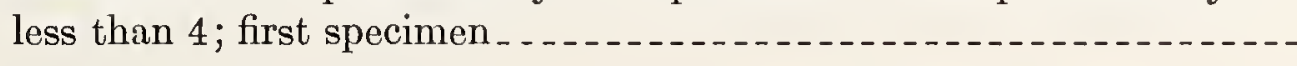

20.00

201.401g Each additional specimen submitted at the same time.

10. 00

201.401z For examination of material found to be unsuitable for test, or for special tests not covered by the above schedule, fees will be charged dependent on the cost of such examination or special test.

201.402 Magnetic materials; a-c permeability and core loss. Test specimens should consist of the proper number of strips $3 \mathrm{~cm}\left(1 \frac{1316}{10}\right.$.) wide and either $28 \mathrm{~cm}$ (111/82 in.) to $30.5 \mathrm{~cm}$ (12 in.), or $50 \mathrm{~cm}$ (191/16 in.) long prepared in accordance with the specifications of the American Society for Testing and Materials, A-34.

\begin{tabular}{|c|c|c|}
\hline Item & Description & Fee \\
\hline $201.402 \mathrm{a}$ & Determination of total core loss at $60 \mathrm{c} / \mathrm{s}$ at one value of maximum induc- & $\$ 45.00$ \\
\hline $201.402 b$ & Same as $201.402 \mathrm{a}$, each additional value of maximum induction & 15.00 \\
\hline
\end{tabular}




\begin{tabular}{|c|c|c|}
\hline Item & Description & Fee \\
\hline $201.402 \mathrm{c}$ & $\begin{array}{l}\text { Determination of a-c permeability at } 60 \mathrm{c} / \mathrm{s} \text { at one value of maximum } \\
\text { induction }\end{array}$ & $\$ 45.0$ \\
\hline $201.402 d$ & Samc as $201.402 c$, cach additional value of maximum induction ...... & 15.0 \\
\hline $201.402 z$ & $\begin{array}{l}\text { For examination of material found to be unsuitable for test, or for spe- } \\
\text { cial tests not covered by the above schedule, fees will be charged de- } \\
\text { pendent on the cost of such examination or special test. }\end{array}$ & \\
\hline
\end{tabular}

201.403 Magnetic testing apparatus; mutual inductors, search coils, and fluxmeters.

\begin{tabular}{|c|c|c|}
\hline Item & Description & Fee \\
\hline $201.403 a$ & Determination of mutual induction by direct current. . . . . . . . & $\$ 30.00$ \\
\hline $201.403 \mathrm{~b}$ & $\begin{array}{l}\text { Same as } 201.403 \mathrm{a} \text {, each additional inductor submitted at the same } \\
\text { time or each additional value for variable or tapped inductors }\end{array}$ & 15. 00 \\
\hline $201.403 c$ & Determination of the area-turns of a search coil, first coil & 35.00 \\
\hline $201.403 \mathrm{~d}$ & Each additional search coil submitted at the same time $\ldots . . . . .$. & 20. 00 \\
\hline $201.403 \mathrm{e}$ & Calibration of fluxmeter at not more than five points on one range_- & 45.00 \\
\hline $201.403 \mathrm{f}$ & Calibration of fluxmeter at one scale point on an additional range & 10.00 \\
\hline $201.403 g$ & Calibration of standard magnets & $30.00-70.00$ \\
\hline $201.403 z$ & $\begin{array}{l}\text { For examination of apparatus unsuitable for test, or for special } \\
\text { tests not covered by the above schedule, fees will be charged de- } \\
\text { pendcnt on the cost of such examination or special test. }\end{array}$ & \\
\hline
\end{tabular}

\section{Dielectric Measurements}

201.500 Dielectric constant and dissipation factor. In general, the Bureau will make tests of insulating and dielectric properties of materials only on (1) specimens of known composition of pure materials for which values are considered of use by the Bureau, or by other government agencies; and (2) dielectric reference standards made from materials exhibiting reproducible behavior under specified environmental conditions (such as humidity), when such standards are needed for improving methods of measurement. Measurements are not made on the effective insulation resistances, dielectric constant or dissipation factor of structures and assemblies of insulation, or on clectric breakdown generally. Inquiries giving comprehensive information regarding any tests desired from low frequencies up to $30 \mathrm{kc} / \mathrm{s}$ should be directed to the National Bureau of Standards, Washington, D.C., 20234. Inquiries concerning tests above $30 \mathrm{kc} / \mathrm{s}$ should be addressed to the National Bureau of Standards, Boulder, Colo., 80310.

\section{Voltage Ratio and High-Voltage Measurements}

Note: See section 201.102 for information relative to the calibration of resistive voltage dividers with direct current. See section 201.302 for information relative to the calibration of volt boxes.

\subsection{Voltage dividers.}

(a) The calibration of ratio devices such as voltage dividers need not be referred to the national standards of inductance or resistance or to any other national standard. However, methods and equipment are available at the Bureau for the measurement of alternatingvoltage ratios with high accuracy, and a routine calibration service for first-quality decade inductive voltage dividers is provided. Inductive voltage dividers which incorporate a resistive divider as a fine adjustment are not accepted for calibration. 
(b) The largest contribution to instability in inductive voltage dividers often arises in the decade switches. Variable contact resistance in these switches sometimes affects the stability of voltage-ratio measurements to a significant extent but is most evident by its effect on the phase angle. When a decade inductive divider exhibits large changes in phase angle on repeated measurements after the switches have been disturbed, the divider should no longer be considered satisfactory for use as a standard of voltage ratio.

(c) Corrections for the separate decades of an inductive divider, in general, cannot be simply combined; however, the correction to a step setting of one of the higher decades is usually independent of the setting of the lowest decades. Stray impedances must be fixed by connecting the case to the divider at one point; and unless otherwise specified, the case will be connected to one of the common terminals. Calibration intervals of three years should be satisfactory for good quality inductive voltage dividers which have not been abused.

(d) Decade inductive voltage dividers are calibrated at the Bureau by a comparison method, using as a working standard a well-constructed inductive divider which has previously been calibrated by capacitance-ratio methods. The comparison method is simple and convenient and can be used in other laboratories for the rapid calibration of other voltage dividers. Accordingly, it is recommended that, in general, only one divider from a laboratory be submitted to the Bureau for calibration and that other dividers be calibrated by a comparison method using it as a standard.

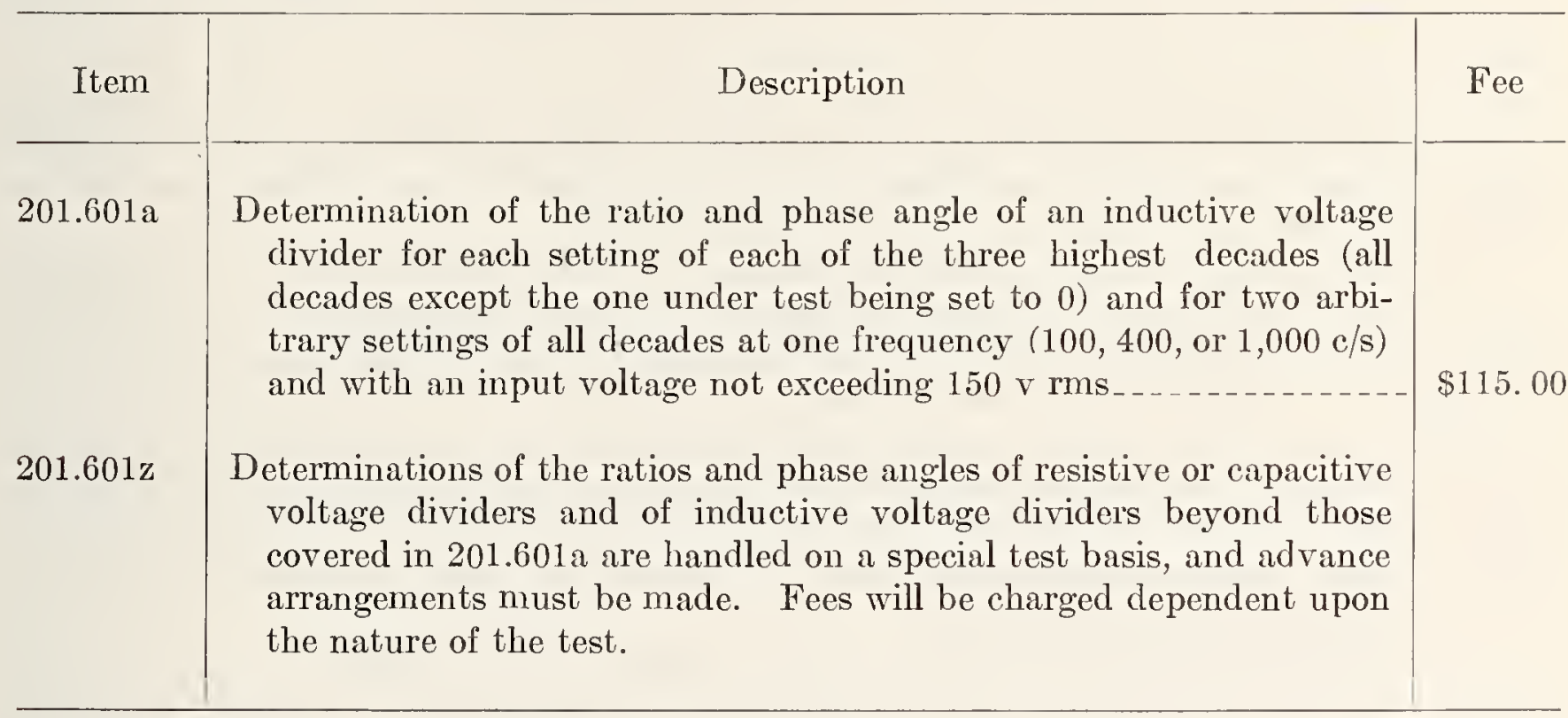

\subsection{Voltage transformers.}

(a) Acceptance: The Bureau normally accepts voltage transformers for calibration only if they are suitable for use as reference standards. Results of tests at or near $60 \mathrm{c} / \mathrm{s}$ will normally be reported to 0.01 percent in ratio and $1 \mathrm{~min}$ in phase angle.

(b) Test information: Tests cannot be started until information is furnished concerning the following test conditions: (1) test frequency, (2) secondary test voltages, (3) secondary burdens, (4) ranges to be tested.

(c) Transformer burdens: The ratio and phase angle of a voltage transformer vary linearly with secondary current under conditions of constant voltage, frequency, and power factor within its rating. Hence, if values of ratio and phase angle are determined on open circuit (zero burden) and at one burden having a particular power factor, values at other current burdens with the same power factor (and at the same voltage and frequency) can be found by linear interpolation. If the ratio and phase angle of a voltage transformer are known both on open circuit (zero burden) and at a single unity power-factor burden, the ratio and phase angle for any burden within its rating at any power factor (at the same voltage and frequency) 
can be computed with sufficient accuracy for many measurement purposes by the following formulas:

and

$$
F=F_{0}+\frac{I}{I_{1}}\left[\left(F_{1}-F_{0}\right) \cos \Phi+\left(\gamma_{0}-\gamma_{1}\right) \sin \Phi\right]
$$

$$
\gamma=\gamma_{0}+\frac{I}{I_{1}}\left[\left(F_{1}-F_{0}\right) \sin \Phi-\left(\gamma_{0}-\gamma_{1}\right) \cos \Phi\right]
$$

where $I_{1}$ and $I$ are the secondary currents at the known unity power factor burden and the desired burden, respectively; $F_{0}, F_{1}$, and $F$ are the ratio correction factors at zero burden, the known unity power-factor burden, and the desired burden, respectively; $\gamma_{0}, \gamma_{1}$, and $\gamma$ are the corresponding phase angles in radians; and $\cos \Phi$ is the power factor of the desired burden ( $\Phi$ being taken as positive for inductive burdens). The following conversion factors apply:

$$
\begin{aligned}
& 1 \text { minute }=0.000291 \text { radian } \\
& 1 \text { radian }=3438 \text { minutes }
\end{aligned}
$$

The "standard burdens" of the ASA Standard for Instrument Transformers (C57.13) are for rating purposes only, and are not recommended for use as test burdens in calibrating a voltage transformer for use as a reference standard. Values of ratio and phase angle at any ASA burden can be computed with sufficient accuracy for rating purposes by using the above formulas. The test burdens recommended are stated in items $201.602 \mathrm{a}$, b, or c below. In these items, the instrument burden "to be specified by the user" should preferably be the burden with which the transformer will be used as a reference standard, in the test circuit, and may be stated either in terms of volt-amperes and power factor at a specified voltage and frequency, or the resistance and reactance of the test circuit elements.

(d) Test voltages: When a secondary burden of fixed impedance is used, the ratio and phase angle of a well-designed voltage transformer are nearly independent of the secondary voltage within its normal operating range. Hence, tests at a single voltage are sufficient unless the transformer is to be operated over an extended voltage range. In extended-range operation the variations of ratio factor and phase angle with voltage are identical for any constantimpedance burden. Hence, it should be sufficient to make ratio and phase-angle determinations at the extremes of the expected voltage-range of operation and at one or perhaps two intermediate voltage points on one burden (preferably zero burden). 'Tests at all additional burdens need be made at only a single voltage.

(e) Multirange transformer: When multiple ranges are provided by series-parallel primary connections, the ratio correction factors and phase angles (for constant secondary voltage, burden, and frequency) are practically identical for all ranges so obtained. (Hence a single determination on each range after the first serves to completely define the transformer performance when the added ranges are obtained by primary series-parallel combinations.) When multiple ranges are obtained by tapping a portion of one of the windings, or by secondary series-parallel combinations, the ratio correction factors and phase angles are not necessarily the same on the various ranges.

(f) Fuses: It is recommended that voltage transformers intended as reference standards be used without fuses, because fuse resistance affects both ratio and phase angle values so that fuse deterioration or replacement may alter the values. When a fused transformer is submitted, tests with the fuses in place will be made only if this is specifically requested by the customer.

(g) Tests at $400 \mathrm{c} / \mathrm{s}$ : Ratio and phase angle determinations at $400 \mathrm{c} / \mathrm{s}$ can be made up to $9,000 \mathrm{v}$. Results of such tests will normally be reported to 0.03 percent in ratio and $3 \mathrm{~min}$ in phase angle.

(h) Recalibration: The ratio and phase angle of a voltage transformer for a given burden, voltage, and frequency should not change significantly with time unless the transformer is damaged. Once stability has been demonstrated, a transformer should not require recalibration at intervals less than five years. 
(i) Shipment: Heavy transformers should be shipped in wooden boxes and held in place, if necessary, by checks or cleats. Large transformers, especially those having oil-filled iron cases, should be crated separately and arranged, whenever possible, so that the terminals can be made accessible for tests without removing the entire crate. The tops of boxes should be marked "this side up." Large transformers (those more than $12 \mathrm{ft}$ high including crating, or weighing more than $6,000 \mathrm{lb}$ ) require special handling; advance arrangements, including provision for delivery inside the laboratory, must be made.

\begin{tabular}{c|c|c}
\hline Item & Description & Fee \\
\hline $201.602 \mathrm{a}-1$ & $\begin{array}{c}\text { Determinations of the ratio and phase angle of a voltage transformer } \\
\text { at one frequency }(25,50, \text { or } 60 \mathrm{c} / \mathrm{s}), \text { one range, and one secondary } \\
\text { voltage, with not more than four values of secondary burden; } \\
\text { namely, those giving zero, half, and full rated noninductive load at } \\
\text { rated voltage, and with one instrument burden of approximately } \\
\text { unity power factor to be specified by the user; primary voltage not }\end{array}$ &
\end{tabular}
to exceed $25,000 \vee$

201.602a-2 As in a-1 except primary voltage greater than $25,000 \mathrm{v}$ but not to exceed 100,000 $\mathrm{v} \ldots \ldots$

201.602b Determination of ratio and phase angle at one value of secondary voltage on an additional range or frequency, and with any of the burdens used in $201.602 \mathrm{a}$

$201.602 \mathrm{c}$

Determination of ratio and phase angle with an additional burden (already used in 201.602a) and with the same combination of range, frequency, and voltage used in $201.602 \mathrm{~b}$

14. 00

201.602d Determination of ratio and phase angle at an additional burden of approximately unity power factor other than those used in 201.602a

$201.602 \mathrm{e}$

Determination of ratio and phase angle at an additional value of secondary voltage on the same combination of range, frequency, and burden used in 201.602a, b, or

For tests of voltage transformers at other frequencies, with primary voltage greater than $100,000 \mathrm{v}$, or with other than unity power factor burdens, and for other special tests not covered by the above schedule, advance arrangements must be made. Fees will be charged depending on the nature of the test. At $400 \mathrm{c} / \mathrm{s}$, test fees are approximately double those at $60 \mathrm{c} / \mathrm{s}$.

16. 00

201.603 Voltage transformer comparators.

\begin{tabular}{c|c|c}
\hline Item & Description & Fee \\
\cline { 2 - 4 } $201.603 \mathrm{z}$ & $\begin{array}{c}\text { Calibrations of voltage transformer comparators are handled on a special } \\
\text { test basis; however, advance arrangements need not be made. Fees } \\
\text { will be charged dependent upon the nature of the calibration required. }\end{array}$ & \\
\hline
\end{tabular}




\begin{tabular}{|c|c|c|}
\hline Item & Description & Fee \\
\hline $201.604 a$ & $\begin{array}{l}\text { Calibration of kilovoltmeters at five scale points on one range using } \\
60 \mathrm{c} / \mathrm{s} \text { alternating voltage (up to } 60 \mathrm{kv} \text { ) }\end{array}$ & $\$ 80.00$ \\
\hline $201.604 b$ & $\begin{array}{l}\text { Calibration of kilovoltmeters at five scale points on one range using } \\
\text { direct voltage of one polarity to ground (up to } 60 \mathrm{kv} \text { ) }\end{array}$ & 80.00 \\
\hline $201.604 \mathrm{c}$ & $\begin{array}{l}\text { Calibration at one scale point on an additional range (up to } 60 \mathrm{kv} \text { ) for } \\
201.604 \mathrm{a} \text { or b }\end{array}$ & 21.00 \\
\hline $201.604 d$ & $\begin{array}{l}\text { Calibration of each additional scale point on one of the ranges calibrated } \\
\text { under } 201.604 \mathrm{a}, \mathrm{b} \text {, or }\end{array}$ & 7.00 \\
\hline $201.604 z$ & $\begin{array}{l}\text { For calibration at voltages above } 60 \mathrm{kv} \text {, advance arrangements must be } \\
\text { made. Fees will be charged dependent upon the nature of the } \\
\text { calibration required. }\end{array}$ & \\
\hline
\end{tabular}

\section{High-Frequency Region}

201.800 (a) General: In the high-frequency region of approximately $30 \mathrm{kc} / \mathrm{s}$ to 300 $\mathrm{Mc} / \mathrm{s}$ and higher, the Electronic Calibration Center, Boulder Laboratories, is equipped to calibrate standards of voltage, power, immittance, attenuation, and field strength. These standards are limited at present to those designed for cw measurements and having coaxial terminals (usually Type $\mathrm{N}$ connectors). No general provisions have yet been made for standards with balanced transmission-line terminals.

Stable rf power sources and detectors are required to perform such measurements. This is accomplished by use of crystal-controlled rf power sources and receivers. Rf power sources have power stabilization circuits that provide a power output constant to within 0.1 percent or better over periods of one hour or more. Special low-noise, crystal-controlled receivers meet the exacting requirements to monitor or detect these signals. In using standards at high frequencies it is often desirable, and even necessary, to duplicate these conditions.

Calibration services for high-frequency standards with coaxial connectors are performed at the fixed frequencies of 30,100 , and $300 \mathrm{kc} / \mathrm{s}$, and $1,3,10,30,100,300$, and $1000 \mathrm{Mc} / \mathrm{s}$. Calibrations are available at other frequencies for some standards, as well as continuous frequency coverage up to $10 \mathrm{Gc} / \mathrm{s}$ for certain calibrations, but usually with less accuracy.

Connectors limit the accuracy of measurements in the high-frequency region to some extent. To avoid instability from this cause, precision connectors should be used on interlaboratory standards. In the case of Type $\mathrm{N}$ connectors, certain mechanical dimensions should fall within tolerances specified by the Armed Services Electro-Standards Agency (ASESA) in Procurement Specification MIL-C-71. If dimensions fall outside the specified tolerances, there is a possibility of damaging the mating connectors on interlaboratory standards and NBS working standards. Critical dimensions of Type $\mathrm{N}$ connectors are indicated on drawings in the brochure entitled "Facilities and Services of the Electronic Calibration Center." This brochure may be obtained from the Electronic Calibration Center, National Bureaı of Standards, Boulder, Colo., 80310.

(b) Fees: The fees to be chargedf or the following calibration services performed at the Boulder Laboratories are not fixed at this time, but estimates will be furnished on request to those who plan to submit standards for calibration. If it becomes apparent that the estimated cost of calibration will be exceeded by more than 10 percent, notification will be made by the Electronic Calibration Center, before further work is done. 
201.810 Rf, rf-d-c voltmeters, and thermal converters in the frequency range of $30 \mathrm{kc} / \mathrm{s}$ to $400 \mathrm{Mc} / \mathrm{s}$; from $0.2 \mathrm{v}$ to $300 \mathrm{v}$. Ordinarily instruments equally suitable for use on $\mathrm{d}$-c and $\mathrm{rf}$ will be calibrated only for $\mathrm{rf}-\mathrm{d}$-c difference by the procedure of item $201.810 \mathrm{a}$, since periodic calibrations can be made by the user on reversed direct current. Such reversed $\mathrm{d}-\mathrm{c}$ calibrations will be made at the Bureau only under unusual circumstances and by advance arrangement. Instruments suitable for use only on rf will be given rf calibrations by the procedures of items $201.810 \mathrm{a}, \mathrm{b}$. Instruments which respond to average or peak values or which are not in ASA accuracy class $1 / 4$ percent or better are not usually accepted for calibration below $30 \mathrm{Mc} / \mathrm{s}$.

\begin{tabular}{|c|c|c|}
\hline Item & Description & Fee \\
\hline $201.810 \mathrm{a}$ & $\begin{array}{l}\text { Determination of voltage at } 30,100,300 \mathrm{kc} / \mathrm{s}, 1,3,10,30 \text {, and } 100 \mathrm{Mc} / \mathrm{s} \\
\text { from } 0.2 \text { to } 300 \mathrm{v}\end{array}$ & $(*)$ \\
\hline $201.810 \mathrm{~b}$ & $\begin{array}{l}\text { Determination of voltage at } 300,400,500,700 \text {, and } 1000 \mathrm{Mc} / \mathrm{s} \text { from } \\
0.2 \text { to } 20 \mathrm{v}\end{array}$ & $(*)$ \\
\hline $201.810 \mathrm{z}$ & Special calibrations not covered by the above schedule & $(*)$ \\
\hline
\end{tabular}

*See 201.800 (b) Fees.

201.811 Rf voltmeters and signal sources in the frequency range of $30 \mathrm{kc} / \mathrm{s}$ to 1000 $\mathrm{Mc} / \mathrm{s}$, from $1 \mu \mathrm{v}$ to $0.1 \mathrm{v}$. The Bureau normally accepts for calibration only high-quality voltmeters suitable for use as interlaboratory standards. These instruments should have a stability of one percent or better and an accuracy of three percent or better. Rf voltmeters will be calibrated by the procedures of items $201.811 \mathrm{a}, \mathrm{b}$. The Bureau usually accepts only signal sources (signal generators) high enough in quality to be considered as interlaboratory standards. If these instruments are equally suitable for use on $\mathrm{d}-\mathrm{c}$ and $\mathrm{rf}$, they will be calibrated for $\mathrm{rf}-\mathrm{d}-\mathrm{c}$ difference by the procedures of items $201.811 \mathrm{a}, \mathrm{b}, \mathrm{c}$. Signal sources suitable for use only on rf will be calibrated by the procedures of items $201.811 \mathrm{a}, \mathrm{c}$.

\begin{tabular}{|c|c|c|}
\hline Item & Description & Fee \\
\hline $201.811 \mathrm{a}$ & $\begin{array}{l}\text { Determination of voltage for voltmeters and signal sources from } 30 \mathrm{kc} / \mathrm{s} \\
\text { to } 400 \mathrm{Mc} / \mathrm{s} \text {, from } 1 \mu \mathrm{v} \text { to } 0.1 \mathrm{v}\end{array}$ & $(*)$ \\
\hline $201.811 b$ & $\begin{array}{l}\text { Determination of voltage for voltmeters from } 400 \text { to } 1000 \mathrm{Mc} / \mathrm{s} \text {, from } \\
100 \mu \mathrm{v} \text { to } 0.1 \mathrm{v}\end{array}$ & $(*)$ \\
\hline $201.811 \mathrm{c}$ & $\begin{array}{l}\text { Determination of voltage for signal sources from } 30 \mathrm{kc} / \mathrm{s} \text { to } 900 \mathrm{Mc} / \mathrm{s} \text {, } \\
\text { from } 100 \mu \mathrm{v} \text { to } 0.1 \mathrm{v}\end{array}$ & $(*)$ \\
\hline $201.811 z$ & Special calibrations not covered by the above schedule & $(*)$ \\
\hline
\end{tabular}

*See 201.800 (b) Fees.

$201.820 \mathrm{Rf}$ calorimeters, $30 \mathrm{kc} / \mathrm{s}$ to $400 \mathrm{Mc} / \mathrm{s}$.

(a) For maximum calibration accuracy, interlaboratory rf calorimetcrs should repeat readings to one percent or better with a constant power input.

(b) At present only rf calorimeters utilizing Type $\mathrm{N}$ connectors for rf power input can be calibrated. Refer to 201.800 for special requirements for Type $\mathrm{N}$ connectors used on interlaboratory standards. 


\begin{tabular}{|c|c|c|}
\hline Item & Description & Fee \\
\hline $201.820 \mathrm{a}$ & $\begin{array}{l}\text { Calibration of rf calorimeter at one frequency at } 100 \text { and } 300 \mathrm{kc} / \mathrm{s} ; 1,3 \text {, } \\
10 \text {, and } 30 \mathrm{Mc} / \mathrm{s} \text {; and at one power level from } 0.001 \text { to } 200 \mathrm{w}_{-}\end{array}$ & $(*)$ \\
\hline $201.820 \mathrm{~b}$ & $\begin{array}{l}\text { Calibration of rf calorimeter at one frequency at } 100,200,300 \text {, and } 400 \\
\mathrm{Mc} / \mathrm{s} \text {; at one power level from } 0.001 \text { to } 100 \mathrm{w}\end{array}$ & $(*)$ \\
\hline $201.820 \mathrm{c}$ & Each additional power level at the same frequency & $(*)$ \\
\hline $201.820 \mathrm{z}$ & Special calibrations not covered by the above schedule & $(*)$ \\
\hline
\end{tabular}

*See 201.800 (b) Fees.

\subsection{Immittance, $30 \mathrm{kc} / \mathrm{s}$ to $1 \mathrm{Gc} / \mathrm{s}$.}

(a) Maximum accuracy can be achieved only in the case of instruments and components equipped with connectors having a plane of reference directly compatible with the Bureau system with no necessity for special adapters. In the interest of preserving higher calibration accuracies, coaxial connectors should be utilized on standard instruments and components wherever possible.

(b) Power applied to any under test will normally not exceed $1 \mathrm{w}$. Where caution in this respect is necessary it should be clearly stated in the calibration request. All calibrations described in this section are performed under ambient conditions of approximately $23{ }^{\circ} \mathrm{C}$ and 50 percent relative humidity.

\begin{tabular}{|c|c|c|}
\hline Item & Description & Fee \\
\hline $201.830 \mathrm{a}-1$ & $\begin{array}{l}\text { Two-terminal impedance measurement at one point in the frequency } \\
\text { range } 30 \text { to } 400 \mathrm{kc} / \mathrm{s}, 0 \text { to } 10,000 \mathrm{ohms} \text { resistance, and } 0 \text { to } 1100 \mu \mathrm{h} \\
\text { inductance. }\end{array}$ & $(*)$ \\
\hline $201.830 \mathrm{a}-2$ & Each additional point within the limits in item $201.830 \mathrm{a}-1 \ldots$ & $(*)$ \\
\hline $201.830 \mathrm{~b}-1$ & $\begin{array}{l}\text { Two-terminal impedance measurement at one point in the frequency } \\
\text { range } 30 \mathrm{kc} / \mathrm{s} \text { to } 1 \mathrm{Mc} / \mathrm{s}, 0 \text { to } 1000 \mathrm{ohms} \text { resistance, and } 0 \text { to } 110 \\
\mu \mathrm{h} \text { inductance. }\end{array}$ & $(*)$ \\
\hline $201.830 \mathrm{~b}-2$ & Each additional point within the limits in item $201.830 \mathrm{~b}-1 \ldots$ & $(*)$ \\
\hline $201.830 \mathrm{c}-1$ & $\begin{array}{l}\text { Two-terminal admittance measurement at one point in the frequency } \\
\text { range } 30 \mathrm{kc} / \mathrm{s} \text { to } 1 \mathrm{Mc} / \mathrm{s}, 0 \text { to } 1100 \mu \mathrm{mho} \text { conductance, and } 0 \text { to } 1100 \\
\text { pf capacitance. }\end{array}$ & $(*)$ \\
\hline $201.830 c-2$ & Each additional point within the limits in item $201.830 \mathrm{c}-1_{----}$ & $(*)$ \\
\hline $201.830 d-1$ & $\begin{array}{l}\text { Two-terminal admittance measurement at one point in the frequency } \\
\text { range } 5 \text { to } 250 \mathrm{Mc} / \mathrm{s}, 0 \text { to } 50 \mu \mathrm{mho} \text { conductance, and } 0 \text { to } 50 \mathrm{pf} \\
\text { capacitance }\end{array}$ & $(*)$ \\
\hline
\end{tabular}




\begin{tabular}{|c|c|c|}
\hline Item & Description & Fee \\
\hline $201.830 \mathrm{~d}-2$ & Each additional point within the limits in item $201.830 \mathrm{~d}-1 \ldots$ & $(*)$ \\
\hline $201.830 \mathrm{e}-1$ & $\begin{array}{l}\text { Two-terminal impedance measurement of coaxial components at } \\
\text { frequencies from } 50 \mathrm{Mc} / \mathrm{s} \text { to } 1 \mathrm{Gc} / \mathrm{s} \text {, within the ranges } 0.5 \text { to } 5000 \\
\text { obms for magnitude and } 0 \text { to } 90^{\circ} \text { for phase angle.-. }\end{array}$ & $(*)$ \\
\hline $201.830 \mathrm{e}-2$ & Each additional point within the limits in item $201.830 \mathrm{e}-1$ & $\left({ }^{*}\right)$ \\
\hline $201.830 f-1$ & $\begin{array}{l}\text { Q-Standard calibration in the frequency range } 50 \mathrm{kc} / \mathrm{s} \text { to } 45 \mathrm{Mc} / \mathrm{s}, 0 \\
\text { to } 1000 \text { for effective } Q \text {, and } 30 \text { to } 450 \mathrm{pf} \text { for effective resonating } \\
\text { capacitance }\end{array}$ & $(*)$ \\
\hline $201.830 \mathrm{z}$ & $\begin{array}{l}\text { Special two-terminal immittance calibrations not covered by the } \\
\text { above schedule. }\end{array}$ & $(*)$ \\
\hline $201.831 \mathrm{a}-1$ & $\begin{array}{l}\text { Three-terminal capacitance calibration at } 100 \mathrm{kc} / \mathrm{s}, 465 \mathrm{kc} / \mathrm{s} \text {, or } 1 \\
\mathrm{Mc} / \mathrm{s} \text { for the following fixed nominal values: } 10^{-2}, 10^{-1}, 10^{0}, 10^{1} \text {, } \\
10^{2} \text {, and } 10^{3} \mathrm{pf} \text {, per frequencey. }\end{array}$ & $(*)$ \\
\hline $201.831 b-1$ & $\begin{array}{l}\text { Three-terminal capacitance calibration at } 465 \mathrm{kc} / \mathrm{s} \text { at one point in the } \\
\text { range } 0.001 \text { to } 100 \mathrm{pf}\end{array}$ & $(*)$ \\
\hline $201.831 b-2$ & Each additional point within the limits in item $201.831 \mathrm{~b}-1 \ldots$ & $(*)$ \\
\hline
\end{tabular}

${ }^{*}$ See 201.800(b) Fees.

\subsection{Dissipative fixed coaxial attenuators.}

(a) Dissipative fixed coaxial attenuators are normally calibrated in a system having a characteristic impedance of $50+j 0$ ohms. Since the accuracy of the calibration is degraded by any deviation or uncertainty in this characteristic impedance, the types of allowable connectors are limited. Precision connectors having a known plane of reference or the Type $\mathrm{N}$ meeting Procurement Specification MIL-C-71 are required. All measurements are made by the substitution method which requires that the connectors used be asexual or the attenuator have a male connector at one port and a female connector at the other port. If an adapter is required to comply with the foregoing, it must be supplied with the attenuator and the combination will be calibrated as one unit. Attenuators having a VSWR of 1.30 or greater at either port are not acceptable.

(b) Maximum power to any attenuator will not exceed $20 \mathrm{mw}$ unless prior arrangements for higher power levels have been made.

\begin{tabular}{c|c|c}
\hline Item & Description & Fee \\
\hline $201.840 a-1$ & $\begin{array}{c}\text { Measurement of insertion loss of fixed attenuator at one of the follow- } \\
\text { ing frequencies: } 1,10,30,60,100, \text { and } 30 \mathrm{Mc} / \mathrm{s} . \quad \text { Range: } 0 \text { to } 100 \\
\mathrm{db}\end{array}$ & $(*)$ \\
*See footnote at end of table.
\end{tabular}




\begin{tabular}{|c|c|c|}
\hline Item & Description & Fee \\
\hline $201.840 a-2$ & $\begin{array}{l}\text { Each additional attenuator at the same frequency and over the same } \\
\text { range as item } 201.840 a-1\end{array}$ & $(*)$ \\
\hline $201.840 \mathrm{~b}-1$ & $\begin{array}{l}\text { Measurement of insertion loss of fixed attenuator at any frequeney } \\
\text { between } 300 \mathrm{Mc} / \mathrm{s} \text { and } 8 \mathrm{Ge} / \mathrm{s} \text {. Range: } 0 \text { to } 60 \mathrm{db}\end{array}$ & $\left({ }^{*}\right)$ \\
\hline $201.840 \mathrm{~b}-2$ & $\begin{array}{l}\text { Each additional attenuator at the same frequeney and over the same } \\
\text { range as item } 201.840 \mathrm{~b}-1\end{array}$ & $(*)$ \\
\hline $201.840 \mathrm{z}$ & Special calibrations not covered by the above schedule........... & $(*)$ \\
\hline
\end{tabular}

-See 201.800(b) Fees.

\subsection{Dissipative variable coaxial attenuators.}

(a) These attenuators are calibrated in accordance with item 201.840 except that the zero or other specified setting of the attenuator is used as the referenee. Because attenuation differenee only is measured, both ports may have the same conneetor.

(b) Variable attenuators must have a repeatability of setting better than $0.1 \mathrm{db}$; incremental attenuators must have a repeatability of $0.01 \mathrm{db}$ or better.

\begin{tabular}{|c|c|c|}
\hline Item & Deseription & Fee \\
\hline $201.841 \mathrm{a}-1$ & $\begin{array}{l}\text { Measurement of one increment on dissipative variable attenuator or } \\
\text { at one of the following frequeneies: } 1,10,30,60,100 \text {, and } 300 \mathrm{Mc} / \mathrm{s} \text {. } \\
\text { Range: } 0 \text { to } 100 \mathrm{db}\end{array}$ & $(*)$ \\
\hline $201.841 \mathrm{a}-2$ & $\begin{array}{l}\text { Each additional increment at the same frequency and over the same } \\
\text { range as item } 201.841 \mathrm{a}-1\end{array}$ & $(*)$ \\
\hline $201.841 b-1$ & $\begin{array}{l}\text { Measurement of one inerement on a dissipative variable attenuator } \\
\text { at any frequency between } 300 \mathrm{Mc} / \mathrm{s} \text { and } 8 \mathrm{Ge} / \mathrm{s} \text {. Range: } 0 \text { to } 60 \mathrm{db} \text { - }\end{array}$ & $(*)$ \\
\hline $201.841 b-2$ & $\begin{array}{l}\text { Each additional inerement at the same frequency and over the same } \\
\text { range as item } 201.841 \mathrm{~b}-1\end{array}$ & $(*)$ \\
\hline $201.841 z$ & Special calibrations not eovered by the above schedule........... & $(*)$ \\
\hline
\end{tabular}

*see 201.800(b) Fees.

\subsection{Waveguide below-cutoff (piston) attenuators.}

(a) Waveguide below-cutoff attenuators are normally ealibrated in a system having a characteristic impedance of $50+j 0 \mathrm{ohms}$. As only attenuation difference measurements are made on this type of attenuator, Type BNC, C, TNC, ete., connectors are acceptable but precision type connectors are preferred. 
(b) An insertion loss measurement at the attenuator zero setting can be made. Maximum power to any attenuator will not exceed $20 \mathrm{mw}$ unless prior arrangements for higher power levels have been made. $\mathrm{Mc} / \mathrm{s}$.

(c) Calibrations are performed at the following frequencies: 1, 10, 30, 60, 100, and 300

\begin{tabular}{|c|c|c|}
\hline Item & Description & Fee \\
\hline $201.842 \mathrm{a}-1$ & $\begin{array}{l}\text { One increment on a waveguide below-cutoff attenuator at one of the } \\
\text { following frequencies: } 1,10,30,60,100 \text {, and } 300 \mathrm{Mc} / \mathrm{s} \text {. Range (in- } \\
\text { cluding initial insertion loss): up to } 110 \mathrm{db}\end{array}$ & $(*)$ \\
\hline $201.842 \mathrm{a}-2$ & $\begin{array}{l}\text { Each additional increment at the same frequency and over the same } \\
\text { range as } 842 a-1\end{array}$ & $(*)$ \\
\hline $201.842 \mathrm{z}$ & Special calibrations not covered by the above schedule.... & $(*)$ \\
\hline
\end{tabular}

*See 201.800(b) Fees.

201.843 Coaxial fixed directional couplers. Fixed directional couplers are calibrated in accordance with item 201.840. Terminations must be supplied for any arm not used during a measurement.

\begin{tabular}{|c|c|c|}
\hline Item & Description & Fee \\
\hline $201.843 a-1$ & $\begin{array}{l}\text { Single insertion loss measurement between any two arms of a coaxial } \\
\text { fixed directional coupler at one of the following frequencies: } 1,10 \text {, } \\
30,60,100 \text {, and } 300 \mathrm{Mc} / \mathrm{s} \text {. Range: } 0 \text { to } 100 \mathrm{db} \text {. }\end{array}$ & $(*)$ \\
\hline $201.843 a-2$ & $\begin{array}{l}\text { Each additional insertion loss measurement between any two arms at } \\
\text { the same frequency and over the same range as item } 201.843 \mathrm{a}-1 \text {. }\end{array}$ & $(*)$ \\
\hline $201.843 \mathrm{~b}-1$ & $\begin{array}{l}\text { Single insertion loss measurement between any two arms at any } \\
\text { frequency between } 300 \mathrm{Mc} / \mathrm{s} \text { and } 8 \mathrm{Gc} / \mathrm{s} \text {. Range: } 0 \text { to } 60 \mathrm{db} \text {. }\end{array}$ & $(*)$ \\
\hline $201.843 b-2$ & $\begin{array}{l}\text { Each additional insertion loss measurement between any two arms at } \\
\text { the same frequency and over the same range as item } 201.843 \mathrm{~b}-1 \text {. }\end{array}$ & $(*)$ \\
\hline $201.843 z$ & Special calibrations not covered by the above schedule.... & $(*)$ \\
\hline
\end{tabular}

*See $201.800(b)$ Fees.

\subsection{Coaxial variable directional couplers.}

(a) Coaxial variable directional couplers are calibrated in accordance with item 201.841. Terminations must be supplied for any arm not used during a measurement.

(b) The change in coupling to the sidearm relative to the minimum setting on the device is normally measured. 


\begin{tabular}{|c|c|c|}
\hline Item & Description & Fee \\
\hline $201.844 a-1$ & $\begin{array}{l}\text { Single coupling increment between input and variable arm of coaxial } \\
\text { variable directional coupler at one of the following frequencies: } 1 \text {, } \\
\text { 10, 30,60,100, and } 300 \mathrm{Mc} / \mathrm{s} \text {. Range (including initial coupling } \\
\text { loss): up to } 110 \mathrm{db} \text {. }\end{array}$ & $(*)$ \\
\hline $201.844 \mathrm{a}-2$ & $\begin{array}{l}\text { Each additional increment at the same frequency, and over the same } \\
\text { range as item } 201.844 a-1 \text {. }\end{array}$ & $(*)$ \\
\hline $201.844 b-1$ & $\begin{array}{l}\text { Same measurement as in item } 201.844 \mathrm{a}-1 \text { at any frequency between } \\
300 \mathrm{Mc} / \mathrm{s} \text { and } 8 \mathrm{Gc} / \mathrm{s} \text {. Range (including initial coupling loss): } \\
\text { up to } 60 \mathrm{db} \text {. }\end{array}$ & $(*)$ \\
\hline $201.844 b-2$ & $\begin{array}{l}\text { Same measurement as in item } 201.844 a-2 \text { at the same frequency and } \\
\text { over the same range as item } 201.844 \mathrm{~b}-1 \text {. }\end{array}$ & $(*)$ \\
\hline $201.844 z$ & Special calibrations not covered by the above schedule & $(*)$ \\
\hline
\end{tabular}

*See 201.800 (b) Fees.

201.850 Field strength meters, $30 \mathrm{c} / \mathrm{s}$ to $1000 \mathrm{Mc} / \mathrm{s}$. Field strength standards and field strength meters are calibrated in terms of $\mathrm{cw}$ signals in the frequency range from $30 \mathrm{c} / \mathrm{s}$ to $1000 \mathrm{Mc} / \mathrm{s}$. Loop antennas are calibrated in the frequency range from $30 \mathrm{c} / \mathrm{s}$ to $30 \mathrm{Mc} / \mathrm{s}$, and horizontally polarized dipole antennas are calibrated from 30 to $1000 \mathrm{Mc} / \mathrm{s}$. The magnitude of the calibrating fields varies from approximately 25 to $200 \mathrm{mv} / \mathrm{m}$ for loop antennas, and approximately $50 \mathrm{mv} / \mathrm{m}$ for dipole antennas.

The internal characteristics of field strength meters, such as the overall linearity of the receiver, accuracy of the signal input attenuators, and the accuracy of the receiver as a twoterminal rf voltmeter can be measured at frequencies from $30 \mathrm{c} / \mathrm{s}$ to $1000 \mathrm{Mc} / \mathrm{s}$.

When field strength standards or meters are submitted for calibration an instruction manual and all accessories should be included, and the instrument should be in excellent operating condition.

\begin{tabular}{|c|c|c|}
\hline Item & Description & Fee \\
\hline $201.850 a-1$ & Calibration of loop antenna at one frequency, $30 \mathrm{c} / \mathrm{s}$ to $30 \mathrm{Mc} / \mathrm{s}_{-}{ }_{--}$ & $(*)$ \\
\hline $201.850 a-2$ & $\begin{array}{l}\text { Calibration of loop antenna at frequencies additional to item } \\
201.250 \mathrm{a}-1,30 \mathrm{c} / \mathrm{s} \text { to } 1 \mathrm{Mc} / \mathrm{s}\end{array}$ & $(*)$ \\
\hline $201.850 \mathrm{a}-3$ & $\begin{array}{l}\text { Calibration of loop antenna at frequencies additional to item } \\
201.850 \mathrm{a}-1,1 \text { to } 30 \mathrm{Mc} / \mathrm{s}\end{array}$ & $(*)$ \\
\hline $201.850 \mathrm{z}$ & Special calibrations not covered by the above schedule & $(*)$ \\
\hline $201.851 \mathrm{a}-1$ & Calibration of dipole antenna at one frequency, 30 to $1000 \mathrm{Mc} / \mathrm{s}_{-}$ & $(*)$ \\
\hline
\end{tabular}




\begin{tabular}{|c|c|c|}
\hline Item & Description & Fee \\
\hline $201.851 \mathrm{a}-2$ & $\begin{array}{l}\text { Calibration of dipole antenna at frequencies additional to item } \\
201.851 \mathrm{a}-1,30 \text { to } 400 \mathrm{Mc} / \mathrm{s}\end{array}$ & $(*)$ \\
\hline $201.851 \mathrm{a}-3$ & $\begin{array}{l}\text { Calibration of dipole antenna at frequencies additional to item } \\
201.851 \mathrm{a}-1,400 \text { to } 1000 \mathrm{Mc} / \mathrm{s}\end{array}$ & $(*)$ \\
\hline $201.851 \mathrm{z}$ & Special calibrations not covered by the above schedule & $(*)$ \\
\hline $201.852 \mathrm{a}-1$ & Calibration of input attenuators at one frequency, initial step...... & $(*)$ \\
\hline $201.852 \mathrm{a}-2$ & $\begin{array}{l}\text { Calibration of additional steps of input attenuator in addition to } \\
\text { item } 201.852 \mathrm{a}-1\end{array}$ & $(*)$ \\
\hline $201.852 b-1$ & $\begin{array}{l}\text { Calibration of the overall linearity of receiver and output circuit at } \\
\text { one frequency and one attenuator setting, initial point }\end{array}$ & $(*)$ \\
\hline $201.852 b-2$ & $\begin{array}{l}\text { Calibration of overall linearity of receiver at other points in addition } \\
\text { to item } 201.852 \mathrm{~b}-1\end{array}$ & $(*)$ \\
\hline $201.852 \mathrm{c}-1$ & $\begin{array}{l}\text { Calibration of the receiver as a two-terminal rf voltmeter, } 1 \text { to } \\
10,000 \mu \mathrm{v}, 0 \text { to } 400 \mathrm{Mc} / \mathrm{s} \text {, at one frequency }\end{array}$ & $(*)$ \\
\hline $200.852 c-2$ & $\begin{array}{l}\text { Calibration of the receiver as a two-terminal rf voltmeter at other } \\
\text { frequencies additional to item } 201.852 \mathrm{c}-1,0 \text { to } 400 \mathrm{Mc} / \mathrm{s}\end{array}$ & $(*)$ \\
\hline $201.852 c-3$ & $\begin{array}{l}\text { Calibration of receiver as a two-terminal rf voltmeter at other fre- } \\
\text { quencies additional to item } 201.852 \mathrm{c}-1,400 \text { to } 1000 \mathrm{Mc} / \mathrm{s} .\end{array}$ & $(*)$ \\
\hline $201.852 \mathrm{z}$ & Special calibrations not covered by the above schedule ... & $(*)$ \\
\hline
\end{tabular}

"See 201.800(b) Fees.

\section{Microwave Region}

\subsection{General.}

(a) Microwave calibration services presently available include measurements in power, impedance, frequency, attenuation, and noise. The frequency range covered for each of the measurements is given below.

In performing microwave calibrations, a considerable amount of time usually is needed to prepare the system for measurement operation. Much of this preparation is related to the adjustment of the system to the frequency of operation selected for the calibration. Time and cost often can be reduced by minimizing the number of times the operating frequency of the calibration system must be readjusted. To help in achieving this reduction in costs, a list of suggested calibration frequencies is presented in the following table. These frequencies are suggested for use in connection with this schedule and for interlaboratory standards utilizing terminations consisting of the standard waveguide sizes given below in the table of suggested calibration frequencies. It should be emphasized that the suggested frequencies are primarily for economy and for convenience to those requesting calibrations. In general the calibration 
instrumentation for the microwave region is intended to provide complete and continuous frequency coverage as appropriate for the various waveguide sizes. Those having need for calibrations at other than suggested frequencies can be accommodated.

\begin{tabular}{|c|c|c|c|c|}
\hline \multirow{2}{*}{ EIA waveguide designation } & \multirow{2}{*}{$\begin{array}{l}\text { Frequency } \\
\text { range, Gc/s }\end{array}$} & \multicolumn{3}{|c|}{$\begin{array}{l}\text { Suggested calibration frequencies } \\
\mathrm{Gc} / \mathrm{s}\end{array}$} \\
\hline & & No. 1 & No. 2 & No. 3 \\
\hline WR 284_......... & $2.60-3.95$ & 2.85 & 3.25 & 3.55 \\
\hline WR $187 \ldots \ldots$ & $3.95-5.85$ & 4.35 & 4.90 & 5.25 \\
\hline WR $137 \ldots \ldots$ & $5.85-8.20$ & 6.45 & 7.00 & 7.40 \\
\hline WR $112 \ldots \ldots$ & $7.05-10.0$ & 7.75 & 8.50 & 9.00 \\
\hline WR $90 \ldots \ldots$ & $8.20-12.4$ & 9.00 & 9.80 & 11.2 \\
\hline WR $62 \ldots \ldots$ & $12.4-18.0$ & 13.5 & 15.0 & 17.0 \\
\hline WR $42 \ldots \ldots$ & $18.0-26.5$ & 19.8 & 22.0 & 23.8 \\
\hline WR $28 \ldots \ldots \ldots$ & $26.5-40.0$ & 29.0 & 33.0 & 37.0 \\
\hline
\end{tabular}

(b) Fees: The fees to be charged for the following calibration services performed at the Boulder Laboratories are not fixed at this time, but estimates will be furnished on request to those who plan to submit standards for calibration. If it becomes apparent that the estimated cost of calibration will be exceeded by more than 10 percent, notification will be made by the Electronic Calibration Center, before further work is done.

\subsection{Continuous low-level, power measurement of waveguide bolometer units} and bolometer-coupler units.

(a) Power measurements are made on barretter-type bolometer units having nominal resistance of either 100 or 200 ohms at a bias current between 3.5 and $10 \mathrm{ma}$, and on thermistortype bolometer units having a nominal resistance of either 100 or 200 ohms at a bias current between 5 and 15 ma. Bolometer units should be of the fixed tuned or untuned broadband type.

(b) Power measurements are made on bolometer units at power values from 0.1 to $10 \mathrm{mw}$.

(c) Power measurements are made on bolometer-coupler combinations having coupling ratios from 3 to $20 \mathrm{db}$. A bolometer unit of the fixed tuned or un tuned broadband type should be permanently attached to the side arm of the coupler. The three-port directional coupler should have good design features with a directivity of $40 \mathrm{db}$ or greater and a VSWR no greater than 1.05 for the input and output ports of the main arm of the coupler.

(d) Effective efficiency, $\eta_{e u}$, for bolometer units is defined as the ratio of the substituted d-c power in the bolometer element to the microwave power dissipated within the bolometer unit.

(e) Calibration factor for bolometer units is defined as the ratio of the substituted d-c power in the bolometer unit to the microwave power incident upon the bolometer unit.

(f) Calibration factor for bolometer-coupler units is defined as the ratio of the substituted $\mathrm{d}$-c power in the bolometer unit on the side arm of the directional coupler to the microwave power incident upon a nonreflecting load attached to the output port of the main arm. 


\begin{tabular}{|c|c|c|}
\hline Item & Description & Fee \\
\hline & $\begin{array}{l}\text { Measurement of effective efficiency of bolometer unit at a single fre- } \\
\text { quency of the following waveguide sizes terminated with standard } \\
\text { waveguide connectors: }\end{array}$ & \\
\hline 201. $910 \mathrm{a}-1$ & WR90 $(8.2-12.4 \mathrm{Ge} / \mathrm{s})$ & $(*)$ \\
\hline \multirow[t]{2}{*}{ 201. $910 \mathrm{a}-2$} & WR62 $(12.4-18.0 \mathrm{Gc} / \mathrm{s})$ & $(*)$ \\
\hline & $\begin{array}{l}\text { Measurement of calibration factor of bolometer unit at a single fre- } \\
\text { quency of the following waveguide sizes terminated with standard } \\
\text { waveguide connectors: }\end{array}$ & \\
\hline 201. $910 b-1$ & WR90 (8.2-12.4 Gc/s) & $(*)$ \\
\hline \multirow[t]{2}{*}{ 201. $910 b-2$} & WR62 $(12.4-18.0 \mathrm{Gc} / \mathrm{s}) \ldots$ & $(*)$ \\
\hline & $\begin{array}{l}\text { Measurement of calibration factor of bolometer-coupler unit at a } \\
\text { single frequency of the following waveguide sizes terminated with } \\
\text { standard waveguide connectors: }\end{array}$ & \\
\hline 201. $910 c-1$ & WR90 $(8.2-12.4 \mathrm{Gc} / \mathrm{s})_{\ldots} \ldots$ & $(*)$ \\
\hline 201. 910c-2 & WR62 $(12.4-18.0 \mathrm{Gc} / \mathrm{s}) \ldots$ & $(*)$ \\
\hline $201.910 z$ & Special calibrations not covered by the above schedule _... & $(*)$ \\
\hline
\end{tabular}

*See 201.900(b) Fees.

201.911 Continuous low-level power measurement of waveguide dry calorimeters.

(a) Power measurements are made on dry calorimeters at power values from 10 to $100 \mathrm{mw}$.

\begin{tabular}{|c|c|c|}
\hline Item & Description & Fee \\
\hline 201. $911 \mathrm{a}-1$ & $\begin{array}{l}\text { Measurement of output voltage versus input microwave power for } \\
\text { dry calorimeter at a single frequency of WR90 waveguide (8.2- } \\
12.4 \mathrm{Gc} / \mathrm{s} \text { ) terminated with standard waveguide connectors. }\end{array}$ & $\left({ }^{*}\right)$ \\
\hline 201. 911a-2 & $\begin{array}{l}\text { Each additional power value at the same frequency as Item } 201.911 \text { a- } \\
1 .\end{array}$ & $(*)$ \\
\hline $201.911 \mathrm{z}$ & Special calibrations not covered by the above schedule... & $(*)$ \\
\hline
\end{tabular}

*See 201.000(b) Fees.

201.920 Reflection coefficient magnitude measurement on waveguide reflectors (mismatches).

(a) Reflection coefficient measurements are made on reflectors producing a reflection coefficient magnitude in the range of 0.025 to 1.0 . 
(b) Reflectors must be fitted with standard types of waveguide flanges. The face of these flanges should be machined flat and smooth and should not contain protrusions or indentations. The connecting holes of the flange should be symmetrically and accurately alined to the rectangular waveguide opening.

\begin{tabular}{|c|c|c|}
\hline Item & Description & Fee \\
\hline $201.920 a-1$ & $\begin{array}{l}\text { Measurement of reflection coefficient magnitude of reflector at a single } \\
\text { frequency of WR } 90 \text { waveguide }(8.2-12.4 \mathrm{Gc} / \mathrm{s}) \text { terminated with } \\
\text { standard waveguide connectors }\end{array}$ & $(*)$ \\
\hline $201.920 \mathrm{z}$ & Special calibrations not covered by the above schedule & $(*)$ \\
\hline
\end{tabular}

*See 201.900 (b) Fees.

\subsection{Frequency measurement on cavity wavemeters.}

(a) Frequency measurements are made on fixed or variable cavity wavemeters of either the reaction (one-port) type or the transmission (two-port) type.

(b) Frequency measurements are made on fixed or variable cavity wavemeters having coaxial terminals with Type $N$ connectors (male or female) in the frequency range of 100 $\mathrm{Mc} / \mathrm{s}$ to $10 \mathrm{Gc} / \mathrm{s}$.

(c) Frequency measurements are made on fixed or variable cavity wavemeters having standard rectangular waveguide terminals with standard type waveguide terminals in the frequency range of 2.6 to $75 \mathrm{Gc} / \mathrm{s}$.

\begin{tabular}{|c|c|c|}
\hline Item & Description & Fee \\
\hline $201.930 \mathrm{a}$ & Measurement of resonant frequency of fixed cavity wavemeter & $(*)$ \\
\hline $201.930 \mathrm{~b}$ & Setting of adjustable cavity wavemeter at prescribed resonant frequency & $(*)$ \\
\hline $201.930 c-1$ & $\begin{array}{l}\text { Calibration of dial setting versus resonant frequency of variable } \\
\text { cavity wavemeter at initial prescribed frequency.-- }\end{array}$ & $(*)$ \\
\hline $201.930 c-2$ & $\begin{array}{l}\text { Calibration of dial setting versus resonant frequency of variable } \\
\text { cavity wavemeter at each prescribed frequency additional to the } \\
\text { initial frequency and on the same wavemeter as } 201.930 \mathrm{c}-1\end{array}$ & $(*)$ \\
\hline $201.930 z$ & Special calibrations not covered by the above schedule & $(*)$ \\
\hline
\end{tabular}

*See 201.900 (b) Fees.

\subsection{Attenuation difference measurements on variable attenuators.}

(a) Attentuation difference measurements are made on step or continuously variable attenuators usually with the zero dial setting used as the reference position. 
(b) Attenuation measurements are made for attenuation ralues from 0 to $50 \mathrm{db}$. This range of attenuation values can be extended to $70 \mathrm{db}$ in some frequency ranges.

(c) Variable attenuators should have a repeatability of dial setting better than $\pm 0.1 \mathrm{db}$.

(d) Variable attenuators should have a VSWR less than 1.1 at each waveguide port.

\begin{tabular}{|c|c|c|}
\hline Item & Description & Fee \\
\hline & $\begin{array}{l}\text { Measurement of attenuation difference of direct-reading variable } \\
\text { attenuator at an initial prescribed dial setting at a single frequency } \\
\text { of the following waveguide sizes terminated with standard wave- } \\
\text { guide connectors: }\end{array}$ & \\
\hline $201.940 a-1$ & WR284 (2.60-3.9j Gc/s) $\ldots$ & $(*)$ \\
\hline $201.940 a-2$ & WR187 (3.95-5.85 Gc/s) & $(*)$ \\
\hline $201.940 \mathrm{a}-3$ & WR137 $(5.85-8.2 \mathrm{Gc} / \mathrm{s})$ & $(*)$ \\
\hline $201.940 \mathrm{a}-4$ & WR112 (7.05-10.0 Gc/s) -- & $(*)$ \\
\hline $201.940 \mathrm{a}-5$ & WR90 $(8.2-12.4 \mathrm{Gc} / \mathrm{s}) \ldots$ & $(*)$ \\
\hline $201.940 \mathrm{a}-6$ & WR62 (12.4-18.0 Gc/s) $\ldots$ & $(*)$ \\
\hline $201.940 a-7$ & WR42 $(18.0-26.5 \mathrm{Gc} / \mathrm{s})$ & $(*)$ \\
\hline $201.940 a-20$ & $\begin{array}{l}\text { Measurement of attenuation difference of direct-reading rariable } \\
\text { attenuator at each prescribed dial setting additional to the initial } \\
\text { dial setting at the same frequency and on the same attenuator as } \\
201.940 \mathrm{a}-1 \text { to } 201.940 \mathrm{a}-7 \text {. }\end{array}$ & $(*)$ \\
\hline & $\begin{array}{l}\text { Calibration of dial setting versus attenuation difference for indirect- } \\
\text { reading variable attenuator at an initial prescribed attenuation } \\
\text { difference value at a single frequency of the following waveguide } \\
\text { sizes terminated with standard waveguide connectors: }\end{array}$ & \\
\hline $201.940 \mathrm{~b}-1$ & WR284 $(2.60-3.95 \mathrm{Gc} / \mathrm{s})$ & $(*)$ \\
\hline $201.940 b-2$ & WR187 $(3.95-5.85 \mathrm{Gc} / \mathrm{s}))_{\ldots}$ & $(*)$ \\
\hline $201.940 b-3$ & WR137 (5.85-8.2 Gc/s) ... & $(*)$ \\
\hline $201.940 \mathrm{~b}-4$ & WR112 $(7.05-10.0 \mathrm{Gc} / \mathrm{s})$ & $(*)$ \\
\hline $201.940 \mathrm{~b}-5$ & WR90 (8.2-12.4 Gc/s) & $(*)$ \\
\hline $201.940 \mathrm{~b}-6$ & WR62 (12.4-18.0 Gc/s) _. & $(*)$ \\
\hline $201.940 \mathrm{~b}-7$ & WR42 (18.0-26.5 Gc/s) & $(*)$ \\
\hline
\end{tabular}




\begin{tabular}{c|c|c}
\hline Item & Description & Fee \\
\hline $201.940 \mathrm{~b}-20$ & $\begin{array}{l}\text { Calibration of dial setting versus attenuation difference for indirect- } \\
\text { reading variable attenuator at each prescribed attenuation differ- } \\
\text { ence value additional to the initial attenuation difference value at } \\
\text { the same frequency and on the same attenuator as 201.940b-1 to } \\
201.940 \mathrm{~b}-7 .\end{array}$ & $(*)$ \\
$201.940 \mathrm{z}$ & Special calibrations not included in the above schedule_.........- & $(*)$ \\
\hline
\end{tabular}

*See 201.900 (b) Fees.

\subsection{Insertion loss measurements on fixed attenuators.}

(a) Insertion loss measurements are made on fixed two-port attenuators.

(b) Insertion loss measurements are made for insertion loss values from 0 to $50 \mathrm{db}$. This range of attenuation values can be extended to $70 \mathrm{db}$ in some frequency ranges.

(c) Fixed attenuators should have a VSWR less than 1.1 at each waveguide port.

\begin{tabular}{|c|c|c|}
\hline Item & Description & Fee \\
\hline & $\begin{array}{l}\text { Measurement of insertion loss of fixed attenuator at a single frequency } \\
\text { of the following waveguide sizes terminated with standard wave- } \\
\text { guide connectors: }\end{array}$ & \\
\hline $201.941 \mathrm{a}-1$ & WR284 $(2.60-3.95 \mathrm{Gc} / \mathrm{s}) \ldots \ldots$ & $(*)$ \\
\hline $201.941 \mathrm{a}-2$ & WR187 (3.95-5.85 Gc/s) & $(*)$ \\
\hline $201.941 \mathrm{a}-3$ & WR137 (5.85-8.2 Gc/s) & $(*)$ \\
\hline $201.941 \mathrm{a}-4$ & WR112 $(7.05-10.0 \mathrm{Gc} / \mathrm{s}) \ldots$ & $(*)$ \\
\hline $201.941 \mathrm{a}-5$ & WR90 $(8.2-12.4 \mathrm{Gc} / \mathrm{s})$ & $(*)$ \\
\hline $201.941 \mathrm{a}-6$ & 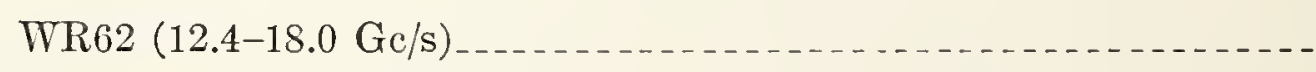 & $(*)$ \\
\hline $201.941 \mathrm{a}-7$ & $\mathrm{WR} 42(18.0-26.5 \mathrm{Gc} / \mathrm{s}) \ldots \ldots \ldots$ & $(*)$ \\
\hline $201.941 \mathrm{z}$ & Special calibrations not included in the above schedule.... & $\left(^{*}\right)$ \\
\hline
\end{tabular}

*See 201.900(b) Fees.

\subsection{Effective noise temperature measurements on noise sources.}

(a) Effective noise temperature measurements are made on waveguide noise sources (usually a gas-discharge tube) under conditions of continuous, unmodulated operation in the range 900 to $300,000{ }^{\circ} \mathrm{K}$ (excess noise ratio range 2.5 to $30 \mathrm{db}$ ). 
(b) The direct current required for normal operation of the gas-discharge tube should not exceed $300 \mathrm{ma}$ but should be sufficient to prevent excessive plasma oscillations.

(c) The waveguide noise source must have an input VSWR no greater than 1.7.

(d) The gas-discharge tube should be secure in the mount, and the output port of the unit should be terminated with a matched load.

\begin{tabular}{c|c|c}
\hline \multicolumn{1}{c|}{ Item } & Description & Fee \\
\hline $201.950 \mathrm{a}-1$ & $\begin{array}{l}\text { Measurement of effective noise temperature of noise source in WR90 } \\
\text { waveguide at a single frequency selected from 9.0, 9.8, and } \\
11.2 \mathrm{Gc} / \mathrm{s}\end{array}$ & (*) \\
$201.950 \mathrm{z}$ & Special calibrations not covered by the above schedule $\ldots \ldots \ldots$ & $\left.*^{*}\right)$ \\
\hline
\end{tabular}

*See 201.900 (b).

\section{Part 202-Metrology}

Photometry and Colorimetry

Sec.

202.181 Lamp standards of candlepower

202.182 Photometric instruments and accessories

202.183 Miscellaneous photometric measurements and tests

202.184 Rating of incandescent electric lamps

202.185 Spectrophotometric standards

202.186 Spectrophotometric measurements

202.187 Colorimetry

202.188 Reflectometry

202.189 Opacimetry

202.191 Lovibond glasses

202.192 Signal glasses

202.193 Haze standards

202.194 Radiometry

Refractometry

202.201 Optical instruments

202.202 Photographic objectives

202.203 Optical components, spectacle lenses, goggle lenses, etc.

202.204 Refractometric instruments

202.205 Refractive indices

202.206 Polarimetric instruments

Photographic Research

202.311 Photography (step table density, residual thiosulfate concentration, etc.)

Length

202.401 Reference line standards of length

202.402 Working line standards of length 
202.403 Commercial line standards of length

202.404 Steel tapes

202.405 lnvar basc-line tapes

202.406 Surveyor's' measuring instruments (other than tapes)

202.407 Sieves

202.408 Haemacytometers

202.409 Areas and area-measuring instruments

202.410 Precision circles

202.411 Linear thermal expansion of solids

202.412 Gage blocks

Engineering Metrology

202.500 General

202.501 End standards of length

202.502 Plain cylindrical plug and ring gages

202.503 Thread plug and ring gages

202.504 Instruments and components

202.505 Optical reference planes

202.506 Angle blocks

202.507 Polygons

202.508 Master balls

202.509 Gears

202.610 General

202.611 Reference standards of mass

202.612 Large mass standards

202.613 Calibration of mass elements of prcssure-gage testing apparatus

202.614 Recalibration of mass standards

202.615 Glass volumetric apparatus

202.616 Metal volumetric apparatus

202.617 Hydrometers

202.618 Density determination of solids and liquids

Photometry and Colorimetry

\subsection{Lamp standards of candlepower.}

(a) The Bureau is prepared to standardize incandescent filament lamps which have been properly seasoned, or to season and standardize lamps when necessary, or to furnish lamps (of the more common types and sizes) that have been seasoned and standardized, the respective fees being as given in the test fee schedule in this section.

(b) A normal incandescent lamp when operated at constant voltage usually increases slightly in candlepower for a short time, the length of which depends upon the temperature of the filament. A relatively stable period is then reached, after which there is a progressive drop in the candlepower. Therefore, in order that a lamp may be useful as a photometric standard, it should be seasoned by a preliminary burning sufficient to bring it to the stable state. This seasoning is usually done by operating the lamp at a voltage somewhat higher than the normal operating voltage of the lamp.

(c) Lamps with coiled filaments are not usually satisfactory as standards unless they have been specially constructed for this purpose. In particular, lamps of this type are not suitable for standards of horizontal candlepower unless they are of the monoplane-filament projection type. This type of gas-filled lamp with clcar bulb (items 202.181a, b, and c) has been found to be satisfactory as a standard of horizontal candlepower when standardized with a diaphragm in front of the lamp. This diaphragm is slightly larger than the filament and allows only the light coming directly from the filament to reach the photometer. In addition, great care must be taken to orient such standards properly because their candlepower varies appreciably 
with change of angle around both a vertical axis and a horizontal axis. Recently made available are gas-filled standards of horizontal candlepower in tubular, inside-frosted bulbs with medium-bipost bases (items $202.181 \mathrm{~d}$, e, f, and g), which are calibrated and used without a diaphragm and for which accurate orientation has been found to be much less critical. These inside-frosted lamps are recommended for use where reproducibility of candlepower to 1 percent or better is required.

(d) When lamps are submitted for standardization it is necessary that they be accompanied by a statement as to whether they have been seasoned. If they have been seasoned, the voltage at which they were burned and the number of hours should be given if known. It should be stated also whether they are to be standardized at a given voltage or current at the fees listed below or at a given candlepower or color temperature at an increased fee. In the reports which are issued with standard lamps, the voltage and the corresponding current and candlepower are given. The Bureau cannot guarantee the permanence of these values, since all lamps change gradually with use.

\begin{tabular}{c|c|c}
\hline Iten & Description & Fee \\
\hline & Incandescent lamps issued from stock as standards of luminous intensity: &
\end{tabular}

202.181a Clear bulb, approximately 120-v lamps, horizontal candles in a specified direction, screw base, 100-w size, calibrated at $105 \mathrm{v}$, one lamp each

Same, 250-w size, one lamp each

$202.181 \mathrm{c}$

Same, 500-watt size, one lamp each

$202.181 d$

Inside-frosted, T-20 bulb, approximately 120-v lamps, horizontal candles in a specified direction, medium-bipost base, 100-w size, calibrated at $110 \mathrm{v}$, one lamp each.

$202.181 \mathrm{e}$

Same, 300-w size, one lamp each

49.00

$202.181 \mathrm{f}$

Same, 500-w size, one lamp each

51.00

$202.181 \mathrm{~g}$

Same, 1,000-w size, one lamp each

$202.181 \mathrm{k}$

Additional fee for calibrating lamps on items 202.181a to $\mathrm{g}$ inclusive

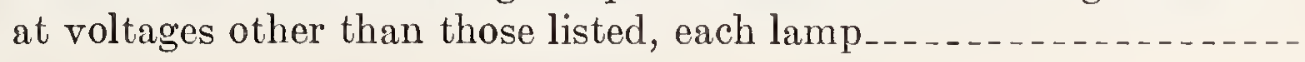

Standardization of seasoned incandescent lamps submitted for standardization, approximately $120-\mathrm{v}$ lamps, medium-screw, mogulscrew, or medium-bipost base:

202.1811 Clear or inside-frosted bulb, horizontal candles in a specified direction, 100- to 1,000-iv sizes, one lamp each . . . . . . . .

Same as item 202.181l, each additional lamp of same size submitted at the same time for calibration at approximately the same voltage

Seasoning of incandescent lamps for standardization, and preliminary measurements, 10 to $200 \mathrm{w}$, each lamp 


\begin{tabular}{|c|c|c|}
\hline Itcm & Description & Fee \\
\hline $202.181 \mathrm{p}$ & $\begin{array}{l}\text { Same, other sizes and types up to } 5,000 \mathrm{w} \text { and all series-burning lamps- } \\
\text { Standardization of seasoned fluorescent and mercury lamps submitted } \\
\text { for calibration: }\end{array}$ & $\$ 9.00$ \\
\hline $202.181 q$ & $\begin{array}{l}\text { Determination of luminous flux (lumens) of "white," "cool white," or } \\
\text { "daylight" fluorescent lamps, one lamp }\end{array}$ & 47.00 \\
\hline $202.181 \mathrm{r}$ & Same, each additional lamp $\ldots \ldots \ldots \ldots$ & 23.00 \\
\hline $202.181 \mathrm{~s}$ & $\begin{array}{l}\text { Determination of luminous flux (lumens) of mercury vapor lamps, one } \\
\text { lamp }\end{array}$ & 63.00 \\
\hline $202.181 t$ & Same, each additional lamp & 35.00 \\
\hline $202.181 z$ & $\begin{array}{l}\text { For special tests not covered by the above schedule, fees will be charged } \\
\text { dependent upon the nature of the test. }\end{array}$ & \\
\hline
\end{tabular}

202.182 Photometric instruments and accessories.

\begin{tabular}{c|c|c}
\hline Item & Description & Fee \\
\hline $202.182 \mathrm{f}$ & $\begin{array}{c}\text { Standard of luminous directional transmittance (approximately 0.5 fl/fc) } \\
\text { supplied from stock, each. }\end{array}$ & $\begin{array}{c}\text { For special tests not covered by the above schedule, fees will be charged } \\
\text { dependent upon the nature of the test. }\end{array}$ \\
\hline
\end{tabular}

202.183 Miscellaneous photometric measurements and tests.

\begin{tabular}{|c|c|c|}
\hline Item & Description & Fee \\
\hline $202.183 a$ & $\begin{array}{l}\text { Determination of luminous transmittance of neutral or colored filter, } \\
\text { one sample. }\end{array}$ & $\$ 33.00$ \\
\hline $202.183 b$ & $\begin{array}{l}\text { Same, each additional sample of approximately the same transmittance } \\
\text { submitted at the same time or at each additional color temperature } \\
\text { of illuminant }\end{array}$ & 10.00 \\
\hline $202.183 z$ & $\begin{array}{l}\text { For special tests not covered by the above schedule, fees will be charged } \\
\text { dependent upon the nature of the test. }\end{array}$ & \\
\hline
\end{tabular}


202.184 Rating of incandescent electric lamps.

\begin{tabular}{|c|c|c|}
\hline Item & Description & Fee \\
\hline & $\begin{array}{l}\text { Rating tests on lamps. These are routine photometric rating tests of } \\
\text { of the type made initially on lamps to be life-tested, the same } \\
\text { standards and equipment being used. The purpose of these tests } \\
\text { is to afford a quick check of the photometric values assigned to } \\
\text { lamps by various lamp life-test laboratories. Lamp standards of } \\
\text { candlepower are issued or calibrated under } 202.181 \text {. }\end{array}$ & \\
\hline $202.184 \mathrm{a}$ & Rating of incandescent lamps up to $1,000 \mathrm{w}$, one lamp & $\$ 22.00$ \\
\hline $202.184 b$ & Same, each additional lamp of same size and type.... & 5. 00 \\
\hline $202.184 \mathrm{z}$ & $\begin{array}{l}\text { For special tests not covered by the above schedule, fees will be charged } \\
\text { dependent upon the nature of the test. }\end{array}$ & \\
\hline
\end{tabular}

\subsection{Spectrophotometric standards.}

Nоте on item a. Transmittances of these disks at wavelengths from 365 to $390 \mathrm{~nm}$ (nanometer, $10^{-9}$ meter) and from 750 to $1,000 \mathrm{~nm}$ will also be determined on request in accordance with item c of fee schedule 202.185. Values will be obtained for a temperature of $25^{\circ} \mathrm{C}$. The effect of change of temperature has not been determined for these glasses outside the range from 390 to $750 \mathrm{~nm}$. It is known, however, that for all four types of glass the temperature effects are very small from 750 to $1,000 \mathrm{~nm}$, probably negligible for the usual room-temperature variations. On the other hand, temperature effects are always large for these kinds of glass when the transmittance curve is decreasing rapidly towards shorter wavelengths, so that increasingly large temperature effects may be expected for these filters in the ultraviolet.

Note on items $j$ and $k$. In the General Electric recording spectrophotometer the design is such that the radiant energy is incident in a slightly diverging beam whose axis is at $6^{\circ}$ to the perpendicular to the surface. The specular component of the reflected energy is thus diverted away from the entrance aperture towards a port on the side. This port may be filled with $\mathrm{MgO}$ or with a black material, so that the specular component may be respectively "included" in, or (for plane surfaces) "excluded" from, the measurements. This is covered in items $\mathrm{j}$ and $\mathrm{k}$.

Only one Vitrolite working standard is needed for the measurement of spectral directional reflectance on the General Electric recording spectrophotometer. This calibrated Vitrolite standard and the samples to be tested are in turn placed at the sample aperture of the integrating spheres, and any highly reflecting substance such as $\mathrm{MgO}$ or $\mathrm{MgCO}_{3}$ may be used at the comparison aperture provided the material to be tested does not reflect more than the comparison material. The directional reflectances of the test samples relative to freshly prepared $\mathrm{MgO}$ are then obtained by multiplying (at the respective corrected wavelength) the values for these samples read from the curve sheet, by the ratios of (a) the standard Vitrolite values reported to (b) the values for the Vitrolite read from the curve sheet.

\begin{tabular}{c|c|c}
\hline Item & Description & Fee \\
\hline $\begin{array}{l}\text { Standards of spectral transmittance for checking the photometric scale } \\
\text { of spectrophotometers; these consist of polished disks of glass, 2 to } 3 \\
\text { mm thick and } 30 \text { mm in diameter, designated as cobalt blue, copper green, } \\
\text { carbon yellow, and selenium orange (copper green filter also available } \\
\text { in 25 mm square size); report includes (1) values of transmittance at }\end{array}$ &
\end{tabular}




Item $\mid$\begin{tabular}{c} 
Description \\
\hline
\end{tabular}

$25^{\circ} \mathrm{C}$ at certain wavelengths from 390 to $750 \mathrm{~nm},(2)$ estimated uncertainty of each value, (3) effect of temperature change on transmittance at each wavelength:

$202.185 \Omega$

Eacli disk

$\$ 100.00$

Transmittance, 365 to $1,000 \mathrm{~nm}$ for standardization purposes. Samples submitted must be in good optical condition. Measurements at room temperature. (If the sample is a disk $29.7 \pm 0.2 \mathrm{~mm}$ in diameter, the measurements can be made at a specified temperature):

$202.185 b$

One sample at one wavelength

39.00

$202.185 \mathrm{c}$

Each additional wavelength on the same sample.

9.00

Didymium glass standards for checking the wavelength calibration of General Electric recording spectrophotometers; these consist of Corning 5120 glass, $2 \times 2$ in., $3.0 \mathrm{~mm}$ thick, polished; report includes table of wavelengths of minimum transmittance:

$202.185 d$

$202.185 \mathrm{e}$

400 to $750 \mathrm{~nm}, 10 \mathrm{~nm}$ slits, each standard

Fee

$202.185 f$

730 to $1,080 \mathrm{~nm}, 20 \mathrm{~nm}$ slits, each standard

50.00

50.00

For two calibrations on the same glass (items $202.185 \mathrm{~d}$ and $202.185 \mathrm{e}$ ), each standard.

76. 00

Holmium oxide glass standards for checking the ultraviolet and visible wavelength calibrations of recording spectrophotometers with slit width less than $2 \mathrm{~nm}$; these consist of Corning 3130 glass $2 \times 2$ in., $2.5 \mathrm{~mm}$ thick, polished; report includes table of wavelengths of minimum transmittance:

$202.185 \mathrm{~g}^{\circ}$

240 to $370 \mathrm{~nm}$, each standard

$202.185 \mathrm{~h}$

$202.185 \mathrm{i}$

360 to $650 \mathrm{~nm}$, each standard

85.00

85.00

For two calibrations on the same glass (items 202.185g and 202.185h), each standard

110.00

Working standards of spectral directional reflectance for use on General Electric rccording spectrophotometers with $6^{\circ}$ from perpendicular irradiation and diffuse reception; standards consist of white structural Vitrolite glass, $4 \times 4$ in., $5 / 16$ in. thick; report includes table of spectral directional reflectances relative to freshly prepared $\mathrm{MgO}$ at every $10 \mathrm{~nm}$ :

$202.185 j$

400 to $750 \mathrm{~nm}$, specular component both included and excluded (on same glass), $10 \mathrm{~nm}$ slits, each standard.

110. 00

730 to $1,080 \mathrm{~nm}$, specular component both included and excluded (on same glass), $20 \mathrm{~nm}$ slits, each standard 


\begin{tabular}{l|l|l}
\hline Item & Description & Fee \\
\hline
\end{tabular}

Working standards of spectral directional reflectance for use on the Beckman Model DU quartz spectrophotometer with nearly perpendicular irradiation and approximately $45^{\circ}$ circular reception; standards consist of white structural Vitrolite glass, $1 \frac{11}{2} \times 2$ in., $7 / 16$ in. thick; report includes table of spectral reflectances relative to freshly prepared $\mathrm{MgO}$ at every $10 \mathrm{~nm}$ :

202.1851

380 to $770 \mathrm{~nm}$, each standard

$\$ 64.00$

$202.185 \mathrm{~m}$

750 to $1,000 \mathrm{~nm}$, each standard

64.00

$202.185 n$

350 to $1,000 \mathrm{~nm}$, each standard

115.00

$202.185 z$

For special tests not covered by the above schedule, fees will be charged dependent upon the nature of the test.

202.186 Spectrophotometric measurements. The tests described in this section are primarily made for informational purposes, and samples so tested should not be accepted as "standards." All measurements are made at room temperature For various types of spectrophotometric standards, see 202.185.

\begin{tabular}{|c|c|c|}
\hline Item & Description & Fee \\
\hline & Spectral transmittance, 210 to $1,000 \mathrm{~nm}$ : & \\
\hline $202.186 a$ & One sample at one wavelength $\ldots$ & $\$ 43.00$ \\
\hline $202.186 \mathrm{~b}$ & Each additional wavelength on the same sample & 4. 00 \\
\hline $202.186 c$ & Each additional sample, each wavelength & 4. 00 \\
\hline
\end{tabular}

$202.186 \mathrm{~d}$

Spectral directional reflectance relative to $\mathrm{MgO}$, normal irradiation and $45^{\circ}$ circular reception, as obtained with the Beckman Model DU spectrophotometer, 254 to $1,000 \mathrm{~nm}$ :

3. 00

4.00

$202.186 \mathrm{e}$

One sample at one wavelength

43.00

Each additional wavelength on the same sample

4. 00

$202.186 \mathrm{f}$

Each additional sample, each wavelength

4. 00

Spectral transmittance or transmittancy curves obtained on General Electric recording spectrophotometer, including 100 percent and zero calibration curves and didymium glass curve for checking the wavelength calibration; report includes ozalids of tracings:

$202.186 \mathrm{~g}$ Testing a single sample, 400 to $750 \mathrm{~nm}$ or 730 to $1,080 \mathrm{~nm}$, with slits 58. 00 approximately $10 \mathrm{~nm}$ or $20 \mathrm{~nm}$ (respectively) of spectrum, eithel' spectral range. 


\begin{tabular}{|c|c|c|}
\hline Item & Description & Fee \\
\hline $202.186 \mathrm{~h}$ & Each additional curve or each additional sample $\ldots \ldots$ & $\$ 9.00$ \\
\hline $202.186 \mathrm{i}$ & Same as $202.186 \mathrm{~g}$, but with both spectral ranges, 400 to $1,080 \mathrm{~nm} \ldots$ & 80.00 \\
\hline \multirow[t]{2}{*}{$202.186 \mathrm{j}$} & Each additional pair of curves or cach additional sample ........... & 14.00 \\
\hline & $\begin{array}{l}\text { Spectral directional reflectance curves obtained on General Electric } \\
\text { recording spectrophotoneter, including (1) Vitrolite calibration } \\
\text { curve for correcting values relative to fresh } \mathrm{MgO} \text { as } 100 \text { percent, } \\
\text { (2) zero curve, (3) didymium glass curve for checking the wave- } \\
\text { length calibration; report includes ozalids of tracings: }\end{array}$ & \\
\hline $202.186 \mathrm{k}$ & $\begin{array}{l}\text { One sample, } 400 \text { to } 750 \mathrm{~nm} \text {, or } 730 \text { to } 1,080 \mathrm{~nm} \text {, with slits approximately } \\
10 \mathrm{~nm} \text { or } 20 \mathrm{~nm} \text { (respectively) of spectrum, with specular component } \\
\text { of reflected energy included or excluded, either specular range, and } \\
\text { either condition of specular reflection. }\end{array}$ & 58.00 \\
\hline $202.186 \mathrm{l}$ & Each additional curve or each additional sample, each curve........ & 9.00 \\
\hline $202.186 \mathrm{~m}$ & Same as $202.186 \mathrm{k}$, but both spectral ranges, 400 to $1,080 \mathrm{~nm} \ldots$ & 80.00 \\
\hline $202.186 n$ & Each additional pair of curves or each pair of curves on each additional & 14.00 \\
\hline 202.1860 & $\begin{array}{l}\text { Reduction of data obtained as in } 202.186 \mathrm{~g} \text { to } 202.186 \mathrm{n} \text {, giving table of } \\
\text { values of transmittance, transmittancy, or directional reflectance } \\
\text { relative to } \mathrm{MgO} \text { for every } 10 \mathrm{~nm} \text {, for each curve. }\end{array}$ & 24.00 \\
\hline $202.186 z$ & $\begin{array}{l}\text { For special tests not covcred by the above schedule, fees will be charged } \\
\text { dependent upon the nature of the test. }\end{array}$ & \\
\hline
\end{tabular}

202.187 Colorimetry.

\begin{tabular}{|c|c|}
\hline Item & Description \\
\hline $202.187 a$ & $\begin{array}{l}\text { Computing chromaticity coordinates and luminous directional reflec- } \\
\text { tance or transmittance from spectrophotometric data for certain } \\
\text { specified light sources, per source per sample }\end{array}$ \\
\hline $202.187 b$ & $\begin{array}{l}\text { Computing luminous directional reflectance or transmittance from } \\
\text { spectrophotometric data for certain specified light sources, per source } \\
\text { per sample. }\end{array}$ \\
\hline $202.187 \mathrm{c}$ & $\begin{array}{l}\text { Determination of the Munsell renotation or book notation of a specimen } \\
\text { from its daylight reflectance and chromaticity coordinates, each } \\
\text { specimen }\end{array}$ \\
\hline
\end{tabular}

Fee

$\$ 13.00$

9. 00 


\begin{tabular}{|c|c|c|}
\hline Item & Description & Fee \\
\hline $202.187 \mathrm{~d}$ & $\begin{array}{l}\text { Conformity to chromaticity of standard, sample and standard illumi- } \\
\text { nated normally by artificial daylight or by incandescent-lamp light, } \\
\text { chromaticity difference expressed in terms of chromaticity coordinates } \\
\text { on fundamental colorimetric coordinate system, one sample relative } \\
\text { to a standard. }\end{array}$ & $\$ 31.00$ \\
\hline $202.187 \mathrm{e}$ & Each additional sample relative to the same standard & 7.00 \\
\hline $202.187 f$ & Each additional sample relative to an additional standard $\ldots \ldots$ & 12.00 \\
\hline $202.187 \mathrm{~g}$ & $\begin{array}{l}\text { Color temperature of } 120-\mathrm{v}, \text { screw-base incandescent lamp, voltage for } \\
\text { specified color temperature, current for neighboring voltage to check } \\
\text { permanence, one color temperature, each lamp. }\end{array}$ & 34.00 \\
\hline $202.187 \mathrm{~h}$ & $\begin{array}{l}\text { Color temperature standard supplied from stock, } 100-\mathrm{w} \text {, medium-screw } \\
\text { base or } 500 \text {-w mogul-screw base projection type lamp, calibrated for } \\
2,854^{\circ} \mathrm{K} \text {, one lamp each }\end{array}$ & 34.00 \\
\hline $202.187 \mathrm{i}$ & $\begin{array}{l}\text { Same, calibrated for any one other specified color temperature, one } \\
\text { lamp each. }\end{array}$ & 37.00 \\
\hline $202.187 j$ & Each additional color temperature on the same lamp_............... & 13.00 \\
\hline $202.187 \mathrm{k}$ & $\begin{array}{l}\text { Equation giving any color temperature from } 2,000 \text { to } 2,854^{\circ} \mathrm{K} \text {, each } \\
\text { lamp (fee includes cost of } 500-\mathrm{w} \text { projection lamp) }\end{array}$ & 85.00 \\
\hline $202.187 \mathrm{z}$ & $\begin{array}{l}\text { For special tests not covered by the above schedule, fees will be charged } \\
\text { dependent upon the nature of the test. }\end{array}$ & \\
\hline
\end{tabular}

202.188 Reflectometry. Standards issued: Standards have been prepared for use in the measurement of daylight $45^{\circ} 0^{\circ}$ directional reflectance $\left(45^{\circ}\right.$ illumination, perpendicular viewing) of paints, paper, textiles, ceramic products, and other opaque materials. The standards are intended for use only with reflectometers designed to measure daylight $45^{\circ} 0^{\circ}$ directional reflectance such as the multipurpose reflectometer developed at the Bureau. (Refer to J. Res. NBS 25, 581 (1940) RP1345.) Standards are available also for the tristimulus colorimetry of reflecting specimens of nearly the same spectral character. A detailed discussion of the method of photoelectric tristimulus colorimetry, its capabilities and limitations, is contained in NBS Circular 429 (1942). ${ }^{3}$ The standards are calibrated in terms of the CIE tristimulus values, $X, Y$, and $Z$. Information sheets describing these standards more fully are available on request.

$\mid$\begin{tabular}{c|c}
\hline Item & Description \\
\hline $\begin{array}{c}\mathrm{KB} \text { chromatic reflectance standards-calibrated for CIE tristimulus } \\
\text { values } X, Y, Z ; 3 \times 5 \text { in. plaques in colors commonly called white, }\end{array} \mid$ & Fee \\
\hline
\end{tabular}

3 NBS Circular 429, Photoelectric tristimulus colorimetry with three filters. In NBS Handbook 77, Precision Measurement and Calibration, Vol. III, Optics, Metrology, and Radiation, p. 529 (see pp. 101-102 for price information and order form). 


\begin{tabular}{|c|c|c|}
\hline Item & Description & Fee \\
\hline & $\begin{array}{l}\text { bath green, kitchen green, orchid, ivory, maize, bath blue, delphin- } \\
\text { ium blue, royal bluc, and red: }\end{array}$ & \\
\hline $202.188 d$ & One KB chromatic standard & $\$ 44.00$ \\
\hline $202.188 \mathrm{e}$ & Each additional KB chromatic standard & 17.00 \\
\hline \multirow[t]{2}{*}{$202.188 f$} & Set of $10 \mathrm{~KB}$ chromatic standards in above listed colors & 138. 00 \\
\hline & $\begin{array}{l}S \text { chromatic reflectance standards-calibrated for CIE tristimulus } \\
\text { values } X, Y, Z ; 4 \frac{1}{4} \mathrm{in.} \text { sq with } 1 / 4 \text {-in., } 90 \text {-deg fold at each edge; in } \\
\text { colors commonly called safety red, aviation orange, safety orange, } \\
\text { school bus chrome, safety yellow, safety green, and safety blue: }\end{array}$ & \\
\hline $202.188 \mathrm{~g}$ & One $S$ chromatic standard _. & 44.00 \\
\hline $202.18 S h$ & Each additional $S$ chromatic standard... & 17.00 \\
\hline \multirow[t]{2}{*}{$202.188 \mathrm{i}$} & Set of $7 \mathrm{~S}$ chromatic standards in above listed colors & 132.00 \\
\hline & Samples or standards submitted for calibration & \\
\hline $202.188 \mathrm{z}$ & $\begin{array}{l}\text { For special tests not covered by the above schedule, fees will be charged } \\
\text { dependent upon the nature of the test. }\end{array}$ & \\
\hline
\end{tabular}

202.189 Opacimetry. Opacity of diffusing glass by contrast-ratio (ratio of luminous directional reflectance with black backing to that with white backing), illumination nearly perpendicular to surface of glass, reception of all reflected flux regardless of angle. Reflectance of white backing taken so as to accord with Bausch \& Lomb type photoelectric opacimeter correctly adjusted to read contrast-ratio for thin samples with a white backing reflecting 0.915 relative to $\mathrm{MgO}$ (TAPPI test method $\mathrm{T} 425 \mathrm{~m}-36$ ). Diffusing glass rectangles, $5 \times 12 \mathrm{~cm}$, supplied by the Bureau.

\begin{tabular}{c|c|c}
\hline Item & Description & Fee \\
\hline $202.189 \mathrm{a}$ & $\begin{array}{l}\text { Each diffusing-glass opacity standard, opacity between } 0.60 \text { and } 0.96 \\
\text { as desired } \ldots\end{array}$ & $\$ 35.00$ \\
$202.189 \mathrm{~b}$ & $\begin{array}{l}\text { Set of four diffusing-glass opacity standards, opacities approximately } \\
\text { equal to 0.72, 0.79, 0.86, and } 0.93 \ldots\end{array}$ & 105.00 \\
$202.189 \mathrm{z}$ & $\begin{array}{l}\text { For special tests not covered by the above schedule, fees will be charged } \\
\text { dependent upon the nature of the test. }\end{array}$ & \\
\hline
\end{tabular}


202.191 Lovibond glasses. Lovibond red glasses, determination of numeral on the additive $\left(N^{\prime \prime}\right)$ scale established (by Priest and Gibson's adjustment set BS 9940) at the Bureau in 1927, the value given being the effective value when the given red glass is used in combination with a 35-yellow glass, each glass to be engraved with the National Bureau of Standards test number and the numeral found for the glass.

\begin{tabular}{|c|c|c|}
\hline Item & Description & Fee \\
\hline $202.191 \mathrm{a}$ & For testing a single red glass & $\$ 32.00$ \\
\hline $202.191 b$ & For each additional red glass____- & 10.00 \\
\hline $202.191 \mathrm{z}$ & $\begin{array}{l}\text { For special tests not covered by the above schedule, fees will be charged } \\
\text { dependent upon the nature of the test. }\end{array}$ & \\
\hline
\end{tabular}

\subsection{Signal glass limit glasses and IPL calibrating filters.}

(a) Railroad, highway (traffic), and aviation signal glasses for use as chromaticity limits or transmittance standards in accord with specifications approved by the cognizant technical association or government agency will be issued when available. The report of calibration includes chromaticity coordinates, luminous transmittance, or both as determined relative to national standards filters for the specified color temperature of source.

(b) Instrument Panel Lighting. (IPL) calibrating filters are available in 2-in. polished squares. They have the following designations (approximate chromaticity coordinates for color temperature $2854^{\circ} \mathrm{K}$ are shown below in parentheses): NBS $3056(\mathbf{x}=0.723, \mathbf{y}=0.277)$, NBS $3114(x=0.712, y=0.288)$, NBS $3215(x=0.698, y=0.302)$, and NBS $3648 \quad(x=0.667$, $\mathbf{y}=0.333$ ). The NBS 3215 filters define the pale limit for airplane red instrument panel lighting and are usually used in pairs; the other types of filters listed are for calibrating photometers used for measuring panel luminance.

\begin{tabular}{|c|c|c|}
\hline Item & Description & Fee \\
\hline $202.192 \mathrm{a}$ & Signal limit glasses, each & $\$ 100.00$ \\
\hline $202.192 b$ & $\begin{array}{l}\text { IPL calibrating filters, calibrated for chromaticity coordinates and } \\
\text { transmittance for } 2854^{\circ} \mathrm{K} \text {, each }\end{array}$ & 56.00 \\
\hline $202.192 \mathrm{c}$ & Calibration for transmittance at an additional color temperature & 10.00 \\
\hline $202.192 \mathrm{z}$ & $\begin{array}{l}\text { For special tests not covered by the above schedule, fees will be charged } \\
\text { dependent upon the nature of the test. }\end{array}$ & \\
\hline
\end{tabular}

202.193 Haze standards. Standards are available for checking the accuracy of hazemeters designed to measure haze according to ASTM Method D1003. Standards consist of hazy cellulose acetate sheeting laminated between glass; they are 2 -in. squares about $1 / 4$ in. thick. Several nominal haze values between 1 and 30 are usually available. 


\begin{tabular}{|c|c|c|}
\hline Item & Description & Fee \\
\hline & Standards issued & \\
\hline $202.193 a$ & One haze standard $\ldots . . . .$. & $\$ 40.00$ \\
\hline $202.193 \mathrm{~b}$ & Each additional haze standard ordered at the same time $\ldots . . . . . . .$. & 12.00 \\
\hline \multirow[t]{2}{*}{$202.193 \mathrm{c}$} & Set of four haze standards_.. & 62.00 \\
\hline & Samples or standards submitted for calibration & \\
\hline $202.193 d$ & One haze sample or standard & 24.00 \\
\hline $202.193 \mathrm{e}$ & Each additional haze sample or standard submitted at the same time... & 8.00 \\
\hline $202.193 z$ & $\begin{array}{l}\text { For special tests not covered by the above schedule, fees will be charged } \\
\text { dependent upon the nature of the test. }\end{array}$ & \\
\hline
\end{tabular}

202.194 Radiometry.

\begin{tabular}{|c|c|c|}
\hline Item & Description & Fee \\
\hline $202.194 a$ & $\begin{array}{l}\text { Eye protective glasses-calibration for transmittance of ultraviolet, } \\
\text { visible, and total radiation }\end{array}$ & $\$ 35.00$ \\
\hline $202.194 b$ & Calibration of radiant energy meter for energy of $2537 \AA$ & 35.00 \\
\hline $202.194 \mathrm{c}$ & Measurement of radiant flux of $2537 \AA$, from germicidal or sterilamp _ - & 35.00 \\
\hline $202.194 \mathrm{~h}$ & $\begin{array}{l}\text { Standard of spectral irradiance-quartz iodine lamp seasoned and cali- } \\
\text { brated for spectral irradiance from } 0.25 \text { to } 2.6\end{array}$ & 325.00 \\
\hline $202.194 \mathrm{z}$ & $\begin{array}{l}\text { For special tests not covered by the above schedule, fees will be charged } \\
\text { dependent upon the nature of the test. }\end{array}$ & \\
\hline
\end{tabular}

202.201 Optical instruments.

\section{Refractometry}

\begin{tabular}{c|c|c}
\hline Item & Description & Fee \\
\hline $202.201 \mathrm{z}$ & $\begin{array}{c}\text { Tests of telescopes, microscopes, binoculars, etc., to determine conform- } \\
\text { ance to specifications of resolving power, aperture, alinement of } \\
\text { axes, etc. Fees determined by the actual cost of the work. }\end{array}$ & \\
\hline
\end{tabular}

202.202 Photographic objectives. The following information is pertinent to the tests a to $o$ in this schedule. 
a. This test is applied to photographic objectives that are mounted in a lens barrel or shutter. A visual or a photographic method is used, depending upon the probable use of the lens. The back focal distance determines the lens position with respect to the focal plane for an airplane camera or other fixed focus camera focused for an infinitely distant objective. The equivalent focal length determines the scale factor for the interpretation of aerial photographs.

b. This test is given to the photographic objectives that are to be used in precision copying cameras. The information is used in calibrating the camera scales that enable the user to obtain the proper settings of lens, object plane, and image plane for any desired magnification without visual focusing.

c, d. The test includes the information obtained in $202.202 \mathrm{~b}$, together with information on distortion. It is applied to photographic objectives that are to be used in precision copying cameras where the user wishes to be certain that the relative proportions of the image are not significantly different from those of the object. Since the distortion changes with magnification, it is advisable to specify a ratio for test that corresponds to the magnification most commonly used.

e. This is a general-purpose test to determine the suitability of a lens so far as its definition characteristics are concerned. It is performed photographically. In general, if a lens yields satisfactory results when subjected to this test, it is probable that no additional test for lateral chromatic aberration is necessary, and the lens will doubtless perform satisfactorily for either black-and-white or color photography.

f. This is the qualifying test for photographic objectives intended for use in airplane mapping projects. It is a photographic test and the determinations are made for the plane of best average definition.

$\mathrm{g}, \mathrm{h}$. The $f$-number may be obtained by dividing the equivalent focal length of the lens by the diameter of the effective aperture. These tests are primarily of value in determining the accuracy of the geometric $f$-number markings at maximum aperture and at additional specified apertures.

$\mathrm{i}, \mathrm{j}$. This test is applied to photographic objectives mounted in cameras. As the test is a photographic one requiring a time exposure, it is necessary that the stop be open when the lens is submitted for test. This is a useful test for nonprecision type airplane cameras where the collimation index markers are located in a detachable magazine.

$\mathrm{k}$. This test is applied to the platen of a precision aerial mapping camera, which is the surface against which the film is pressed during exposure. It is a test to determine conformance to specifications requiring that the platen shall not depart from a true plane by more than \pm 0.0005 in.

1. 'This test is applied to photographic objectives mounted in cameras. It gives the same information as test $202.202 \mathrm{f}$ except for back-focal distance. It is preferable that these lens characteristics be determined for the lens as mounted in a barrel shutter, but occasionally it is desirable to determine these quantities for the lens mounted in a camera. The shutter of the lens should be open when the camera is submitted for test.

$\mathrm{m}$. This test is applied to a lens-camera combination that is to be used in photogrammetric mapping. It gives the departure of the principal point from the center of collimation which is the intersection point of lines joining opposite pairs of collimation index markers. Since it is necessary to determine the shift of the principal point resulting from the prism effect in the lens, the equivalent focal length of the lens as mounted in the camera is incidentally determined in this test, which checks whether the lens has been properly mounted to yield best average definition throughout the image field.

This test cannot be performed on a camera having a detachable magazine which bears the collimation index markers. This is the preliminary test on a precision type camera to determine compliance with specifications. If no provision has been made for ready adjustment of the collimation index markers and the $90^{\circ}$ condition is not satisfied, the camera is returned to the firm or agency submitting the camera with recommendations regarding the necessary adjustments. If the $90^{\circ}$ condition is satisfied, but no provision has been made for 
ready adjustment of the principal point with respect to the center of collimation, the camera is returned with recommendations regarding the necessary adjustments.

n. If no provision has been mado for ready adjustment of the lens in a transverse direction to properly position the principal point with respect to the center of collimation, or if this can be done by ready movement of the collimation index markers, this task is done in the course of the test. Following adjustment, the camera is checked and, if satisfactory, pins are set to insure preservation of the space relations between collimation index markers and principal point.

When a camera is submitted for test, it is mandatory that the drill holes for the pins be already present in one of the members that move with respect to one another. In addition, a proper sized drill and reamer and a sufficient number of pins to perform the doweling must accompany the camera. It is desired that roll pins be submitted for this task.

\begin{tabular}{|c|c|c|}
\hline Item & Description & Fee \\
\hline $202.202 \mathrm{a}$ & Determination of focal length and back focal distance_........ & $\$ 26.00$ \\
\hline $202.202 \mathrm{~b}$ & $\begin{array}{l}\text { Determination of equivalent focal length, back focal distance, separa- } \\
\text { tion of nodal points, and thickness }\end{array}$ & 38.00 \\
\hline $202.202 \mathrm{c}$ & $\begin{array}{l}\text { Determination of equivalent focal length, back focal distance, separa- } \\
\text { tion of nodal points, and distortion at } 5^{\circ} \text { intervals from the center to } \\
\text { edge of field for one specified ratio of object to image size }\end{array}$ & 105.00 \\
\hline $202.202 \mathrm{~d}$ & Fee for each additional ratio $\ldots \ldots \ldots$ & 55.00 \\
\hline $202.202 \mathrm{e}$ & $\begin{array}{l}\text { Determination of resolving power at } 5^{\circ} \text { intervals from center to edge of } \\
\text { ficld for parallel light at one aperture }\end{array}$ & 30.00 \\
\hline $202.202 \mathrm{f}$ & $\begin{array}{l}\text { Determination of back focal distance, equivalent focal length, distor- } \\
\text { tion and resolving power at } 5^{\circ} \text { intervals from the center to edge of the } \\
\text { field }\end{array}$ & 69.00 \\
\hline & $\begin{array}{l}\text { This is the test usually required for lenses that are to be mounted in precision } \\
\text { airplane cameras. }\end{array}$ & \\
\hline $202.202 \mathrm{~g}$ & $\begin{array}{l}\text { Determination of equivalent focal length and true geometric } f \text {-number } \\
\text { for one marked stop }\end{array}$ & 35.00 \\
\hline $202.202 \mathrm{~h}$ & Fee for each additional stop $\ldots \ldots$ & 10.00 \\
\hline $202.202 \mathrm{i}$ & 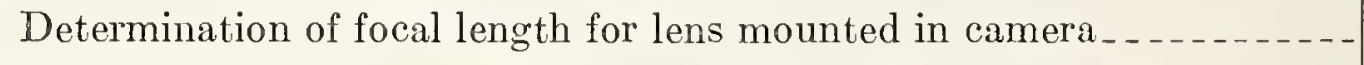 & 43.00 \\
\hline $202.202 \mathrm{j}$ & Fee for each extra magazine & 25.00 \\
\hline $202.202 \mathrm{k}$ & $\begin{array}{l}\text { Determination of compliance of camera platen with flatness require- } \\
\text { ments to } \pm 0.0005 \text { in }\end{array}$ & 15.00 \\
\hline 202.2021 & $\begin{array}{l}\text { Determination of equivalent focal length, distortion, and resolving pow- } \\
\text { er at } 7.5^{\circ} \text { intervals from center to edge of field for lens mounted in } \\
\text { camera. }\end{array}$ & 82.00 \\
\hline $202.202 \mathrm{~m}$ & $\begin{array}{l}\text { Location of the principal point, and check of } 90^{\circ} \text { condition for lens } \\
\text { mountcd in camera }\end{array}$ & 95.00 \\
\hline $202.202 \mathrm{n}$ & $\begin{array}{l}\text { Setting the principal point and } 90^{\circ} \text { condition, checking and doweling for } \\
\text { lens mounted in camera }\end{array}$ & 72.00 \\
\hline $202.202 \mathrm{z}$ & $\begin{array}{l}\text { For special tests not covered by the above schedule, fees will be charged } \\
\text { dependent upon the nature of the test. }\end{array}$ & \\
\hline
\end{tabular}


202.203 Optical components, spectacle lenses, goggle lenses, etc.

\begin{tabular}{|c|c|c|}
\hline Item & Description & Fee \\
\hline & Optical components & \\
\hline $202.203 \mathrm{a}$ & Determination of equivalent focal length of single-component lens & $\$ 26.00$ \\
\hline $202.203 \mathrm{~b}$ & $\begin{array}{l}\text { Determination of a single radius of curvature (single surface or matched } \\
\text { pair). Fee determined by the nature of the work required; minimum }\end{array}$ & 56.00 \\
\hline $202.203 c$ & $\begin{array}{l}\text { Determination of spherical and cylindrical power, axis of sphere, and } \\
\text { axis of cylinder for a single spectacle lens }\end{array}$ & 16.00 \\
\hline $202.203 d$ & Fee for each additional lens...... & 10.00 \\
\hline $202.203 \mathrm{e}$ & $\begin{array}{l}\text { Determination of spherical and cylindrical powers, axis of sphere, and } \\
\text { axis of cylinder for a single spectacle lens with bifocal segment }\end{array}$ & 23.00 \\
\hline $202.203 \mathrm{f}$ & $\begin{array}{c}\text { Fee for each additional lens } \\
\text { Sunglass lenses }\end{array}$ & 15.00 \\
\hline $202.203 \mathrm{~g}$ & $\begin{array}{l}\text { Determination of refractive power, surface quality, and definition to } \\
\text { determine compliance of a single sunglass lens with commercial } \\
\text { standards }\end{array}$ & 16.00 \\
\hline $202.203 \mathrm{~h}$ & $\begin{array}{l}\text { Fee for each additional lens } \\
\text { Goggle lenses }\end{array}$ & 10.00 \\
\hline $202.203 \mathrm{i}$ & $\begin{array}{l}\text { Determination of lens dimensions, refractive power, prismatic power, } \\
\text { and definition; and making drop test on a single hardened goggle } \\
\text { lens to determine compliance with Federal Specification GGG-G- }\end{array}$ & 16. 00 \\
\hline $202.203 \mathrm{j}$ & Fee for each additional lens & 10.00 \\
\hline $202.203 z$ & $\begin{array}{l}\text { For special tests not covered by the above schedule, fees will be charged } \\
\text { dependent upon the nature of the test. }\end{array}$ & \\
\hline
\end{tabular}

202.204 Refractometric instruments. Every instrument submitted for test should be in good working order. The test slab or standard supplied by the maker, and the tables if any, must accompany each refractometer. Upon request special attention will be given to such portions of the scale as may be of particular importance in the contemplated use of the instrument. Refractometers with compensators will be tested with "white" light unless otherwise specified. Refractometers without compensators will be tested only with sodium light unless otherwise specified. 


\begin{tabular}{c|c|c}
\hline Item & Description & Fee \\
\hline $202.204 \mathrm{z}$ & $\begin{array}{c}\text { For special tests and calibrations of refractometric measurements, fees } \\
\text { will be charged dependent upon the nature of the test. }\end{array}$ & \\
\hline
\end{tabular}

202.205 Refractive indices. When submitting media for index measurement, the temperature, wavelength of light (or spectral line), and approximate degree of desired precision should be specified. Liquid samples should usually be as large as $10 \mathrm{ml}$. Solids for item d must be in the form of test slabs, approximately $1 \times \frac{1}{2} \times \frac{3116}{10}$ in., such as are commonly used for the adjustment of Abbe refractometers. Two surfaces must be pitch polished (plane within approximately one wavelength) and intersect at $90^{\circ}$ to form an unbeveled edge.

\begin{tabular}{|c|c|c|}
\hline Item & Description & Fee \\
\hline & $\begin{array}{l}\text { Index of refraction }\left( \pm 1 \times 10^{-4}\right) \text { for } D \text { spectrum line for one liquid by } \\
\text { precision Abbe refractometer: }\end{array}$ & \\
\hline $202.205 \mathrm{a}$ & Determination of index for single temperature & $\$ 29.00$ \\
\hline $202.205 b$ & $\begin{array}{l}\text { Determination of index for each additional sample submitted at the } \\
\text { same time for same temperature, or for each determination and } \\
\text { additional spectral lines for same temperature }\end{array}$ & 11. 00 \\
\hline $202.205 \mathrm{c}$ & $\begin{array}{l}\text { One index determination at each additional temperature } \\
\text { Index of refraction }\left( \pm 1 \times 10^{-4}\right) \text { for } D \text { spectrum line for one solid by pre- } \\
\text { cision Abbe refractometer: }\end{array}$ & 16. 00 \\
\hline $202.205 \mathrm{~d}$ & Determination of index for one sample & 16. 00 \\
\hline $202.205 \mathrm{e}$ & $\begin{array}{l}\text { Determination of index for each additional spectrum line, } C, F \text {, or } G_{-\ldots} \\
\text { Determination of index of refraction }\left( \pm 1 \times 10^{-5}\right) \text { of solid submitted in } \\
\text { form of } 60^{\circ} \text { prism for one visible spectrum line: }\end{array}$ & 6.50 \\
\hline $202.205 f$ & Determination of index & 26. 00 \\
\hline $202.205 \mathrm{~g}$ & For each additional line in the visible spectrum & 12. 00 \\
\hline $202.205 \mathrm{z}$ & $\begin{array}{l}\text { For special tests not covered by the above schedule, fees will be charged } \\
\text { dependent upon the nature of the test. }\end{array}$ & \\
\hline
\end{tabular}

202.206 Polarimetric instruments.

\begin{tabular}{c|c|c}
\hline Item & Description & Fee \\
\hline $202.206 z$ & $\begin{array}{c}\text { Calibration of polarimeters, saccharimeters, and quartz control plates. } \\
\text { Fees determined by the nature and difficulty of the test. }\end{array}$ & \\
\hline
\end{tabular}




\section{Photographic Research}

202.311 Photography. The following information is pertinent to the tests a to $f$ in this schedule.

a. American Standard Printing Transmission Density (Type P2-b) is measured on step tablets of 21 steps or less, with a densitometer calibrated to \pm 0.01 density or \pm 1 percent of the density, whichever is the greater. This type of density is the one most commonly employed in the photographic industry and is customarily implied when the type of density is not specified.

b. American Standard Diffuse Visual Transmission Density (Type VI-b) is measured on step tablets of 21 steps or less, witn a densitometer calibrated to \pm 0.01 density or \pm 1 percent of the density, whichever is the greater.

$c, d$. The determination of the residual sodium thiosulfate content of processed photographic film is made according to American Standard Method PH4.8-1958 or the latest revision thereof.

Hypo concentrations less than $0.005 \mathrm{mg}$ per square inch are reported as "nil." When hypo concentration is $0.005 \mathrm{mg}$ per square inch or over, it is reported to one significant figure.

Each sample submitted should be properly identified, contain no image (slight fog permissible), and must be submitted immediately after processing.

Each sample submitted should be 6 to 8 in. in length and should be attached securely to request letter by stapling.

Samples are not returned since they are destroyed during the test.

e, $\mathrm{f}$. The determination of residual sodium thiosulfate concentration of processed photographic paper is made according to American Standard Method PH4.30-1962 or the latest revision thereof.

Each sample submitted should be properly identified, contain no image (slight fog permissible), and be of such dimensions that two strips, $1 \times 4$ in., can be cut for test.

\begin{tabular}{|c|c|c|}
\hline Item & Description & Fee \\
\hline $202.311 \mathrm{a}$ & $\begin{array}{l}\text { Calibration of photographic step tablets for printing density, one } \\
\text { sample }\end{array}$ & $\$ 28.00$ \\
\hline $202.311 b$ & Calibration of photographic step tablets for visual density, one sample & 28.00 \\
\hline $202.311 \mathrm{c}$ & $\begin{array}{l}\text { Residual sodium thiosulfate concentration of processed film, one } \\
\text { sample }\end{array}$ & 12.00 \\
\hline $202.311 d$ & $\begin{array}{l}\text { Each additional sample for the determination of residual sodium } \\
\text { thiosulfate in film submitted at the same time }\end{array}$ & 3.00 \\
\hline $202.311 \mathrm{e}$ & $\begin{array}{l}\text { Residual sodium thiosulfate concentration of processed photographic } \\
\text { paper, one sample }\end{array}$ & 20.00 \\
\hline $202.311 \mathrm{f}$ & $\begin{array}{l}\text { Each additional sample for the determination of residual thiosulfate } \\
\text { concentration of processed photographic paper submitted at the } \\
\text { same time. }\end{array}$ & 5.00 \\
\hline $202.311 z$ & $\begin{array}{l}\text { For special tests not covered by the above schedule, such as precise } \\
\text { determination of contact printing density and measurements of } \\
\text { resolving power of photographic materials, fees will be charged } \\
\text { dependent upon the nature of the test. }\end{array}$ & \\
\hline
\end{tabular}




\section{Length}

202.401 Reference line standards of length.

\begin{tabular}{c|c|c|c|c|c|c|c|}
\hline Item & Description & Fee \\
\hline $202.401 \mathrm{z}$ & $\begin{array}{l}\text { Calibrations of reference line standards to a higher precision than that } \\
\text { provided in schedule 202.402 are regarded as special tests. Fees } \\
\text { will be charged dependent upon the nature of the test; they may } \\
\text { be approximately estimated as twice the corresponding fees of } \\
\text { schedule 202.402. }\end{array}$ & \\
\hline
\end{tabular}

202.402 Working line standards of length.

\begin{tabular}{|c|c|c|}
\hline Item & Description & Fee \\
\hline $202.402 \mathrm{a}$ & $\begin{array}{l}\text { Yard or meter working line standard-determination of the total } \\
\text { length at room temperature to an accuracy of } 0.001 \mathrm{~mm} \text { if the char- } \\
\text { acter of the graduation justifies }\end{array}$ & $\$ 125.00$ \\
\hline $202.402 \mathrm{~b}$ & $\begin{array}{l}\text { Yard or meter working line standard-determination of the total } \\
\text { length at an additional lower temperature to obtain the coefficient } \\
\text { of expansion. }\end{array}$ & 110.00 \\
\hline $202.402 c$ & $\begin{array}{l}\text { Yard or meter working line standard-determination of equal sub- } \\
\text { multiples of a length, each }\end{array}$ & 20.00 \\
\hline $202.402 d$ & $\begin{array}{l}\text { Yard or meter working line standard-determination of any other single } \\
\text { interval }\end{array}$ & 65.00 \\
\hline $202.402 z$ & $\begin{array}{l}\text { For special tests not covered by the above schedule, fees will be charged } \\
\text { dependent upon the nature of the test. }\end{array}$ & \\
\hline
\end{tabular}

202.403 Commercial line standards of length.

\begin{tabular}{c|c|c}
\hline Item & Description & Fee \\
\hline $202.403 \mathrm{z}$ & $\begin{array}{c}\text { Calibrations of commercial line standards of length to an accuracy of } \\
0.01 \mathrm{~mm} \text { or } 0.0004 \text { in., if the character of the graduation justifies, } \\
\text { are regarded as special tests. Fees will be charged dependent upon } \\
\text { the nature of the test; they may be approximately estimated as one- } \\
\text { half of the corresponding fees of schedule } 202.402 .\end{array}$ & \\
\hline
\end{tabular}

202.404 Steel tapes.

(a) Steel tapes accepted by the Bureau as suitable for calibration will be issued a National Bureau of Standards Report of Calibration. Steel tapes are used for many types of long- 
interval length measurements. The varied requirements for the application of calibrated steel tapes to length measurements necessarily require variance in type and location of interval markings and accessory attachments. Some tapes, although being of excellent quality and having application that justifies NBS calibration, are not necessarily suitable for use as reference tapes (see paragraph b). Such steel tapes for which a Report of Calibration has been issued will be engraved with an NBS serial number for identification puposes. A steel tape considered by the Bureau to be suitable for use as a reference tape for checking other calibrated or uncalibrated steel tapes, or for other appropriate uses, will also be engraved with a mark indicating the year of calibration. Reports of Calibration normally will indicate the measured lengths of intervals to the nearest 0.001 foot or $0.1 \mathrm{~mm}$. Length values will be reported at $68^{\circ} \mathrm{F}\left(20^{\circ} \mathrm{C}\right)$.

(b) A steel tape considered suitable for use as a reference tape, as defined above, should possess the following minimum requirements: The error in total length of the tape at the standard temperature of $68{ }^{\circ} \mathrm{F}\left(20^{\circ} \mathrm{C}\right)$ and at standard tension shall not exceed 0.1 in. per $100 \mathrm{ft}(2 \mathrm{~mm}$ per $25 \mathrm{~m})$. The standard tension is $10 \mathrm{lb}(4.5 \mathrm{~kg})$ for tapes 25 to $100 \mathrm{ft}$, or from 10 to $30 \mathrm{~m}$ in length and $20 \mathrm{lb}(9 \mathrm{~kg})$ for tapes longer than $100 \mathrm{ft}$ or $30 \mathrm{~m}$. From the standpoint of inherent stability and to prevent the possibility of accidental displacement of reference graduations, a reference tape should normally possess the following characteristic: All interval graduations should be on a single piece of metal ribbon. This is usually construed to imply that the graduations should not be on pieces of solder, sleeves, thin plates or blocks bonded or attached to the tape, or on wire loops, spring balances, tension handles, or other accessories likely to be detached or changed in shape.

\begin{tabular}{c|c|c}
\hline Item & Description & Fee \\
\hline $202.404 \mathrm{a}$ & Steel tape-determination of correction to the total length of the tape &
\end{tabular}
when supported throughout at standard tension and at standard temperature, for a tape not exceeding $200 \mathrm{ft}$ or $50 \mathrm{~m}$ in length

This is the regular standard test which will be made and charged for in each case. To this amount must be added the fees for any additional tests made, and for item ( $\mathrm{n})$, if applicable, in accordance with the following schedule.

202.404b Steel tape-determination of the correction to the total length when supported throughout at any tension other than standard tension,

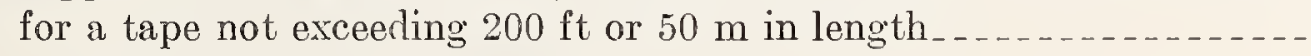

Tension desired must be specified.

202.404c Steel tape-determination of the correction to the total length when supported at the ends only

The Bureau is not prepared to make this test on tapes having a greater length than $200 \mathrm{ft}$ or $50 \mathrm{~m}$.

Standard tension will be used in this test unless another tension is specified.

202.404d Steel tape determination of the correction to the total length when supported at the ends and one or more intermediate points, for a tape not exceeding $200 \mathrm{ft}$ or $50 \mathrm{~m}$ in length

Standard tension will be used unless another tension is specified.

202.404e Steel tape-determination of the correction to the length of a subinterval under the same conditions as to tension and points of support as

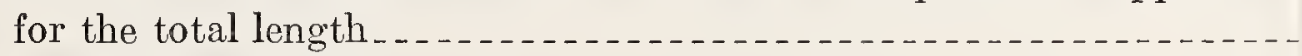

The points at which these measurements are made must be points at which the tape is supported.

The Bureau is not prepared to test tapes supported at points more than 200 $\mathrm{ft}$ or $50 \mathrm{~m}$ apart. 


\begin{tabular}{|c|c|c|}
\hline Item & Description & Fee \\
\hline $202.404 \mathrm{f}$ & $\begin{array}{l}\text { Steel tapc-detcrmination of the correction to the length of a subinter- } \\
\text { val under different specified conditions as to tension and points of sup- } \\
\text { port from those used for the total length } \\
\text { See item (e) above. }\end{array}$ & $\$ 5.00$ \\
\hline $202.404 \mathrm{~g}$ & $\begin{array}{l}\text { Steel tape-determination of the tension to the nearest integral half- } \\
\text { pound or quarter kilogram at which the correction to the length of } \\
\text { an interval is most nearly zero, under a specified condition of support, } \\
\text { for a tape not exceeding } 200 \mathrm{ft} \text { or } 50 \mathrm{~m} \text {. }\end{array}$ & 5.00 \\
\hline $202.404 \mathrm{~h}$ & $\begin{array}{l}\text { Steel tape-determination of the correction to a subinterval at the ten- } \\
\text { sion at which the correction to the total length is most nearly zero } \\
\text { and under the conditions of support used in the test under item (g)- }\end{array}$ & 3.00 \\
\hline $202.404 \mathrm{i}$ & $\begin{array}{l}\text { Steel tapc-determination of correction to the total length of an inter- } \\
\text { val on the reverse side of the tape, when supported at standard ten- } \\
\text { sion and at standard temperature, for a tape not exceeding } 200 \mathrm{ft} \text { or } \\
50 \mathrm{~m} \text { in length }\end{array}$ & 5. 00 \\
\hline $202.404 j$ & $\begin{array}{l}\text { Steel tape-determination of the coefficient of expansion of a tape, fee } \\
\text { will be determined in each individual case. }\end{array}$ & \\
\hline $202.404 \mathrm{k}$ & $\begin{array}{l}\text { Steel tape-determination of Young's modulus of elasticity, for a tape } \\
\text { not exceeding } 200 \mathrm{ft} \text { or } 50 \mathrm{~m} \text { in length } \\
\text { Not recommended for tapes having enameled, plastic, or heavy varnish } \\
\text { coatings. }\end{array}$ & 15.00 \\
\hline 202.4041 & Steel tape-determination of the weight per foot or per meter of a tape_- & 6.00 \\
\hline $202.404 \mathrm{~m}$ & Spring balance-testing in horizontal position & 10. 00 \\
\hline $202.404 n$ & Steel tape-additional charge for each tape scnt without reel_._._._.-_ & 4.00 \\
\hline 202.4040 & Steel tape-determination of $\mathrm{AE}_{\ldots} \ldots \ldots$ & 10.00 \\
\hline $202.404 p$ & $\begin{array}{l}\text { Steel tape-computed values (this does not include charge for neces- } \\
\text { sary measurements) }\end{array}$ & 5.00 \\
\hline $202.404 z$ & $\begin{array}{l}\text { For special tests not covered in the above schedule, fees will be charged } \\
\text { dependent upon the nature of the test. }\end{array}$ & \\
\hline
\end{tabular}

202.405 Invar base-line tapes. For testing of steel tapes, see schedule 202.404. The test of an Invar base-line tape of any length less than $50 \mathrm{~m}$ on the NBS geodetic-tape comparator will, in general, be made for the same fee as a $50-\mathrm{m}$ Invar base-line tape. Attention is called to the fact that only Invar base-line tapes of certain lengths can be tested on this comparator. Invar tapes not tested on the geodetic-tape comparator will be tested on the bench standard under items 202.405 (l) and (m). 


\begin{tabular}{c|c} 
Item & Description \\
\hline &
\end{tabular}

202.405a Invar 50-m base-line tape-determination on the geodetic comparator of total length with a probable error not greater than $\pm 0.050 \mathrm{~mm}$

202.405b Invar 50-m base-line tape- determination on the geodetic comparator of total length at an additional tension and/or method of support, with a probable error not greater than $\pm 0.050 \mathrm{~mm}$

$\$ 130.00$

$202.405 \mathrm{c}$

Invar 50-m base-line tape--determination of total length supported throughout, by computation from the observed length when supported at the ends and one or more intermediate points

40.00

20.00

202.405d Invar 50-m base-line tape-high-precision calibration of a group of uniformly spaced subintervals when supported on a horizontal flat surface, using the same tension specified for test item $202.405 \mathrm{c}$. Charge for each interval

20.00

$202.405 e$

Invar 50-m base-line tape-determination on the geodetic comparator of the coefficient of expansion with an accuracy of at least 0.000001 per degree Celsius using the electrical resistance method and calibration of its total length at one temperature, tension, and method of support with a probable error not greater than $\pm 0.050 \mathrm{~mm}$

$202.405 f$

Invar base-line tape-determination of Young's modulus of elasticity.

202.405g Invar base-line tape-determination of the weight per meter (or per foot)

$202.405 \mathrm{~h}$

Spring balance-testing in horizontal position

$202.405 i$

Invar base-line tape-additional charge for each tape sent without a reel_

$202.405 j$

$202.405 \mathrm{k}$

Invar base-line tape-determination of $\mathrm{AE}_{-}$

Invar base-line tape-computed values other than as provided in item $202.405 \mathrm{c}$

202.4051

Invar base-line tape not more than $50 \mathrm{~m}$ in nominal length-determination on bench standard at room temperature of length of one interval when supported at one method of support and under one tension, or determination of the tension to the nearest integral half pound or quarter kilogram at which the correction to the length of the interval is most nearly zero at a specified method of support

33.00

202.405m Invar base-line tape not more than $50 \mathrm{~m}$ in nominal length-each additional determination on bench standard at room temperature of length of interval, or tension to the nearest integral half pound $\mathrm{ol}^{\circ}$ quarter kilogram at which the correction to the length of an interval is most nearly zero

4.00

For special tests not covered by the above schedule, fees will be charged dependent upon the nature of the test. 
202.406 Surveyors' measuring instruments (other than tapes).

\begin{tabular}{c|c|c}
\hline Item & Description & Fee \\
\hline $202.406 \mathrm{a}$ & $\begin{array}{l}\text { Leveling rod-testing principal intervals_ } \\
202.406 \mathrm{z}\end{array}$ & $\begin{array}{l}\text { For special tests not covered by the above schedule, fees will be charged } \\
\text { dependent upon the nature of the test. }\end{array}$ \\
\hline
\end{tabular}

\subsection{Sieves.}

Note: The precision seal of the National Bureau of Standards on any sieve indicates that the sieve has been tested at the Bureau and found to conform to specification. Except by special arrangements, the testing of sieves at the Bureau is limited to No. 21/2 to No. 400 inclusive.

\begin{tabular}{|c|c|c|}
\hline Item & Description & Fee \\
\hline $202.407 a$ & $\begin{array}{l}\text { Sieve - test of a sieve No. } 2 \frac{1}{2} \text { to No. } 400 \text { inclusive to determine conform- } \\
\text { ity to specification, but not including the sieving test }\end{array}$ & $\$ 16.00$ \\
\hline $202.407 \mathrm{z}$ & $\begin{array}{l}\text { For special tests not covered by the above schedule, fees will be charged } \\
\text { dependent upon the nature of the test. }\end{array}$ & \\
\hline
\end{tabular}

202.408 Haemacytometers. Each haemacytometer chamber and each cover glass which passes the specification is marked with a National Bureau of Standards precision seal. In general, work will be discontinued when a substantial number of items in a lot fail to comply with the specifications, and the fee will be computed on the basis of the number of jtems tested plus a special handling charge. Items 202.408a to e inclusive will be applicable if a minimum of 12 chambers are submitted at one time; otherwise item $202.408 \mathrm{z}$ will be applicable. Only one letter reporting results of test will be supplied for any one test at the prices of items $202.408 \mathrm{a}$ to e inclusive.

\begin{tabular}{|c|c|c|}
\hline Item & Description & Fee \\
\hline $202.408 a$ & $\begin{array}{l}\text { Single Neubauer haemacytometer chamber-testing single cell chamber } \\
\text { (having Neubauer ruling) and two cover glasses for conformity with } \\
\text { specification. }\end{array}$ & $\$ 7.00$ \\
\hline $202.408 \mathrm{~b}$ & $\begin{array}{l}\text { Single Fuchs-Rosenthal haemacytometer chamber--testing single cell } \\
\text { chamber (having Fuchs-Rosenthal ruling) and two cover glasses for } \\
\text { conformity with specification. }\end{array}$ & 10.00 \\
\hline $202.408 \mathrm{c}$ & $\begin{array}{l}\text { Double Neubauer haemacytometer chamber-testing double cell } \\
\text { chamber (having two Neubauer rulings) and two cover glasses for } \\
\text { conformity with specification. }\end{array}$ & 8.00 \\
\hline
\end{tabular}




\begin{tabular}{|c|c|c|}
\hline Item & Description & Fee \\
\hline $202.408 d$ & $\begin{array}{l}\text { Double Fuchs-Rosenthal haemacytometer chamber-testing double } \\
\text { cell chamber (having two Fuchs-Rosenthal rulings) and two cover } \\
\text { glasses for conformity with specification. }\end{array}$ & $\$ 20.00$ \\
\hline $202.408 \mathrm{e}$ & $\begin{array}{l}\text { Quadruple haemacytometer chamber-testing quadruple cell chamber } \\
\text { (having two Neubauer rulings and two Fuchs-Rosenthal rulings) and } \\
\text { two cover glasses for conformity with specification. }\end{array}$ & 21.00 \\
\hline $202.408 z$ & $\begin{array}{l}\text { For special tests not covered by the above schedule, fees will be charged } \\
\text { dependent upon the nature of the test. }\end{array}$ & \\
\hline
\end{tabular}

\subsection{Areas and area-measuring instruments.}

\begin{tabular}{c|c|c}
\hline Item & Description & Fee \\
\hline $202.409 \mathrm{z}$ & $\begin{array}{c}\text { Special tests only are conducted in this category and fees will be charged } \\
\text { dependent upon the nature of the test. }\end{array}$ & \\
\hline
\end{tabular}

\subsection{Precision circles.}

\begin{tabular}{c|c|c}
\hline Item & Description & Fee \\
\hline $202.410 \mathrm{z}$ & $\begin{array}{c}\text { Special tests only are conducted in this category and fees will be charged } \\
\text { dependent upon the nature of the test. }\end{array}$ & \\
\hline
\end{tabular}

\subsection{Linear thermal expansion of solids.}

\begin{tabular}{c|c|c}
\hline Item & Description & Fee \\
\hline $202.411 \mathrm{z}$ & $\begin{array}{c}\text { Special tests only are conducted in this category and fees for accepted } \\
\text { tests will be charged dependent upon their nature. Only those tests } \\
\text { that cannot be carried out elsewhere may be accepted. }\end{array}$ & \\
\hline
\end{tabular}

\subsection{Gage blocks.}

(a) Test fee schedules in 202.412 include a statement of the accuracy to which measurements are ordinarily made; however, if the character of the defining surfaces of a gage block is not such as to warrant this accuracy, the report will show the accuracy actually obtained. All gage blocks submitted for test should be in substantially new block condition and each block should be marked with an identification number.

(b) In the shipment of gage blocks extreme precaution should be taken both against corrosion and damage by contact with other gage blocks during transit. All defining steel surfaces should be greased and the blocks padded with waxed paper or volatile rust inhibitor 
treated paper. A greased steel surface coming in contact with newspaper, wrapping paper (unwaxed) or excelsior is very likely to corrode. Sets of gage blocks should have packing inside the case, and the case should be bound shut as the clasps frequently open or break during shipment.

(c) Shipments and purchase orders should be sent to the National Bureau of Standards, Washington, D.C. 20234, marked to the attention of the Length Section.

\begin{tabular}{c|c|}
\hline Item & Description \\
\hline &
\end{tabular}

202.412a Gage blocks-determination of length to \pm 0.000004 in. and excessive errors in flatness and parallelism, for sizes from 0.100 in. to and including 1.000 in., in lots of 10 or more, each

Fee

Actual cost of calibration will be charged for smaller lots.

$202.412 \mathrm{~b}$ Gage blocks-determination of length to $\pm 0.000005, \pm 0.000006$, and \pm 0.000007 in., respectively, for blocks from 1 to 2 in., 2 to 3 in., and 3 to 4 in. in length, and excessive errors in flatness and parallelism,

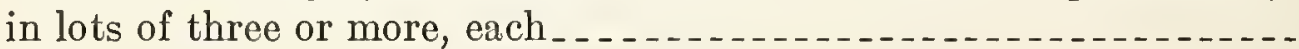

Actual cost of calibration will be charged for smaller lots.

202.412ab Measurements as described under items (a) and (b) for usual 81-block set, per set. . .

Extra blocks will be charged for under items (a) or (e).

202.412c Gage blocks-determination of length to \pm 0.000002 in. and excessive errors in flatness and parallelism, for sizes from 0.100 in. to and including 1.000 in., in lots of 10 or more, each.

$\$ 7.00$

Actual cost of calibration will be charged for smaller lots.

202.412d Gage blocks-determination of length to $\pm 0.000002, \pm 0.000003$, and \pm 0.000004 in. respectively, for blocks from 1 to 2 in., 2 to 3 in., and 3 to 4 in. in length, and excessive errors in flatness and parallelism,

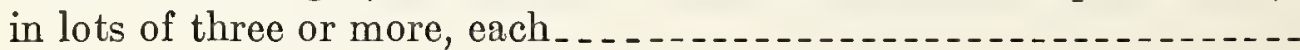

Actual cost of calibration will be charged for smaller lots.

202.412cd Measurements as described under items (c) and (d) for usual 81-block set, per set.

Extra blocks will be charged for under items (c) or (e).

$202.412 \mathrm{e}$

Gage blocks-determination of length to \pm 0.000003 in. and excessive errors in flatness and parallelism, for sizes from 0.010 to and including $0.090 \mathrm{in.}$, in lots of 10 or more, each

Blocks in this size range are usually warped and do not warrant calibration to a higher accuracy. In special cases blocks 0.040 in. and thicker will be calibrated under item (c) if the errors in flatness of the blocks are not excessive.

202.412f Gage blocks-determination of length to \pm 0.000001 in. per inch of length and excessive errors in flatness and parallelism, for blocks of the following length: $5,6,7,8,10,12,16$, and 20 in., in lots of three

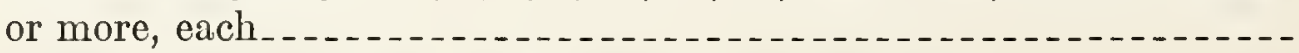

525.00

21.00

11.00

32. 00

880.00

Actual cost of calibration will be charged for smaller lots.

50. 00 


\begin{tabular}{c|c|c}
\hline Item & Description & Fee \\
\hline $202.412 \mathrm{z}$ & $\begin{array}{l}\text { For special tests not covered by the above schedule, fees will be charged } \\
\text { dependent upon the nature of the test. }\end{array}$ & \\
\hline
\end{tabular}

\subsection{General.}

\section{Engineering Metrology}

(a) Test fee schedules 202.501 to 202.509 include a statement of the relative accuracy to which measurements are ordinarily made. However, if the character of the defining surface of a gage or other article is not such as to warrant the measurement to this accuracy, the report will show the accuracy actually obtained. If a greater accuracy is requested and the defining surfaces are such as to permit measurements to the accuracy requested, the necessary measurements will be made and a special fee will be charged.

(b) In addition to the items covered by schedules 202.501 to 202.509 other items such as gage block accessories, taper plug and ring gages, and gill net gages are occasionally calibrated. Other sizes than those listed in the fee schedules are also calibrated on special request. These tests and calibrations are made so infrequently that it is not practical to list a definite fee, and such work will be done on the basis of the cost of the work.

(c) In the shipment of gages, extreme precautions should be taken both against corrosion and damage by contact with other gages during transit. All defining steel surfaces should be greased and protected with waxed paper or a suitable strippable plastic coating. A greased steel surface coming in contact with newspaper, wrapping paper (unwaxed), or excelsior is very likely to corrode. Small gages suitably wrapped may be fastened in place in a strong rigid container so that no movement is possible. Plug and ring gages should ordinarily not be shipped mated. In the case of large-size threaded plugs and rings, however, mating is permissible as a means of protecting the plug threads. In such cases a grease must be used that will prevent electrolytic corrosion between the mating gages.

(d) Minimum test fee for calibration work is $\$ 20.00$.

202.501 End standards of length.

\begin{tabular}{l|l|c}
\hline Item & Description & Fee \\
\hline
\end{tabular}

End standards with spherical or pointed ends, or flat ends with area of contact less than $1 / 3$ in. ${ }^{2}$ :

202.501a Determination of length to \pm 0.00005 in. for lengths up to and including 8 in., each._._._._. $\$ 12.00$

202.501b Determination of length to \pm 0.000005 in. per inch of length for lengths over 8 in. up to and including 20 in., each._._._._............ 16.00

202.501c Determination of length to \pm 0.000005 in. per inch of length for lengths over 20 in. up to and including 40 in., each.....................

20.00

202.510d Determination of length to \pm 0.000005 in. per inch of length for lengths over 40 in. up to and including 72 in., each.....................

24.00

202.501e Determination of length to \pm 0.00002 in. for lengths up to and inincluding 8 in., each......... 24.00 


\begin{tabular}{|c|c|c|}
\hline Item & Description & Fee \\
\hline $202.501 \mathrm{f}$ & $\begin{array}{l}\text { Determination of length to } \pm 0.000003 \mathrm{in} \text {. per inch of length for lengths } \\
\text { over } S \text { in. up to and including } 20 \mathrm{in} \text {, each. }\end{array}$ & $\$ 32.00$ \\
\hline $202.501 \mathrm{~g}$ & $\begin{array}{l}\text { Determination of length to } \pm 0.000003 \mathrm{in} \text {. per inch of length for lengths } \\
\text { over } 20 \mathrm{in.} \text { up to and including } 40 \mathrm{in} \text {, each. }\end{array}$ & 40.00 \\
\hline $202.501 \mathrm{~h}$ & $\begin{array}{l}\text { Determination of length to } \pm 0.000003 \text { in. per inch of length for lengths } \\
\text { over } 40 \text { in. up to and including } 72 \text { in., each }\end{array}$ & 48.00 \\
\hline $202.502 \mathrm{z}$ & $\begin{array}{l}\text { For special tests not covered by the above schedule, fees will be charged } \\
\text { dependent upon the nature of the test. }\end{array}$ & \\
\hline
\end{tabular}

202.502 Plain cylindrical plug and ring gages.

\begin{tabular}{|c|c|c|}
\hline Item & Description & Fee \\
\hline $202.502 \mathrm{a}$ & $\begin{array}{l}\text { Plain cylindrical plug gages-determination of diameter, taper, and } \\
\text { roundness to } \pm 0.00005 \text { in. for sizes up to and including } 4 \text { in., each - }\end{array}$ & $\$ 12.00$ \\
\hline $202.502 \mathrm{~b}$ & $\begin{array}{l}\text { Plain cylindrical plug gages-determination of diameter, taper, and } \\
\quad \text { roundness to } \pm 0.00001 \text { in. for sizes up to and including } 2 \text { in., each } . .\end{array}$ & 35.00 \\
\hline $202.502 \mathrm{c}$ & $\begin{array}{l}\text { Plain cylindrical plug gages-determination of diameter, taper, and } \\
\text { roundness to } \pm 0.000005 \text { in. for sizes up to and including } 2 \text { in., each - }\end{array}$ & 50.00 \\
\hline $202.502 \mathrm{~d}$ & $\begin{array}{l}\text { Plain cylindrical ring gages-determination of diameter, taper, and } \\
\text { roundness to } \pm 0.00001 \text { in. for sizes } 0.03 \text { in. up to and including } 2 \text { in., } \\
\text { each }\end{array}$ & 50.00 \\
\hline $202.502 \mathrm{e}$ & $\begin{array}{l}\text { Plain cylindrical ring gages-determination of diameter, taper, and } \\
\text { roundness to } \pm 0.000005 \text { in. for sizes } 0.03 \text { in. up to and including } 2 \text { in., } \\
\text { each }\end{array}$ & 75.00 \\
\hline $202.502 \mathrm{f}$ & $\begin{array}{l}\text { Plain cylindrical ring gages-determination of diameter, taper, and } \\
\text { roundness to } \pm 0.000003 \text { in. for sizes } 0.25 \text { in. up to and including } 2 \text { in., } \\
\text { each }\end{array}$ & 100.00 \\
\hline $202.502 \mathrm{z}$ & $\begin{array}{l}\text { For special tests not covered by the above schedule, fees will be charged } \\
\text { dependent upon the nature of the test. }\end{array}$ & \\
\hline
\end{tabular}

\subsection{Thread plug and ring gages.}

\begin{tabular}{|c|c|c|}
\hline Item & Description & Fee \\
\hline $202.503 a$ & $\begin{array}{l}\text { Straight thread plug gages and setting thread plug gages-determination } \\
\text { of angle to } 3^{\prime} \text { to } 15^{\prime} \text { depending on pitch and diameter; lead error and } \\
\text { pitch diameter to } 0.0001 \text { in., major diameter to } 0.0002 \text { in. thread form } \\
\text { as to clearance, for sizes } 1 / 4 \text { in. to } 6 \text { in., each }\end{array}$ & $\$ 30.00$ \\
\hline
\end{tabular}




\begin{tabular}{c|c|c}
\hline Item & Description & Fee \\
\hline $202.503 \mathrm{~b}$ & Straight thread ring gages—determination of angle to $3^{\prime}$ to $15^{\prime}$ depend- &
\end{tabular}

202.503b Straight thread ring gages - determination of angle to $3^{\prime}$ to $15^{\prime}$ depending on pitch and diameter, lead error to 0.0001 in., minor diameter to 0.0002 in., thread form as to clearance, and fit on setting plug, for sizes $1 / 4$ in. to 6 in., each $\ldots$

202.503c Taper thread plug gages having $60^{\circ}$ threads (except API Cable and Rotary gages) - determination of half angles to $3^{\prime}$ to $15^{\prime}$ depending on pitch and diameter, lead error, pitch diameter and taper to 0.0001 in. major diameter to 0.0003 in., and thread form as to clearance, for sizes up to and including 10 in., each

75.00

$202.503 \mathrm{~d}$

Taper thread plug gages having $60^{\circ}$ threads-determination of half angles to $3^{\prime}$ to $15^{\prime}$ depending on pitch and diameter, lead error and taper to 0.0001 in., pitch diameter to 0.0002 in., major diameter to $0.0004 \mathrm{in}$., and thread form as to clearance, for sizes over $10 \mathrm{in.} \mathrm{to}$

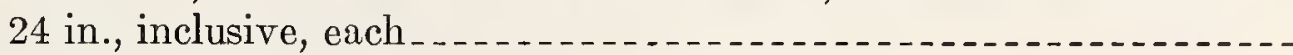

202.503e Taper thread ring gages having $60^{\circ}$ threads (except APT Cable and Rotary gages)-determination of angle to $3^{\prime}$ to $15^{\prime}$ depending on pitch and diameter, lead error to 0.0001 in., taper to 0.0002 in., minor diameter to $0.0005 \mathrm{in}$. (or truncation of thread crest), thread form as to clearance, and standoff from mating plug to 0.002 in. for sizes up to 10 in., each

60.00

$202.503 f$

Taper thread ring gages having $60^{\circ}$ threads-determination of angle to $3^{\prime}$ to $15^{\prime}$ depending on pitch and diameter, lead error to 0.0001 in., taper to 0.0002 in., minor diameter to 0.0005 in. (or truncation of thread crest), thread form as to clearance, and standoff from mating plug to $0.002 \mathrm{in}$, for sizes over $10 \mathrm{in}$. to $24 \mathrm{in}$. inclusive, each.....

95.00

$202.503 \mathrm{~g}$

$202.503 \mathrm{~h}$

API Cable and Rotary taper thread plug gages-determination of dimensions specified in API Standard 7, each

110.00

API Cable and Rotary taper thread ring gages-determination of di-

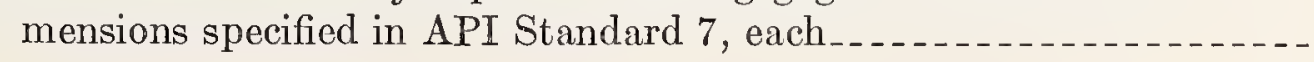

202.503 i

API Cable and Rotary tool connection gages - determination of mating standoff and standoff from grand master gages, per set_...........

30.00

202.503j API sucker rod plug gages designated as P1, P5, P7, B2, and B6determination of dimensions specified in API Standard 11B, each

30.00

202.503k API sucker rod plug gages designated as P3 and B4-determination of dimensions specified in API Standard 11B, each

202.5031 API sucker rod ring gages designated as P2, P6, P8, B1, and B5determination of dimensions specified in API Standard 11B, each.---

202.503m API sucker rod ring gages designated as P4 and B3-determination of dimensions specified in API Standard $11 \mathrm{~B}$, each................ 


\begin{tabular}{|c|c|c|}
\hline Item & Description & Fee \\
\hline $202.503 n$ & $\begin{array}{l}\text { API sucker rod gages-determination of dimensions specified in API } \\
\text { Standard } 11 \mathrm{~B} \text { for the inspection of used gages, per set of any size }\end{array}$ & $\$ 140.00$ \\
\hline 202.5030 & $\begin{array}{l}\text { API buttress casing plug gages-determination of dimensions specified } \\
\text { in API Standard } 5 \mathrm{~B} \text { for sizes up to } 10 \text { in., each }\end{array}$ & 85.00 \\
\hline $202.503 p$ & $\begin{array}{l}\text { API buttress casing plug gages-determination of dimensions specified } \\
\text { in API Standard } 5 \mathrm{~B} \text {, for sizes over } 10 \mathrm{in} \text {, each }\end{array}$ & 105.00 \\
\hline $202.503 q$ & $\begin{array}{l}\text { API buttress casing ring gages-determination of dimensions specified } \\
\text { in API Standard } 5 \mathrm{~B} \text {, for sizes up to } 10 \mathrm{in} \text {, each }\end{array}$ & 70.00 \\
\hline $202.503 \mathrm{r}$ & $\begin{array}{l}\text { API buttress casing ring gages-determination of dimensions specified } \\
\text { in API Standard } 5 \mathrm{~B} \text {, for sizes over } 10 \text { in., each }\end{array}$ & 95.00 \\
\hline $202.503 z$ & $\begin{array}{l}\text { For special tests not covered by the above schedule fees will be charged } \\
\text { dependent upon the nature of the test. }\end{array}$ & \\
\hline
\end{tabular}

\subsection{Instruments and components.}

\begin{tabular}{c|c|}
\hline Item & Description \\
\hline $202.504 \mathrm{a}$ & $\begin{array}{c}\text { Micrometer calipers-determination of errors at } 10 \text { points selected to } \\
\text { test uniformity of graduations as well as lead errors. Also determi- } \\
\text { nation of planeness and parallelism errors of contact surfaces, each.-- }\end{array}$ \\
\hline
\end{tabular}

Fee

$202.504 \mathrm{~b}$

Dial micrometers-determination of errors in each one-tenth revolution of the pointer for one revolution and each half revolution up to five revolutions, each

$\$ 50.00$

In the case of dial micrometers, the accuracy obtainable depends on the value of the smallest division on the dial and on the mechanical condition of the instrument as evidenced by the degree to which it will repeat its indications.

$202.504 \mathrm{c}$

Thread wires-determination of diameter, straightness, and roundness of each of three wires in a set in accordance with specification for wires in NBS Handbook H28, Screw Thread Standards for Federal Services, and determination of mean diameter and $\mathrm{C}$ correction, for the best sizes of wires for standard $60^{\circ}$ screw threads, from 2 to 80 threads per inch and for $29^{\circ}$ Acme screw threads from 1 to 20 threads

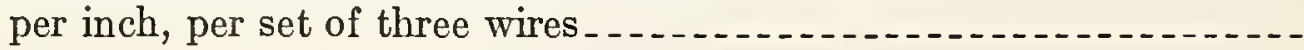

35.00

202.504d Gear wires-determination of diameter, straightness, and roundness of each of two wires in a set to an accuracy of \pm 0.000010 in., per set...

202.504e Master wires-determination of mean diameter, and straightness to an accuracy of \pm 0.000005 in., each 


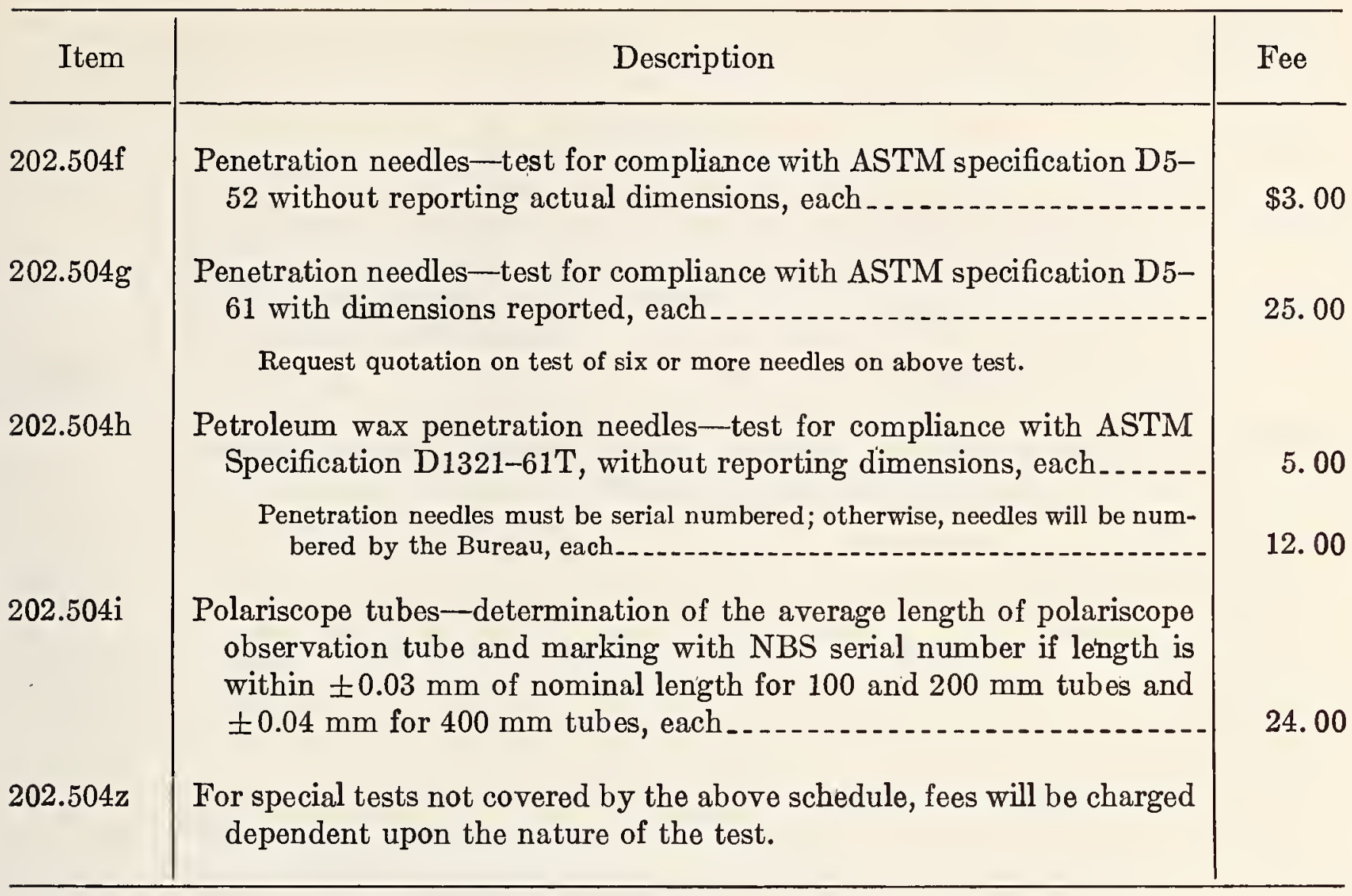

202.505 Optical reference planes.

\begin{tabular}{|c|c|c|}
\hline Item & Description & Fee \\
\hline & $\begin{array}{l}\text { Optical reference planes are tested interferometrically, horizontally sup- } \\
\text { ported with test surface supported on three equally spaced pads lo- } \\
\text { cated at } 0.7 \text { of the radius from the center. The test is performed } \\
\text { along two marked diameters at } 90^{\circ} \text { to each other on each surface, } \\
\text { when each diameter is parallel to two of the support pads. Graphs } \\
\text { of the profiles are supplied. }\end{array}$ & \\
\hline $202.505 a$ & $\begin{array}{l}\text { Optical reference plane - to an accuracy of } \pm 0.0000005 \text { in. for sizes not } \\
\text { exceeding } 6 \text { in., per surface }\end{array}$ & $\$ 70.00$ \\
\hline $202.505 b$ & $\begin{array}{l}\text { Optical reference plane-to an accuracy of } \pm .0000005 \text { in. for sizes } \\
\text { larger than } 6 \text { in. but not exceeding } 8 \text { in. in diameter, per surface }\end{array}$ & 100.00 \\
\hline $202.505 \mathrm{c}$ & $\begin{array}{l}\text { Optical reference plane-to an accuracy of } \pm 0.0000005 \text { in. for sizes } \\
\text { larger than } 8 \text { in. but not exceeding } 10 \mathrm{in.} \text { in diameter, per surface }\end{array}$ & 150.00 \\
\hline $202.505 d$ & $\begin{array}{l}\text { Optical true plane not exceeding } 3 \text { in. in diameter-measured along four } \\
\text { marked diameters at } 45^{\circ} \text { to each other, to an accuracy of } \pm 0.0000002 \\
\text { in. Test performed by intercomparison of a group of three similar } \\
\text { planes supplied by customer. Total of } 12 \text { diameters-four each on } \\
\text { one surface of three planes. }\end{array}$ & 500.00 \\
\hline $202.505 z$ & $\begin{array}{l}\text { For special tests not covered by the above schedule, fees will be charged } \\
\text { dependent upon the nature of the test. }\end{array}$ & \\
\hline
\end{tabular}


202.506 Angle blocks.

\begin{tabular}{|c|c|c|}
\hline Item & Description & Fee \\
\hline $202.506 a$ & $\begin{array}{l}\text { Calibration of set of } \mathrm{AA} \text { grade angle blocks consisting of one each of the } \\
\text { following sizes: } 1,3,5,20 \text {, and } 30^{\prime \prime} ; 1,3,5,20 \text {, and } 30^{\prime} ; 1,3,5,15,30 \text {, } \\
\text { and } 45^{\circ} ; \text { - detcrmination of flatness of faces, parallelism of elemcnts } \\
\text { of surfaces and angle between faces. Accuracy of angle between faces } \\
0.5^{\prime \prime} \text {. Pcr set_- }\end{array}$ & $\$ 350.00$ \\
\hline $202.506 z$ & $\begin{array}{l}\text { For special tests not covered by the above schedule, fees will be charged } \\
\text { dependent upon the nature of the test. }\end{array}$ & \\
\hline
\end{tabular}

202.507 Polygons.

\begin{tabular}{|c|c|c|}
\hline Item & Description & Fee \\
\hline & $\begin{array}{l}\text { Calibration of polygons-determination of flatncss of faces, variation of } \\
\text { the angles between faces and the base of the polygon (where possible } \\
\text { the polygon will be adjusted for minimum variation) and the angle } \\
\text { between faces. Accuracy of values for angles between faces } 0.5^{\prime \prime} \text { or } \\
\text { less. }\end{array}$ & \\
\hline $202.507 a$ & Polygons having 4 or 5 sides, each & $\$ 175.00$ \\
\hline $202.507 \mathrm{~b}$ & Polygons having 8,9 , or 10 sides, each & 200.00 \\
\hline $202.507 \mathrm{c}$ & Polygons having 12 sides, each $\ldots . .$. & 250.00 \\
\hline $202.507 \mathrm{~d}$ & 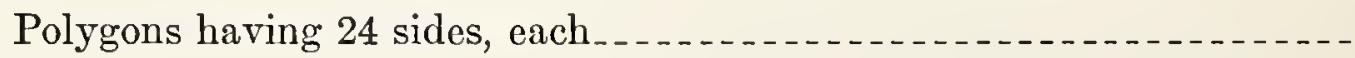 & 400.00 \\
\hline $202.507 \mathrm{e}$ & Polygons having 36 sides, each. & 800.00 \\
\hline $202.507 \mathrm{f}$ & Polygons having 72 sides, each & $2,000.00$ \\
\hline $202.507 \mathrm{z}$ & $\begin{array}{l}\text { For special tests not covered by the above schedule, fees will be } \\
\text { charged dependent upon the nature of the test. }\end{array}$ & \\
\hline
\end{tabular}

202.508 Master balls.

\begin{tabular}{|c|c|}
\hline Item & Description \\
\hline $202.508 \mathrm{a}$ & $\begin{array}{l}\text { Steel or Carbide balls - determination of diameter to } \pm 0.000050 \mathrm{in} \text {. for } \\
\text { sizes from } y_{16} \text { in. to } 1 \text { in., each }\end{array}$ \\
\hline $202.508 \mathrm{~b}$ & $\begin{array}{l}\text { Steel or Carbide balls-determination of diameter to } \pm 0.000010 \mathrm{in} \text {. for } \\
\text { sizes from } 1 / 16 \text { in. to } 1 \text { in., each }\end{array}$ \\
\hline
\end{tabular}

Fee

$\$ 10.00$

15.00 


\begin{tabular}{|c|c|c|}
\hline Item & Description & Fee \\
\hline $202.508 \mathrm{c}$ & $\begin{array}{l}\text { Master ball-determination of diameter to } \pm 0.000005 \text { in. by compari- } \\
\text { son with NBS master and measurement of roundness of two equators, } \\
\text { for sizes from } 1 / 8 \text { in. to } 1 / 2 \text { in. by } 1 / 32 \text { in. steps and } 1 / 2 \text { in. to } 1 \text { in. by } 1 / 16 \text { in. } \\
\text { steps. Test applied only on balls with diameter variation of } 0.000005 \\
\text { in. or less and deviation from nominal size within } \pm 0.000030 \text { in., each. }\end{array}$ & $\$ 25.00$ \\
\hline $202.508 \mathrm{~d}$ & $\begin{array}{l}\text { Master balls-determination of mean diameter from five interferometric } \\
\text { readings to an accuracy of } \pm 0.000003 \mathrm{in} \text {. and measurement of round- } \\
\text { ness of four equators. For sizes up to } 1 \mathrm{in} \text {. in diameter. Test made } \\
\text { only on balls with diameter variation of } 0.000003 \text { in. or less, each }\end{array}$ & 60.00 \\
\hline $202.508 z$ & $\begin{array}{l}\text { For special tests not covered by the above schedule, fees will be charged } \\
\text { dependent upon the nature of the test. }\end{array}$ & \\
\hline
\end{tabular}

202.509 Gears.

\begin{tabular}{|c|c|c|}
\hline Item & Description & Fee \\
\hline $202.509 a$ & $\begin{array}{l}\text { Tooth index measurement-calibration results recorded in tape form } \\
\text { with each tooth location being represented by a plateau and another } \\
\text { tape (taken simultaneously) of the reference diameter location during } \\
\text { the tooth index calibration. Gears, master gears, gear cutters, and } \\
\text { index plates, from } 0.125 \text { in. diam to about } 8.0 \text { in. diam and from about } \\
24 \text { teeth to about } 500 \text { teeth. The maximum overall length of the } \\
\text { part must be less than } 3 \text { in. Suitable reference and calibration sur- } \\
\text { faces must be available to obtain the estimated accuracy of } \pm 3^{\prime \prime} \text { of } \\
\text { arc. For } 71 \text { teeth or less, each. } \\
\text { For } 72 \text { teeth or more, each. } \\
\text { The cost of any needed adaptors will be added to the calibration cost, if made } \\
\text { by the Bureau. } \\
\text { For special tests not covered by the above schedule, fees will be charged } \\
\text { dependent upon the nature of the test. }\end{array}$ & $\begin{array}{r}\$ 160.00 \\
200.00\end{array}$ \\
\hline
\end{tabular}

202.610 General.

\section{Mass and Volume}

(a) Calibration and testing.

(1) Calibration consists of determining the value, either mass or volume, relative to an accepted standard. It is assumed that all items submitted for calibration will be used as reference standards. (This designation implies the use of a correction or actual value of the standard in all measurements relative to it.) Results of a calibration will be reported in a National Bureau of Standards Report of Calibration listing the value together with an appropriate uncertainty. The Report of Calibration makes no reference to the compliance with existing class tolerances which limit the departure of actual value from the nominal value.

(2) Testing consists of establishing compliance with applicable specifications or tolerances. If the need is critical and the service is not available elsewhere, items may be accepted 
for test. The results of the test will be reported in a National Bureau of Standards Report of Test, which generally is a statement indicating the compliance, or noncompliance, with the particular specification or tolerance.

(3) Acceptance for calibration or test is based on inspection at the Bureau. Acceptance is based on suitability for use as a reference standard. Items not accepted for calibration or test will be returned, the appropriate cleaning, handling, and inspection fee being applicable.

(4) The established fees are based on satisfactory test or calibration effected by normal procedures. Total cost of test or calibration will include cost of items required to facilitate the use of normal procedures. Examples of items, the cost of which will be added to the established fees as routine procedure, are replacement of missing small weights, repairs to damaged surfaces, the cleaning and greasing of glass stopcocks, repairs to shipping cases or crates, and the reconditioning or modification of closures for weight-adjustment cavities.

(5) Occasionally items are received for test which vary excessively from nominal. Such variation becomes evident in the actual calibration or test. Completion of calibration or test may require considerable deviation from normal procedures. For such cases, the fee will be computed on a cost basis.

(6) When requested, receipt of items and purchase orders will be acknowledged. Such acknowledgment will not contain a price quotation. Actual cost of the calibration or test will be stated in the acknowledgment copy of NBS Form 64. Usually, this acknowledgment is issued sufficiently in advance of the completion of the work so that change orders can be processed prior to return shipment.

(b) Correspondence and purchase orders.

(1) All correspondence concerning calibration and testing should be addressed to the National Bureau of Standards, Attention: Mass and Volume Section, 2.06, Washington, D.C., 20234.

(2) The purchase order or calibration request must include complete inform ation concerning the following items:

(i) Purchase order number or authority to charge against existing open purchase order.

(ii) Legal owner of item.

(iii) Nominal designation and total number of items by count.

(iv) Shipping instructions for shipment to other than name stated in (i).

(v) Previous Bureau of Standards test number if appropriate.

(3) After completion of calibration or test, items will be packed and shipped as directed. The Report of Calibration or the Report of Test, whichever is applicable, will be mailed under separate cover.

\subsection{Reference standards of mass.}

(a) Reference standards of mass are weights or weight sets of design, material, and surface finish comparable to, but not necessarily limited to present Class A, B, M, S, or S-1 as described in Circulars $3^{4}$ and $547^{5}$ in Volume III of NBS Handbook 77 . Stand ards accepted are calibrated with reference to NBS standards of mass, with an uncertainty com patible with the equipment and methods used.

(b) Packing and shipping.

(1) Weights must be carefully packed. If shipped in their regular cases the weights should be tightly packed in their pockets by the use of extra material of some sort.

(2) In many instances the sheet-metal weights that are packed under the glass covers of the regular cases reach the Bureau bent or otherwise damaged. Care should be given the

\footnotetext{
4 NBS Circular 3, Design and test of standards of mass. In NBS Handbook 77, Precision Measureme nt and Calibration, Vol. III, Optics, Metrology, and Radiation, p. 615 (see pp. 101-102 for price in formation and order form).

- NBS Circular 547, Precision laboratory standards of mass and laboratory weights. Price 35 cents. Available from Superintendent of Documents, U.S. Government Printing Office, Washington, D.C., 20402. Also in NBS Handbook 77, Precision M eas urement and Calibration, Vol. III, Optics, Metrology, and Radiation, p. 588 (see pp. 101-102 for price information and order form).
} 
packing of these weights. Sufficient extra packing should be used to hold the glass cover firmly in place.

(3) Many of the laboratory and storage weight cases now in service are not designed to retain the weights in the pockets during shipment. Also, shipments of weights are sometimes subjected to exceptionally rough handling. It is strongly recommended that weights larger than about $200 \mathrm{~g}$ be removed from the laboratory or storage cases and packed for shipment as described in this section. Do not ship empty storage cases.

(4) Some soft but firm material should be used next to the weight and bound tightly against it to avoid possibility of abrasion. If tissue paper is used, many thicknesses should be firmly wrapped on. This should then be covered with thicker, tougher material such as cotton gauze or knit goods. The whole should then be wrapped securely in heary wrapping paper to exclude the dust and grit from rough packing material. Each package should be clearly labeled.

(5) Weight identification, purchase order number, and legal owner must be clearly designated on the packing slip. Enclose packing slip in envelope and attach to outside of box (wrap with weights if package is small). Envelope should be clearly marked. Also package with the weights an information sheet stating the density and composition or accepted trade name of the material of which the weights are made, also the construction and surface protection of the weights.

(c) Calibration.

(1) Cleaning, inspection, and handling in accordance with fee 202.611 (a through d) will apply to all weights accepted for calibration.

(2) The true mass and/or apparent mass corrections are determined using computed volumes based on the manufacturers statement of density of the material. (In the absence of this information, estimated densities are used.) The apparent mass correction at $20{ }^{\circ} \mathrm{C}$ is computed with reference to Normal Brass (density $8.4 \mathrm{~g} / \mathrm{cm}^{3}$ at $0{ }^{\circ} \mathrm{C}$ : Volume coefficient expansion $0.000054 / \mathrm{C}^{\circ}$, air density $1.2 \mathrm{mg} / \mathrm{cm}^{3}$ ). Apparent mass corrections computed to any other basis will be furnished if requested. Fee in accordance with 202.611 (e through $z$ ) will apply for calibration.

(3) Measurement of volumes for use in computing corrections will be done on a cost basis $(202.611 \mathrm{z})$. Correspondence or consultation as to the exact requirements must provide a basis for such calibration.

\begin{tabular}{|c|c|c|}
\hline Item & Description & Fee \\
\hline & $\begin{array}{l}\text { Inspection, cleaning, and handling (also applies to weights not accepted } \\
\text { for calibration) }\end{array}$ & \\
\hline $202.611 \mathrm{a}$ & For single weight not greater than $50 \mathrm{lb}$ or $20 \mathrm{~kg}$ & $\$ 12.00$ \\
\hline $202.611 b$ & $\begin{array}{l}\text { For each set or group of weights submitted as a unit, when the largest } \\
\text { weight is not greater than } 2 \mathrm{lb} \text { or } 1 \mathrm{~kg}\end{array}$ & 17.00 \\
\hline $202.611 \mathrm{c}$ & $\begin{array}{l}\text { For each set or group of weights submitted as a unit, when the largest } \\
\text { weight is not greater than } 20 \mathrm{lb} \text { or } 10 \mathrm{~kg} \text { but is greater than } 2 \mathrm{lb} \text { or } 1 \mathrm{~kg} \text { - }\end{array}$ & 25.00 \\
\hline $202.611 d$ & $\begin{array}{l}\text { For each set or group of weights submitted as a unit when the largest } \\
\text { weight is not greater than } 50 \mathrm{lb} \text { but is greater than } 20 \mathrm{lb} \text { or } 10 \mathrm{~kg}--- \\
\text { Calibration, in addition to appropriate inspection, cleaning, and } \\
\text { handling fees }\end{array}$ & 35.00 \\
\hline
\end{tabular}




\begin{tabular}{|c|c|c|}
\hline Item & Description & Fee \\
\hline $202.611 \mathrm{e}$ & For sets $100 \mathrm{~g}$ to $1 \mathrm{mg}$, or sets within this range & $\$ 140.00$ \\
\hline 202. $611 \mathrm{f}$ & For sets $100 \mathrm{~g}$ to $50 \mathrm{mg}$, or sets within this range & 120.00 \\
\hline $202.611 \mathrm{~g}$ & For sets $100 \mathrm{~g}$ to $1 \mathrm{~g}$, or sets within this range & 60.00 \\
\hline $202.611 \mathrm{~h}$ & For sets $1 \mathrm{~g}$ to $1 \mathrm{mg}$, or sets within this range & 80.00 \\
\hline $202.611 \mathrm{i}$ & For individual weights, $100 \mathrm{~g}$ or less $\ldots$ & 10.00 \\
\hline $202.611 \mathrm{j}$ & For each individual weight greater than $100 \mathrm{~g}$ but not greater than $2 \mathrm{~kg}$ & 15.00 \\
\hline $202.611 k$ & For each individual weight greater than $2 \mathrm{~kg}$ but not greater than $20 \mathrm{~kg}-$ - & 20.00 \\
\hline $202.611 \mathrm{z}$ & $\begin{array}{l}\text { Other operations will be charged for on the basis of actual cost of time } \\
\text { and materials. }\end{array}$ & \\
\hline
\end{tabular}

202.612 Large mass standards.

(a) Large mass reference standards are weights over $50 \mathrm{lb}$ (up to and including 10,000 lb). Acceptance for calibration is based on suitability with regard to general design and upon assurance of usage as a reference standard.

(b) Weights over $50 \mathrm{lb}$ will be accepted for testing or standardization provided the need is critical and the service is not available elsewhere. (Testing is to determine compliance or noncompliance with accepted specifications. Standardization includes testing and adjustment to comply with appropriate adjustment tolerance.)

(c) Packing and shipping:

(1) Arrangements for testing or calibration should be completed before weights are shipped to the Bureau. All correspondence must be addressed to the National Bureau of Standards, Mass and Volume Section, 2.06, Washington, D.C., 20234.

(2) Weights from $51 \mathrm{lb}$ to approximately $250 \mathrm{lb}$ must be clean, suitably protected, and shipped in wooden boxes having screw-fastened covers. Larger weights must be clean, suitably protected, and shipped in reusable crates. Adjustment cavity seals must be packed separately and included with all new weights shipped to the Bureau for standardization. The empty adjustment cavities must be suitably protected to exclude dirt and moisture while in transit.

(3) Ship weights as follows:

(i) Test weights of $50 \mathrm{lb}$ and reference standards of 51 to 1,000 lb: From the West Coast and the Rocky Mountain area, ship to the National Bureau of Standards, Boulder, Colo., 80310; from the Midwest, ship to the National Bureau of Standards Master Scale Depot, 5800 West 69 th Street, Chicago, Ill., 60600; from the East, ship to the National Bureau of Standards, Connecticut Avenue and Van Ness Street, N.W., Washington, D.C., 20234.

(ii) 1,001 to $10,000 \mathrm{lb}$ : It is desirable that weights larger than $1,000 \mathrm{lb}$ be submitted to the National Bureau of Standards Master Scale Depot, 5800 West 69th Street, Chicago, Ill., 60600; however, by previous correspondence, arrangements can be made for accepting such weights at the National Bureau of Standards in Washington, D.C.

(d) Adjusting material: When large amounts of adjusting material are required for new weights, the Bureau reserves the right to add the cost to the test fee or to require the owner or maker to furnish the material.

(e) Calibration, test, and standardization: For a calibration, the value of the weight or object (apparent mass with reference to Normal Brass) together with a statement of uncertainty 
will be reported on an NBS Report of Calibration. Weights accepted for test will be reported as either complying or not complying with appropriate specifications on an NBS Report of Test. Weights accepted for standardization will be reported as complying with appropriate adjustment tolerance specifications on an NBS Report of Test. Fees in accordance with 202.612 (a thru z) apply.

\begin{tabular}{c|c}
\hline Item & Description \\
\hline $202.612 \mathrm{a}$ & $\begin{array}{c}\text { A handling fee of } \$ 2.25 \text { per weight in addition to the applicable test fee } \\
\text { will be charged for each weight of a group submitted; the minimum } \\
\text { handling charge shall be } 50 \text { lb }\end{array}$ \\
\hline
\end{tabular}

Fee

The Bureau no longer tests weights of this kind on a routine basis. Special need or requirement for this work must be established.

$\$ 12.00$

8.00

$202.612 b$

Tolerance testing (no adjustment), per weight

16. 00

$202.612 \mathrm{c}$

Standardization, per weight

Test weights, 51 to $1,000 \mathrm{lb}$

$202.612 \mathrm{~d}$

$202.612 \mathrm{e}$

$202.612 \mathrm{f}$

Test and, when adjustable, standardize within Class $\mathrm{C}$ adjustment tolerances

25.00

Calibration only (precision $1 / 100,000$ )

20.00

Test weights, 1,001 to $2,500 \mathrm{lb}$

Test and, when adjustable, standardize to nominal value with precision of $0.01 \mathrm{lb}$

35.00

$202.612 g$

Calibration only (precision $1 / 100,000$ )

30.00

Test weights, 2,501 to $10,000 \mathrm{lb}$

$202.612 \mathrm{~h}$

Calibration only (precision $1 / 25,000$ )

35.00

$202.612 \mathrm{i}$

Calibration only (precision 1/100,000)

42.00

$202.612 j$

Standardization, in addition to either $202.612 \mathrm{~h}$ or $202.612 \mathrm{i}$

25.00

Cars, railway track scale test

$202.612 \mathrm{k}$

Standardization on Master Track Scale at National Bureau of Standards Master Scale Depot, 5800 West 69th Street, Chicago, Ill........

40.00

Test weights, 10,000 to $150,000 \mathrm{Ib}$

$202.612 \mathrm{z}$

Fees for tests of weights in this grouping will be charged dependent upon the nature of the test. 


\subsection{Calibration of mass elements of pressure-gage testing apparatus.}

Calibration consists of cleaning, marking with suitable designation when required, and determining the value, which for weights of one pound and greater is reported to a precision of 1 part in 100,000. The fee is in accordance with fee schedule item 202.613a.

\begin{tabular}{c|c|c}
\hline \multirow{2}{*}{ Item } & Description & Fee \\
\hline \multirow{2}{*}{$212.613 \mathrm{a}$} & Each item to be calibrated $\ldots$ & $\$ 6.00$ \\
\hline
\end{tabular}

202.614 Recalibration of mass standards. Recalibration of reference mass standards should be based on monitoring the difference between weights or groups of weights in the set. As long as the differences as measured agree with the computed differences, the set can be considered constant. Mass standards submitted for recalibration will be cleaned, inspected, and tested by intercomparison. If this intercomparison shows there has not been a sufficient change to warrant complete recalibration, a letter so stating and referring to the previous National Bureau of Standards Report of Calibration will be issued. Such a letter may include new values for one or two weights if necessary. Fee will not exceed that listed under 212.611, 202.612, or 202.613, whichever is applicable.

\subsection{Glass volumetric apparatus.}

(a) Glass volumetric apparatus is tested generally by weighing the amount of distilled water contained or delivered with reference to the graduations marked on the instrument. The quality of the markings and the care exercised in reading or setting the liquid level are major factors in both calibration and usage. Occasionally such instruments are used as reference or transfer standards which require calibration. Many usage requirements are satisfied by testing for compliance with existing capacity tolerance specifications. The Mass and Volume Section offers both calibration and testing, subject to certain restrictions.

(b) Instruments suitable for, and to be used for, reference or transfer standards will be accepted for calibration. Such instruments must essentially conform to the specifications contained in NBS Circular 602, ${ }^{6}$ Testing of Glass Volumetric Apparatus. Acceptance for calibration is based on correspondence or consultation concerning the exact manner in which the instrument is to be used. If accepted for calibration, the instrument will be marked with an identification number, calibrated, and the results reported on an NBS Report of Calibration. The report will state the capacity under the conditions of test together with an associated statement concerning uncertainty. Fee for calibration will be computed on a cost basis.

(c) Precision grade glass volumetric apparatus will be accepted for testing to determine compliance with specifications and tolerances if the need is critical and the service is not available elsewhere. Acceptance for test is based on conformance with the specifications contained in NBS Circular $602,{ }^{6}$ or other appropriate specifications. The item will be marked with an appropriate stamp if test results indicate conformity with NBS-approved specifications and tolerances. No individual report will be issued (see paragraph d below for exception). Fee for testing is in accordance with 202.615 (a through l).

(d) A report will be furnished listing the test results for groups of blood pipets to be used as factory standards, if requested. Fees in accordance with 202.615p.

\footnotetext{
- NBS Circular 602, Testing of glass volumetric apparatus. Price 20 cents. Avallable from Superintendent of Documents, U.S. Government, Printing Office, Washington, D.C., 20402. Also in NBS Handbook 77, Precision Measurement and Calibration, Vol. III, Optics, Metrology and Radiation, p. 723 (see pp. 101 and 103 for price information and order form).
} 


\begin{tabular}{|c|c|c|}
\hline Item & Description & Fee \\
\hline & $\begin{array}{c}\text { Testing in accordance with specifications in NBS Circular } 602^{6} \text { or } \\
\text { other approved specifications. }\end{array}$ & \\
\hline $202.615 a$ & Flasks of capacities up to and including $250 \mathrm{ml}$, each $\ldots . .$. & $\$ 3.50$ \\
\hline $202.615 b$ & Flasks of capacities exceeding $250 \mathrm{ml}$, each & 4. 50 \\
\hline $202.615 \mathrm{c}$ & Flasks marked both "to contain" and "to deliver," each........... & 6.50 \\
\hline $202.615 d$ & $\begin{array}{l}\text { Flasks, of any capacity, when bearing more than one graduation mark. } \\
\text { Primary capacity, each. }\end{array}$ & 4.00 \\
\hline $202.615 e$ & $\begin{array}{l}\text { Each capacity in addition to primary (number determined by the } \\
\text { Bureau) }\end{array}$ & 1. 75 \\
\hline $202.615 f$ & Flasks, specific gravity, each & 8. 50 \\
\hline $202.615 \mathrm{~g}$ & Cylindrical graduates, capacities up to and including $250 \mathrm{ml}$, each...-- & 10.00 \\
\hline $202.615 \mathrm{~h}$ & 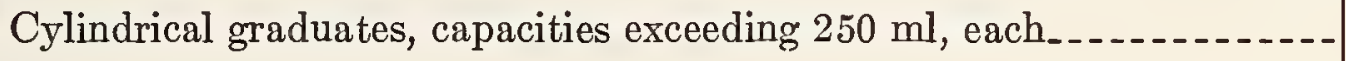 & 12. 00 \\
\hline $202.615 \mathrm{i}$ & Transfer pipets, each... & 3.00 \\
\hline $202.615 j$ & Burets, except automatic, each & 12.00 \\
\hline $202.615 \mathrm{k}$ & Burets, automatic, each & 14. 00 \\
\hline 202.6151 & Measuring pipets, each & 9.00 \\
\hline $202.615 \mathrm{~m}$ & Items a thru 1 disqualified for test on initial inspection, per item..... & 3. 00 \\
\hline $202.615 n$ & Dilution pipet, including Trenner automatic and Sahli, each.......... & 1. 00 \\
\hline 202.6150 & Dilution pipets, automatic, other than Trenner, each & 5.00 \\
\hline $202.615 p$ & $\begin{array}{l}\text { Report of test for quality control purposes (applies to } 202.615 \mathrm{n} \text { and o } \\
\text { only), each item }\end{array}$ & 1.00 \\
\hline $202.615 q$ & Apparatus $\mathrm{n}$ and o disqualified for test on initial inspection, each & 1. 00 \\
\hline $202.615 \mathrm{r}$ & $\begin{array}{l}\text { Items except those above for which there are accepted specifications, } \\
\text { such as microazotometers, spirits measuring flasks, etc., will be } \\
\text { tested on a cost basis in accordance with } 2026.15 \mathrm{z} \text {. (Report of test } \\
\text { will include capacities at test points if appropriate.) }\end{array}$ & \\
\hline $202.615 z$ & $\begin{array}{l}\text { For special calibrations not covered by above schedules, fees will be } \\
\text { determined on a cost basis. }\end{array}$ & \\
\hline
\end{tabular}




\subsection{Metal volumetric apparatus.}

(a) Only those instruments suitable for usc as refcrence standards (sce, for example, specifications containcd in NBS Monograph 62,7 Testing of Mctal Volumetric Standards) will be acceptcd for calibration, based on inspcction at the Bureau. Calibration consists of detcrmining the value "to contain" or "to deliver" by either gravimetric means or by thc use of transfer standards. The item will be marked, and the value determined will be reported, together with a statement concerning the uncertainty, on a National Bureau of Standards Report of Calibration. Fee in accordance with 202.616 (a thru z) applies. Specify "to contain," "to deliver," or both.

(b) Items not accepted for calibration as a result of initial inspection will be returned, fee in accordance with 202.6160 being applicable.

(c) Packing and shipping:

(1) The apparatus should be securely packed in cases or packages which will protect against possible damage.

(2) When submitting immersion bottles for calibration, do not include the tank as it is not used in the calibration.

(3) Arrangements for calibration of field standards in excess of 10 gal capacity must be completed before shipping apparatus to the Bureau.

(4) If requested, the zcro index or gage scales will be adjusted and sealed to within accepted tolcrance specifications. Adjustment of slicker plate type standards should be made by the manufacturer.

\begin{tabular}{|c|c|c|}
\hline Itcm & Description & Fee \\
\hline & $\begin{array}{l}\text { Calibration "to contain." Fee for calibration "to deliver" is same. } \\
\text { For both calibrations, double fee shown. }\end{array}$ & \\
\hline $202.616 \mathrm{a}$ & Slicker plate measures of capacity less than 5 gal, each & $\$ 19.00$ \\
\hline $202.616 b$ & Slicker plate measures of 5 gal capacity, each & 25. 00 \\
\hline & $\begin{array}{l}\text { Adjustments of slicker plate measures to within accpted capacity } \\
\text { tolerances, if requested, are done on a cost basis under } 202.616 \mathrm{z} \text {. }\end{array}$ & \\
\hline $202.616 \mathrm{c}$ & $y_{10} \mathrm{ft}^{3}$ bottles for use in testing gas meters, each & 25.00 \\
\hline $202.616 \mathrm{~d}$ & Cubic foot bottles for use in testing gas meters, each & 41.00 \\
\hline $202.616 \mathrm{e}$ & Portable cubic foot standards (Stillman type) & 135.00 \\
\hline $202.616 \mathrm{f}$ & Field standards of capacity less than 5 gal (graduated neck type), each _- & 19.00 \\
\hline $202.616 \mathrm{~g}$ & Field standards of 5 gal capacity, each $\ldots$ & 25.00 \\
\hline $202.616 \mathrm{~h}$ & $\begin{array}{l}\text { Field standards in excess of } 5 \text { gal but less than } 50 \text { gal capacity, first } 10 \\
\text { gal increment }\end{array}$ & 25.00 \\
\hline $202.616 \mathrm{i}$ & 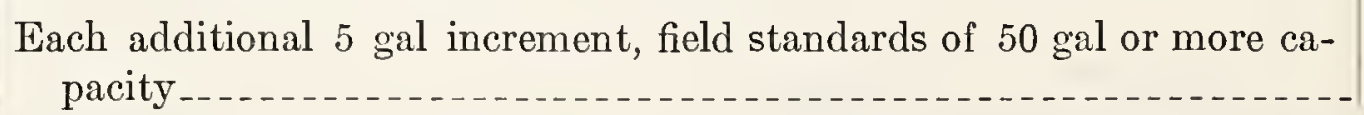 & 4. 50 \\
\hline
\end{tabular}

7 NBS Monograph 62, Testing of metal volumetric standards. Price 15 cents. Available from Superintendent of Documents, U.S. Government Printing Office, Washington, D.C., 20402 (see p. 103 for order form). 


\begin{tabular}{|c|c|c|}
\hline Item & Description & Fee \\
\hline $202.616 \mathrm{j}$ & First 50 gal increment... & $\$ 43.00$ \\
\hline $202.616 \mathrm{k}$ & Each additional 50 gal increment..... & 7.50 \\
\hline 202.6161 & Each additional 5 gal increment_... & 4.50 \\
\hline $202.616 \mathrm{~m}$ & $\begin{array}{l}\text { Calibration of field standards, graduated neck type, at more than one } \\
\text { scale point, each additional point }\end{array}$ & 15.00 \\
\hline $202.616 \mathrm{n}$ & Adjustment of zero index or gage, each.... & 13.00 \\
\hline 202.6160 & Apparatus disqualified for test, inspection and handling fee, each & 7.00 \\
\hline $202.616 \mathrm{z}$ & $\begin{array}{l}\text { For calibration not covered by the above schedule, fees will be charged } \\
\text { on a cost basis. }\end{array}$ & \\
\hline
\end{tabular}

\subsection{Hydrometers.}

(a) Hydrometers are considered reference standards. Those instruments conforming with the recommendations on construction contained in NBS Circular $555,{ }^{8}$ Testing of Hydrometers, will be accepted for calibration, acceptance based on inspection at the Bureau.

(b) For the purposes of this fee schedule, the following changes are made in Circular 555:

(1) Hydrometers with duplex scales or flat scales are not considered suitable for use as laboratory standards and will not be accepted for calibration.

(2) The thermometer element of a thermohydrometer will not be calibrated. (See ASTM specification E100, Standard Specification for ASTM Hydrometers.)

(3) The results of calibration will be furnished together with a statement of uncertainty, on a National Bureau of Standards Report of Calibration. Use as a laboratory standard implies the use of corrections; therefore no reference to tolerance compliances will be made on the report.

(c) Calibration consists of comparison at three or more points with a standard hydrometer. Fee in accordance with 202.617 applies.

(d) Apparatus not accepted for calibration will be returned, appropriate inspection and handling fee being applicable. Each scale card must state the name of the manufacturer and his serial number, the standard temperature and type of scale.

\begin{tabular}{c|c|c}
\hline Item & Description & Fee \\
\hline $202.617 \mathrm{a}$ & Hydrometers, calibrated at three points, lots of 10 or more of identical &
\end{tabular}

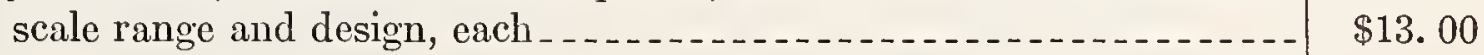

202.617b Hydrometers, calibrated at three points, lots of less than 10, each of identical range and design, each

${ }^{8}$ NBS Circular 555, Testing of hydrometers. Price 10 cents. Available from Superintendent of Documents, U.S. Government Printing Office, Wasbington, D.C., 20402; also in NBS Handbook 77, Precision Mcasurement and Calibration, Vol. III, Optics, Metrology, and Radie- 


\begin{tabular}{|c|c|c|}
\hline Item & Description & Fee \\
\hline $202.617 c$ & Calibration at additional points, each point & $\$ 3.50$ \\
\hline $202.617 d$ & $\begin{array}{l}\text { Hydrometers disqualified for calibration-inspection and handling } \\
\text { charge }\end{array}$ & 3.00 \\
\hline $202.617 \mathrm{z}$ & $\begin{array}{l}\text { For special calibrations not covered by the above schedule, fees will } \\
\text { be determined on a cost basis. }\end{array}$ & \\
\hline
\end{tabular}

\subsection{Density determinations of solids and liquids.}

(a) If the need is critical and the service is not available elsewhere, request may be accepted for the following density determinations:

(1) Density of solids, determined by hydrostatic weighing in appropriate liquid. Solids generally to have a mass less than $175 \mathrm{~g}$ and a maximum dimension less than $15 \mathrm{~cm}$.

(2) Density of liquids, determined by weighing in picnometers at temperatures between 0 and $70^{\circ} \mathrm{C}$.

(3) Associated tests such as the volume of solids, coefficient of thermal expansion for both solids and liquids.

(b) Acceptance for test is based on consultation or correspondence regarding the exact nature of the requirements. Do not ship materials to the Bureau until all arrangements for test have been completed. Fees for all tests are computed on a cost basis.

\begin{tabular}{c|c|c}
\hline Item & Description & Fee \\
\hline $202.618 \mathrm{z}$ & $\begin{array}{l}\text { Density determinations for solids and liquids, fees computed on a cost } \\
\text { basis. }\end{array}$ & \\
\hline
\end{tabular}

\section{Part 203-Heat}

Sec.

Temperature Physics

203.101 Laboratory thermometers

203.102 Thermocouples, thermocouple materials, and pyrometer indicators

203.103 Resistance thermometers

203.104 Clinical thermometers

203.105 Optical pyrometers and ribbon filament lamps

Temperature Physics

203.101 Laboratory thermometers. Only thermometers identified uniquely by serial number will be accepted for test.

\begin{tabular}{c|c|c}
\hline Item & Description & Fee \\
\hline $203.101 \mathrm{a}$ & $\begin{array}{c}\text { Thermometers, testing at points from } 0 \text { to } 100^{\circ} \mathrm{C} \text { inclusive, or from } \\
32 \text { to } 212^{\circ} \mathrm{F} \text { inclusive, for each point tested } \ldots \ldots\end{array}$ & \\
\hline 10.00
\end{tabular}




\begin{tabular}{|c|c|c|}
\hline Item & Description & Fee \\
\hline $203.101 b$ & $\begin{array}{l}\text { Thermometers, testing at points from } 101 \text { to } 300{ }^{\circ} \mathrm{C} \text { inclusive, or from } \\
213 \text { to } 600{ }^{\circ} \mathrm{F} \text { inclusive, for each point tested }\end{array}$ & $\$ 18.00$ \\
\hline $203.101 \mathrm{c}$ & $\begin{array}{l}\text { Thermometers, testing at points from } 301 \text { to } 500{ }^{\circ} \mathrm{C} \text { inclusive, or from } \\
601 \text { to } 950{ }^{\circ} \mathrm{F} \text { inclusive, for each point tested }\end{array}$ & 30.00 \\
\hline $203.101 d$ & $\begin{array}{l}\text { Thermometers, testing at points from }-1 \text { to }-110^{\circ} \mathrm{C} \text { inclusive, or from } \\
31 \text { to }-166^{\circ} \mathrm{F} \text { inclusive, for each point tested }\end{array}$ & 32.00 \\
\hline $203.101 \mathrm{e}$ & $\begin{array}{l}\text { Thermometers, testing in liquid air, oxygen, or liquid nitrogen }(-183 \\
\left.\text { to }-196^{\circ} \mathrm{C}\right) \text {, for each point tested }\end{array}$ & 53.00 \\
\hline $203.101 f$ & Calorimeter thermometers & 67.00 \\
\hline $203.101 \mathrm{~g}$ & $\begin{array}{l}\text { Beckmann thermometers, with } 5^{\circ} \text { or } 6^{\circ} \text { scale, testing at } 1^{\circ} \text { intervals by } \\
\text { comparison with precision standards. }\end{array}$ & 73.00 \\
\hline $203.101 \mathrm{~h}$ & $\begin{array}{l}\text { When instruments submitted are found to be unsuitable for test or un- } \\
\text { reliable a charge will be made to cover the cost of the work done. Min- } \\
\text { imum fee. }\end{array}$ & 1.00 \\
\hline $203.101 \mathrm{i}$ & $\begin{array}{l}\text { Preliminary examination for foreign material in the mercury column and } \\
\text { bulb and for a separated mercury column will be made as required. } \\
\text { Separated mercury column will be reunited provided this can be ac- } \\
\text { complished readily. Maximum fee. }\end{array}$ & 3.00 \\
\hline $203.101 z$ & $\begin{array}{l}\text { For special tests not covered by the above schedule, fees will be charged } \\
\text { dependent upon the nature of the test. }\end{array}$ & \\
\hline
\end{tabular}

203.102 Thermocouples, thermocouple materials and pyrometer indicators.

(a) Only the bare wires are required in order to perform the thermocouple calibrations in this schedule. It is preferable not to send insulating and protecting tubes, as the rate of breakage of these in shipment is high. If the thermocouple is furnished mounted (as in a protection-tube assembly) a charge of $\$ 5.00$ will be made for dismantling the mounting, and the various parts will be returned to the sender without reassembling them.

(b) Thermocouple length requirements listed below are exclusive of lead wire. Lead wire need not be sent with thermocouples.

(c) All thermocouple calibration data furnished in reports will be on the basis of a reference junction temperature of $0{ }^{\circ} \mathrm{C}$, or $32^{\circ} \mathrm{F}$.

(d) The calibration or test of an article will not be undertaken if, in our opinion, the article will not yield the specified accuracy, or if it possesses such unusual characteristics as to prevent the carrying out of the calibration or test at a reasonable cost. 


\begin{tabular}{c|c}
\hline Item & Description \\
\hline $203.102 \mathrm{a}$ & High-temperature thermocouples and thermocouple materials. Mini-
\end{tabular}
mum length $24 \mathrm{in.} \mathrm{Corresponding} \mathrm{values} \mathrm{of} \mathrm{emf} \mathrm{and} \mathrm{temperature}$ at 4 to 15 points in the range 0 to $1450{ }^{\circ} \mathrm{C}\left(32\right.$ to $\left.2650{ }^{\circ} \mathrm{F}\right)$

$\$ 75.00$

The reported uncertainty of calibration of platinum versus platinum-rhodium thermocouples is 0.5 degree Celsius from 0 to $1100^{\circ} \mathrm{C}$ and increases from 0.5 degree at $1100^{\circ} \mathrm{C}$ to 2 degrees at $1450^{\circ} \mathrm{C}$. Values above $1100^{\circ} \mathrm{C}$ are obtained by extrapolation. Results for platinum versus platinum-10\% rhodium thermocouples are given at 1 degree intervals over the entire range 0 to $1450{ }^{\circ} \mathrm{C}$.

The reported uncertainty of calibration of base-metal thermocouples is 1 degree Celsius. Base-metal thermocouples are not tested above $1100{ }^{\circ} \mathrm{C}$ $\left(2000^{\circ} \mathrm{F}\right)$.

Ther mocouple materials are tested against platinum thermoelectric standards maintained by the Bureau.

203.102b High-temperature thermocouples and thermocouple materials. Calibration as per item 203.102a at less than four points, per point

$203.102 \mathrm{c}$

Platinum ver'sus platinum-10\% rhodium thermocouples. The thermocouple shall be at least 36 in. long and made of wire not less than 0.014 in. in diameter. Emf of a thermocouple at any of the following temperatures, per point

$1063{ }^{\circ} \mathrm{C}$ (gold point), $960.8^{\circ} \mathrm{C}$ (silver point), $630.5^{\circ} \mathrm{C} 419.5^{\circ} \mathrm{C}$ (zinc point) Calibration uncertainty $2 \mu \mathrm{v}$ (about 0.2 degree Celsius).

$203.102 d$

Platinum versus platinum-10\% rhodium thermocouples. The thermocouple shall be at least $36 \mathrm{in.} \mathrm{long} \mathrm{and} \mathrm{made} \mathrm{of} \mathrm{wire} \mathrm{not} \mathrm{less} \mathrm{than}$ $0.014 \mathrm{in}$. in diameter. Primary calibration at all of the temperatures listed in item $203.102 \mathrm{c}$, plus a table of corresponding values of emf and temperature at 1 degree intervals in the range 0 to $1450{ }^{\circ} \mathrm{C}$.

255.00

Uncertainty in emf reported for the fixed point temperatures $2 \mu \mathrm{v}$. Uncertainties in values given in the table do not exceed 0.3 degree Celsius in the range 0 to $1100{ }^{\circ} \mathrm{C}$, and then increase from 0.3 degree at $1100^{\circ} \mathrm{C}$ to not more than 2 degrees at $1450^{\circ} \mathrm{C}$.

If the submitted thermocouple meets the requirements of the International Practical Temperature Scale for standard thermocouples (see the International Practical Temperature Scale of 1948 by H. F. Stimson, J. Res. NBS 65A, 139, 1961), $9^{9}$ a quadratic equation fitted at $1063,960.8$, and $630.5{ }^{\circ} \mathrm{C}$ will also be furnished.

$203.102 \mathrm{e}$

High-temperature thermocouples and thermocouple materials. Interpolated corresponding values of emf and temperature as per item 203.102a per point

Based-metal thermocouples. Minimum length of 36 in. Corresponding values of emf and temperature with an uncertainty of $0.1{ }^{\circ} \mathrm{C}$

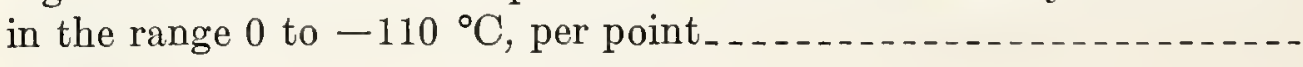

Minimum calibration per thermocouple, two points. 


\begin{tabular}{|c|c|c|}
\hline Item & Description & Fee \\
\hline $203.102 \mathrm{~g}$ & $\begin{array}{l}\text { Base-metal thermocouples. Minimum length of } 36 \text { in. Correspond- } \\
\text { ing values of emf and temperature with an uncertainty of about } 0.1^{\circ} \\
\text { in the range } 0 \text { to } 300^{\circ} \mathrm{C} \text { and with an uncertainty of about } 0.2^{\circ} \text { above } 300 \\
{ }^{\circ} \mathrm{C} \text {, per point.-. } \\
\text { Minimum calibration per thermocouple, two points. }\end{array}$ & $\$ 28.00$ \\
\hline $203.102 \mathrm{~h}$ & $\begin{array}{l}\text { Base-metal thermocouples. Minimum length of } 36 \text { in. Correspond- } \\
\text { ing values of emf and temperature with an uncertainty of about } 0.1^{\circ} \text { in } \\
\text { the range }-183 \text { to }-196{ }^{\circ} \mathrm{C} \text {, per point } \\
\text { Minimum calibration per thermocouple, two points. }\end{array}$ & 48.00 \\
\hline $203.102 \mathrm{i}$ & $\begin{array}{l}\text { Pyrometer indicators. Calibration of single scale or meter of single } \\
\text { dial of potentiometer (reference junction compensator counting as a } \\
\text { dial) }\end{array}$ & 23.00 \\
\hline $203.102 j$ & $\begin{array}{l}\text { Pyrometer indicators. Calibration of each additional dial of a multi- } \\
\text { dial instrument (reference junction compensator counting as a dial) } \\
\text { or of each additional range of each dial or scale of a multi-range instru- } \\
\text { ment. }\end{array}$ & 8.00 \\
\hline $203.102 z$ & $\begin{array}{l}\text { Calibration of a thermocouple and pyrometer indicator as a unit will be charged } \\
\text { for as if the thermocouple and indicator were separately calibrated. } \\
\text { For special tests not covered by the above schedule, fees will be charged } \\
\text { dependent upon the nature of the test. }\end{array}$ & \\
\hline
\end{tabular}

203.103 Resistance thermometers. Resistance thermometers will normally be tested only if they may reasonably be expected to meet the requirements as a standard on the International Practical Temperature Scale. In general, this requires a four-lead resistor of very pure platinum hermetically sealed in a protecting tube.

\begin{tabular}{|c|c|}
\hline Item & Description \\
\hline $203.103 a$ & $\begin{array}{l}\text { Standard platinum resistance thermometers-calibration at the ice, } \\
\text { steam and sulfur points. Table will be furnished with entries at } \\
\text { 1-degree intervals. }\end{array}$ \\
\hline $203.103 b$ & $\begin{array}{l}\text { Standard platinum resistance thermometers-calibration under 203.- } \\
\text { 103a and at the oxygen point. Table will be furnished with entries } \\
\text { at 1-degree intervals }\end{array}$ \\
\hline $203.103 c$ & $\begin{array}{l}\text { Calorimetric type platinum resistance thermometers-calibration at } \\
\text { the ice and steam points and at approximately } 50{ }^{\circ} \mathrm{C} \text {. Table will be } \\
\text { furnished with entries at 1-degree intervals }\end{array}$ \\
\hline $203.103 d$ & $\begin{array}{l}\text { Capsule-type platinum resistance thermometers-comparison calibra- } \\
\text { tion over the range from } 12 \text { to } 90^{\circ} \mathrm{K} \text {. Results will be in the form of } \\
\text { a table with entries at } 0.1-\mathrm{degree} \text { intervals. Additional tables are } \\
\text { not available unless requested at the time of test. See item } 203.103 \mathrm{f}\end{array}$ \\
\hline
\end{tabular}

Fee $\$ 165.00$ 220.00 165.00 


\begin{tabular}{|c|c|c|}
\hline Item & Description & Fee \\
\hline $203.103 \mathrm{e}$ & $\begin{array}{l}\text { Determination of the average temperature coefficient of electrical resist- } \\
\text { ance over the interval } 0 \text { to } 100^{\circ} \mathrm{C} \text {. Minimum length, } 16 \mathrm{in} \text {. Samples } \\
\text { must have a resistance of at least } 0.1 \mathrm{ohm} \text { per foot at the ice point }\end{array}$ & $\$ 70.00$ \\
\hline $203.103 f$ & $\begin{array}{l}\text { Each additional table expressing the results of test under items } 203.103 \text { a, } \\
\text { b, or c. } \\
\text { Additional tables under item 203.103d are not available unless requsted at the } \\
\text { time of test. }\end{array}$ & 30.00 \\
\hline $203.103 \mathrm{~g}$ & $\begin{array}{l}\text { Item } 203.103 \mathrm{f} \text { if requested at the same time as the test of the thermom- } \\
\text { eter under items } 203.103 \mathrm{a}, \mathrm{b}, \mathrm{c} \text {, or } \mathrm{d}\end{array}$ & 25.00 \\
\hline $203.103 \mathrm{~h}$ & $\begin{array}{l}\text { Capsule-type platinum resistance thermometers-mounting this type } \\
\text { of thermometer for test under item } 203.103 \text { a or b. Not applicable } \\
\text { to item } 203.103 \mathrm{~d}\end{array}$ & 10.00 \\
\hline $203.103 y$ & $\begin{array}{l}\text { When instruments submitted are found to be unsuitable for test or } \\
\text { unreliable, a charge will be made to cover the cost of the work done. }\end{array}$ & \\
\hline $203.103 z$ & $\begin{array}{l}\text { For special tests not covered by the above schedule, fees will be charged } \\
\text { dependent upon the nature of the test. }\end{array}$ & \\
\hline
\end{tabular}

203.104 Glinical thermometers.

\begin{tabular}{c|c|c}
\hline Item & Description & Fee \\
\hline $203.104 \mathrm{z}$ & $\begin{array}{c}\text { Test of clinical thermometers for compliance with the current edition of } \\
\text { the Commercial Standard for Clinical Thermometers. Fees will be } \\
\text { charged dependent upon the time required for making the test. }\end{array}$ & \\
\hline
\end{tabular}

\subsection{Optical pyrometers and ribbon filament lamps.}

(a) Optical pyrometers and ribbon filament lamps submitted for calibration should be accompanied by an order requesting the test and specifying the fee schedule item number. If desired, the calibration points may be specified. A bill will be rendered at the completion of the work.

(b) The calibration of an article will not be undertaken if it possesses such unusual characteristics as to prevent the carrying out of the calibration at a reasonable cost. If, in the course of a calibration, the device is found to behave abnormally, work may be discontinued and a fee covering the cost of the work performed will be charged. 


\begin{tabular}{|c|c|c|}
\hline Item & Description & Fee \\
\hline $203.105 \mathrm{a}$ & $\begin{array}{l}\text { Optical pyrometers: Calibration of one range between } 800 \text { and } 2400{ }^{\circ} \mathrm{C} \\
\text { or the first range, between } 800 \text { and } 2400{ }^{\circ} \mathrm{C} \text {, of a calibration involving } \\
\text { more than one range; } 4 \text { to } 12 \text { values. }\end{array}$ & $\$ 185.00$ \\
\hline $203.105 b$ & $\begin{array}{l}\text { Optical pyrometers: Calibration of ranges in addition to item } 203.105 \text { a } \\
\text { up to } 420{ }^{\circ} \mathrm{C} ; 4 \text { to } 12 \text { values in each range, per range. }\end{array}$ & 120.00 \\
\hline $203.105 \mathrm{c}$ & Optical pyrometers: Three or fewer values, 800 to $2400^{\circ} \mathrm{C}$ & 95.00 \\
\hline $203.105 \mathrm{~d}$ & $\begin{array}{l}\text { Ribbon filament lamps: Values of brightness temperature (at wave- } \\
\text { length of } 0.65 \mu \text { ) versus direct current at } 6 \text { to } 16 \text { points in the range, } \\
800 \text { to } 2300^{\circ} \mathrm{C} \text {. }\end{array}$ & 165.00 \\
\hline 203.105 e & $\begin{array}{l}\text { Ribbon filament lamps: Values of brightness temperature (at wave- } \\
\text { length of } 0.65 \mu \text { ) versus direct current at five or fewer points in the } \\
\text { range, } 800 \text { to } 2300^{\circ} \mathrm{C} \text {. }\end{array}$ & 90.00 \\
\hline $203.105 f$ & $\begin{array}{l}\text { Additional interpolated values as per item } 203.105 \mathrm{a} \text { and } 203.105 \mathrm{~b} \text {, per } \\
\text { point. }\end{array}$ & 2.25 \\
\hline $203.105 z$ & $\begin{array}{l}\text { For special tests not covered by the above schedule, fees will be charged } \\
\text { dependent upon the nature of the test. }\end{array}$ & \\
\hline
\end{tabular}

\section{Part 204-Radiation Physics}

Sec.

Radioactivity

204.201 Calibration of gamma-emitting radioactive samples

204.202 Calibration of alpha-emission rate of sources

204.203 Calibration of beta-emitting radioactive samples

$$
\text { Radiological Equipment-Gamma-Ray Sources }
$$

204.501 X-ray and gamma-ray instruments

204.502 Gamma-ray sources

204.701 Neutron sources

\section{Neutron Physics}

204.702 Neutron instruments

204.703 Neutron irradiation of foils

\section{Radioactivity}

204.201 Calibration of gamma-e mitting radioactive samples that conform to the physical, chemical, and activity level specifications for measurement in the Bureau's gamma ionization chamber. 


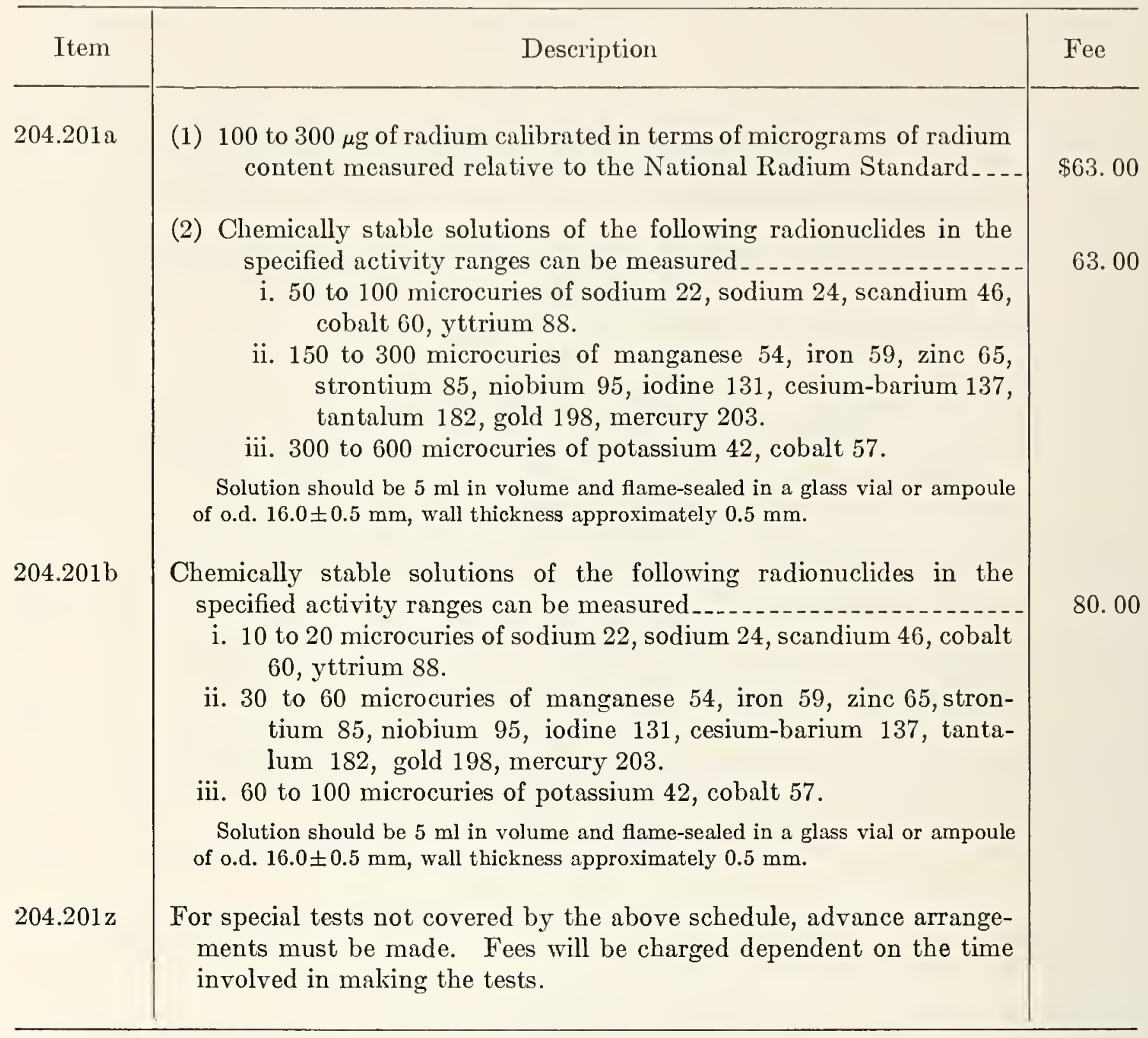

204.202 Calibration of alpha emission rate of sources.

\begin{tabular}{c|c|c}
\hline Item & Description & Fee \\
\hline $204.202 \mathrm{a}$ & Calibration of alpha emission rate of sources submitted for test $\ldots \ldots \ldots$ & $\$ 51.00$ \\
\hline
\end{tabular}

204.203 Calibration of beta-emitting radioactive samples that conform to the physical, chemical, and activity level specifications for measurement in the Bureau's $2 \pi \beta$ windowless proportional flow counter, or in the Bureau's $2 \pi \beta$-ionization chamber.

\begin{tabular}{c|c|c}
\hline Item & Description & Fee \\
\hline $204.203 a$ & $\begin{array}{r}\text { Chemically stable solutions of the following radionuclides in the specified } \\
\text { activity ranges can be measured }\end{array}$ & \$158.00
\end{tabular}




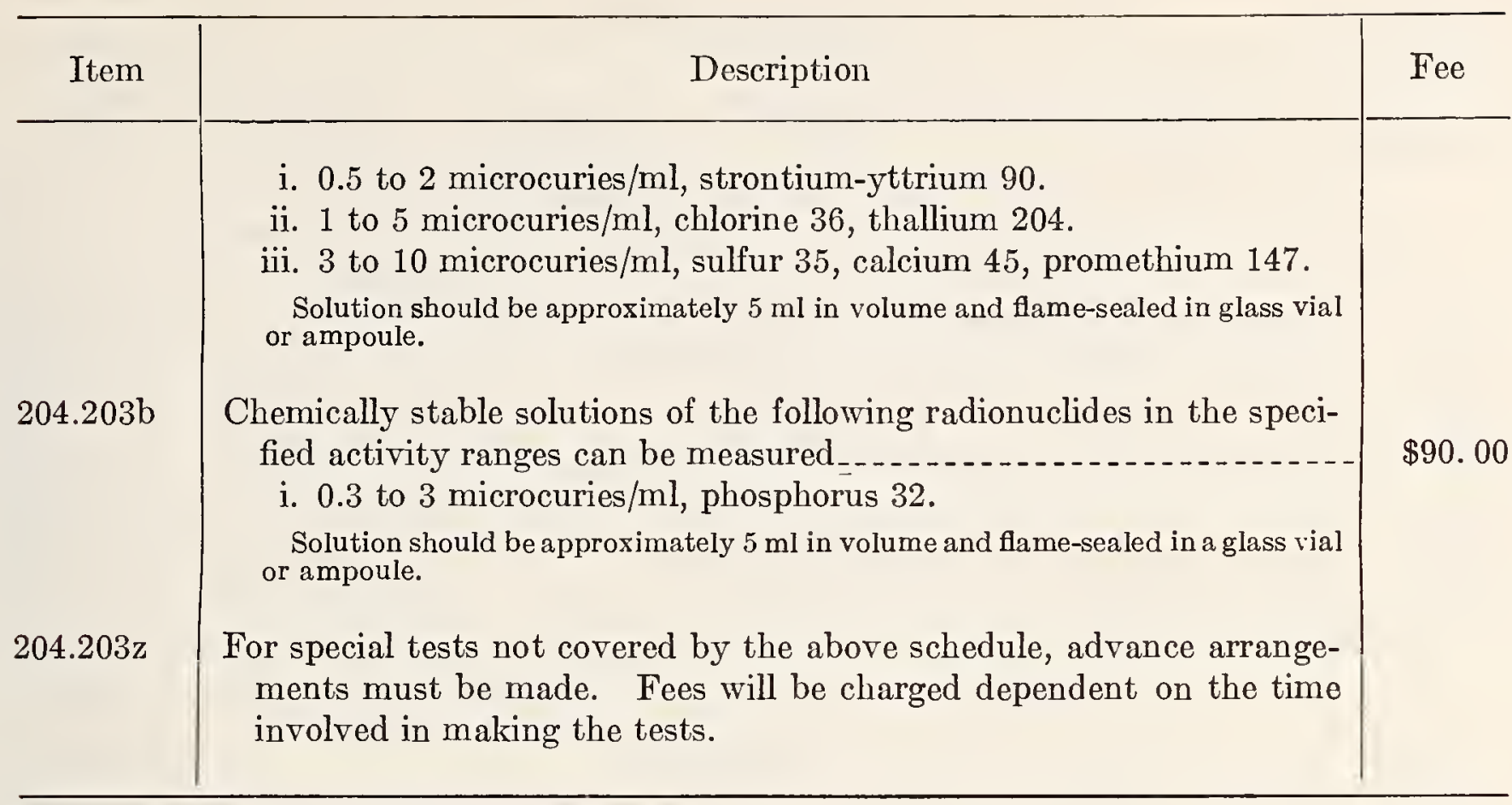

\section{Radiological Equipment-Gamma-Ray Sources}

\subsection{X-ray and gamma-ray instruments}

Note: Calibration of radiation beam within \pm 2 percent.

\begin{tabular}{c|c|c}
\hline Item & Description & Fce \\
\hline $204.501 \mathrm{a}$ & $\begin{array}{l}\text { Calibration of one X-ray exposure-indicating instrument of one range, } \\
\text { in international roentgens for lightly or moderately filtered X-rays of } \\
\text { one half-value layer from the following selections } \ldots \ldots\end{array}$ & $\$ 48.00$ \\
\hline
\end{tabular}

Lightly filtered $X$-rays

\begin{tabular}{|c|c|c|c|c|c|c|c|c|c|c|}
\hline \multirow[t]{2}{*}{ Technique } & \multirow[t]{2}{*}{ kvep } & \multirow{2}{*}{$\begin{array}{l}\text { Approx. } \\
\text { inherent } \\
\text { filter }\end{array}$} & \multirow{2}{*}{$\begin{array}{l}\text { Added } \\
\text { filter }\end{array}$} & \multirow{2}{*}{$\begin{array}{l}\text { Dis- } \\
\text { tance }\end{array}$} & \multirow{2}{*}{$\begin{array}{l}\text { Approx. } \\
\text { first half- } \\
\text { value } \\
\text { layer }\end{array}$} & \multirow{2}{*}{$\begin{array}{c}\text { Homogeneity } \\
\text { coefflcient } \\
\text { (1st HVL/2d HVL) }\end{array}$} & \multicolumn{2}{|c|}{$\begin{array}{l}\text { Instrument } \\
\text { range from } \\
\text { zero }\end{array}$} & \multicolumn{2}{|c|}{$\begin{array}{l}\text { Exposure } \\
\text { rate }\end{array}$} \\
\hline & & & & & & & $\min$. & $\max$. & $\min$. & $\max$. \\
\hline & & $m m \mathrm{Be}$ & $m m \mathrm{Al}$ & $\mathrm{cm}$ & $m m \mathrm{Al}$ & & $R$ & $R$ & $R / \min$ & $R / \min$ \\
\hline LFD_ & 20 & 0.25 & 0 & 50 & 0.06 & 0.42 & 100 & 500 & 50 & 200 \\
\hline $\mathrm{LFD}_{-}$ & 20 & .25 & 0 & 70 & .07 & & 50 & 100 & 20 & 80 \\
\hline LFD -- & 20 & .25 & 0 & 100 & .08 & $-\ldots$ & 25 & 50 & 7 & 30 \\
\hline $\mathrm{LFE}_{-}$ & 20 & .25 & 0.5 & 50 & .20 & .68 & 10 & 100 & 2 & 8 \\
\hline $\mathrm{LFG}_{-}$ & 30 & .25 & .5 & 50 & .33 & .67 & 25 & 250 & 5 & 20 \\
\hline LFI_- & 50 & .25 & 1. 0 & 50 & .90 & .68 & 25 & 250 & 6 & 25 \\
\hline LFK & 75 & .25 & 1. 5 & 50 & 1.6 & .66 & 25 & 250 & 10 & 22 \\
\hline LFM $\ldots$ & 100 & .25 & 2. 0 & 50 & 2.5 & .63 & 25 & 250 & 14 & 25 \\
\hline
\end{tabular}


Moderately filtered X-rays

\begin{tabular}{|c|c|c|c|c|c|c|c|c|c|c|c|}
\hline \multirow[t]{2}{*}{ Technique } & \multirow[t]{2}{*}{ kvep } & \multirow{2}{*}{$\begin{array}{l}\text { Approx. } \\
\text { inherent } \\
\text { filter }\end{array}$} & \multicolumn{2}{|c|}{ Added filter } & \multicolumn{2}{|c|}{$\begin{array}{l}\text { Approx. first } \\
\text { half-value } \\
\text { layer }\end{array}$} & \multirow{2}{*}{$\begin{array}{c}\text { Homogeneity } \\
\text { coefficient } \\
\text { (1st HVL/2d HVL) }\end{array}$} & \multicolumn{2}{|c|}{$\begin{array}{l}\text { Instrument } \\
\text { range from } \\
\text { zero }\end{array}$} & \multicolumn{2}{|c|}{$\begin{array}{l}\text { Exposure } \\
\text { rate }\end{array}$} \\
\hline & & & $\mathrm{Cu}$ & $\mathrm{Al}$ & $\mathrm{Cu}$ & $\mathrm{Al}$ & & $\min$. & $\max$. & $\min$. & $\max$. \\
\hline & & $m m A l$ & $m m$ & $m m$ & $m m$ & $m m$ & & $R$ & $R$ & $R / \min$ & $R / \min$ \\
\hline MFB_-_.- & 60 & 1.5 & 0 & 0 & $\ldots$ & 1.64 & 0.67 & 5 & 100 & 0.4 & 3. 0 \\
\hline MFC_..... & 60 & 1.5 & 0 & 2.5 & 0.09 & 2. 79 & .77 & 5 & 100 & .4 & 2.5 \\
\hline MFE_.... & 75 & 1.5 & 0 & 2.5 & .11 & 3. 41 & .73 & 5 & 100 & .4 & 4. 0 \\
\hline MFG_-..- & 100 & 1.5 & 0 & 3.5 & .20 & 5.05 & .73 & 5 & 100 & .9 & 6.0 \\
\hline MFI_.... & 150 & 1.5 & .25 & 3.5 & .66 & 10.1 & .87 & 5 & 100 & 1.0 & 8.0 \\
\hline MFK_---- & 200 & 1.5 & .5 & 3.5 & 1.26 & 13. 2 & .92 & 10 & 250 & 2. 0 & 13.0 \\
\hline MFM_--- & 250 & 1.5 & 1.0 & 3. 5 & 2. 17 & 16. 2 & .94 & 10 & 250 & 2. 5 & 17.0 \\
\hline MFO_....- & 250 & 1.5 & 3.2 & 3.5 & 3. 20 & 18.4 & .98 & 10 & 250 & 1.3 & 10.0 \\
\hline
\end{tabular}

\begin{tabular}{|c|c|c|}
\hline Item & Description & Fee \\
\hline $204.501 \mathrm{~b}$ & $\begin{array}{l}\text { Calibration of each additional X-ray exposure-indicating instrument of } \\
\text { the same range and for the same half-value layer of lightly or moder- } \\
\text { ately filtered X-rays as selected under } 204.501 \text { a and not requiring a } \\
\text { change in setup and when the instruments are submitted at the same } \\
\text { time. }\end{array}$ & \multirow{2}{*}{$\begin{array}{l}\$ 18.00 \\
60.00\end{array}$} \\
\hline $204.501 \mathrm{c}$ & $\begin{array}{l}\text { Calibration of one X-ray instrument, either exposure- or exposure-rate- } \\
\text { indicating, in international roentgens for heavily filtered X-rays of } \\
\text { one effective energy from the following selections. }\end{array}$ & \\
\hline
\end{tabular}

Heavily filtered $X$-rays*

\begin{tabular}{|c|c|c|c|c|c|c|c|c|c|c|c|c|c|}
\hline \multirow{3}{*}{ Technique } & \multirow{3}{*}{ kvep } & \multirow{3}{*}{$\begin{array}{c}\text { Approx. } \\
\text { inherent } \\
\text { filter }\end{array}$} & \multicolumn{4}{|c|}{ Added filter } & \multicolumn{3}{|c|}{ Approximate } & \multirow{2}{*}{\multicolumn{2}{|c|}{$\begin{array}{l}\text { Instrument } \\
\text { range from } \\
\text { zero }\end{array}$}} & \multirow{2}{*}{\multicolumn{2}{|c|}{$\begin{array}{l}\text { Exposure } \\
\text { rate }\end{array}$}} \\
\hline & & & $\mathrm{Pb}$ & $\mathrm{Sn}$ & $\mathrm{Cu}$ & $\mathrm{Al}$ & Effective & HVL & HVL & & & & \\
\hline & & & & & & & & & & $\min$. & $\max$. & $\min$. & $\max$ \\
\hline HFC_ & 50 & $\begin{array}{cc}m m & \mathrm{Al} \\
1.5\end{array}$ & $\begin{array}{c}m m \\
.12\end{array}$ & $\begin{array}{c}m m \\
0\end{array}$ & $\begin{array}{c}m m \\
0\end{array}$ & $\begin{array}{c}m m \\
2.5\end{array}$ & kev & $\begin{array}{r}m m \mathrm{Cu} \\
0.16\end{array}$ & $\begin{array}{cc}m m & \mathrm{Al} \\
& 4.4\end{array}$ & $\begin{array}{c}R \\
0.1\end{array}$ & $R_{1}$ & $\begin{array}{r}R / \min \\
0.02\end{array}$ & $\begin{array}{r}R / \min \\
0.09\end{array}$ \\
\hline $\mathrm{HFE}_{\text {- }}$ & 100 & 1. 5 & .53 & 0 & 0 & 2.5 & 70 & .72 & 11. 2 & 1 & 5 & .05 & .27 \\
\hline HFG... & 150 & 1.5 & 0 & 1. 5 & 4.0 & 2.5 & 120 & 2.4 & 16.8 & .1 & 5 & .04 & .22 \\
\hline HFI._. & 200 & 1. 5 & .7 & 4. 0 & 0.6 & 2.5 & 170 & 4. 1 & 19.5 & .1 & 5 & .03 & .21 \\
\hline HFK $\ldots . . .$. & 250 & 1. 5 & 2. 7 & 1. 0 & .6 & 2. 5 & 215 & 5.4 & 21.5 & .1 & 5 & .03 & .21 \\
\hline
\end{tabular}

"A vailable on"special arrangement.

\begin{tabular}{|c|c|c|}
\hline Item & Description & Fee \\
\hline $204.501 d$ & $\begin{array}{l}\text { Calibration of each additional X-ray instrument of the same exposure } \\
\text { or exposure-rate range, for heavily filtered X-rays of one effective } \\
\text { energy as selected under } 204.501 \text { c, not requiring a change in setup and } \\
\text { when the instruments are submitted at the same time. }\end{array}$ & $\$ 24.00$ \\
\hline
\end{tabular}




\begin{tabular}{|c|c|c|}
\hline Item & Description & Fee \\
\hline $204.501 \mathrm{e}$ & $\begin{array}{l}\text { Calibration of one instrument: } \\
\text { (1) Exposure-rate-indicating instrument for exposure rates ranging } \\
\quad \text { from } 0.01 \text { to } 15 \mathrm{R} / \mathrm{min} \text {; or } \\
\text { (2) Exposure-indicating instrument of range } 0 \text { to } 0.1 \mathrm{R} \text { to } 0 \text { to } 25 \mathrm{R} \text {, in } \\
\text { international roentgens for cobalt } 60 \text { or cesium } 137 \text { gamma-rays.- }\end{array}$ & $\$ 42.00$ \\
\hline $204.501 \mathrm{f}$ & $\begin{array}{l}\text { Calibration of each additional instrument having the same exposure or } \\
\text { exposure-rate range for cobalt } 60 \text { or cesium } 137 \text { gamma-rays, as under } \\
204.501 \text { e, when the instruments are submitted at the same time...- }\end{array}$ & 17.00 \\
\hline $204.501 \mathrm{z}$ & $\begin{array}{l}\text { Calibration of one X-ray or gamma-ray instrument, exposure- or ex- } \\
\text { posure-rate-indicating, in international roentgens: } \\
\text { (1) Calibration of higher accuracy than that routinely furnished; or } \\
\text { (2) Calibrations on X-rays of energies other than those listed under } \\
204.501 \mathrm{a}, \mathrm{c} \text {, or e; or } \\
\text { (3) Calibrations requiring a special setup or special procedures. Fees } \\
\text { will be charged dependent upon the nature of the test. } \\
\text { Only a limited number of special calibrations can be undertaken and requests } \\
\text { for such should be submitted with full details for consideration. }\end{array}$ & \\
\hline
\end{tabular}

204.502 Gamma-ray sources. Radioactive preparations submitted to the Bureau for test are subject to the following conditions:

(a) Financial responsibility: The Bureau assumes no responsibility for loss or damage to radioactive preparations while in its possession. The risk should be covered by insurance.

(b) Period of measurement: Approximately 10 days are required for measurement of these radioactive preparations.

(c) Preparation of specimens: Radioactive preparations submitted for test must be carefully sealed so that there can be no escape of any radioactive material, including any gaseous decay products. The preparations, shielding, and packaging must be free of contamination. Contaminated or leaking preparations cannot be measured and may cause considerable loss of time and damage to laboratory facilities. Preparations must have been sealed for a sufficient time to be substantially in radioactive equilibrium with their decay products when these contribute to the gamma emission (at least 30 days for radium).

(d) Packaging for shipment: Regulations of the Interstate Commerce Commission regarding the shipment of radioactive substances by rail must be complied with. These regulations are enforceable by law and prospective shippers of these substances need to be familiar with them. Copies of the regulations can be obtained from the Interstate Commerce Commission, Washington, D.C., 20423.

(e) Possession of licensed material: In submitting specimens of cobalt 60 or other licensed source material (except radium, which is not licensed) for calibration, it will be necessary for the submitter to certify that he is duly authorized to possess the material under license by the USAEC, except in the case of individuals residing in a State which has entered into agreement with the USAEC, in which case State regulations are applicable. This certification may be by letter, by a suitable statement on the purchase order covering the calibration fee, or by a clear copy of the submitter's Possession License for the source material.

(f) Type of measurements:

(1) Radium is calibrated in terms of milligrams of equivalent radium content measured relative to the National Radium Standard through comparison of the gamma radiation from the specimen and the standard. Where the details of encapsulation of the specimen are known, corrections can be made to obtain milligrams of radium content. Cobalt 60 is calibrated in terms of exposure rate, milliroentgens per hour at one meter, based upon comparison with derived standards of cobalt 60 . 
(2) Postal regulations prohibit mailing radioactive materials which require a caution label under ICC regulations. This effectively prohibits placing radioactive preparations in the mail.

\begin{tabular}{c|c|}
\hline Item & Description \\
\hline &
\end{tabular}

Gamma-ray measurements of radioactive preparations; measurements of milligrams equivalent content to \pm 0.7 percent for radium; and milliroentgens per hour at one meter to \pm 3 percent for cobalt 60 :

$204.502 \mathrm{a}$

0.5 to $15 \mathrm{mg}$ equivalent radium content or cobalt 60 having gammarays 0.5 to $15 \mathrm{mRhm}$ (milliroentgens per hour at one meter)

$\$ 18.00$

$204.502 \mathrm{~b}$

$15+$ to $100 \mathrm{mg}$ equivalent radium content or cobalt 60 having gammarays $15+$ to $100 \mathrm{mRhm}$

Fee

$204.502 \mathrm{c} \quad 100+$ to $250 \mathrm{mg}$ equivalent radium content or cobalt 60 having gamma rays 100 to $200 \mathrm{mRhm}$.

40. 00

204.502d For measurements in groups not exceeding 10 preparations, double the fee for preparations of same content as the total content of the group.

204.502e For handling and examination of a shipment containing contaminated or leaking preparations the fee will be the same as for measurements of a preparation having a content equal to the total nominal radioactive content of the shipment.

204.502z For special tests not covered by the above schedule, fees will be charged dependent upon the nature of the test. As only a limited number of special tests can be carried out, prior arrangements must be made including submission of full details concerning the required test.

204.701 Neutron sources.

Neutron Physics

\begin{tabular}{|c|c|c|}
\hline Item & Description & Fee \\
\hline $204.701 a$ & $\begin{array}{l}\text { Determination of ratio of neutron emission rate of unknown source to } \\
\text { primary standard in } \mathrm{MnSO}_{4} \text { bath or graphite column }\end{array}$ & $\$ 385.00$ \\
\hline
\end{tabular}

204.702 Neutron instruments.

\begin{tabular}{c|c|c}
\hline Item & Description & Fee \\
\hline $204.702 \mathrm{a}$ & Calibration of a set (one to three) of thermal neutron dosimeters $\ldots$ & $\$ 78.00$ \\
\hline
\end{tabular}


204.703 Neutron irradiation of foils.

\begin{tabular}{c|c|c}
\hline Item & Description & Fee \\
\hline $204.703 \mathrm{a}$ & $\begin{array}{c}\text { Activation of a set (one to four) of foils in the NBS standard thermal } \\
\text { neutron flux geometry }-\ldots\end{array}$ & $\$ 59.00$ \\
\hline
\end{tabular}

\section{Part 205-Analytical and Inorganic Chemistry \\ Pure Substances}

205.101 Measurement of physical properties of primary reference fuels used for octane number determination.

\begin{tabular}{c|c|c}
\hline Item & Description & Fee \\
\cline { 2 - 3 } $205.101 \mathrm{a}$ & $\begin{array}{c}\text { Measurement of physical properties of primary reference fuels used } \\
\text { for octane number determination }\end{array}$ & $\$ 445.00$ \\
\hline
\end{tabular}

\section{Part 206-Mechanics}

Vibration

Sec.

206.001 Vibration pickups

206.101 Acoustic measurements

\section{Sound}

\section{Pressure and Vacuum}

206.201 Pressure measurements

$$
\text { Fluid Mechanics }
$$

206.301 Aerodynamical measurements

206.302 Fluid meters, including gas-measuring instruments

206.401 Hardness tests

$$
\text { Engineering Mechanics }
$$

206.402 Calibration of load cells with remote-reading electrical indicators

206.403 Special mechanical tests of devices, materials, and structures

206.404 Calibration of proving rings

206.405 Calibration of elastic force measuring devices

206.001 Vibration pickups.

\section{Vibration}

(a) This applies to the calibration of displacement, velocity, and acceleration types of vibration pickups. A report of calibration is issued. 
(b) Each piezoelectric acceleration pickup which is used with a cathode-follower or amplifier shall be accompanied by the cathode-follower or amplifier, the power supply if other than batterics, and the output and connecting cables.

(c) Each piezoelectric acceleration pickup whose output is read directly with a highimpedance meter can be but need not be accompanied by the meter, but shall be accompanied by the output cable and a suitable shielded connector.

(d) When instruments submitted are found to be unsuitable for test or unreliable, a charge will be made to cover the cost of the work done.

\begin{tabular}{|c|c|}
\hline Item & Description \\
\hline $206.001 a$ & $\begin{array}{l}\text { Static calibration on a tilting support in the earth's gravitational field } \\
\text { for accelerations up to } 1 \mathrm{~g} \text {, the acceleration of gravity, with an error } \\
\text { not greater than } 0.001 \mathrm{~g} \text {. Calibration for } 10 \text { different applied acceler- }\end{array}$ \\
\hline
\end{tabular}

206.001b Static calibration on a centrifuge at four different applied accelerations up to $80 \mathrm{~g}$ for not more than two orientations with an estimated error not greater than 0.2 percent of the applied acceleration (eight calibration points). Acceleration will be determined at radii measured to designated reference points on the pickup case.

Fee

For additional tests or measurements required to determine location of seismic mass, fees will be charged to cover the cost of work done.

206.001c Dynamic calibration of velocity pickups weighing up to $2 \mathrm{lb}$ in the frequency range from 10 to $2,000 \mathrm{c} / \mathrm{s}$ at double displacement amplitudes up to $0.4 \mathrm{in}$. or accelerations up to $10 \mathrm{~g}$, whichever is less. The pickup is subjected to sinusoidal motion on an electrodynamic vibration standard previously calibrated by the reciprocity method. The estimated errors of the applied accelerations do not exceed 1 percent for frequencies up to $900 \mathrm{c} / \mathrm{s}$ and 2 percent above $900 \mathrm{c} / \mathrm{s}$. The magnitude and phase angle of the calibration factor are determined at up to 10 frequencies. The magnitude of the calibration factor is determined for up to three accelerations at each frequency (up to 30 calibration points)

275. 00

For each test frequency in excess of 10 , an additional charge equal to one-tenth of the fee is made.

206.001d Dynamic calibration of acceleration and displacement pickups weighing up to $2 \mathrm{lb}$ in the frequency range of 10 to $2,000 \mathrm{c} / \mathrm{s}$ at double displacement amplitudes up to $0.4 \mathrm{in}$. or accelerations up to $10 \mathrm{~g}$, whichever is less. The pickup is subjected to sinusoidal motion on an electrodynamic vibration standard previously calibrated by the reciprocity method. The estimated errors of the applied accelerations do not exceed 1 percent for frequencies up to $900 \mathrm{c} / \mathrm{s}$ and 2 percent above 900 $\mathrm{c} / \mathrm{s}$. The magnitude and phase angle of the calibration factor are determined at up to 10 frequencies. The magnitude of the calibration factor is determined for up to three accelerations at each frequency (up to 30 calibration points)

For each test frequency in excess of 10 , an additional charge equal to one-tenth of the fee is made. 


\begin{tabular}{|c|c|c|}
\hline Item & Description & Fee \\
\hline $206.001 \mathrm{e}$ & $\begin{array}{l}\text { Dynamic calibration of piezoelectric acceleration pickups weighing up } \\
\text { to } 4 \mathrm{oz} \text { in the frequency range of } 10 \text { to } 2,000 \mathrm{c} / \mathrm{s} \text { at double displacement } \\
\text { amplitudes up to } 0.4 \mathrm{in} \text {. or accelerations up to } 10 \mathrm{~g} \text {, whichever is less } \\
\text { or if requested, up to } 20 \mathrm{~g} \text { at two unspecified frequencies. The pick- } \\
\text { up is subjected to sinusoidal motion on an electrodynamic vibration } \\
\text { standard previously calibrated by the reciprocity method. The esti- } \\
\text { mated errors of the applied accelerations do not exceed } 1 \text { percent for } \\
\text { frequencies up to } 900 \mathrm{c} / \mathrm{s} \text { and } 2 \text { percent above } 900 \mathrm{c} / \mathrm{s} \text {. The magn- } \\
\text { tude of the calibration factor is determined for up to three accelera- } \\
\text { tions at up to } 10 \text { frequencies within a specified range (up to } 30 \text { cali- } \\
\text { bration points) }\end{array}$ & $\$ 255.00$ \\
\hline & $\begin{array}{l}\text { For each test frequency in excess of } 10 \text {, an additonal charge equal to one-tenth } \\
\text { of the fee is made. }\end{array}$ & \\
\hline $206.001 z$ & $\begin{array}{l}\text { For special tests not covered by the above schedule, such as dynamic } \\
\text { calibrations of pickups weighing more than } 2 \mathrm{lb} \text {, calibrations of small, } \\
\text { lightweight piezoelectric ceramic pickups over an extended fre- } \\
\text { quency range up to } 20,000 \mathrm{c} / \mathrm{s} \text {, or calibrations at higher accelerations, } \\
\text { fees will be charged dependent on the nature of the test. }\end{array}$ & \\
\hline
\end{tabular}

\section{Sound}

206.101 Acoustic measurements.

\begin{tabular}{|c|c|}
\hline Item & Description \\
\hline $206.101 \mathrm{a}$ & $\begin{array}{l}\text { Pressure calibration of Western Electric Co. Type } 640 \mathrm{AA} \text { condenser } \\
\text { microphone or equivalent from } 50 \text { to } 10,000 \mathrm{c} / \mathrm{s} \text { at discrete frequencies. } \\
\text { Response given in terms of open-circuit voltage per unit sound pres- } \\
\text { sure applied to the microphone. }\end{array}$ \\
\hline $206.101 b$ & $\begin{array}{l}\text { Pressure calibration of Western Electric Co. Type } 640 \mathrm{AA} \text { condenser } \\
\text { microphone or equivalent from } 50 \text { to } 20,000 \mathrm{c} / \mathrm{s} \text { at discrete frequencies. } \\
\text { Response given in terms of open-circuit voltage per unit sound pres- } \\
\text { sure applied to the microphone. }\end{array}$ \\
\hline $206.101 \mathrm{c}$ & 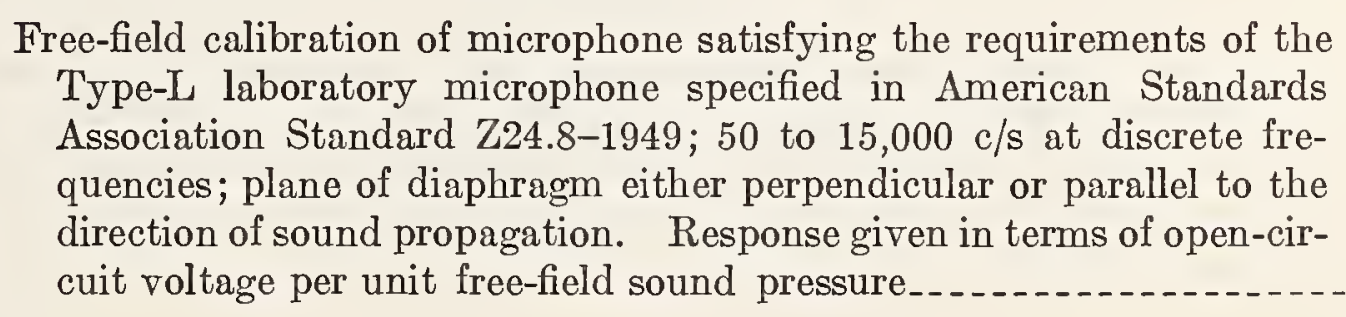 \\
\hline $206.101 d$ & $\begin{array}{l}\text { Calibration of earphones; applied voltage response as prescribed in the } \\
\text { American Standards Association Specification Z24.9-1949, at not } \\
\text { more than } 20 \text { frequencies between } 100 \text { and } 10,000 \mathrm{c} / \mathrm{s}\end{array}$ \\
\hline $206.101 \mathrm{e}$ & $\begin{array}{l}\text { Calibration of pure tone audiometers for screening purposes at nine } \\
\text { fixed frequencies. }\end{array}$ \\
\hline
\end{tabular}

Fee

$\$ 205.00$

280.00

280.00

320.00 


\begin{tabular}{|c|c|c|}
\hline Item & Description & Fee \\
\hline $206.101 \mathrm{f}$ & Artificial ear at audiometric frequencies & $\$ 430.00$ \\
\hline \multirow[t]{3}{*}{$206.101 \mathrm{~g}$} & $\begin{array}{l}\text { Sound absorption coefficient, obtained by reverberation room method, } \\
\text { using } 72 \mathrm{ft}^{2} \text { of material at frequencies of } 125,250,500,1,000,2,000 \text {, and }\end{array}$ & \\
\hline & $4,000 \mathrm{c} / \mathrm{s} \ldots$ & 430.00 \\
\hline & $\begin{array}{l}\text { In case of tests on acoustical plasters or paintability tests, any construction } \\
\text { work or painting done by the Bureau is charged to the sponsor in addition to } \\
\text { the fee given above. }\end{array}$ & \\
\hline $206.101 \mathrm{~h}$ & $\begin{array}{l}\text { Sound absorption coefficient by impedance tube method at } 500 \mathrm{c} / \mathrm{s} \text { in } \\
\text { the laboratory on acoustical tiles }\end{array}$ & 110.00 \\
\hline \multirow[t]{2}{*}{$206.101 \mathrm{i}$} & $\begin{array}{l}\text { Sound transmission loss, wall panel, } 71 \text { in. } \times 88 \text { in. at frequencies of } 125 \text {, } \\
175,250,350,500,700,1,000,1,500,2,000,3,000, \text { and } 4,000 \mathrm{c} / \mathrm{s}\end{array}$ & 430.00 \\
\hline & $\begin{array}{l}\text { The construction of the wall panel is the responsibility of the sponsor of the } \\
\text { test. }\end{array}$ & \\
\hline \multirow[t]{2}{*}{$206.101 \mathrm{j}$} & $\begin{array}{l}\text { Sound transmission loss, floor panel, } 71 \mathrm{in.} \times 88 \mathrm{in} \text {. at frequencies of } \\
125,175,250,350,500,700,1,000,1,500,2,000,3,000 \text {, and } 4,000 \mathrm{c} / \mathrm{s} \\
\text { plus impact sound transmission }\end{array}$ & 575.00 \\
\hline & $\begin{array}{l}\text { The construction of the floor panel is the responsibility of the sponsor of the } \\
\text { test. }\end{array}$ & \\
\hline $206.101 \mathrm{z}$ & $\begin{array}{l}\text { For special tests not covered by the above schedule, fees will be charged } \\
\text { dependent on the nature of the test. }\end{array}$ & \\
\hline
\end{tabular}

\section{Pressure and Vacuum}

206.201 Pressure measurements.

\begin{tabular}{|c|c|}
\hline Item & Description \\
\hline $206.201 \mathrm{a}$ & $\begin{array}{l}\text { Deadweight piston gages other than controlled clearance gages (also } \\
\text { called deadweight gage testers and pressure balances). Determina- } \\
\text { tion of effective area of the piston by comparison with a pressure } \\
\text { standard, up to five test points at room temperature, } 20 \text { to } 25^{\circ} \mathrm{C} \text {. } \\
\text { Pressure fluid may be air, up to } 600 \mathrm{psi} \text {, petroleum oil up to } 60,000 \\
\text { psi, or synthetic lubricant (dioctyl sebacate) up to } 120,000 \text { psi. } \\
\text { Determination of effective area requires previous weighing of piston } \\
\text { assembly and the use of calibrated weights. If the Bureau has } \\
\text { weights to fit, the gage may be calibrated using NBS weights. For } \\
\text { each piston. }\end{array}$ \\
\hline $206.201 b$ & $\begin{array}{l}\text { Controlled clearance piston gages. Determination of effective area, } \\
\text { jacket pressure for zero clearance and variation of effective area with } \\
\text { jacket pressure. Test is made on an assembly of piston, cylinder } \\
\text { and jacket, not to be disassembled later. Determination of effective } \\
\text { area requires previous weighing of piston assembly and the use of } \\
\text { calibrated weights. If the Bureau has weights to fit, the gage may }\end{array}$ \\
\hline
\end{tabular}




\begin{tabular}{|c|c|c|}
\hline Item & Description & Fee \\
\hline & $\begin{array}{l}\text { be calibrated using NBS weights. Inquiry should be made as to the } \\
\text { parts to be submitted. Fee usually does not exceed } \$ 1,000.00 \text {. } \\
\text { Work to be charged at cost. }\end{array}$ & \\
\hline $206.201 \mathrm{c}$ & $\begin{array}{l}\text { Barometers, Fortin or similar types, range } 28 \text { to } 31 \mathrm{in} . \mathrm{Hg} \text {, tube bore } \\
0.5 \text { in. or greater, calibration at room temperature }\left(20 \text { to } 25^{\circ} \mathrm{C}\right) \text { and } \\
\text { atmospheric pressure. }\end{array}$ & $\$ 220.00$ \\
\hline $206.201 \mathrm{~d}$ & $\begin{array}{l}\text { Manometers, manually operated, with tube bore } 0.5 \text { in. or greater, in } \\
\text { which both mercury surfaces are observed. Range to } 100 \mathrm{in} \text {. } \mathrm{Hg} \text {, } \\
\text { calibration test at room temperature }\left(20 \text { to } 25^{\circ} \mathrm{C}\right) \text { up to ten test } \\
\text { points. Fee usually does not exceed } \$ 1,000.00 . \text { Work to be charged } \\
\text { at cost. }\end{array}$ & \\
\hline $206.201 \mathrm{e}$ & $\begin{array}{l}\text { Manometers, with tube bore } 0.5 \text { in. or greater, in which both mercury } \\
\text { surfaces are observed, and of design which permits calibration in } \\
\text { terms of length, temperature, etc. Calibration of scale and thermom- } \\
\text { eter, performance verified by comparison with pressure standard. } \\
\text { Fee usually does not exceed } \$ 1,000.00 \text {. Work to be charged at cost. }\end{array}$ & \\
\hline $206.201 \mathrm{z}$ & $\begin{array}{l}\text { For special tests not covered by the above schedule. For example, } \\
\text { calibration of pressure gages of high precision and stability. Work } \\
\text { to be charged at cost. }\end{array}$ & \\
\hline
\end{tabular}

\section{Fluid Mechanics}

206.301 Aerodynamical measurements.

\begin{tabular}{|c|c|c|}
\hline Item & Description & Fee \\
\hline $206.301 \mathrm{a}$ & $\begin{array}{l}\text { Wind-speed indicators-calibration of cup, vane, and thermal type } \\
\text { anemometers, pitot tubes, and venturi tubes at wind speeds within } \\
\text { the range } 2 \text { to } 90 \mathrm{mph} \text { or (optional) } 10 \text { to } 170 \mathrm{mph}\end{array}$ & $\$ 83.00$ \\
\hline $206.301 \mathrm{z}$ & $\begin{array}{l}\text { For special tests not covered by the above schedule, fees will be charged } \\
\text { dependent upon the nature of the test. }\end{array}$ & \\
\hline
\end{tabular}

206.302 Fluid meters, including gas-measuring instruments.

\begin{tabular}{c|c|c|}
\hline Item & Description \\
\hline $206.302 \mathrm{a}$ & $\begin{array}{l}\text { Dry gas meters, rated capacity } 600 \mathrm{ft}^{3} / \mathrm{hr} \text { or less - testing with prover } \\
\text { in laboratory at two rates of flow and reporting }\end{array}$ \\
$206.302 \mathrm{~b}$ & $\begin{array}{l}\text { Displacement type meters for liquids which can be calibrated with } \\
\text { water at rates of flow not exceeding } 300 \mathrm{gpm} \text {-testing at one to five } \\
\text { rates of flow and reporting }\end{array}$
\end{tabular}

Fee

$\$ 60.00$ 


Item

Fee

206.302c Rate of flow meters, self-contained and direct reading; for gases, capacities not over $25 \mathrm{cfm}$; for liquids, capacities not over $300 \mathrm{gpm}-\mathrm{cali}-$ bration at not more than five rates of flow and reporting........

206.302d Orifices, flow nozzles, laminar flow meters, and similar differential head meters for use in pipes up to and including 2-in. pipe; calibration with water or air at a number of flow rates sufficient to develop a performance curve.

$206.302 e$

Additional fee for meter in pipes larger than those included in item $206.302 \mathrm{~d}$-for each 1 -in. increment of size over 2 in.........

$\$ 295.00$

430.00

28.00

206.302f Meters listed in item 206.302d, when two or more are used interchangeably in the same mounting-for each meter or orifice plate after the

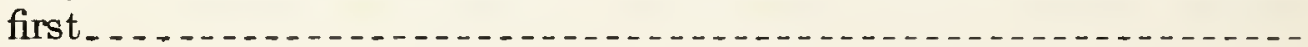

130.00

206.302g Water current meters-rating of Price, Pigmy, and Hoff types at not over eight velocities, and reporting results in equation form only, or in graph form only

43.00

206.302h Water current meters-rating of Hoff type at 10 or 11 velocities and reporting results in both graphical and equation forms, for each propeller

56.00

206.302i Water current meters-Ekman type, for each propeller submitted therewith; rating at not over eight velocities and reporting results in both

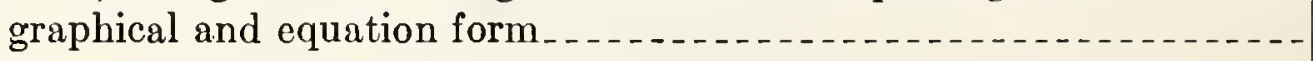

120. 00

206.302j Water current meters-all types, for each velocity in excess of the num-

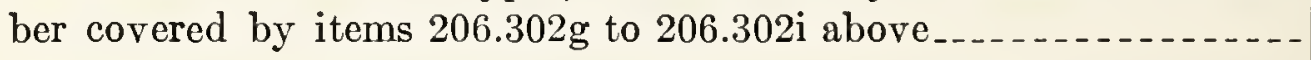

206.302k Furnishing results of water current meter calibration in graphical form, or in equation form when requested subsequent to completion of test. -

For special tests not covered by the above schedule, fees will be charged dependent upon the nature of the test.

206.401 Hardness tests.

\section{Engineering Mechanics}

\begin{tabular}{c|c|c}
\hline Item & Description & Fee \\
\hline $206.401 \mathrm{a}$ & $\begin{array}{c}\text { Determination of Brinell number of a block to be used for calibration } \\
\text { purposes, three separate indentations on each specimen } \ldots \ldots\end{array}$ & $\$ 41.00$ \\
\hline
\end{tabular}

206.402 Calibration of load cell with remote-reading electrical indicators.

(a) These fees apply to calibration of load cells with remote-reading electrical indicators. 
(b) Individual load cells or load cell systems must be accompained by readout or indicating equipment and all associated cables and fixtures.

(c) Up to 10 different loads are applied consecutively without return to zero.

(d) For each load in excess of 10, an additional fee equal to one-tenth of the applicable fee is charged.

(e) When devices submitted are found to be unsuitable for test or unrealiable, the test may be discontinued and a charge will be made to cover the cost of the work done.

\begin{tabular}{|c|c|c|}
\hline Item & Description & Fee \\
\hline & Capacity not exceeding $10,000 \mathrm{lb}$ : & \\
\hline $206.402 \mathrm{a}$ & Compression & $\$ 70.00$ \\
\hline $206.402 b$ & 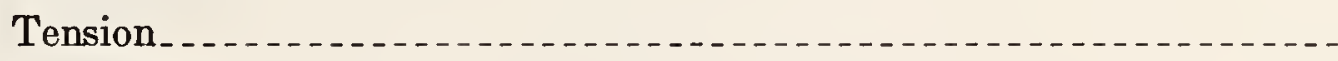 & 81.00 \\
\hline \multirow[t]{2}{*}{$206.402 \mathrm{c}$} & Tension and compression $\ldots . . . . . . .$. & 125.00 \\
\hline & Capacity exceeding $10,000 \mathrm{lb}$ but not exceeding $111,000 \mathrm{lb}$ : & \\
\hline $206.402 \mathrm{~d}$ & Compression & 87.00 \\
\hline $206.402 \mathrm{e}$ & Tension & 120.00 \\
\hline \multirow[t]{2}{*}{$206.402 \mathrm{f}$} & Tension and compression $\ldots$ & 165.00 \\
\hline & Capacity exceeding $111,000 \mathrm{lb}$ but not exceeding $200,000 \mathrm{lb}$ : & \\
\hline \multirow[t]{2}{*}{$206.402 \mathrm{~g}$} & Compression & 255.00 \\
\hline & Capacity exceeding $200,000 \mathrm{lb}$ but not exceeding $300,000 \mathrm{lb}$ : & \\
\hline $206.402 \mathrm{~h}$ & Compression & 300.00 \\
\hline $206.402 \mathrm{z}$ & $\begin{array}{l}\text { For special tests not covered by the above schedule, fees will be charged } \\
\text { dependent upon the nature of the test. }\end{array}$ & \\
\hline
\end{tabular}

206.403 Special mechanical tests of devices, materials, and structures.

(a) These fees apply to all mechanical tests of devices, materials, and structures performed in the Mechanics Division not covered by other fee schedules.

(b) The charge for special mechanical tests is made on the basis of the hours of service furnished by members of the staff.

(c) Where tests require travel outside the limits of 30 miles from the Bureau, transportation and subsistence charges will be added to the service charge.

(d) The time shall be computed as the number of official working hours from the time the members of the staff leave the Bureau until they return to it plus any overtime spent on the tests. 


\begin{tabular}{|c|c|c|}
\hline Item & Description & Fee \\
\hline $206.403 a$ & $\begin{array}{l}\text { Service of a member of the staff of grade GS-9, or any higher grade, } \\
\text { per hour }\end{array}$ & $\$ 12.00$ \\
\hline $206.403 \mathrm{~b}$ & Service of a member of the staff of grades below GS-9, per hour & 7.00 \\
\hline
\end{tabular}

\subsection{Calibration of proving rings.}

(a) These fees apply to calibration of proving rings suitable for use as laboratory or transfer standards.

(b) These fees apply to calibration in accordance with sections I, II, III, and IV of the Appendix of NBS Circular ${ }^{10} 454$.

(c) Up to 10 independent loads for compression or tension are applied.

(d) Fees for complete calibrations apply to rings submitted for initial calibration.

(e) For each load in excess of 10 , an additional fee equal to one-tenth of the applicable fee for complete calibration or recalibration is charged.

(f) When devices submitted are found to be unsuitable for test or unreliable, a test may be discontinued and a charge will be made to cover the cost of the work done.

\begin{tabular}{|c|c|c|}
\hline Item & Description & Fee \\
\hline & Complete calibration of proving rings, capacity not exceeding $10,000 \mathrm{lb}$ : & \\
\hline $206.404 a$ & Compression & $\$ 140.00$ \\
\hline \multirow[t]{2}{*}{$206.404 \mathrm{~b}$} & Tension and compression $\ldots \ldots \ldots$ & 225.00 \\
\hline & Recalibration of proving rings, capacity not exceeding 10,000 lb: & \\
\hline $206.404 \mathrm{c}$ & Compression & 98.00 \\
\hline \multirow[t]{2}{*}{$206.404 d$} & Tension and compression & 170.00 \\
\hline & $\begin{array}{l}\text { Complete calibration of proving rings, capacity exceeding } 10,000 \mathrm{lb} \text { but } \\
\text { not exceeding } 111,000 \mathrm{lb} \text { : }\end{array}$ & \\
\hline $206.404 \mathrm{e}$ & Compression & 175.00 \\
\hline \multirow[t]{2}{*}{$206.404 f$} & Tension and compression & 280.00 \\
\hline & $\begin{array}{c}\text { Recalibration of proving rings, capacity exceeding } 10,000 \mathrm{lb} \text { but not } \\
\text { exceeding } 111,000 \mathrm{lb} \text { : }\end{array}$ & \\
\hline $206.404 \mathrm{~g}$ & Compression $\ldots$ & 125.00 \\
\hline $206.404 \mathrm{~h}$ & Tension and compression & 230.00 \\
\hline
\end{tabular}

${ }^{10}$ NBS Circular 454, Proving rings for calibration testing machines. In NBS Handbook 77, Precision Measurement and Calibration, Vol. II, Heat and Mechanics, p. 573 (see pp. 101 and 103 for price information and order form). 


\begin{tabular}{|c|c|c|}
\hline Item & Description & Fee \\
\hline & $\begin{array}{c}\text { Complete calibration of proving rings, capacity exceeding } 111,000 \mathrm{lb} \\
\text { but not exceeding } 200,000 \mathrm{lb} \text { : }\end{array}$ & \\
\hline \multirow[t]{2}{*}{$206.404 \mathrm{i}$} & Compression & $\$ 390.00$ \\
\hline & $\begin{array}{l}\text { Recalibration of proving rings, capacity exceeding } 111,000 \mathrm{lb} \text { but not } \\
\text { exceeding } 200,000 \mathrm{lb} \text { : }\end{array}$ & \\
\hline \multirow[t]{2}{*}{$206.404 j$} & 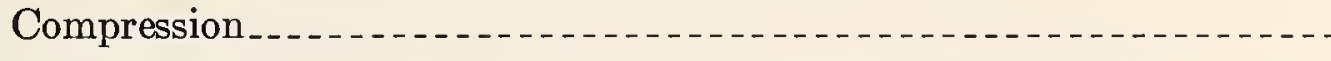 & 280.00 \\
\hline & $\begin{array}{c}\text { Complete calibration of proving rings, capacity exceeding } 200,000 \mathrm{lb} \\
\text { but not exceeding } 300,000 \mathrm{lb} \text { : }\end{array}$ & \\
\hline \multirow[t]{2}{*}{$206.404 \mathrm{k}$} & Compression...... & 470.00 \\
\hline & $\begin{array}{c}\text { Recalibration of proving rings, capacity exceeding } 200,000 \mathrm{lb} \text { but not } \\
\text { exceeding } 300,000 \mathrm{lb} \text { : }\end{array}$ & \\
\hline 206.4041 & Compression & 345.00 \\
\hline $206.404 \mathrm{z}$ & $\begin{array}{l}\text { For special tests not covered by the above schedule, fees will be charged } \\
\text { dependent upon the nature of the test. }\end{array}$ & \\
\hline
\end{tabular}

\subsection{Calibration of elastic force measuring devices.}

(a) These fees apply to calibration of elastic force measuring devices of a type suitable for use as laboratory or transfer standards.

(b) Before a device is accepted for calibration under this schedule it will be inspected for damage, wear, and operability. Loading surfaces, tension adaptors, and pulling rods must be complete and suitable for use with Bureau equipment. The device must be uniquely and permanently marked with the manufacturers' serial numbers and rated capacities.

(c) A temperature coefficient must be supplied by the submitter of the device.

(d) Devices will be overloaded repeatedly to approximately 10 percent in excess of the manufacturers' rated capacity.

(e) Up to 10 different independent loads for compression or tension will be applied.

(f) For each load in excess of 10, an additional fee equal to one-tenth of the applicable fee is charged.

(g) When devices submitted are found to be unsuitable for test or unreliable, a test may be discontinued and a charge will be made to cover the cost of the work done.

\begin{tabular}{c|c|c}
\hline Item & Description & Fee \\
\cline { 2 - 3 } & Capacity not exceeding $10,000 \mathrm{lb}:$ & \\
$206.405 \mathrm{a}$ & Compression & \\
$206.405 \mathrm{~b}$ & Tension $\ldots \ldots 9.00$ \\
$206.405 \mathrm{c}$ & Tension and compression &
\end{tabular}




\begin{tabular}{|c|c|c|}
\hline Item & Description & Fce \\
\hline & Capacity exceeding $10,000 \mathrm{lb}$ but not cxceeding $111,000 \mathrm{lb}$ : & \\
\hline $206.405 \mathrm{~d}$ & Compression & $\$ 125.00$ \\
\hline $206.405 \mathrm{e}$ & Tension & 175.00 \\
\hline $206.405 f$ & Tension and compression & 235.00 \\
\hline $206.405 \mathrm{~g}$ & Capacity exceeding 200,000 lb but not exceeding $300,000 \mathrm{lb}:$ & 280.00 \\
\hline $\begin{array}{l}206.405 \mathrm{~h} \\
206.405 \mathrm{z}\end{array}$ & $\begin{array}{l}\text { For special tests not covered by the above schedule, fees will be charged } \\
\text { dependent upon the nature of the tests. }\end{array}$ & 345.00 \\
\hline
\end{tabular}

\section{Part 208-Metallurgy}

\section{Electrodeposition}

208.601 Standard thickness samples of electroplated coatings.

\begin{tabular}{c|c|c}
\hline Item & Description & Fee \\
\hline \multirow{2}{*}{$208.601 \mathrm{a}$} & $\begin{array}{l}\text { Standard thickness samples of electroplated coatings, set of four samples_- } \\
\text { Individual samples, each_ } \$ 15.00\end{array}$ & 4.00 \\
\hline
\end{tabular}

\section{Part 210-Building Research}

Sec.

Fire Resistance

210.201 Fire resistance tests of building components

210.601 Thermal conductivity

Thermal Conductivity

\section{Fire Resistance}

210.201 Fire resistance tests of building components. Requests for tests should be made in writing to the Fire Research Section, National Bureau of Standards, Washington, D.C., 20234, and should be accompanied with detailed drawings and specifications of the structures proposed for test. Tests will be conducted for the public only until adequate facilities become available elsewhere. 


\begin{tabular}{c|c|c}
\hline Item & Description & Fee \\
\hline $210.201 \mathrm{a}$ & Fire endurance test of a floor, roof, or ceiling, $13 \frac{1}{2} \times 18 \mathrm{ft} \ldots \ldots 0.00$ \\
$210.201 \mathrm{~b}$ & $\begin{array}{l}\text { Fire endurance test of structural column } 13 \mathrm{ft} \text { high subjected to load, } \\
\text { or without load } \ldots \ldots, 200.00\end{array}$ \\
\hline
\end{tabular}

\section{Thermal Conductivity}

\subsection{Thermal conductivity.}

\begin{tabular}{|c|c|c|}
\hline Item & Description & Fee \\
\hline $210.601 a$ & $\begin{array}{l}\text { Determination for calibration purposes of the thermal conductivity of } \\
\text { a selected pair of specimens, by means of guarded hot-plate ap- } \\
\text { paratus (conforming to ASTM C177) for mean temperatures be- } \\
\text { tween } 20 \text { and } 130^{\circ} \mathrm{F} \text { (ordinarily } 20,30,75 \text {, and } 130^{\circ} \mathrm{F} \text { ), per deter- } \\
\text { mination at one mean temperature. }\end{array}$ & $\$ 130.00$ \\
\hline $2.10 .601 b$ & $\begin{array}{l}\text { Determination of thermal conductivity of a metal specimen for a } \\
\text { range of mean temperatures from }-150 \text { to } 750^{\circ} \mathrm{C} \text {, per specimen } \\
\text { Required sample is a cylindrical bar, } 46.0 \mathrm{~cm} \text { long, and approximately } 2.54 \\
\text { cm uniform diameter. }\end{array}$ & $1,625.00$ \\
\hline $210.601 \mathrm{c}$ & $\begin{array}{l}\text { Determination of thermal conductivity of a metal specimen for a } \\
\text { range of mean temperatures from }-150 \text { to } 200^{\circ} \mathrm{C} \text {, per specimen.- } \\
\text { Required sample is a cylindrical bar, } 46.0 \mathrm{~cm} \text { long, and approximately } 2.54 \\
\mathrm{~cm} \text { uniform diameter. }\end{array}$ & $1,150.00$ \\
\hline $210.601 d$ & $\begin{array}{l}\text { Determination of thermal conductivity of a metal specimen for a } \\
\text { range of mean temperatures from } 100 \text { to } 750^{\circ} \mathrm{C} \text {, per specimen } \\
\text { Required sample is a cylindrical bar, } 46.0 \mathrm{~cm} \text { long, and approximately } 2.54 \\
\text { cm uniform diameter. }\end{array}$ & $1,250.00$ \\
\hline $210.601 \mathrm{z}$ & $\begin{array}{l}\text { For special tests not covered by the above schedule, fees will be } \\
\text { charged dependent upon the nature of the test and time required. }\end{array}$ & \\
\hline
\end{tabular}

\section{Part 215-Physical Ghemistry}

Sec.

\section{Organic Chemistry}

215.301 Synthesis of $\mathrm{C}^{14}$ labeled sugars and related products

215.302 Synthesis of tritium-labeled carbohydrates 


\section{Organic Chemistry}

215.301 Synthesis of $\mathrm{C}^{14}$ labeled sugars and related products.

\begin{tabular}{|c|c|c|}
\hline Item & Description & Fee \\
\hline $215.301 \mathrm{a}$ & $\begin{array}{l}\text { Synthesis of } 10 \text { microcuries of } \mathrm{C}^{14} \text { labeled sugars and related products, } \\
\text { Type I (carbohydrates labeled at carbon 1) } \\
\text { Each microcurie }\end{array}$ & $\begin{array}{r}\$ 12.50 \\
1.25\end{array}$ \\
\hline $215.301 b$ & $\begin{array}{l}\text { Synthesis of } 10 \text { microcuries of } \mathrm{C}^{14} \text { labeled sugars and related products, } \\
\text { Type } 2 \text { (carbohydrates labeled in positions other than carbon } 1 \text { ) } \\
\text { Each microcurie }\end{array}$ & $\begin{array}{r}17.50 \\
1.75\end{array}$ \\
\hline
\end{tabular}

215.302 Synthesis of tritium-labeled carbohydrates.

\begin{tabular}{c|c|c}
\hline Item & Description & Fee \\
\hline $215.302 \mathrm{a}$ & $\begin{array}{c}\text { Synthesis of } 10 \text { microcuries of tritium-labeled carbohydrates (carbo- } \\
\text { hydrates labeled without extensive alteration of the carbon skeleton) }\end{array}$ & $\$ 12.50$ \\
\hline
\end{tabular}




\section{Index}

Acceleration

Aerodynamical measurements.

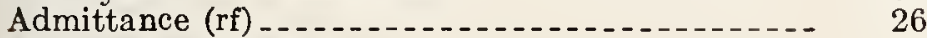

Alpha emission rate..... 82

Angle measurements:

on angle gage blocks.

on plug and ring gages

on polygons..._.

Area p... 59

Artifical-ear calibrations... 90

Attenuation:

high frequency

microwave._._._._._._._. 34

Audiométers

Balls, diameter of

Barometers _..._._._._._._. 91

Beckman thermometers

Beta emission range _. _..._._.

Billing charges

Binoculars

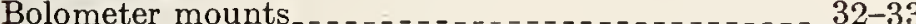

Bridge:

calorimetric ....

Kelvin

Wheatstone

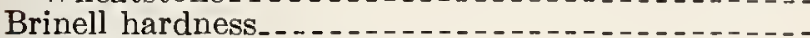

Burets

Calorimetric thermometers

Capacitive voltage divider

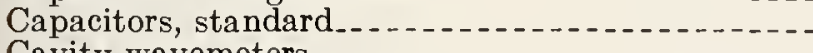

Cavity wavemeters

Carbon 14 labeled sugars.......

Cells, saturated.

Chromaticity coordinates.-.

Circles -

Clinical thermometers -

Coaxial directional couplers......

Coefficient of expansion:

liquid and solid

length standards

Color temperature of lamp.

Colorimetry

Current transformer comparators.-.

Current transformers

Density determinations

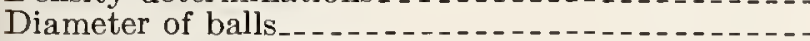

Dielectric measurements

Displacement-type meters

Dipole antennas

Directional couplers, coaxial

Displacement pickups_-.

Dissipation factor

Dissipative coaxial attenuators.

Dosimeters . . .

Dry calorimeters.

Dry gas meters...

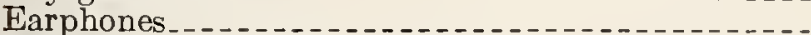

Elastic force measuring devices._-

Electricity_._.

Electroplated coatings, thickness

End standards

Fees

Field strength meters.

Fire resistance.... 96
Flasks, volumetric $\quad$ Page

Flatness:

camera plates. 50

gage blocks

polygons.... 66

Fluid meters

Fluxmeters._._.

Focal length.... 50

Force -

Frequency measurements, microwave........ 34

Fuels, octane number of

Gage blocks....... 59-61

Gear wires........

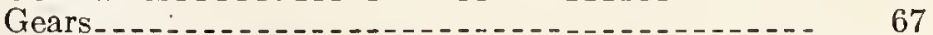

Gamma-ray measurements:

instruments

sources $81-82,85-86$

Goggle lenses . .

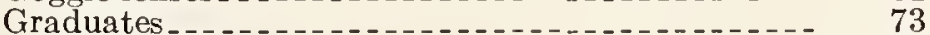

Haemacytometers _. _...

Hardness tests . .

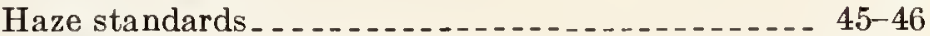

High-frequency measurements

Hydrometers . . . .

Immersion bottles

Immittance.............. 26

Impedance $\mathrm{rf} \ldots \ldots \ldots$

Index plates

Inductance.....

Invar base-line tapes............... 56-57

Input attenuators....... 31

Insurance $\ldots \ldots \ldots$

Kilovoltmeters............ 24

Laboratory thermometers

Lamp rating tests............. 39

Lamp standards

Line standards of length

Load cells

Loop antennas... 30

Lovibond glasses....... 47

Luminous directional reflectance....... 44

Luminous directional transmittance............ 44

Luminous direction transmittance standards ...... 40

Luminous intensity, lamp standards . . . . . . $38-40$

Luminous transmittance measurements........ 40

Magnetic hysteresis

Magnetic induction

Magnetic permeability

Magnets standard

Manometers

Mass

Master balls.... 66

Master wires

Micrometers

Microphones... 89

Microscopes

Mechanical tests, special__...

Microwave measurements _...

Munsell renotation or book notation............ 44

Mutual inductors

Needles, penetration 65

Neutron emission rate

Neutron irradiation of foils

Octane number.

Opacimetry

Optical components 
Optical pyrometers

Optical referenec planes _....................

Parallclisin of gage bloeks $\ldots \ldots \ldots \ldots$

Penetration needles

Paeking -

Permeability, magnetie

Phase angle, current transformer.

Phase angle, induetive voltage divider...........

Photography_._-_._-

Photographie objectives_._._.

Photographic step tablets

Piezoeleetrie aeceleration piekups

Pipets, dilution _....-.

Piston gages

Platiuum resistance thermometers $\ldots \ldots \ldots \ldots . . . . . .$.

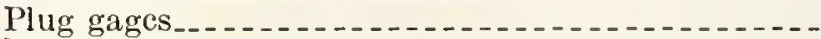

Polarimeters_.............

Polariseope tubes

Polygons _._._._._._._.

Power ineters rf

Power, mierowave

Precision eircles

Pressure.--n-

Proving rings
Quartz eontrol plates $\ldots \ldots$

Radioaetivity measurements

Radiometry

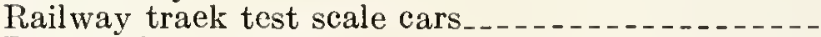

Rate-of-flow ineters

Referenee planes optieal

Refleetion coeffieient, mierowave ..............

Refleetometry

Refraetive index._._........................

Refraetometers

Refractometric instruments_............... 51-52

Refractometry

Report of test....-......-.

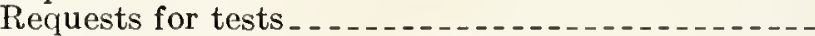

Resistanee of apparatus, preeision

Resistanee eleetrieal

Resistanee thermometers

Resistive voltage divider

Resistors -multi megohm _.

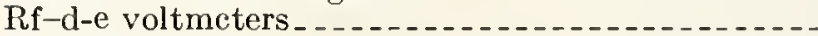

Rf voltmeters

Resistors, preeision standard

Resistors, standard, for current measurements

Resolving power

Ribbon filament lamps.

Ring gages._.

Saeeharimeters

Shipping -

Sieves_-_-_-

Signal glasses

Slieker plate measures._._.

Sodium thiosulfate, residual
Sound loss

Spceial meehanieal tests

Speeifie gravity flasks.......

Spcetrophotometric measurements

Spcetrophotolnctrie standards

Standard eells...............

Steel tapes.

Sunglass lenses....

Surveyors' leveling rod

Telescopes_.-.

Temperature, color

Testing policy

Thermal eonduetivity

Thiekness samples...

Thread wires

Thermal convertors

Thermal eonvertors, $\mathrm{rf}_{\text {- }}$

Thermal expansion of solids

Thermal neutron dosimeters.

Thermoeouple materials

Thermoeouples

Thermometers:

laloratory

Beckman

ealorimetric .

resistance

Thread plug gages

Time for tests

Transformers eurrent

Transformers voltage.

Tritium labeled earbohydrate

Universal ratio set......

Veloeity piekups...

Vibration.

Volt boxes.-1..

Voltage dividers

Voltage transformers............

Voltage transformer eomparators

Voltmeters, rf

Volume.

Volume of solids

Water eurrent metcrs

Watthour meters

Wattmeters, a-e-d-c....

Wattmeters, rf $\ldots \ldots$

Waveguide below cutoff attenuators

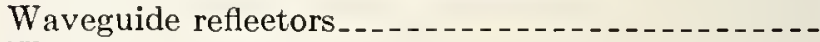

Weight calibrations

Wind-speed indieators

Wires:

gear master

thread . . .

Witnessing of tests

$\mathrm{X}$-ray instruments. 


\section{Publications}

NBS publications provide a means of keeping abreast of the Bureau's research programs, and often contain information on standards, calibration, and measurement techniques. The Bureau's publications are: The Journal of Research of the National Bureau of Standards (published in four sections), which contains major scientific papers describing NBS research and developments in physics, chemistry, mathematics, and engineering, as well as review articles on subjects related to the Bureau's research program; the NBS Technical News Bulletin, a monthly publication containing summary articles concerning all phases of the NBS research program, a list of Bureau publications, and columns on "Standard Materials" and "Standards and Calibration;" Monthly CRPL Ionospheric Predictions, which provide data necessary for calculating optimum communication frequencies; and five series of nonperiodicals (Monographs, Applied Mathematics Series, Handbooks, Technical Notes, and Miscellaneous Publications).

Of direct interest to measurement personnel is NBS Handbook 77, Precision Measurement and Calibration (issued Feb. 1961). In this Handbook are reprinted some of those publications of NBS staff members most frequently referred to in conferences with persons connected with standards laboratories. This Handbook, published in three volumes-(1) Electricity and Electronics, (2) Heat and Mechanics, and (3) Optics, Metrology, and Radiation-provides a "textbook" and reference source for training in measurement sciences.

Articles by NBS staff members appearing in outside publications are listed regularly in the Journal of Research, the Technical News Bulletin, and the annual Research Highlights of the National Bureau of Standards. In general these articles are available directly from the authors.

The following list contains the title and prices of those documents referred to in the text of this publication. On the reverse of this page is an order blank for all NBS publications.

NBS Circular 3, Design and test of standards of mass (in NBS Handbook 77).

NBS Circular 429, Photoelectric tristimulus colorimetry with three filters (in NBS Handbook 77 ).

NBS Circular 454, Proving rings for calibrating testing machines (in NBS Handbook 77).

NBS Circular 555, Testing of hydrometers, 10 cents (also in NBS Handbook 77).

NBS Circular 602, Testing of glass volumetric apparatus, 20 cents (also in NBS Handbook 77).

NBS Monograph 37, International Practical Temperature Scale of 1948, text revision of 1960,10 cents.

NBS Monograph 47, Basic magnetic quantities and the measurement of the magnetic properties of materials,

30 cents.

NBS Monograph 62, Testing of metal volumetric standards, 15 cents.

NBS Handbook 77, Precision measurement and calibration. Three-volume set, \$19.75.

Vol. I, Electricity and electronics, $\$ 6.00$.

Vol. II, Heat and mechanics, $\$ 6.75$.

Vol. III, Optics, metrology, and radiation, $\$ 7.00$.

NBS Miscellaneous Publication 236, Standard frequencies from NBS stations WWV and WWVH, 10 cents.

NBS Miscellaneous Publication 241, Standard Materials, 30 cents. 



\section{ORDER BLANK}

Order from your nearest U.S. Department of Commerce Field Office or Superintendent of Documents, U.S. Government Printing Office, Washington, D.C., 20402.

Please enter my subscription (1 year) for NBS publications as indicated:

$\ldots .$. TECHNICAL NEWS BULLETIN, \$1.50 (foreign, \$2.25) JOURNAL OF RESEARCH:
A. Physics and Chemistry, $\$ 4.00$ (foreign, $\$ 4.75$ )
B. Mathematics and Mathematical Physics, $\$ 2.25$ (foreign, \$2.75)
C. Engineering and Instrumentation, \$2.25 (foreign, \$2.75)
D. Radio Science, $\$ 9.00$ (foreign, $\$ 11.50$ )

Please send me the following NBS Nonperiodical Publication(s).

Please send me the following volumes of NBS Handbook 77:

Vol. I, Electricity and electronics, $\$ 6.00 *$

$\ldots . .$. Vol. II, Heat and mechanics, $\$ 6.75^{*}$

$\ldots .$. Vol. Ili, Optics, metrology, and radiation, $\$ 7.00^{*}$

$\ldots . .$. Vols. I, II, and III, \$19.75*

Please send me the following lists of NBS publications: Circular 460 (1901-1947), \$1.25*

...... Supplement to C $460(1947-1957), \$ 1.50^{*}$

MAKE ALL CHECKS PAYABLE TO SUPERINTENDENT OF DOCUMENTS

Name

Address

Company

City

State.

ZIP Code.....

*Foreign postage, one-fourth additional. 



\section{Changes in Calibration and Test Services}

As services are initiated or discontinued, or fees are changed, announcements will appear in the Federal Register, and major changes will be noted in the Standards and Calibration column of the NBS Technical News Bulletin. The Bureau also plans to issue periodic listings of such changes. If you wish to be placed on a mailing list to receive these inserts as they are issued, please complete the post card below, detach it, and mail to the National Bureau of Standards.

Affiliation

Address. .

City. . State

Date.

Office of Technical Information:

Please place the foregoing name on your special mailing list to receive inserts to Misc. Publ. 250, Calibration and Test Services of the National Bureau of Standards, as they are issued. 


Place
stamp
here

\section{National Bureau of Standards}

Office of Technical Information

Washington, D.C. 20234 


\title{
U.S. DEPARTMENT OF COMMERCE
}

Luther H. Hodges, Secretary

\section{NATIONAL BUREAU OF STANDARDS}

\author{
A. V. Astin, Director
}

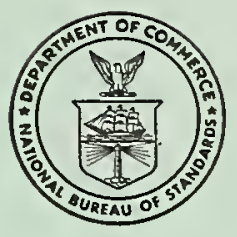

\section{THE NATIONAL BUREAU OF STANDARDS}

The scope of activities of the National Bureau of Standards at its major laboratories in Washington, D.C., and Boulder, Colorado, is suggested in the following listing of the divisions and sections engaged in technical work. In general, each section carries out specialized research, development, and engineering in the field indicated by its title. A brief description of the activities, and of the resultant publications, appears on the inside of the front cover.

\section{WASHINGTON, D.C.}

Electricity. Resistance and Reactance. Electrochemistry. Electrical Instruments. Magnetic Measurements. Dielectrics. High Voltage. Absolute Electrical Measurements.

Metrology. Photometry and Colorimetry. Refractometry. Photographic Research. Length. Engineering Metrology. Mass and Volume.

Heat. Temperature Physics. Heat Measurements. Cryogenic Physics. Equation of State. Statistical Physics. Radiation Physics. X-ray. Radioactivity. Radiation Theory. High Energy Radiation. Radiological Equipment. Nucleonic Instrumentation. Neutron Physics.

Analytical Chemistry. Pure Substances. Spectrochemistry. Solution Chemistry. Standard Reference Materials. Applied Analytical Research.

Mechanics. Sound. Pressure and Vacuum. Fluid Mechanics. Engineering Mechanics. Rheology. Combustion Controls.

Polymers. Macromolecules: Synthesis and Structure. Polymer Chemistry. Polymer Physics. Polymer Characterization. Polymer Evaluation and Testing. Applied Polymer Standards and Research. Dental Research.

Metallurgy. Engineering Metallurgy. Metal Reactions. Metal Physics. Electrolysis and Metal Deposition. Inorganic Solids. Engineering Ceramics. Glass. Solid State Chemistry. Crystal Chemistry. Physical Properties. Crystallography.

Building Research. Structural Engineering. Fire Research. Mechanical Systems. Organic Building Materials. Codes and Safety Standards. Heat Transfer. Inorganic Building Materials. Metallic Building Materials.

Applied Mathematics. Numerical Analysis. Computation. Statistical Engineering. Mathematical Physics. Operations Research.

Data Processing Systems. Components and Techniques. Computer Technology. Measurements Automation. Engineering Applications. Systems Analysis.

Atomic Physics. Spectroscopy. Infrared Spectroscopy. Far Ultraviolet Physics. Solid State Physics. Electron Physics. Atomic Physics. Plasma Spectroscopy.

Instrumentation. Engineering Electronics. Electron Devices. Electronic Instrumentation. Mechanical Instruments. Basic Instrumentation.

Physical Chemistry. Thermochemistry. Surface Chemistry. Organic Chemistry. Molecular Spectroscopy. Elementary Processes. Mass Spectrometry. Photochemistry and Radiation Chemistry.

Office of Weights and Measures.

BOULDER, COLO.

Cryogenic Engineering Laboratory. Cryogenic Processes. Cryogenic Properties of Solids. Cryogenic Technical Services. Properties of Cryogenic Fluids.

\section{CENTRAL RADIO PROPAGATION LABORATORY}

Ionosphere Research and Propagation. Ultra Low Frequency Research. Low Frequency and Very Low Frequency Research. Ionosphere Research. Prediction Services. Sun-Earth Relationships. Field Engineering. Radio Warning Services. Vertical Soundings Research.

Troposphere and Space Telecommunications. Data Reduction Instrumentation. Radio Noise. Tropospheric Measurements. Tropospheric Analysis. Spectrum Utilization Research. Radio-Meteorology. Lower Atmosphere Physics.

Radio Systems. Applied Electromagnetic Theory. High Frequency and Very High Frequency Research. Frequency Utilization. Modulation Research. Antenna Research. Radiodetermination.

Upper Atmosphere and Space Physics. Upper Atmosphere and Plasma Physics. High Latitude Ionosphere Physics. Ionosphere and Exosphere Scatter. Airglow and Aurora. Ionospheric Radio Astronomy.

\section{RADIO STANDARDS LABORATORY}

Radio Standards Physics. Frequency and Time Dissemination. Radio and Microwave Materials. Atomic Frequency and Time-Interval Standards. Radio Plasma. Microwave Physics.

Radio Standards Engineering. Coordinator Calibration Service. High Frequency Electrical Standards. High Frequency Calibration Services. High Frequency Impedance Standards. Microwave Calibration Services. Microwave Circuit Standards. Low Frequency Calibration Services. 



\title{
GALIBRATION AND TEST SERVIGES OF THE National Bureau of Standards Notice of Change to NBS Misc. Publ. 250, 1965 Edition*
}

\section{Change 1.}

The following announcement from the Federal Register for November , 1965 modifies the information given in paragraph 200.112, p. 10 of MP250, 1965 edition.

\section{Centralization of Low Frequency Calibration Services}

In the interest of economy and managerial efficiency, the low frequency calibration services previously available at both Washington and Boulder laboratories of the National Bureau of Standards are being centralized at the Bureau's laboratories in the Washington area. Effective immediately plants shipping low frequency standards to the Bureau should make arrangements for scheduling of their calibration by letter to the Electricity Division, NBS, Washington, D. C. 20234. This Division will be moving from Washington to the new laboratories at Gaithersburg, Maryland in early 1966. Such advance arrangements will minimize delays during the double move and assure that the material reaches the proper location. All items for frequencies in the $0-30 \mathrm{kHz}$ range will be affected, except signal sources (Section 201.701), which will continue to be calibrated at Boulder. No other low frequency work (Sections 201.100 through 201.604) will be scheduled at Boulder after November 18, and material received after that date will be returned, collect, to the sender. Standards received before that date, and which are covered by a valid Purchase Order, will be calibrated so far as possible, in accordance with previously maintained schedules. All calibration services at frequencies greater than $30 \mathrm{kHz}$ (i.e., high frequency and microwave calibration services) will continue to be available only at the Electronic Calibration Center, Radio Standards Laboratory, Boulder Laboratories of the Department of Commerce, Boulder, Colorado 80301.

\section{Title 15-COMMERCE AND FOREIGN TRADE}

Chapter II-National Bureau of Standards, Department of Commerce

$$
\text { Subchapter A-Test Fee Schedules. Part 200-General }
$$

Under the provisions of 15 U.S.C. 275 (a) and 277, the following revision supersedes Section 200.112 issued in the Federal Register of August 13, 1965. The revision provides that low frequency calibration services $(0-30 \mathrm{kHz})$ will hereafter be available only through the facilities of the National Bureau of Standards in Washington.

\section{Section 200.112 Location of Laboratories}

The calibrations listed in Parts 202, 203, 204, 205, 206, and 210 of this subchapter and the low frequency electrical calibrations of Parts 201.100 through 201.604 of this subchapter will after July 1, 1966 be performed in the Gaithersburg Laboratories of the National Bureau of Standards whose address is Washington, D. C. 20234. Calibrations of signal sources (Section 201.701) and all electrical standards in the radio frequency region (Parts 201.810 through 201.950 of this subchapter) are performed by the Radio Standards Laboratory of NBS at Boulder, Colorado 80301.

After November 18, 1965, low frequency calibration services will be available only through the Electricity Division in Washington. All requests for such services, and inquiries (giving full details of ranges, frequencies, and electrical burdens) concerning schedules and shipping instructions, should be directed to

\author{
Electricity Division \\ Institute for Basic Standards \\ National Bureau of Standards \\ Washington, D. C. 20234
} * Changes should be made immediately in your copy of NBS Misc. Publ. 250, 1965 Edition. Additional copies of
insert sheet are available from NBS Office of Technical Information and Publications. 
If the apparatus is to be calibrated at both high and low frequencies, arrangements may be initiated with either the Boulder or Washington laboratories. The cost of shipping the apparatus between laboratories will be billed to the client.

\section{Change 2.}

The following supplements the information in paragraph 201.821, pp. 36-37 of MP 250, 1965 edition.

\section{Calibration of Coaxial Bolometer Mounts}

The Radio Standards Laboratory announces that an additional service is now available for the measurement of the calibration factor** of nominal 50-ohm coaxial bolometer units. The new service provides for calibration at $3 \mathrm{GHz}$, in addition to the frequencies of $100 \mathrm{MHz}$ and $1 \mathrm{GHz}$ that have been available for a number of months. Measurements are made at the 1 and 10 milliwatt power levels only, with no provision at present for the calibration of bolometer-coupler units.

The limit of uncertainty in determining the calibration factor at $3 \mathrm{GHz}$ is within $1.5 \%$ for welldesigned bolometer units. Limits of uncertainty may be greater for bolometer units having a VSWR higher than 1.1. The service includes the calibration of both barretter and thermistor types of bolometer units having operating resistances of 50,100, and $200 \mathrm{ohms}$.

** The calibration factor of a bolometer unit is defined as the ratio of the substituted d-c power in the unit to the rf power incident upon the bolometer unit.

\section{Change .3.}

Delete item 202.114 h, p. 58 of MP 250, 1965 edition. 


\section{CALIBRATION AND TEST SERVICES OF THE \\ National Bureau of Standards \\ Notice of Change to NBS Misc. Publ. 250, 1965 Edition*}

\section{ChANGE 4.}

ATTENTION! The National Bureau of Standards laboratories at Washington, D.C. are now in the midst of a move to new quarters at Gaithersburg, Maryland. To make certain that equipment submitted for calibration reaches the proper laboratory, the following rules should be observed:

(1) Equipment sent by U. S. Mail, and intended for laboratories in Washington or Gaithersburg, should be addressed, as before, to the appropriate laboratory or other local destination, National Bureau of Standards, Washington, D. C. 20234.

(2) Equipment hand carried in for calibration, or sent by railway or air express, should be brought or addressed to the appropriate laboratory or other local destination, National Bureau of Standards, Gaithersburg, Maryland. This applies after May 15, 1966 to all calibration services previously performed at Washington, with the following exceptions:

Voltage Ratio and High-Voltage Measurements: schedules 201.601 through 201.604 .

Length: schedules 202.401 through 202.412.

Engineering Metrology: schedules 202.500 through 202.509.

Sound: schedule 206.011 .

Fluid Meters: schedule 206.311.

Aerodynamics: schedule 206.331.

Until further notice, equipment for the excepted services just listed should be brought or sent to Washington, D. C., as indicated in (1) just above.

(3) In case of doubt, consult the laboratory that performs the calibrations. For the procedure to follow in requesting services, see section 200.103 of MP250.

(4) The NBS laboratories at Boulder, Colorado, are not affected by these changes. As before, equipment to be calibrated at Boulder should be addressed or carried to: Radio Standards Laboratory, National Bureau of Standards, Boulder, Colorado 80301.

* Changes should be made immediately in your copy of NBS Misc. Publ, 250, 1965 Edition. Additional copies of insert sheet are available from NBS Office of Technical Information and Publications. 


\section{CALIBRATION AND TEST SERVICES OF THE \\ National Bureau of Standards \\ Notice of Change to NBS Misc. Publ. 250, 1965 Edition}

\section{Change 5 .}

Effective March 28, 1966, a reduction in charges for calibration services in high-frequency and microwave regions ( $30 \mathrm{kHz}$ and $\mathrm{up}$ ) has been announced by the Electronic Calibration Center of the NBS Radio Standards Laboratory. Charges previously based on the rate of $\$ 30$ per hour are now based on a rate of $\$ 20$ per hour, and charges previously based on $\$ 35$ per hour are now based on a rate of $\$ 25$ per hour. This reduction was largely made possible by a reduction now occurring in depreciation costs for Electronic Calibration Center equipment.

\section{CHANGE 6.}

In item 202.403z, p. 65 of Misc. Publ. 250, delete the clause: "they may be approximately estimated as one-half of the corresponding fees of schedule 202.402."

\section{Change 7.}

Delete the first listings of items $201.950 \mathrm{a}-1$ and $201.950 \mathrm{z}$ on the upper part of p. 49 of MP250.

\section{Change 8.}

The following new schedule is added (on page 45) to those under the general heading, "Microwave Region":

201.912 Continuous low-level measurement of coaxial bolometer units.

See Section 201.910 above for definitions and information on the calibration of bolometer units.

\begin{tabular}{|c|c|c|}
\hline Item & Description & Fee \\
\hline $201.912 \mathrm{a}$ & $\begin{array}{l}\text { Measurement of effective efficiency of a coaxial bolometer unit at a frequency of } \\
9 \mathrm{GHz} \text {, and a power level of } 10 \mathrm{~mW} \text {. Bolometer unit must be fitted with male } \\
\text { Type } \mathrm{N} \text { connector and thermistor-type element of nominal operating resist- } \\
\text { ance of } 200 \text { ohms. }\end{array}$ & $(* *)$ \\
\hline
\end{tabular}

- Changes should be made immediately in your copy of NBS Misc. Puhl. 250, 1965 Edition. Additional copies of insert sheet are availahle from NBS Office of Technical Information and Publications.

* See $201.900(\mathrm{~h})$. 


\section{CHANGE 9.}

Changes have been made in items throughout all schedules listed under "Engineering Mechanics," starting in the middle of p. 102 and ending in the middle of p. 106 of MP250. The changed schedules are those numbered 201.041 to 201.045, inclusive. Instead of detailing each individual change, the revised texts of these schedules, incorporating all modifications, deletions, and additions, are given on the next two Insert Sheets. These can be inserted at the appropriate place in the publication; and the old schedules should be deleted, for example, by drawing diagonal lines through them.

\section{Change 10.}

Changes have also been made in most of the fees for items in the Engineering Mechanics schedules (201.041 through 201.045) and fees have been announced for the newly added items. In addition, the fee for item $202.402 \mathrm{c}$ has been reduced. All of these are included in the following list. The changes should be entered in the List of Fees, Appendix "C" of MP250.

TABLE 1. List of schedules with the fee changes.

\begin{tabular}{|c|c|c|c|c|c|}
\hline Item & Old Fee & New Fee & Item & Old Fee & New Fee \\
\hline \multirow[t]{2}{*}{$202.402 \mathrm{c}$} & $\$ 33.00$ & $\$ 3.00$ & $206.044 f$ & 365.00 & 480.00 \\
\hline & & & $206.044 \mathrm{~g}$ & 165.00 & 215.00 \\
\hline \multirow[t]{2}{*}{$206.041 \mathrm{a}$} & 53.00 & 54.00 & $206.044 \mathrm{~h}$ & 300.00 & 335.00 \\
\hline & & & $206.044 \mathrm{i}$ & 510.00 & 650.00 \\
\hline $206.042 \mathrm{a}$ & 95.00 & 150.00 & $206.044 \mathrm{j}$ & 365.00 & 1050.00 \\
\hline $206.042 b$ & 105.00 & 165.00 & $206.044 \mathrm{k}$ & 610.00 & 390.00 \\
\hline $206.042 c$ & 165.00 & 200.00 & 206.0441 & 450.00 & 760.00 \\
\hline $206.042 d$ & 115.00 & 170.00 & $206.044 \mathrm{~m}$ & ----- & 870.00 \\
\hline $206.042 \mathrm{e}$ & 155.00 & 175.00 & $206.044 n$ & ---.- & 1425.00 \\
\hline $206.042 \mathrm{f}$ & 215.00 & 240.00 & 206.0440 & - & 560.00 \\
\hline $206.042 \mathrm{~g}$ & 340.00 & 315.00 & $206.044 p$ & - - - & 870.00 \\
\hline $206.042 \mathrm{~h}$ & 390.00 & 340.00 & & & \\
\hline $206.042 \mathrm{i}$ & ---- & 495.00 & $206.045 a$ & 130.00 & 170.00 \\
\hline $206.042 j$ & -...- & 435.00 & $206.045 b$ & 150.00 & 180.00 \\
\hline $206.042 \mathrm{k}$ & -.- - & 470.00 & $206.045 \mathrm{c}$ & 230.00 & 245.00 \\
\hline \multirow[t]{2}{*}{206.0421} & .... & 690.00 & $206.045 d$ & 165.00 & 220.00 \\
\hline & & & $206.045 \mathrm{e}$ & 230.00 & 245.00 \\
\hline $206.043 \mathrm{a}$ & 13.00 & 15.00 & $206.045 f$ & 305.00 & 335.00 \\
\hline \multirow[t]{2}{*}{$206.043 b$} & 8.00 & $8.00 *$ & $206.045 \mathrm{~g}$ & 365.00 & 380.00 \\
\hline & & & $206.045 \mathrm{~h}$ & 450.00 & 410.00 \\
\hline $206.044 \mathrm{a}$ & 185.00 & 205.00 & $206.045 \mathrm{i}$ & - . - & 690.00 \\
\hline $206.044 b$ & 295.00 & 330.00 & $206.045 \mathrm{j}$ & - - - - & 510.00 \\
\hline $206.044 c$ & 130.00 & 150.00 & $206.045 \mathrm{k}$ & ----- & 580.00 \\
\hline $206.044 d$ & 220.00 & 205.00 & 206.0451 & - - - - & 880.00 \\
\hline $206.044 \mathrm{e}$ & 230.00 & 295.00 & & & \\
\hline
\end{tabular}

* No change. 


\section{CALIBRATION AND TEST SERVICES OF THE \\ National Bureau of Standards \\ Notice of Change to NBS Misc. Publ, 250, 1965 Edition**}

CHANGE 9. This Insert Sheet and the one following contain the revised texts of schedules 201.041 through 201.045. The two sheets should be inserted after p. 102 of MP250, and the old schedule should be deleted.

\section{Engineering Mechanics}

206.041 Hardness tests.

\begin{tabular}{c|c|c}
\hline Item & Description & Fee \\
\hline \multirow{2}{*}{$206.041 \mathrm{a}$} & $\begin{array}{c}\text { Determination of Brinell number of a block to be used for calibration purposes, } \\
\text { 3 separate indentations on each specimen. }\end{array}$ & $(*)$ \\
\hline
\end{tabular}

* For current fees, see Change 10 on Insert Sheet 3.

206.042 Calibration of load cells with remote reading electrical indicators.

(a) Individual load cells or load cell systems must be accompanied by readout or indicating equipment and all associated cables and fixtures.

(b) For the fee quoted, calibration will be made on one machine with up to 10 incremental loads applied consecutively without return to zero load. For each load in excess of 10, an additional fee equal to one-tenth of the applicable fee will be charged. For any device requiring the use of more than one machine, a charge will be made covering the cost of the additional work involved.

(c) When devices submitted are found to be unsuitable for test or unreliable, the test may be discontinued and a charge will be made to cover the cost of the work done.

\begin{tabular}{|c|c|c|}
\hline Item & Description & Fee \\
\hline & Capacity not exceeding 10,000 lb: & \\
\hline $206.042 \mathrm{a}$ & 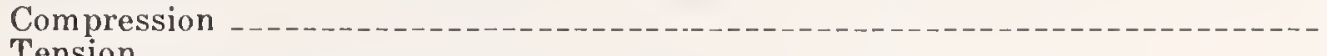 & $(*)$ \\
\hline $\begin{array}{l}206.042 b \\
206.042 c\end{array}$ & $\begin{array}{l}\text { Tension } \\
\text { Tension and compression }\end{array}$ & $\begin{array}{l}(*) \\
(*)\end{array}$ \\
\hline & Capacity exceeding $10,000 \mathrm{lb}$ but not exceeding $112,000 \mathrm{lbs}$ : & \\
\hline $206.042 \mathrm{~d}$ & Compression - & $(\%)$ \\
\hline $206.042 \mathrm{e}$ & Tension & $(*)$ \\
\hline $206.042 \mathrm{f}$ & Tension and compression & $(*)$ \\
\hline & Capacity exceeding $112,000 \mathrm{lb}$ but not exceeding $300,000 \mathrm{lb}$ : & $(\%)$ \\
\hline $\begin{array}{l}206.042 \mathrm{~g} \\
206.042 \mathrm{~h}\end{array}$ & $\begin{array}{l}\text { Compression } \\
\text { Tension }\end{array}$ & $(*)$ \\
\hline $206.042 \mathrm{i}$ & Tension and compression & $(*)$ \\
\hline & Capacity exceeding $300,000 \mathrm{lb}$ but not exceeding $1,000,000 \mathrm{lb}:$ & \\
\hline $206.042 \mathrm{j}$ & Compression & $(*)$ \\
\hline $206.042 \mathrm{k}$ & Tension - & $\left(x^{*}\right)$ \\
\hline 206.0421 & Tension and compression & $(*)$ \\
\hline $206.042 \mathrm{z}$ & $\begin{array}{l}\text { For special tests not covered by the above schedule, fees will be charged } \\
\text { dependent upon the nature of the test. }\end{array}$ & \\
\hline
\end{tabular}

* For current fees, see Change 10 on Insert Sheet 3.

* Changes should be made immediately in your copy of NBS Misc. Publ. 250, 1965 Edition. Additional copies of insert sheet are available from NBS Office of Technical Information and Publications. 
206.043 Special mechanical tests of devices, materials and structures.

(a) These fees apply to all mechanical tests of devices, materials and structures performed in the Mechanics Division not covered by other fee schedules.

(b) The charge for special mechanical tests is made on the basis of the hours of service furnished by members of the staff.

(c) The time shall be computed as the number of official working hours from the time the members of the staff leave the National Bureau of Standards until they return to it plus any overtime spent on the tests.

(d) Where tests require travel outside the limits of 30 miles from the Bureau, transportation and subsistence charges will be added to the service charge.

\begin{tabular}{|c|c|c|}
\hline Item & Description & Fee \\
\hline $206.043 a$ & Service of a member of the staff of grade GS-9, or any higher grade, per hour-- & $(*)$ \\
\hline $206.043 \mathrm{~b}$ & Service of a member of the staff of grades below GS-9, per hour & $(*)$ \\
\hline
\end{tabular}

For current fees, see Change 10 on Insert Sheet 3.

206.044 Calibration of proving rings.

(a) These fees apply to calibration or recalibration of proving rings suitable for use as laboratory or transfer standards in accordance with Sections I, II, III, and IV of the appendix of NBS Circular $454 .{ }^{23}$

(b) For the fee quoted, calibration will be made on one machine with up to 10 independent loads for compression or tension applied. Fees for complete calibrations apply to rings submitted for initial calibration. For each load in excess of 10 , an additional fee equal to one-tenth of the applicable fee for complete calibration or recalibration is charged. For any device requiring the use of two or more machines, a charge will be made covering the cost of the additional work involved.

(c) When devices submitted are found to be unsuitable for test or unreliable, a test may be discontinued and a charge will be made to cover the cost of work done.

\begin{tabular}{|c|c|c|}
\hline Item & Description & Fee \\
\hline & Complete calibration of proving rings, capacity not exceeding $10,000 \mathrm{lb}$ : & \\
\hline $\begin{array}{l}206.044 \mathrm{a} \\
206.044 \mathrm{~b}\end{array}$ & $\begin{array}{l}\text { Compression } \\
\text { Tension and compression }\end{array}$ & $\begin{array}{l}(*) \\
(*)\end{array}$ \\
\hline $\begin{array}{l}206.044 \mathrm{c} \\
206.044 \mathrm{~d}\end{array}$ & $\begin{array}{l}\text { Recalibration of proving rings, capacity not exceeding } 10,000 \mathrm{lb} \text { : } \\
\text { Compression } \\
\text { Tension and compression }\end{array}$ & $\stackrel{(*)}{(*)}$ \\
\hline & $\begin{array}{l}\text { Complete calibration of proving rings, capacity exceeding } 10,000 \mathrm{lbs} \text { but not } \\
\text { exceeding } 112,000 \mathrm{lb} \text { : }\end{array}$ & \\
\hline $\begin{array}{l}206.044 \mathrm{e} \\
206.044 \mathrm{f}\end{array}$ & $\begin{array}{l}\text { Compression } \\
\text { Tension and compression }\end{array}$ & $\begin{array}{l}(*) \\
(*)\end{array}$ \\
\hline
\end{tabular}

${ }^{23}$ NBS Circular 454, Proving Rings for Calibration Testing Machines. In NBS Handbook 77, Precision Measurement and Calibration, Vol. II, Heat and Mechanics, p. 573. (See pp. 133-5 for price information and order form.)

* For current fees, see Change 10 on Insert Sheet 3. 


\section{CALIBRATION AND TEST SERVICES OF THE \\ National Bureau of Standards \\ Notice of Change to NBS Misc. Publ. 250, 1965 Edition}

CHANGE 9. This Insert Sheet and the one preceding contain the revised texts of schedules 201.041 through 201.045. The two sheets should be inserted after p. 102 of MP250, and the old schedule should be deleted.

\begin{tabular}{|c|c|c|}
\hline Item & Description & Fee \\
\hline & Recalibration of proving rings, capacity exceeding $10,000 \mathrm{lb}$ but not exceeding & \\
\hline \multirow{3}{*}{$\begin{array}{l}206.044 \mathrm{~g} \\
206.044 \mathrm{~h}\end{array}$} & Compression & $(*)$ \\
\hline & Tension and compression & (*) \\
\hline & $\begin{array}{l}\text { Complete calibration of proving rings, capacity exceeding } 112,000 \mathrm{lb} \text { but not } \\
\text { exceeding } 300,000 \mathrm{lb} \text { : }\end{array}$ & \\
\hline $206.044 \mathrm{i}$ & Compression & $(*)$ \\
\hline \multirow[t]{2}{*}{$206.044 \mathrm{j}$} & Tension and compression & $(*)$ \\
\hline & $\begin{array}{l}\text { Recalibration of proving rings, capacity exceeding } 112,000 \mathrm{lb} \text { but not exceeding } \\
300,000 \mathrm{lb} \text { : }\end{array}$ & \\
\hline \multirow{3}{*}{$\begin{array}{l}206.044 \mathrm{k} \\
206.0441\end{array}$} & Compression -1 & $(*)$ \\
\hline & Tension and compression & $(*)$ \\
\hline & $\begin{array}{l}\text { Complete calibration of proving rings, capacity exceeding } 300,000 \mathrm{lb} \text { but not } \\
\text { exceeding } 1,000,000 \mathrm{lb} \text { : }\end{array}$ & \\
\hline $206.044 \mathrm{~m}$ & Compression & $(*)$ \\
\hline \multirow[t]{2}{*}{$206.044 \mathrm{n}$} & Tension and compression & $(*)$ \\
\hline & $\begin{array}{l}\text { Recalibration of proving rings, capacity exceeding } 300,000 \mathrm{lb} \text { but not exceeding } \\
1,000,000 \mathrm{lb} \text { : }\end{array}$ & \\
\hline 206.0440 & Compression & $(*)$ \\
\hline $206.044 p$ & Tension and compression & $(*)$ \\
\hline $206.044 \mathrm{z}$ & $\begin{array}{l}\text { For special tests not covered by the above schedule, fees will be charged } \\
\text { dependent upon the nature of the test. }\end{array}$ & \\
\hline
\end{tabular}

* For current fees, see Change 10 on Insert Sheet 3.

\subsection{Calibration of elastic force measuring devices.}

(a) These fees apply to calibration of elastic force measuring devices suitable for use as laboratory or transfer standards.

(b) Before a device is accepted for calibration under this schedule it will be inspected for damage, wear, and operability. Loading surfaces, tension adaptors, and pulling rods must be complete and suitable for use with NBS equipment. The device must be uniquely and permanently marked with the manufacturer's serial number and rated capacity.

(c) For the fee quoted, calibration will be made on one machine with up to 10 different independent loads for compression or tension applied. Devices will be overloaded repeatedly to approximately 10 percent in excess of the manufacturer's rated capacity. A temperature coefficient must be supplied by the submitter of the device. 
(d) For each load in excess of 10, an additional fee equal to one-tenth of the applicable fee is charged. For any device requiring the use of more than one machine, a charge will be made covering the cost of additional work involved.

(e) When devices submitted are found to be unsuitable for test or unreliable, a test may be discontinued and a charge will be made to cover the cost of the work done.

\begin{tabular}{|c|c|c|}
\hline Item & Description & Fee \\
\hline & Capacity not exceeding 10,000 lb: & \\
\hline $206.045 \mathrm{a}$ & Compression & $(*)$ \\
\hline $206.045 \mathrm{~b}$ & Tension & $(*)$ \\
\hline $206.045 c$ & Tension and compression & (*) \\
\hline $206.045 d$ & $\begin{array}{l}\text { Capacity exceeding } 10,000 \mathrm{lb} \text { but not exceeding } 112,000 \mathrm{lb} \text { : } \\
\text { Compression }\end{array}$ & $(*)$ \\
\hline $206.045 \mathrm{e}$ & Tension & $(*)$ \\
\hline $206.045 \mathrm{f}$ & Tension and compression & $(*)$ \\
\hline $206.045 \mathrm{~g}$ & $\begin{array}{l}\text { Capacity exceeding } 112,000 \mathrm{lb} \text { but not exceeding } 300,000 \mathrm{lb} \text { : } \\
\text { Compression }\end{array}$ & $(*)$ \\
\hline $206.045 \mathrm{~h}$ & Tension & (*) \\
\hline $206.045 \mathrm{i}$ & Tension and compression & $(*)$ \\
\hline $206045 i$ & Capacity exceeding $300,000 \mathrm{lb}$ but not exceeding $1,000,000 \mathrm{lb}$ : & (*) \\
\hline $206.045 \mathrm{k}$ & Tension & (*) \\
\hline 206.0451 & Tension and compression & $(*)$ \\
\hline $206.045 \mathrm{z}$ & $\begin{array}{l}\text { For special tests not covered by the above schedule, fees will be charged } \\
\text { deperident upon the nature of the tests. }\end{array}$ & \\
\hline
\end{tabular}

* For current fees, see Change 10 on Insert Sheet 3 , 


\section{CALIBRATION AND TEST SERVICES OF THE National Bureau of Standards Notice of Change to NBS Misc. Publ. 250, 1965 Edition*}

\section{Change 11.}

Calibration of gamma-, beta-, and alpha-emitting radioactive samples: The text of schedules 204.201, 204.202, and 204.203, which appears on pp. 93 to 95 of MP250, is replaced by the revised text given below. Minor changes of phraseology have been made in several places; cerium-139 and cerium-141 have been added to the materials listed in 204.201b(iii); and strontium-89 has been added to the materials listed in $204.203 \mathrm{~b}$ (ii). The fees have been generally revised upwards to yield full recovery of the cost of providing the services. The old fees, given on p. 128 of MP250, should be crossed out and the new ones written beside them.

\subsection{Calibration of gamma-emitting radioactive samples}

Calibration of gamma-emitting radioactive samples that conform to the physical, chemical, and activity level specifications for measurement in the National Bureau of Standards calibrated $4 \pi \gamma$ ionization chamber.

\begin{tabular}{|c|c|c|}
\hline ITEM & DESCRIPTION & $\mathrm{FEE}$ \\
\hline $204.201 \mathrm{a}$ & $\begin{array}{l}\text { (1) } 100-300 \text { micrograms radium } \\
\text { (2) Chemically stable solutions of the following radionuclides in the } \\
\text { i. } 50-100 \text { microcuries sodium-22, sodium-24, scandium-46, } \\
\text { cobalt-60, yttrium-88. } \\
\text { ii. } 150-300 \text { microcuries manganese-54, iron-59, zinc-65, stron- } \\
\text { tium-85, niobium-95, iodine-131, cesium-137, tantalum- } \\
\quad 182 \text {, gold-198, mercury-203. } \\
\text { iii. } 300-600 \text { microcuries potassium-42, cobalt-57, cerium-139, } \\
\text { cerium-141. } \\
\text { Solutions should be } 5 \mathrm{ml} \text { in volume and flame-sealed in glass } \\
\text { vials or ampoules of } 0 . D \text {. } 16.0 \pm 0.5 \mathrm{~mm} \text {, wall thickness approxi- } \\
\text { mately } 0.5 \mathrm{~mm} \text {. }\end{array}$ & $\$ 110.00$ \\
\hline $204.201 b$ & $\begin{array}{l}\text { Chemically stable solutions of the following radionuclides in the } \\
\text { specified activity ranges can be measured } \\
\text { i. } 10-20 \text { microcuries sodium-22, sodium-24, scandium-46, } \\
\text { cobalt-60, yttrium- } 88 \text {. }\end{array}$ & $\$ 135.00$ \\
\hline
\end{tabular}

* Changes should be made immediately in your copy of NBS Misc. Publ. 250, 1965 Edition. Additional copies of insert sheet are available from NBS Office of Technical Information and Publications. 


\begin{tabular}{|c|c|c|}
\hline ITEM & DESCRIPTION & $\mathrm{FEE}$ \\
\hline & $\begin{array}{l}\text { ii. 30-60 microcuries manganese-54, iron-59, zinc-65, stron- } \\
\text { tium-85, niobium-95, iodine-131, cesium-137, tantalum } \\
182 \text {, gold-198, mercury-203. } \\
\text { iii. } 60-100 \text { microcuries potassium }-42 \text {, cobalt-57, cerium-139, } \\
\text { cerium-141. } \\
\text { Solutions should be } 5 \mathrm{ml} \text { in volume and flame-sealed in glass } \\
\text { vials or ampoules of O.D. } 16.0 \pm 0.5 \mathrm{~mm} \text {, wall thickness approxi- } \\
\text { mately } 0.5 \mathrm{~mm} \text {. }\end{array}$ & \\
\hline $204.201 \mathrm{z}$ & $\begin{array}{l}\text { For tests not covered by the above schedule, fees will be charged } \\
\text { dependent on the time involved in making the tests. }\end{array}$ & \\
\hline
\end{tabular}

\subsection{Calibration of alpha-emission rate of sources.}

Calibration of alpha-emitting radioactive samples that conform to the physical and activity level specifications for measurement in the National Bureau of Standards $2 \pi \alpha$ proportional counter.

\begin{tabular}{|c|c|c|}
\hline ITEM & DESCRIPTION & $\mathrm{FEE}$ \\
\hline $204.202 \mathrm{a}$ & $\begin{array}{l}\text { Chemically stable samples that conform to the physical and activity } \\
\text { level specifications listed below can be measured } \\
\text { i. Source diameter should not exceed } 10 \mathrm{~cm} \text {. } \\
\text { ii. Source thickness should be such that more than } 99.5 \% \text { of } \\
\text { the emitted alpha particles have an energy greater than } 400 \\
\text { keV. } \\
\text { iii. Emission rate should not exceed } 5 \times 10^{3} \alpha \mathrm{ps} \text {. }\end{array}$ & $\$ 88.00$ \\
\hline $204.202 \mathrm{z}$ & $\begin{array}{l}\text { For tests not covered by the above schedule, fees will be charged } \\
\text { dependent on time involved in making the tests. }\end{array}$ & \\
\hline
\end{tabular}

\subsection{Calibration of beta-emitting radioactive samples.}

Calibration of beta-emitting radioactive samples that conform to the physical, chemical, and activity level specifications for measurement in either the National Bureau of Standards calibrated $2 \pi \beta$ windowless proportional flow counter, or in the National Bureau of Standards calibrated $2 \pi \beta$ ionization chamber. 


\begin{tabular}{|c|c|c|}
\hline ITEM & DESCRIPTION & $\mathrm{FEE}$ \\
\hline $204.203 a$ & $\begin{array}{l}\text { Chemically stable solutions of the following radionuclides in the } \\
\text { specified activity ranges can be measured in the National Bureau of } \\
\text { Standards calibrated } 2 \pi \beta \text { windowless proportional flow counter --- } \\
\text { i. } 1-10 \text { microcuries/milliliter chlorine-36, strontium-yttrium- } \\
\quad 90 \text {. } \\
\text { ii. } 2-20 \text { microcuries/milliliter thallium-204. } \\
\text { iii. } 5-50 \text { microcuries/milliliter calcium }-45 \text {, promethium-147. } \\
\text { iv. } 10-100 \text { microcuries/milliliter sulfur-35. } \\
\text { Solutions should be approximately } 5 \mathrm{ml} \text { in volume and flame-sealed } \\
\text { in glass vials or ampoules. }\end{array}$ & $\$ 285.00$ \\
\hline $204.203 \mathrm{~b}$ & $\begin{array}{l}\text { Chemically stable solutions of the following radionuclides in the } \\
\text { specified activity ranges can be measured in the National Bureau } \\
\text { of Standards calibrated } 2 \pi \beta \text { ionization chamber } \\
\text { i. } 2-20 \text { microcuries/milliliter phosphorus-32. Solution should } \\
\text { be neutral or weak acid with not more than } 0.2 \mathrm{mg} / \mathrm{ml} \text { total } \\
\text { solids. } \\
\text { ii. } 2-20 \text { microcuries/milliliter strontium-89, strontium-yttrium- } \\
\quad 90 \text {. Solution should be weak } \mathrm{HCl}(1 \mathrm{~N} \text { or less) with not more } \\
\text { than } 0.2 \mathrm{mg} / \mathrm{ml} \text { total solids. } \\
\text { Solutions should be approximately } 5 \mathrm{ml} \text { in volume and flame-sealed } \\
\text { in glass vials or ampoules. }\end{array}$ & $\$ 150.00$ \\
\hline $204.203 z$ & $\begin{array}{l}\text { For tests not covered by the above schedule, fees will be charged } \\
\text { dependent on the time involved in making the tests. }\end{array}$ & \\
\hline
\end{tabular}

\section{ChANGE 12.}

Working standards of length: As a result of new calibration instrumentation, the fee for item 204.402c (relating to the calibration of submultiples of length intervals) is reduced to $\$ 3.00$. The old fee of $\$ 33.00$ for item $204.402 \mathrm{c}$, listed on p. 127 of MP250, should be deleted. The text of the item, on p. 65 of MP250, remains unchanged. 


\section{CALIBRATION AND TEST SERVICES OF THE \\ National Bureau of Standards \\ Notice of Change to NBS Misc. Publ. 250, 1965 Edition*}

\section{Change 13.}

Calibration and measurement services of the NBS Radio Standards Laboratory, Boulder, Colorado: The schedules of services performed by the Radio Standards Laboratory, covered in Section 201.701 through 201.950, have been generally extended and revised as shown in detail below. Additional services are listed in Sections 201.812, 201.830, 201.861, 201.912, and 201.940, and changes in wording and arrangement have been made at various places to improve clarity. The new schedules, which follow, replace the old ones which appear on pp. 34-49 of MP250; the latter should be deleted.

The schedules covered by this Insert are the following:

\section{Low-Frequency Region}

201.701 Frequency stability of signal sources, to $30 \mathrm{kHz}$

\section{High-Frequency Region}

$201.800 \quad$ General

$201.810 \mathrm{Rf}$, rf-d-c voltmeters, and thermal converters in the frequency range of $30 \mathrm{kHz}$ to $1000 \mathrm{MHz}$, from 0.1 to $300 \mathrm{~V}$

201.811 Rf micropotentiometers, voltmeters, and signal sources in the frequency range of $30 \mathrm{kHz}$ to $1000 \mathrm{MHz}$, from $1 \mu \mathrm{V}$ to $0.1 \mathrm{~V}$

201.812 Pulse voltage, peak measurement, coaxial systems

201.820 Rf calorimeters, $30 \mathrm{kHz}$ to $500 \mathrm{MHz}$

201.821 Coaxial bolometer units and bolometer-coupler units, continuous wave, low-level power

201.822 Pulse power, peak measurement, coaxial systems

201.830 Immittance, two-terminal devices, $30 \mathrm{kHz}$ to $8 \mathrm{GHz}$

201.831 Immittance, three-terminal devices, $100 \mathrm{kHz}$ to $1 \mathrm{MHz}$

201.840 Dissipative fixed coaxial attenuators

201.841 Dissipative variable coaxial attenuators

201.842 Waveguide below-cutoff (piston) attenuators

201.843 Coaxial fixed directional couplers

201.844 Coaxial variable directional couplers

* Changes should be made immediately in your copy of NBS Misc. Publ. 250, 1965 Edition. Additional copies of insert sheet are available from NBS Office of Technical Information and Publications. 
201.850 Electric and magnetic field strength measurements

201.851 Field-strength receivers (0 to $1000 \mathrm{MHz}$ )

201.852 Loop antennas $(30 \mathrm{~Hz}$ to $30 \mathrm{MHz})$

201.853 Dipole antennas (30 to $1000 \mathrm{MHz}$ )

201.860 Frequency stability of signal sources, $30 \mathrm{kHz}$ to $500 \mathrm{MHz}$

201.861 Power spectral analysis of signal sources

Microwave Region

201.900 General

201.910 Waveguide bolometer units and bolometer-coupler units, continuous wave, lowlevel power

201.911 Waveguide dry calorimeters, continuous wave, low-level power

201.912 Coaxial bolometer units, continuous wave, low-level power

201.920 Waveguide reflectors (mismatches), reflection coefficient magnitude

201.930 Cavity wavemeters, frequency measurement

201.940 Waveguide variable attenuators, attenuation difference

201.941 Waveguide fixed attenuators, insertion loss

201.950 Waveguide noise sources, effective noise temperature

\section{Low-Frequency Region}

\subsection{Frequency stability of signal sources, to $30 \mathrm{kHz}$.}

(Services available only at the NBS Radio Standards Laboratory, Boulder, Colorado.)

(a) Frequency stability calibrations are made on signal sources up to $30 \mathrm{kHz}$. (See Section 201.860 for calibration service at higher frequencies.)

(b) The signal source should have a power output of at least $10 \mathrm{~mW}$ (into a matched load).

(c) Frequency stability of the signal source should be better than approximately one part in $10^{\top}$.

\begin{tabular}{r|c|c}
\hline ITEM & DESCRIPTION & FEE \\
\hline $201.701 \mathrm{a}$ & Measurement of frequency stability of signal sources, up to $30 \mathrm{kHz}$ & $(*)$ \\
$201.701 \mathrm{z}$ & Special calibrations not covered by the above schedule & $(*)$ \\
\hline
\end{tabular}

* As fees have not been fixed for these services, charges will be made for actual costs incurred. Upon request, estimates will be furnished for specific tasks which should provide a close approximation of actual costs. 


\section{High-Frequency Region}

\subsection{General.}

The "High-Frequency Region" for purposes of this schedule, extends approximately from $30 \mathrm{kHz}$ to $18 \mathrm{GHz}$. As the "Microwave Region" starts at approximately $1 \mathrm{GHz}$, the two regions overlap in that portion of the spectrum between $1 \mathrm{GHz}$ and $18 \mathrm{GHz}$. The present coverage in the "High-Frequency Region" above $1 \mathrm{GHz}$ is quite limited and involves only coaxial structures. It should be noted that some calibration services for coaxial instruments are listed in the "Microwave Region" sections of this schedule in addition to the waveguide services listed therein.

In the "High-Frequency Region" the Radio Standards Laboratory, Boulder, Colorado, is equipped to calibrate standards of pulse and CW voltage, pulse and CW power, immittance, attenuation, and field strength. Calibrations are performed at discrete frequencies as well as continuously over certain frequency bands (depending upon the particular item).

Connectors limit the accuracy of measurements in the high-frequency region to some extent, particularly at the higher frequencies. To avoid uncertainty from this cause, all interlaboratory standards submitted for calibration, fitted with coaxial connectors, should be equipped with Type $\mathrm{N}$ connectors complying with the MIL C 39012/1, 2 specification, or with the new precision 7 or $14 \mathrm{~mm}$ connectors. The critical mating dimensions required by NBS for Type $\mathrm{N}$ connectors are shown in the following diagram.

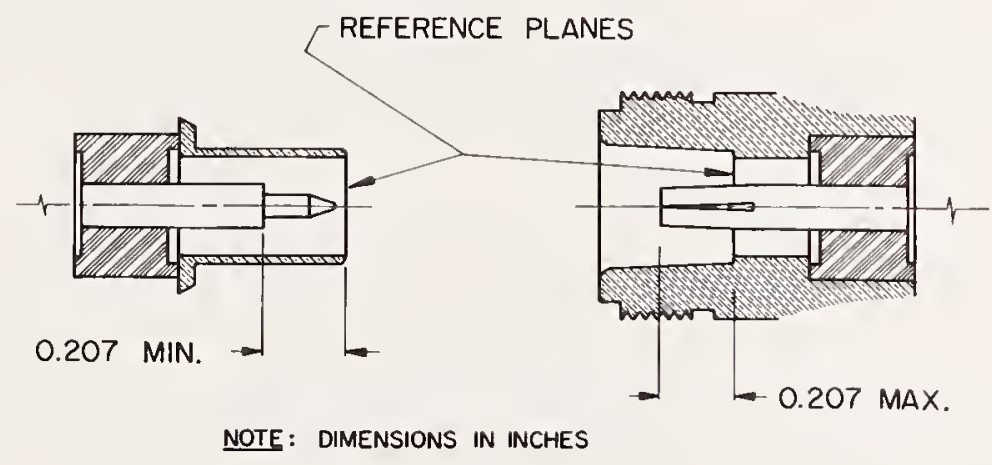

201.810 Rf, rf-d-c voltmeters, and thermal converters in the frequency range of $30 \mathrm{kHz}$ to $1000 \mathrm{MHz}$, from 0.1 to $3000 \mathrm{~V}$.

Ordinarily instruments equally suitable for use on $\mathrm{dc}$ and $\mathrm{rf}$ will be calibrated only for $\mathrm{rf}-\mathrm{d}-\mathrm{c}$ difference by the procedure of Item $201.810 \mathrm{a}$, since periodic calibrations can be made by the user on reversed direct current. Such reversed d-c calibrations will be made only under unusual circumstances and by advance arrangement. Instruments suitable for use only on rf will be given rf calibrations by the procedures of Items 201.810a, $\mathrm{b}, \mathrm{c}, \mathrm{d}$. Instruments which respond to average or peak values or which are not in ASA accuracy class one-quarter percent or better are not usually accepted for calibration below $30 \mathrm{MHz}$. 


\begin{tabular}{|c|c|c|}
\hline ITEM & DESCRIPTION & FEE \\
\hline $201.810 \mathrm{a}$ & $\begin{array}{l}\text { Measurement of a voltage or an } \mathrm{rf}-\mathrm{d} \text {-c difference at } 30,100,300 \\
\mathrm{kHz}, 1,3,10,30 \text {, or } 100 \mathrm{MHz} \text { in the range of } 0.1 \text { to } 300 \mathrm{~V}\end{array}$ & $(*)$ \\
\hline $201.810 b$ & $\begin{array}{l}\text { Each measurement additional to } 201.810 \text { a at a different frequency } \\
\text { or voltage }\end{array}$ & $(*)$ \\
\hline $201.810 \mathrm{c}$ & $\begin{array}{l}\text { Measurement of a voltage at } 300,400,500,700 \text {, or } 1000 \mathrm{MHz} \text {, in } \\
\text { the range of } 0.2 \text { to } 20 \mathrm{~V}\end{array}$ & $(*)$ \\
\hline $201.810 \mathrm{~d}$ & $\begin{array}{l}\text { Each measurement additional to } 201.810 \mathrm{c} \text { at a different frequency } \\
\text { or voltage }\end{array}$ & $(*)$ \\
\hline $201.810 \mathrm{z}$ & Special calibrations not covered by the above schedule & $(*)$ \\
\hline
\end{tabular}

* As fees have not been fixed for these services, charges will be made for actual costs incurred. Upon request, estimates will be furnished for specific tasks which should provide a close approximation of actual costs.

201.811 RF micropotentiometers, voltmeters, and signal sources in the frequency range of $30 \mathrm{kHz}$ to $1000 \mathrm{MHz}$, from $1 \mu \mathrm{V}$ to $0.1 \mathrm{~V}$.

Only high-quality voltmeters, suitable for use as interlaboratory standards, are normally accepted for calibration. These instruments should have a stability of one percent or better and an accuracy of three percent or better. Rf voltmeters will be calibrated by the procedures of Items $201.811 \mathrm{a}, \mathrm{b}, \mathrm{c}, \mathrm{d}$.

Only signal sources high enough in quality to be considered as interlaboratory standards are accepted for calibration. If these instruments are equally suitable for use on dc and rf, they will be calibrated for rf-dc difference by the procedures of Items 201.811a, b, $c$, d. Signal sources suitable for use only on $\mathrm{rf}$ will ho ralibrated by the procedures of Items $201.811 \mathrm{a}, \mathrm{b}$.

\begin{tabular}{|c|c|c|}
\hline ITEM & DESCRIPTION & FEE \\
\hline $201.811 \mathrm{a}$ & $\begin{array}{l}\text { Measurement of a voltage for micropotentiometers, voltmeters, and } \\
\text { signal sources in the range of } 50 \mathrm{kHz} \text { to } 900 \mathrm{MHz} \text {, from } 1 \mu \mathrm{V} \text { to } \\
0.1 \mathrm{~V}\end{array}$ & $(*)$ \\
\hline $201.811 b$ & $\begin{array}{l}\text { Each measurement additional to } 201.811 \text { a at a different frequency } \\
\text { or voltage }\end{array}$ & $(*)$ \\
\hline $201.811 \mathrm{c}$ & $\begin{array}{l}\text { Measurement of a voltage for voltmeters in the range of } 900 \text { to } 1000 \\
\mathrm{MHz} \text {, from } 100 \mu \mathrm{V} \text { to } 0.1 \mathrm{~V}\end{array}$ & $\left({ }^{*}\right)$ \\
\hline $201.811 d$ & $\begin{array}{l}\text { Each measurement additional to } 201.811 \mathrm{c} \text { at a different frequency } \\
\text { or voltage }\end{array}$ & $(*)$ \\
\hline $201.811 \mathrm{z}$ & Special calibrations not covered by the above schedule & $(*)$ \\
\hline
\end{tabular}

*As fees have not been fixed for these services, charges will be made for actual costs incurred. Upon request. estimates will be furnished for specific tasks which should provide a close approximation of actual costs. 
201.812_Pulse voltage, peak measurement, coaxial systems.

(a) For general information on pulse terminology reference is made to the following: "Standards on Pulses: Definition of Terms-Part I, 1951," Proc. IRE, Vol. 39, No. 6, June 1951.

"Standards on Pulses: Definition of Terms-Part II, 1952," Proc. IRE, Vol. 40, No. 5, May 1952.

Specifically, in this schedule, the term "peak duration for a trapezoidal pulse" denotes the time interval between the leading edge and trailing edge at 99.8 percent of maximum pulse amplitude.

"Pulse duration for a trapexoidal pulse" denotes the time interval between the leading edge and trailing edge at 50 percent of maximum pulse amplitude.

(b) Measurements are made with unidirectional, trapezoidal pulses with a rise and fall time of 10 nanoseconds or greater and with a peak duration of $10 \mathrm{nsec}$ or greater for pulse amplitudes less than $100 \mathrm{~V}$.

(c) For amplitudes greater than $100 \mathrm{~V}$, the pulses have a rise and fall time of 30 nsec or greater and a peak duration of $30 \mathrm{nsec}$ or greater.

\begin{tabular}{|c|c|c|}
\hline ITEM & DESCRIPTION & FEE \\
\hline $201.812 a$ & $\begin{array}{l}\text { Calibration of instrument for peak voltage measurement of pulse } \\
\text { waveforms in coaxial systems in the voltage range of } 5 \text { to } 100 \mathrm{~V} \text {; } \\
\text { pulse duration } 20 \mathrm{nsec} \text { to } 100 \mu \mathrm{sec} \text {; pulse repetition rate } 60 \text { to } \\
2 \times 10^{6} \mathrm{pps} \text {, with a maximum duty cycle of } 0.1\end{array}$ & $(*)$ \\
\hline $201.812 b$ & $\begin{array}{l}\text { Calibration of each additional instrument for peak voltage meas- } \\
\text { urement, performed under conditions of } 201.812 \mathrm{a}\end{array}$ & $(*)$ \\
\hline $201.812 c$ & $\begin{array}{l}\text { Calibration of instrument for peak voltage measurement of pulse } \\
\text { waveforms in coaxial systems in the voltage range of } 100 \text { to } 1000 \\
\mathrm{~V} \text {; pulse duration } 60 \mathrm{nsec} \text { to } 5 \mu \mathrm{sec} \text {; pulse repetition rate, } 60 \text { to } \\
1.66 \times 10^{5} \mathrm{pps} \text {, with a maximum duty cycle of } 0.01\end{array}$ & $(*)$ \\
\hline $201.812 d$ & $\begin{array}{l}\text { Calibration of each additional instrument for peak voltage meas- } \\
\text { urement, performed under conditions of } 201.812 \mathrm{c}\end{array}$ & $(*)$ \\
\hline $201.812 \mathrm{z}$ & Special calibrations not covered by the above schedule & $(*)$ \\
\hline
\end{tabular}

* As fees have not been fixed for these services, charges will be made for actual costs incurred. Upon request, estimates will be furnished for specific tasks which should provide a close approximation of actual costs.

\section{$201.820 \mathrm{RF}$ calorimeters, $30 \mathrm{kHz}$ to $500 \mathrm{MHz}$.}

(a) For maximum calibration accuracy, interlaboratory rf calorimeters should repeat readings to one-half percent or better with a constant power input.

(b) At present only rf calorimeters utilizing Type $\mathrm{N}$ or precision connectors for $\mathrm{rf}$ power input can be calibrated. Refer to 201.800 for special requirements for the connectors used on interlaboratory standards. 


\begin{tabular}{|c|c|c|}
\hline ITEM & DESCRIPTION & FEE \\
\hline $201.820 \mathrm{a}$ & $\begin{array}{l}\text { Measurement of } \mathrm{rf} \text { calorimeter at one frequency at } 100 \text { or } 300 \mathrm{kHz} \text {, } \\
1,3,10 \text {, or } 30 \mathrm{MHz} \text {; and at one power level, from } 0.001 \text { to } 200 \mathrm{~W}-\text { - }\end{array}$ & $\left.{ }^{*}\right)$ \\
\hline $201.820 \mathrm{~b}$ & $\begin{array}{l}\text { Measurement of each additional power level at the same frequency } \\
\text { as for } 201.820 \mathrm{a}\end{array}$ & $(*)$ \\
\hline $201.820 \mathrm{c}$ & $\begin{array}{l}\text { Measurement of rf calorimeter at one frequency at } 100,200,300 \text {, } \\
400 \text {, or } 500 \mathrm{MHz} \text {; at one power level, from } 0.001 \text { to } 100 \mathrm{~W}\end{array}$ & $\left(^{*}\right)$ \\
\hline $201.820 \mathrm{~d}$ & $\begin{array}{l}\text { Measurement of each additional power level at the same frequency } \\
\text { as for } 201.820 \mathrm{c}\end{array}$ & $\left(^{*}\right)$ \\
\hline $201.820 \mathrm{z}$ & Special calibrations not covered by the above schedule & $(*)$ \\
\hline
\end{tabular}

* As fees have not been fixed for these services, charges will be made for actual costs incurred. Upon request, estimates will be furnished for specific tasks which should provide a close approximation of actual costs.

\subsection{Coaxial bolometer units and bolometer-coupler units, continuous wave,} low-level power.

(a) A bolometer unit includes both the bolometer element or elements and the bolometer mount in which they are supported.

(b) Power measurements are made on barretter-type bolometer units having nominal resistance of 50,100, or $200 \mathrm{ohms}$ at a bias current between 3.5 and $10 \mathrm{~mA}$; and on thermistor-type bolometer units having a nominal resistance of 50, 100, or $200 \mathrm{ohms}$ at a bias current between 5 and $15 \mathrm{~mA}$. Bolometer units should be of the fixed tuned or untuned broadband type and must have suitable ${ }^{13}$ male or female Type $\mathrm{N}$ or precision connectors.

(c) Power measurements are made on bolometer units at cw power levels of 1 and $10 \mathrm{~mW}$ only.

(d) Power measurements are made on bolometer-coupler combinations having coupling ratios from 3 to $30 \mathrm{~dB}$. A bolometer unit of the fixed tuned or untuned broadband type should be permanently attached to the side arm of the directional coupler. The directional coupler should have good design features, with a directivity of $30 \mathrm{~dB}$ or greater, and a VSWR no greater than 1.10 for the input and output ports of the main arm of the coupler.

(e) Effective efficiency for bolometer units is defined as the ratio of the substituted dc power in the bolometer unit to the power dissipated within the bolometer unit ${ }^{14}$.

(f) Calibration factor for bolometer units is defined as the ratio of the substituted dc power in the bolometer unit to the rf power incident upon the bolometer unit ${ }^{14}$.

(g) Calibration factor for bolometer-coupler units is defined as the ratio of the substituted dc power in the bolometer unit on the side arm of the directional coupler to the rf power incident upon a 50-ohm load (with a VSWR less than 1.05) attached to the output port of the main $\operatorname{arm}^{14}$.

\footnotetext{
${ }^{13}$ See Section 201.800

${ }^{14}$ Desch, R. F., and R. E. Larson, Bolometric microwave power calibration techniques at NBS, IEEE Trans. Instr. Meas. IM-12, No. 1, 29 (June 1963).
} 
NBS Misc. Publ. 250, INSERT 5 - Continued

\begin{tabular}{|c|c|c|}
\hline ITEM & DESCRIPTION & FEE \\
\hline $201.821 \mathrm{a}$ & $\begin{array}{l}\text { Determination of calibration factor of coaxial bolometer unit at one } \\
\text { frequency at } 100 \mathrm{MHz} \text { or } 1 \mathrm{GHz} \text {; and at one power level, } 1 \text { or } \\
10 \mathrm{~mW}\end{array}$ & $(*)$ \\
\hline $201.821 b$ & $\begin{array}{l}\text { Determination at each additional power level at the same frequency } \\
\text { as for } 201.821 \mathrm{a}\end{array}$ & $(*)$ \\
\hline $201.821 \mathrm{c}$ & $\begin{array}{l}\text { Determination of calibration factor of coaxial bolometer unit at } 3^{* *} \\
\mathrm{GHz} \text {; and at one power level, } 1 \text { or } 10 \mathrm{~mW}\end{array}$ & $(*)$ \\
\hline $201.821 d$ & Determination at each additional power level at $3^{* *} \mathrm{GHz}$, as for & $(*)$ \\
\hline $201.821 \mathrm{e}$ & $\begin{array}{l}\text { Determination of calibration factor of coaxial bolometer-coupler } \\
\text { unit at one frequency at } 30,100,200,300,400,500 \mathrm{MHz} \text {, or } 1 \\
\mathrm{GHz} \text {; and at one power level }\end{array}$ & $(*)$ \\
\hline $201.821 \mathrm{f}$ & $\begin{array}{l}\text { Determination at each additional power level at the same frequency } \\
\text { as for } 201.821 \mathrm{e}\end{array}$ & $(*)$ \\
\hline $201.821 z$ & Special calibrations not covered by the above schedule & $(*)$ \\
\hline
\end{tabular}
* As fees have not been fixed for these services, charges will be made for actual costs incurred. Upon request, estimates
will be furnished for specific tasks which should provide a close approximation of actual costs.

For measurements on coaxial bolometer units at $4 \mathrm{GHz}$ and higher frequencies, see 201.912.

\subsection{Pulse power, peak measurement, coaxial systems.}

(a) Instruments submitted for calibration should have a nominal impedance of 50 ohms, and be fitted with Type $\mathrm{N}, \mathrm{BNC}, \mathrm{HN}$, or precision input connectors. ${ }^{13}$

(b) Measurements are made with pulsed rf signals having a rectangular envelope.

\begin{tabular}{|c|c|c|}
\hline ITEM & DESCRIPTION & FEE \\
\hline $201.822 \mathrm{a}$ & $\begin{array}{l}\text { Calibration of instrument for measuring peak power of pulsed sig- } \\
\text { nals in coaxial systems, in the frequency range of } 950 \text { to } 1200 \\
\mathrm{MHz} \text {, at a peak power in the range of } 1 \mathrm{~mW} \text { to } 3 \mathrm{~kW} \text {; at a pulse } \\
\text { width in the range of } 2 \text { to } 10 \mu \mathrm{sec} \text {, and at a pulse repetition rate } \\
\text { in the range of } 100 \text { to } 1600 \mathrm{pps} \text { with a maximum duty cycle of } \\
0.0033\end{array}$ & $(*)$ \\
\hline $201.822 b$ & $\begin{array}{l}\text { Calibration of instrument for measuring peak power of pulsed sig- } \\
\text { nals in coaxial systems at each additional peak power level or a } \\
\text { different pulse width or pulse repetition rate, at the same fre- } \\
\text { quency as for } 201.822 \mathrm{a}\end{array}$ & $(*)$ \\
\hline $201.822 z$ & Special calibrations not covered by the above schedule & $(*)$ \\
\hline
\end{tabular}

${ }^{13}$ See Section 201.800

* As fees have not been fixed for these services, charges will be made for actual costs incurred. Upon request, estimates will be furnished for specific tasks which should provide a close approximation of actual costs. 


\subsection{Immittance, two-terminal devices, $30 \mathrm{kHz}$ to $8 \mathrm{GHz}$.}

(a) Maximum accuracy can be achieved only in the case of instruments and components equipped with connectors having a plane of reference directly compatible with the NBS system with no necessity for special adapters. In the interest of preserving higher calibration accuracies, coaxial connectors should be utilized on standard instruments and components wherever possible. Calibrations are not performed on capacitors with unshielded terminals; e.g., binding posts and banana-plug connectors.

(b) Power applied to any item under test will normally not exceed $1 \mathrm{~W}$. Where caution in this respect is necessary it should be clearly stated in the calibration request. All calibrations described in this section are performed under ambient conditions of 23 \pm 2 degrees $\mathrm{C}$ and $40 \pm 2$ percent relative humidity.

\begin{tabular}{|c|c|c|}
\hline ITEM & DESCRIPTION & FEE \\
\hline $201.830 a-1$ & $\begin{array}{l}\text { Two-terminal impedance measurement at one point in the frequency } \\
\text { range } 30 \text { to } 400 \mathrm{kHz}, 0 \text { to } 10,000 \mathrm{ohms} \text { resistance, and } 0 \text { to } 1100 \\
\mu \mathrm{H} \text { inductance }\end{array}$ & $(*)$ \\
\hline $201.830 a-2$ & $\begin{array}{l}\text { Two-terminal impedance measurement at each additional point } \\
\text { within limits of } 201.830 \mathrm{a}-1\end{array}$ & $(*)$ \\
\hline $201.830 \mathrm{~b}-1$ & $\begin{array}{l}\text { Two-terminal impedance measurement at one point in the frequency } \\
\text { range } 30 \mathrm{kHz} \text { to } 1 \mathrm{MHz}, 0 \text { to } 1000 \mathrm{ohms} \text { resistance, and } 0 \text { to } 110 \\
\mu \mathrm{H} \text { inductance }\end{array}$ & $(*)$ \\
\hline $201.830 \mathrm{~b}-2$ & $\begin{array}{l}\text { Two-terminal impedance measurement at each additional point } \\
\text { within limits of } 201.830 \mathrm{~b}-1\end{array}$ & $(*)$ \\
\hline $201.830 c-1$ & $\begin{array}{l}\text { Two-terminal admittance measurement at one point in the fre- } \\
\text { quency range } 30 \mathrm{kHz} \text { to } 1 \mathrm{MHz}, 0 \text { to } 110 \mu \mathrm{mhos} \text { conductance, and } \\
0 \text { to } 1100 \mathrm{pF} \text { capacitance }\end{array}$ & $(*)$ \\
\hline $201.830 c-2$ & $\begin{array}{l}\text { Two-terminal admittance measurement at each additional point } \\
\text { within limits of } 201.830 \mathrm{c}-1\end{array}$ & $(*)$ \\
\hline $201.830 d-1$ & $\begin{array}{l}\text { Two-terminal admittance measurement at one point in the fre- } \\
\text { quency range } 5 \text { to } 300 \mathrm{MHz}, 0 \text { to } 50 \mathrm{mmhos} \text { conductance, and } 0 \\
\text { to } 50 \mathrm{pF} \text { capacitance }\end{array}$ & $(*)$ \\
\hline $201.830 \mathrm{~d}-2$ & $\begin{array}{l}\text { Two-terminal admittance measurement at each additional point } \\
\text { within limits of } 201.830 \mathrm{~d}-1\end{array}$ & $(*)$ \\
\hline $201.830 \mathrm{e}-1$ & $\begin{array}{l}\text { Q-Standard measurement in the frequency range } 50 \mathrm{kHZ} \text { to } 45 \\
\mathrm{MHz}, 0 \text { to } 1000 \text { for effective } \mathrm{Q} \text {, and } 30 \text { to } 450 \mathrm{pF} \text { for effective } \\
\text { resonating capacitance }\end{array}$ & $(*)$ \\
\hline $201.830 f-1$ & $\begin{array}{l}\text { Two-terminal impedance measurement of coaxial component at one } \\
\text { point in frequency range } 50 \mathrm{MHz} \text { to } 8 \mathrm{GHz} \text {, within range of } 0.5 \\
\text { to } 5000 \mathrm{ohms} \text { for magnitude and } 0 \text { to } 90^{\circ} \text { for phase angle }\end{array}$ & $(*)$ \\
\hline
\end{tabular}

As fees have not been fixed for these services, charges will be made for actual costs incurred. Upon request, estimates will be furnished for specific tasks which should provide a close approximation of actual costs. 


\begin{tabular}{|c|c|c|}
\hline ITEM & DESCRIPTION & $\mathrm{FEE}$ \\
\hline $201.830 \mathrm{~g}-1$ & $\begin{array}{l}\text { Measurement of magnitude of reflection coefficient of a coaxial } \\
\text { matched termination in } 50 \text {-ohm line at one point in frequency } \\
\text { range } 1 \text { to } 4 \mathrm{GHz} \text {, by coaxial reflectometer to provide greater } \\
\text { accuracy than provided by } 201.830 \mathrm{f}-1\end{array}$ & $(*)$ \\
\hline $201.830 \mathrm{~g}-2$ & Each additional point within limits of $201.830 \mathrm{~g}-1$ & $(*)$ \\
\hline $201.830 z$ & $\begin{array}{l}\text { Special two-terminal immittance measurements not covered by the } \\
\text { above }\end{array}$ & $(*)$ \\
\hline
\end{tabular}

* As fees have not been fixed for these services, charges will be made for actual costs incurred. Upon request, estimates will be furnished for specific tasks which should provide a close approximation of actual costs.

201.831 Immitance, three-terminal devices, $100 \mathrm{kHz}$ to $1 \mathrm{MHz}$.

(a) Three-terminal techniques are required for the measurement of extremely low admittance so that unwanted admittance to ground (especially capacitances) do not significantly affect the measurements. Conductance or dissipation factor is not included in Reports of Calibration for three-terminal capacitance.

(b) All measurements described in this section are performed under ambient conditions of $23 \pm 2$ degrees $\mathrm{C}$ and $40 \pm 2$ percent relative humidity.

\begin{tabular}{|c|c|c|}
\hline ITEM & DESCRIPTION & FEE \\
\hline $201.831 a-1$ & $\begin{array}{l}\text { Three-terminal capacitance measurement at } 100 \mathrm{kHz}, 465 \mathrm{kHz} \text {, or } 1 \\
\mathrm{MHz} \text { for fixed nominal values of } 10^{-2}, 10^{-1}, 10^{\circ}, 10^{1}, 10^{2} \text {, and } 10^{3} \\
\mathrm{pF} \text {, per frequency }\end{array}$ & $(*)$ \\
\hline $201.831 b-1$ & $\begin{array}{l}\text { Three-terminal capacitance measurement at } 465 \mathrm{kHz} \text { at one point } \\
\text { in the range } 0.001 \text { to } 100 \mathrm{pF}\end{array}$ & $(*)$ \\
\hline $201.831 b-2$ & $\begin{array}{l}\text { Three-terminal capacitance measurement at } 465 \mathrm{kHz} \text { at each addi- } \\
\text { tional point within limits of } 201.831 \mathrm{~b}-1\end{array}$ & $(*)$ \\
\hline $201.831 z$ & $\begin{array}{l}\text { Special three-terminal immitance measurements not covered by } \\
\text { above schedule }\end{array}$ & $(*)$ \\
\hline
\end{tabular}

*As fees have not been fixed for these services, charges will be made for actual costs incurred. Upon request. estimates will be furnished for specific tasks which should provide a close approximation of actual costs.

\subsection{Dissipative fixed coaxial attenuators.}

(a) Dissipative fixed coaxial attenuators are normally calibrated in a system having a characteristic impedance of $50 \mathrm{ohms}$. Since the accuracy of the calibration is degraded by any deviation or uncertainty in this characteristic impedance, the types of allowable connectors are limited. Connectors having a known plane of reference, or the Type $\mathrm{N}$ or precision connectors ${ }^{13}$ are required. All measurements are made by the substitution 
method, which requires that the connectors used be asexual or the attenuator have a male connector at one port and a female connector at the other port. If an adapter is required to comply with the foregoing, it must be supplied with the attenuator and the combination will be calibrated as one unit.

(b) Maximum power to any attenuator will not exceed $20 \mathrm{~mW}$ unless prior arrangements for higher power levels have been made.

(c) Insertion loss is defined as the loss encountered when a standard connector ${ }^{15}$ pair is broken and the attenuator under test is inserted. The parameters of the standard connector pair must be known, and the generator and load impedances have been adjusted so that the system is non-reflecting. These conditions cannot be strictly realized and an allowance for mismatch must be made.

\begin{tabular}{|c|c|c|}
\hline ITEM & DESCRIPTION & FEE \\
\hline $201.840 \mathrm{a}-1$ & $\begin{array}{l}\text { Measurement of insertion loss of coaxial attenuator at one of the } \\
\text { following frequencies: } 1,10,60 \text {, and } 100 \mathrm{MHz} \text {, in the range of } \\
0 \text { to } 80 \mathrm{~dB}\end{array}$ & $(*)$ \\
\hline $201.840 \mathrm{a}-2$ & $\begin{array}{l}\text { Measurement of insertion loss of fixed coaxial attenuator at a fre- } \\
\text { quency of } 30 \mathrm{MHz} \text {, in the range of } 0 \text { to } 100 \mathrm{~dB}\end{array}$ & $(*)$ \\
\hline $201.840 \mathrm{a}-3$ & $\begin{array}{l}\text { Measurement of insertion loss of each additional fixed coaxial at- } \\
\text { tenuator at the same frequency and over the same ranges as for } \\
201.840 \mathrm{a}-1 \text { to } 201.840 \mathrm{a}-2\end{array}$ & $(*)$ \\
\hline $201.840 \mathrm{~b}-1$ & $\begin{array}{l}\text { Measurement of insertion loss of fixed coaxial attenuator at any } \\
\text { frequency from } 0.100 \text { to } 8.19 \mathrm{GHz} \text { in the range of } 0 \text { to } 60 \mathrm{~dB}(\dagger) \text { - }\end{array}$ & $(*)$ \\
\hline $201.840 \mathrm{~b}-2$ & $\begin{array}{l}\text { Measurement of insertion loss of fixed coaxial attenuator at any fre- } \\
\text { quency from } 8.2 \text { to } 12.39 \mathrm{GHz} \text {, in the range of } 0 \text { to } 60 \mathrm{~dB}(\dagger)\end{array}$ & $(*)$ \\
\hline $201.840 \mathrm{~b}-3$ & $\begin{array}{l}\text { Measurement of insertion loss of fixed coaxial attenuator at any } \\
\text { frequency from } 12.4 \text { to } 18.0 \mathrm{GHz} \text {, in the range of } 0 \text { to } 60 \mathrm{~dB}(\dagger)\end{array}$ & $(*)$ \\
\hline $201.840 \mathrm{~b}-4$ & $\begin{array}{l}\text { Measurement of insertion loss of each additional fixed coaxial at- } \\
\text { tenuator at the same frequency and over the same ranges as for } \\
201.840 \mathrm{~b}-1 \text { to } 201.840 \mathrm{~b}-3\end{array}$ & $(*)$ \\
\hline $201.840 z$ & Special calibrations not covered by the above schedule & $(*)$ \\
\hline
\end{tabular}

(†) Measurement of insertion loss available to $80 \mathrm{~dB}$ at reduced accuracy.

* As fees have not been fixed for these services, charges will be made for actual costs incurred. Upon request, estimates will be furnished for specific tasks which should provide a close approximation of actual costs.

\subsection{Dissipative variable coaxial attenuators.}

(a) These attenuators are calibrated in acordance with Item 201.840 except that the zero or other specified setting is used as the reference. Because attenuation difference only is measured, both ports may have the same connector.

\footnotetext{
${ }^{15}$ Beatty, Roberts.W. Effects of connectors and adapters on accurate attenuation measurements at microwave frequencies, IEEE Trans. Instr. Meas. IM-13, No.4, 272 (Dec. 1964). In this referenced publication a "standard connector" is defined as one which is made precisely to standard specifications for the particular type of connector under consideration. Standard connector pairs usually have low but appreciable loss and reflection.
} 
(b) Variable attenuators must have a repeatability of setting better than $0.1 \mathrm{~dB}$; incremental attenuators must have a repeatability of $0.01 \mathrm{~dB}$ or better.

\begin{tabular}{c|c|c}
\hline ITEM & DESCRIPTION & FEE \\
\hline $201.841 \mathrm{a}-1$ & $\begin{array}{l}\text { Measurement of one increment on a dissipative variable attenuator } \\
\text { at one of the following frequencies: } 1,10,60 \text {, and } 100 \mathrm{MHz}, \text { in } \\
\text { the range of } 0 \text { to } 80 \mathrm{~dB}\end{array}$ & $(*)$
\end{tabular}

201.841a-2 Measurement of one increment on a dissipative variable attenuator at a frequency of $30 \mathrm{MHz}$, in the range of 0 to $100 \mathrm{~dB}$

201.841a-3 Measurement of each additional increment on a dissipative variable attenuator at the same frequency and over the same ranges as for 201.841a-1 to 201.841a-2

201.841b-1 Measurement of one increment on a dissipative variable attenuator at any frequency from 0.100 to $8.19 \mathrm{GHz}$, in the range of 0 to $60 \mathrm{~dB}$

201.841b-2 Measurement of one increment on a dissipative variable attenuator at any frequency from 8.2 to $12.39 \mathrm{GHz}$, in the range of 0 to 60 $\mathrm{dB}$

201.841b-3 Measurement of one increment on a dissipative variable attenuator at any frequency from 12.4 to $18.0 \mathrm{GHz}$, in the range of 0 to 60 $\mathrm{dB}$

201.841b-4 Measurement of each additional increment on a dissipative variable attenuator at same frequency and over the same ranges as for $201.841 \mathrm{~b}-1$ to $201.841 \mathrm{~b}-3$

$201.841 z$

Special calibrations not covered by the above schedule

\footnotetext{
* As fees have not been fixed for these services, charges will be made for actual costs incurred. Upon request, estimates will be furnished for specific tasks which should provide a close approximation of actual costs.
}

\subsection{Waveguide below-cutoff (piston) attenuators.}

(a) Waveguide below-cutoff attenuators are calibrated normally in a system having a characteristic impedance of $50 \mathrm{ohms}$. As only attenuation difference measurements are made on this type of attenuator, Type BNC, C, TNC connectors and other types are acceptable but precision connectors are preferred.

(b) An insertion loss measurement at the attenuator zero setting can be made. Maximum power to any attenuator will not exceed $20 \mathrm{~mW}$ unless prior arrangements for higher power levels have been made.

(c) Calibrations are performed at the following frequencies: 1, 10, 30, 60, and 100 $\mathrm{MHz}$. 


\begin{tabular}{|c|c|c|}
\hline ITEM & DESCRIPTION & FEE \\
\hline $201.842 a-1$ & $\begin{array}{l}\text { Measurement of one increment on a waveguide below-cutoff at- } \\
\text { tenuator at one of the following frequencies: } 1,10,60 \text {, and } 100 \\
\mathrm{MHz} \text {, in the attenuation range (including initial insertion loss) } \\
\text { of } 0 \text { to } 120 \mathrm{~dB}\end{array}$ & $(*)$ \\
\hline $201.842 a-2$ & $\begin{array}{l}\text { Measurement of one increment on a waveguide below-cutoff at- } \\
\text { tenuator at } 30 \mathrm{MHz} \text {, in the attenuation range (including initial } \\
\text { insertion loss) of } 0 \text { to } 140 \mathrm{~dB}\end{array}$ & $(*)$ \\
\hline $201.842 a-3$ & $\begin{array}{l}\text { Measurement of each additional increment on a waveguide below- } \\
\text { cutoff attenuator at the same frequency and over the same ranges } \\
\text { as for } 201.842 \mathrm{a}-1 \text { to } 201.842 \mathrm{a}-2\end{array}$ & $(*)$ \\
\hline $201.842 \mathrm{z}$ & Special calibrations not covered by the above schedule & $(*)$ \\
\hline
\end{tabular}

* As fees have not been fixed for these services, charges will be made for actual costs incurred. Upon request, estimates will be furnished for specific tasks which should provide a close approximation of actual costs.

\subsection{Coaxial fixed directional couplers.}

Coaxial fixed directional couplers are calibrated in accordance with Item 201.840. Terminations must be supplied for any arm not used during a measurement.

\begin{tabular}{|c|c|c|}
\hline ITEM & DESCRIPTION & $\mathrm{FEE}$ \\
\hline $201.843 a-1$ & $\begin{array}{l}\text { Measurement of insertion loss between any two ports of a coaxial } \\
\text { fixed directional coupler at any one of the following frequencies: } \\
1,10,60 \text {, and } 100 \mathrm{MHz} \text {, in the range of } 0 \text { to } 80 \mathrm{~dB}\end{array}$ & $(*)$ \\
\hline $201.843 a-2$ & $\begin{array}{l}\text { Measurement of insertion loss between any two ports of a coaxial } \\
\text { fixed directional coupler at a frequency of } 30 \mathrm{MHz} \text {, in the range } \\
\text { of } 0 \text { to } 100 \mathrm{~dB}\end{array}$ & $(*)$ \\
\hline $201.843 a-3$ & $\begin{array}{l}\text { Each additional measurement of insertion loss between any two } \\
\text { ports of a coaxial fixed directional coupler at same frequency and } \\
\text { over the same range as for } 201.843 \mathrm{a}-1 \text { to } 201.843 \mathrm{a}-2 \text {------- }\end{array}$ & $(*)$ \\
\hline $201.843 b-1$ & $\begin{array}{l}\text { Measurement of insertion loss between any two ports of a coaxial } \\
\text { fixed directional coupler at any frequency from } 0.100 \text { to } 8.19 \mathrm{GHz} \text {, } \\
\text { in the range of } 0 \text { to } 60 \mathrm{~dB}\end{array}$ & $(*)$ \\
\hline $201.843 b-2$ & $\begin{array}{l}\text { Measurement of insertion loss between any two ports of a coaxial } \\
\text { fixed directional coupler at any frequency from } 8.2 \text { to } 12.39 \mathrm{GHz} \text {, } \\
\text { in the range of } 0 \text { to } 60 \mathrm{~dB}\end{array}$ & $(*)$ \\
\hline $201.843 b-3$ & $\begin{array}{l}\text { Measurement of insertion loss between any two ports of a coaxial } \\
\text { fixed directional coupler at any frequency from } 12.4 \text { to } 18.0 \mathrm{GHz} \text {, } \\
\text { in the range of } 0 \text { to } 60 \mathrm{~dB}\end{array}$ & $(*)$ \\
\hline
\end{tabular}

* As fees have not been fixed for these services, charges will be made for actual costs incurred. Upon request, estimates will be furnished for specific tasks which should provide a close approximation of actual costs. 


\begin{tabular}{|c|c|c|}
\hline ITEM & DESCRIPTION & FEE \\
\hline $201.843 b-4$ & $\begin{array}{l}\text { Each additional measurement of insertion loss between same two } \\
\text { ports of a coaxial fixed directional coupler, and at the same fre- } \\
\text { quency, and over the same range as for } 201.843 \mathrm{~b}-1 \text { to } 201.843 \mathrm{~b}-3 \text { - }\end{array}$ & $(*)$ \\
\hline $201.843 z$ & Special calibrations not covered by the above schedule & $(*)$ \\
\hline
\end{tabular}

* As fees have not been fixed for these services, charges will be made for actual costs incurred. Upon request, estimates will be furnished for specific tasks which should provide a close approximation of actual costs.

\subsection{Coaxial variable directional couplers.}

(a) Coaxial variable directional couplers are calibrated in accordance with Item 201.841. Terminations must be supplied for any arm not used during a measurement.

(b) The change in coupling to the sidearm relative to the minimum setting on the device is normally measured.

\begin{tabular}{c|c|c}
\hline ITEM & DESCRIPTION & FEE \\
\hline $201.844 \mathrm{a}-1$ & $\begin{array}{l}\text { Measurement of single coupling increment between input and vari- } \\
\text { able arm of coaxial variable directional coupler at one of the fol- } \\
\text { lowing frequencies: } 1,10,60, \text { and } 100 \mathrm{MHz} \text {, in the range (includ- } \\
\text { ing initial coupling loss) of } 0 \text { to } 80 \mathrm{~dB} \ldots-\ldots\end{array}$ & $(*)$
\end{tabular}

201.844a-2 Measurement of single coupling increment between input and variable arm of coaxial variable directional coupler at a frequency of $30 \mathrm{MHz}$, in the range of 0 to $100 \mathrm{~dB}$

201.844a-3 Each additional measurement of coupling increment between input and variable arm of coaxial variable directional coupler at same frequency and over the same ranges as for $201.844 \mathrm{a}-1$ to $201.844 a-2$

$201.844 \mathrm{~b}-1$

Measurement of single coupling increment between input and variable arm of coaxial variable directional coupler at any frequency from 0.100 to $8.19 \mathrm{GHz}$, in the range of 0 to $60 \mathrm{~dB}$ (including initial coupling loss)

201.844b-2 Measurement of single coupling increment between input and variable arm of coaxial variable directional coupler at any frequency from 8.2 to $12.39 \mathrm{GHz}$, in the range of 0 to $60 \mathrm{~dB}$ (including initial coupling loss)

$20.844 b-3$

Measurement of single coupling increment between input and variable arm of coaxial variable directional coupler at any frequency from 12.4 to $18.0 \mathrm{GHz}$, in the range of 0 to $60 \mathrm{~dB}$ (including initial coupling loss) 


\begin{tabular}{c|c|c}
\hline ITEM & DESCRIPTION & FEE \\
\hline $201.844 \mathrm{~b}-4$ & $\begin{array}{c}\text { Each additional measurement of coupling increment between input } \\
\text { and variable arm of coaxial variable directional coupler at the } \\
\text { same frequency and over the same ranges as for 201.844b-1 to } \\
201.844 \mathrm{~b}-3 \ldots\end{array}$ & (*) \\
$201.844 \mathrm{z}$ & \begin{tabular}{c} 
Special calibrations not covered by the above schedule $\ldots \ldots \ldots$ \\
\hline
\end{tabular}
\end{tabular}

* As fees have not been fixed for these services, charges will be made for actual costs incurred. Upon request, estimates will be furnished for specific tasks which should provide a close approximation of actual costs.

\subsection{Electric and magnetic field strength measurements.}

Field-strength standards and field-strength meters are calibrated in terms of $\mathrm{rms} \mathrm{cw}$ signals in the frequency range of $30 \mathrm{~Hz}$ to $1000 \mathrm{MHz}$. Loop antennas are calibrated from $30 \mathrm{~Hz}$ to $30 \mathrm{MHz}$, and horizontally-polarized dipole antennas are calibrated from 30 to $1000 \mathrm{MHz}$. The antennas of field-strength meters are calibrated normally when terminated in their respective field-strength receivers. The field-strength receivers are calibrated normally for use in a 50-ohm system.

When field-strength standards or meters are submitted for calibration an instruction manual and all accessories should be included, and the instrument must be in excellent operating condition.

\subsection{Field-strength receivers ( 0 to $1000 \mathrm{MHz})$.}

There are three basic calibrations that can be performed on a field-strength receiver:

1. Calibration of the receiver as a two-terminal rf voltmeter.

2. Calibration of the signal input attenuators.

3. Determination of overall linearity of the receiver in terms of the output indicating circuits.

\begin{tabular}{|c|c|c|}
\hline ITEM & DESCRIPTION & FEE \\
\hline $201.851 \mathrm{a}-1$ & $\begin{array}{l}\text { Calibration of receiver as a two-terminal rf voltmeter, } 1 \text { to } 10,000 \\
\mu \mathrm{V}, 0 \text { to } 1000 \mathrm{MHz} \text {, at one frequency }\end{array}$ & $(*)$ \\
\hline $201.851 \mathrm{a}-2$ & $\begin{array}{l}\text { Calibration of receiver as a two-terminal rf voltmeter at each fre- } \\
\text { quency additional to Item } 201.851 \mathrm{a}-1,0 \text { to } 400 \mathrm{MHz}\end{array}$ & $(*)$ \\
\hline $201.851 \mathrm{a}-3$ & $\begin{array}{l}\text { Calibration of receiver as a two-terminal rf voltmeter at each fre- } \\
\text { quency additional to Item 201.851-a, } 400 \text { to } 1000 \mathrm{MHz}\end{array}$ & $(*)$ \\
\hline $201.851 b-1$ & $\begin{array}{l}\text { Calibration of initial step of the input attenuator at one frequency, } \\
0 \text { to } 1000 \mathrm{MHz}\end{array}$ & $(*)$ \\
\hline
\end{tabular}

* As fees have not been fixed for these services, charges will be made for actual costs incurred. Upon request, estimates will be furnished fol specific tasks which should provide a close approximation of actual costs. 
NBS Misc. Publ. 250, INSERT 5 - Continued

\begin{tabular}{|c|c|c|}
\hline ITEM & DESCRIPTION & FEE \\
\hline $201.851 b-2$ & $\begin{array}{l}\text { Calibration of each additional step of the input attenuator, addi- } \\
\text { tional to Item } 201.851 \mathrm{~b}-1,0 \text { to } 1000 \mathrm{MHz}\end{array}$ & $(*)$ \\
\hline $201.851 c-1$ & $\begin{array}{l}\text { Determination of overall linearity of receiver and output circuit, at } \\
\text { one frequency and one attenuator setting, initial point, } 0 \text { to } 1000 \\
\mathrm{MHz}\end{array}$ & $(*)$ \\
\hline $201.851 c-2$ & $\begin{array}{l}\text { Determination of overall linearity at each additional point, at same } \\
\text { frequency and at same attenuator setting as for } 201.851 \mathrm{c}-1\end{array}$ & $(*)$ \\
\hline $201.851 \mathrm{z}$ & Special calibrations not covered by the above schedule & $(*)$ \\
\hline
\end{tabular}

* As fees have not been fixed for these services, charges will be made for actual costs incurred. Upon request, estimates will be furnished for specific tasks which should provide a close approximation of actual costs.

\subsection{Loop antennas $(30 \mathrm{~Hz}$ to $30 \mathrm{MHz})$.}

Loop antennas are calibrated in terms of a quasi-static magnetic field at frequencies from $30 \mathrm{~Hz}$ to $30 \mathrm{MHz}$. The magnitude of the calibrating field varies from approximately 20 to $200 \mathrm{mV} / \mathrm{m}$.

\begin{tabular}{|c|c|c|}
\hline ITEM & DESCRIPTION & FEE \\
\hline $201.852 \mathrm{a}$ & Calibration of loop antenna at one frequency, $30 \mathrm{~Hz}$ to $30 \mathrm{MHz}_{----}$ & $(*)$ \\
\hline $201.852 b$ & $\begin{array}{l}\text { Calibration of loop antenna at each frequency additional to Item } \\
201.852 \mathrm{a}, 30 \mathrm{~Hz} \text { to } 30 \mathrm{MHz}\end{array}$ & $(*)$ \\
\hline $201.852 \mathrm{z}$ & Special calibrations not covered by the above schedule & $(*)$ \\
\hline
\end{tabular}

* As fees have not been fixed for these services, charges will be made for actual costs incurred. Upon request, estimates will be furnished for specific tasks which should provide a close approximation of actual costs.

\subsection{Dipole antennas ( 30 to $1000 \mathrm{MHz}$ ).}

Dipole antennas are calibrated in terms of horizontally-polarized fields at frequencies from 30 to $1000 \mathrm{MHz}$. The magnitude of the calibrating field varies from approximately 20 to $400 \mathrm{mV} / \mathrm{m}$.

\begin{tabular}{|c|c|c|}
\hline ITEM & DESCRIPTION & $\mathrm{FEE}$ \\
\hline $201.853 a$ & Calibration of dipole antenna at one frequency, 30 to $400 \mathrm{MHz}$ & $(*)$ \\
\hline $201.853 b$ & Calibration of dipole antenna at one frequency, 400 to $1000 \mathrm{MHz}_{--}$ & $(*)$ \\
\hline $201.853 \mathrm{c}$ & $\begin{array}{l}\text { Calibration of dipole antenna at each frequency additional to Items } \\
201.853 \mathrm{a} \text { and } 201.853 \mathrm{~b}, 30 \text { to } 1000 \mathrm{MHz}\end{array}$ & $(*)$ \\
\hline $201.853 \mathrm{z}$ & Special calibrations not covered by the above schedule & $(*)$ \\
\hline
\end{tabular}

* As fees have not been fixed for these services, charges will be made for actual costs incurred. Upon request, estimates will be furnished for specific tasks which should provide a close approximation of actual costs. 
201.860 Frequency stability of signal sources, $30 \mathrm{kHz}$ to $500 \mathrm{MHz}$.

(a) Frequency stability calibrations are made on signal sources from $30 \mathrm{kHz}$ to 500 $\mathrm{MHz}$. (See Schedule 201.701 for calibration service at lower frequencies.)

(b) The signal source should have a power output of at least $10 \mathrm{~mW}$ (into a matched load).

(c) Frequency stability of the signal source should be better than approximately one part in $10^{7}$.

\begin{tabular}{|c|c|c|}
\hline ITEM & DESCRIPTION & FEE \\
\hline $201.860 \mathrm{a}$ & $\begin{array}{l}\text { Measurement of frequency stability of precision fixed-frequency } \\
\text { signal source in the frequency range of } 30 \mathrm{kHz} \text { to } 500 \mathrm{MHz}_{----}\end{array}$ & $(*)$ \\
\hline $201.860 \mathrm{z}$ & Special calibrations not covered by the above schedule & $(*)$ \\
\hline
\end{tabular}

* As fees have not been fixed for these services, charges will be made for actual costs incurred. Upon request, estimates will be furnished for specific tasks which should provide a close approximation of actual costs.

\subsection{Power spectral analysis of signal sources.}

(a) Power spectral analysis of frequency-modulation components of frequency standards and other high-quality signal sources are made at nominal frequencies of $1,2.5,5$, and $10 \mathrm{MHz}$.

(b) Frequency-modulation components are measured to limits of $\pm 10 \mathrm{kHz}$ from the carrier frequency for magnitudes greater than $6 \mathrm{~dB}$ above the continuous noise spectrum.

(c) Noise power level of the continuous spectrum relative to the power level of the carrier frequency is measured at any selected frequency within $\pm 10 \mathrm{kHz}$ of the carrier frequency.

(d) The signal source should have a power output of at least $20 \mathrm{~mW}$ (into a matched load).

\begin{tabular}{r|c|c}
\hline ITEM & DESCRIPTION & FEE \\
\hline $201.861 \mathrm{a}$ & $\begin{array}{l}\text { Measurement of the power spectrum of a fixed signal source }----- \\
\left.\text { Special calibrations not covered by the above schedule }---{ }^{*}\right)\end{array}$ \\
$201.861 \mathrm{z}$ & $\left(^{*}\right)$ \\
\hline
\end{tabular}

* As fees have not been fixed for these services, charges will be made for actual costs incurred. Upon request, estimates will be furnished for specific tasks which should provide a close approximation of actual costs.

\section{Microwave Region}

\subsection{General}

(a) Microwave calibration services presently available include measurements of power, impedance, frequency, attenuation, and noise. The frequency range covered for each of the waveguide measurements is given below. While most of the calibration services are for waveguide, it should be noted there are a few services listed in the "Microwave Re- 
gion" for coaxial instruments. Additional services in the $1 \mathrm{GHz}$ to $18 \mathrm{GHz}$ range for coaxial instruments are listed in the "High-Frequency Region" sections of this schedule.

(b) In performing microwave calibrations, a considerable amount of time is needed to prepare the system for measurement operation. Much of this preparation is related to the adjustment of the system to the frequency of operation selected for the calibration. Time and cost often can be reduced by minimizing the number of times the operating frequency of the calibration system must be readjusted. To help in achieving this reduction in costs, a list of suggested calibration frequencies is presented in the following table. These frequencies are suggested for use in connection with this schedule and for interlaboratory standards utilizing terminations consisting of the standard waveguide sizes given below in the table of suggested calibration frequencies. It should be emphasized that the suggested frequencies are primarily for economy and for convenience to those requesting calibrations. In general the calibration instrumentation for the microwave region is intended to provide complete and continuous frequency coverage as appropriate for the various waveguide sizes. Those having need for calibrations at other than suggested frequencies can be accommodated.

\begin{tabular}{|c|c|c|c|c|}
\hline \multirow[b]{2}{*}{ EIA waveguide designation } & \multirow{2}{*}{$\begin{array}{c}\text { Frequency } \\
\text { range, GHz }\end{array}$} & \multicolumn{3}{|c|}{$\begin{array}{c}\text { Suggested calibration frequencies } \\
\mathrm{GHz}\end{array}$} \\
\hline & & No. 1 & No. 2 & No. 3 \\
\hline WR430 & $1.70-2.60$ & 1.80 & 2.20 & 2.50 \\
\hline 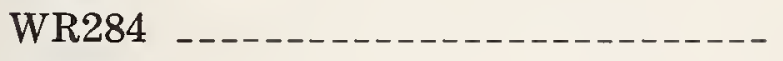 & $2.60-3.95$ & 2.85 & 3.25 & 3.55 \\
\hline WR187 & $3.95-5.85$ & 4.35 & 4.90 & 5.25 \\
\hline WR137 & $5.85-8.20$ & 6.45 & 7.00 & 7.40 \\
\hline WR112 & $7.05-10.0$ & 7.75 & 8.50 & 9.00 \\
\hline WR90 - & $8.20-12.4$ & 9.00 & 9.80 & 11.2 \\
\hline WR62 & $12.4-18.0$ & 13.5 & 15.0 & 17.0 \\
\hline WR42 & $18.0-26.5$ & 19.8 & 22.0 & 23.8 \\
\hline WR28 & $26.5-40.0$ & 29.0 & 33.0 & 37.0 \\
\hline
\end{tabular}

201.910 Waveguide bolometer units and bolometer-coupler units, continuous wave, low-level power.

(a) Power measurements are made on barretter-type bolometer units having nominal resistance of either 100 or $200 \mathrm{ohms}$ at a bias current between 3.5 and $10 \mathrm{~mA}$, and on thermistor-type bolometer units having a nominal resistance of either 100 or $200 \mathrm{ohms}$ at a bias current between 5 and $15 \mathrm{~mA}$. Bolometer units should be of the fixed tuned or untuned broadband type.

(b) Power measurements are made on waveguide bolometer units at power levels from 0.1 to $10 \mathrm{~mW}$.

(c) Power measurements are made on bolometer-coupler combinations having coupling ratios from 3 to $20 \mathrm{~dB}$. A bolometer unit of the fixed tuned or untuned broadband type should be permanently attached to the side arm of the coupler. The three-port directional coupler should have good design features, with a directivity of $40 \mathrm{~dB}$ or greater and a VSWR no greater than 1.05 for the input and output ports of the main arm of the coupler. 
(d) Efficiency for bolometer units is defined as the ratio of the microwave power absorbed by the barretter element to the microwave power dissipated within the bolometer

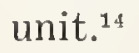

(e) Calibration factor for bolometer units is defined as the ratio of the substituted dc power in the bolometer unit to the microwave power incident upon the bolometer unit. ${ }^{14}$

(f) Calibration factor for bolometer-coupler units is defined as the ratio of the substituted dc power in the bolometer unit on the side arm of the directional coupler to the microwave power incident upon a nonreflecting load attached to the output port of the main arm. ${ }^{14}$

(g) Effective efficiency for bolometer units is defined as the ratio of the substituted dc power in the bolometer unit to the microwave power dissipated within the bolometer unit. ${ }^{11}$

\begin{tabular}{|c|c|c|}
\hline ITEM & DESCRIPTION & FEE \\
\hline & $\begin{array}{l}\text { Determination of effective efficiency of bolometer unit at a single } \\
\text { frequency of the following waveguide sizes terminated with } \\
\text { standard waveguide connectors: }\end{array}$ & \\
\hline $201.910 \mathrm{a}-1$ & WR90 (8.20-12.4 GHz) & $(*)$ \\
\hline $201.910 a-2$ & WR62 $(12.4-18.0 \mathrm{GHz})$ & $(*)$ \\
\hline $201.910 a-3$ & WR137 (5.85-8.20 GHz) & $(*)$ \\
\hline $201.910 \mathrm{a}-4$ & WR112 (7.05-10.0 GHz) & $(*)$ \\
\hline $201.910 \mathrm{a}-5$ & WR187 (3.95-5.85 GHz) & $(*)$ \\
\hline $201.910 a-20$ & $\begin{array}{l}\text { Determination of effective efficiency of each additional bolometer } \\
\text { unit at the same frequency as for } 201.910 \mathrm{a}-1\end{array}$ & $(*)$ \\
\hline $201.910 a-21$ & $\begin{array}{l}\text { Determination of effective efficiency of each additional bolometer } \\
\text { unit at the same frequency as for } 201.910 \mathrm{a}-2 \text { to } 201.910 \mathrm{a}-5 \\
\text { Determination of calibration factor of bolometer unit at a single } \\
\text { frequency of the following waveguide sizes terminated with } \\
\text { standard waveguide connectors: }\end{array}$ & $(*)$ \\
\hline $201.910 b-1$ & WR90 (8.20-12.4 GHz) & $(*)$ \\
\hline $201.910 b-2$ & WR62 (12.4-18.0 GHz) & $(*)$ \\
\hline $201.910 b-3$ & WR137 (5.85-8.20 GHz) & $(*)$ \\
\hline $201.910 b-4$ & WR112 (7.05-10.0 GHz) & $(*)$ \\
\hline $201.910 b-5$ & WR187 (3.95-5.85 GHz) & $(*)$ \\
\hline
\end{tabular}

${ }^{14}$ Desch, R. F., and R. E. Larson, Bolometric microwave power calibration techniques at NBS, IEEE Trans. Instr. Meas. IM-12, No. 1, 29 ", June 1963).

- As fees have not been fixed for these services, charges will be made for actual costs incurred. Upon request, estimates will be furnished for specific tasks which should provide a close approximation of actual costs. 


\begin{tabular}{|c|c|c|}
\hline ITEM & DESCRIPTION & FEE \\
\hline $201.910 b-20$ & $\begin{array}{l}\text { Determination of calibration factor of each additional bolometer } \\
\text { unit at the same frequency as for } 201.910 \mathrm{~b}-1 \text { to } 201.910 \mathrm{~b}-5 \\
\text { Determination of calibration factor of bolometer-coupler unit at a } \\
\text { single frequency of the following waveguide sizes terminated } \\
\text { with standard waveguide connectors: }\end{array}$ & $(*)$ \\
\hline $201.910 c-1$ & WR90 (8.20-12.4 GHz) & $(*)$ \\
\hline $201.910 c-2$ & WR62 (12.4-18.0 GHz) & $(*)$ \\
\hline $201.910 \mathrm{c}-3$ & WR137 (5.85-8.20 GHz) & $(*)$ \\
\hline $201.910 c-4$ & WR112 (7.05-10.0 GHz) & $(*)$ \\
\hline $201.910 c-5$ & $\begin{array}{l}\text { WR187 (3.95-5.85 GHz) } \\
\text { Determination of efficiency of bolometer unit at a single frequency } \\
\text { of the following waveguide sizes terminated with standard wave- } \\
\text { guide connectors: }\end{array}$ & $(*)$ \\
\hline $201.910 d-1$ & WR137 (5.85-8.20 GHz) --- & $(*)$ \\
\hline $201.910 \mathrm{~d}-2$ & WR187 $(3.95-5.85 \mathrm{GHz})$ & $(*)$ \\
\hline $201.910 \mathrm{~d}-20$ & $\begin{array}{l}\text { Determination of efficiency of each additional bolometer unit at the } \\
\text { same frequency as for } 201.910 \mathrm{~d}-1 \text { to } 201.910 \mathrm{~d}-2\end{array}$ & $(*)$ \\
\hline $201.910 \mathrm{z}$ & Special calibrations not covered by the above schedule & $(*)$ \\
\hline
\end{tabular}

* As fees have not been fixed for these services, charges will be made for actual costs incurred. Upon request, estimates will be furnished for specific tasks which should provide a close approximation of actual costs.

201.911 Waveguide dry calorimeters, continuous wave, low-level power.

\begin{tabular}{|c|c|c|}
\hline ITEM & DESCRIPTION & FEE \\
\hline $201.911 \mathrm{a}-1$ & $\begin{array}{l}\text { Measurement of output voltage versus input microwave power for } \\
\text { dry calorimeter at a single frequency of WR90 waveguide }(8.20- \\
12.4 \mathrm{GHz} \text { ) terminated with a standard waveguide connector at } \\
\text { power levels from } 10 \mathrm{~mW} \text { to } 1 \mathrm{~W}\end{array}$ & $(*)$ \\
\hline $201.911 a-2$ & Each additional power level at the same frequency as for 201.911a- & $(*)$ \\
\hline $201.911 z$ & Special calibrations not covered by the above schedule & $(*)$ \\
\hline
\end{tabular}

* As fees have not been fixed for these services, charges will be made for actual costs incurred. Upon request, estimates will be furnished for specific tasks which should provide a close approximation of actual costs. 
201.912 Coaxial bolometer units, continous wave, low-level power.

\begin{tabular}{|c|c|c|}
\hline ITEM & DESCRIPTION & FEE \\
\hline $201.912 \mathrm{a}-1$ & $\begin{array}{l}\text { Determination of effective efficiency of a coaxial bolometer unit at } \\
\text { a single frequency in the range } 4^{* *} \text { to } 10 \mathrm{GHz} \text { and a power level } \\
\text { of } 10 \mathrm{~mW} \text {. Bolometer unit must be fitted with male Type } \mathrm{N} \\
\text { connector and thermistor-type element of nominal operating } \\
\text { resistance of } 200 \mathrm{ohms}\end{array}$ & $(*)$ \\
\hline $201.912 \mathrm{a}-20$ & $\begin{array}{l}\text { Determination of effective efficiency of each additional coaxial } \\
\text { bolometer unit at the same frequency** as for } 201.912 \mathrm{a}-1\end{array}$ & $\left(^{*}\right)$ \\
\hline $201.912 z$ & Special calibrations not covered by the above schedule & $(*)$ \\
\hline
\end{tabular}

* As fees have not been fixed for these services, charges will be made for actual costs incurred. Upon request, estimates will be furnished for specific tasks which should provide a close approximation of actual costs.

For measurements on coaxial bolometer units below $4 \mathrm{GHz}$, see Section 201.821 .

\subsection{Waveguide reflectors (mismatches), reflection coefficient magnitude.}

(a) Reflection coefficient measurements are made on reflectors producing a reflection coefficient magnitude in the range of 0.024 to 0.2 .

(b) Reflectors must be fitted with standard types of waveguide flanges. The faces of these flanges should be machined flat and smooth and should not contain protrusions or indentations. The connecting holes of the flange should be symmetrically and accurately aligned to the rectangular waveguide opening.

\begin{tabular}{|c|c|c|}
\hline ITEM & DESCRIPTION & FEE \\
\hline & $\begin{array}{l}\text { Measurement of reflection coefficient magnitude of reflector at a } \\
\text { single frequency of the following waveguide sizes terminated } \\
\text { with standard waveguide connectors: }\end{array}$ & \\
\hline $201.920 a-1$ & WR90 (8.20-12.4 GHz) & $(*)$ \\
\hline $201.920 a-2$ & WR62 (12.4-18.0 GHz) & $(*)$ \\
\hline $201.920 \mathrm{a}-3$ & WR137 (5.85-8.20 GHz) & $(*)$ \\
\hline $201.920 \mathrm{a}-4$ & WR112 (7.05-10.0 GHz) _.-. & $(*)$ \\
\hline $201.920 a-5$ & WR187 (3.95-5.85 GHz) & $(*)$ \\
\hline $201.920 \mathrm{a}-20$ & $\begin{array}{l}\text { Measurement of reflection coefficient magnitude of each additional } \\
\text { reflector at the same frequency as for } 201.920 \mathrm{a}-1 \text { to } 201.920 \mathrm{a}-5 \text {. }\end{array}$ & $\left({ }^{*}\right)$ \\
\hline $201.920 z$ & Special calibrations not covered by the above schedule & $(*)$ \\
\hline
\end{tabular}

* As fees have not been fixed for these services, charges will be made for actual costs incurred. Upon request. estimates will be furnished for specific tasks which should provide a close approximation of actual costs. 


\subsection{Cavity wavemeters, frequency measurement.}

(a) Frequency measurements are made on fixed or variable cavity wavemeters of either the reaction (one-port) type or the transmission (two-port) type.

(b) Frequency measurements are made on fixed or variable cavity wavemeters having coaxial terminals with Type $\mathrm{N}$ connectors (male or female) in the frequency range of 1000 $\mathrm{MHz}$ to $10 \mathrm{GHz}$.

(c) Frequency measurements are made on fixed or variable cavity wavemeters having standard type waveguide terminals in the frequency range of 2.6 to $90 \mathrm{GHz}$.

\begin{tabular}{|c|c|c|}
\hline ITEM & DESCRIPTION & FEE \\
\hline $201.930 \mathrm{a}$ & Measurement of resonance frequency of fixed cavity wavemeter --- & $(*)$ \\
\hline $201.930 b$ & $\begin{array}{l}\text { Setting of adjustable cavity wavemeter at prescribed resonance } \\
\text { frequency }--\end{array}$ & $(*)$ \\
\hline $201.930 \mathrm{c}-1$ & $\begin{array}{l}\text { Calibration of dial setting versus resonance frequency of variable } \\
\text { cavity wavemeter at initial prescribed frequency }\end{array}$ & $(*)$ \\
\hline $201.930 c-2$ & $\begin{array}{l}\text { Calibration of dial setting versus resonance frequency of variable } \\
\text { cavity wavemeter at each prescribed frequency additional to the } \\
\text { initial frequency and on the same wavemeter as } 201.930 \mathrm{c}-1\end{array}$ & $(*)$ \\
\hline $201.930 \mathrm{z}$ & Special calibrations not covered by the above schedule & $(*)$ \\
\hline
\end{tabular}

* As fees have not been fixed for these services, charges will be made for actual costs incurred. Upon request, estimates will be furnished for specific tasks which should provide a close approximation of actual costs.

\subsection{Waveguide variable attenuators, attenuation difference.}

(a) Attenuation difference measurements are made on step or continuously variable attenuators, usually with the zero dial setting used as the reference position.

(b) Attenuation measurements are made for attenuation values from 0 to $50 \mathrm{~dB}$. This range of attenuation values can be extended to $70 \mathrm{~dB}$ in some frequency ranges.

(c) Variable attenuators should have a repeatability of dial setting better than \pm 0.1 dB.

(d) Variable attenuators should have a VSWR less than 1.1 at each waveguide port.

\begin{tabular}{c|c|c}
\hline ITEM & DESCRIPTION & FEE \\
\hline & $\begin{array}{l}\text { Measurement of attenuation difference of direct-reading variable } \\
\text { attenuator at an initial prescribed dial setting at a single fre- } \\
\text { quency of the following waveguide sizes terminated with stand- } \\
\text { ard waveguide connectors: }\end{array}$ & \\
$201.940 \mathrm{a}-1$ & WR284 (2.60-3.95 GHz) & $(*)$ \\
\hline
\end{tabular}

* As fees have not been fixed for these services, charges will be made for actual costs incurred. Upon request, estimates will be furnished for specific tasks which should provide a close approximation of actual costs. 


\begin{tabular}{|c|c|c|}
\hline ITEM & DESCRIPTION & FEE \\
\hline $201.940 a-2$ & WR187 (3.95-5.85 GHz) & $(*)$ \\
\hline $201.940 \mathrm{a}-3$ & WR137 (5.85-8.20 GHz) & $(*)$ \\
\hline $201.940 \mathrm{a}-4$ & WR112 (7.05-10.0 GHz) & $(*)$ \\
\hline $201.940 a-5$ & WR90 $(8.20-12.4 \mathrm{GHz})$ & $(*)$ \\
\hline $201.940 a-6$ & WR62 (12.4-18.0 GHz) _-- & $(*)$ \\
\hline $201.940 a-7$ & WR42 (18.0-26.5 GHz) & $(*)$ \\
\hline $201.940 a-8$ & WR28 (26.5-40.0 GHz) & $(*)$ \\
\hline $201.940 a-9$ & WR430 (1.70-2.60 GHz) _- & $(*)$ \\
\hline $201.940 \mathrm{a}-20$ & 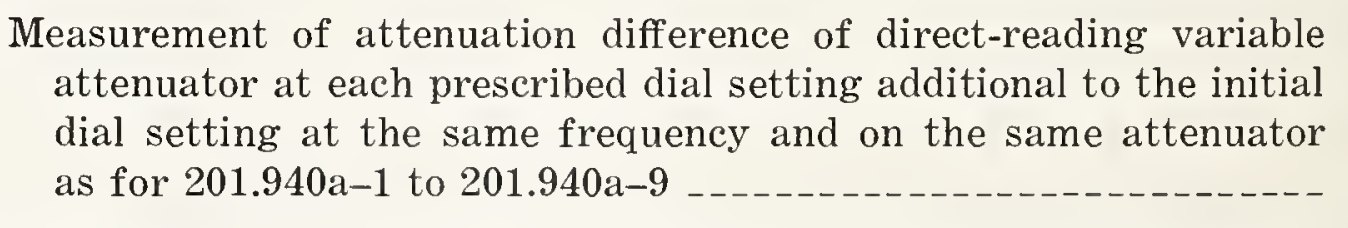 & $(*)$ \\
\hline $201.940 \mathrm{a}-21$ & $\begin{array}{l}\text { Measurement of attenuation difference of direct-reading variable } \\
\text { attenuator at an initial prescribed dial setting at a single fre- } \\
\text { quency as for } 201.940 \mathrm{a}-5 \text { to } 201.940 \mathrm{a}-6 \text {, by means of modulated } \\
\text { sub-carrier method to obtain greater accuracy of measurement }--\end{array}$ & $(*)$ \\
\hline $201.940 a-22$ & $\begin{array}{l}\text { Measurement of attenuation difference of direct-reading attenuator } \\
\text { at each prescribed dial setting additional to the initial dial setting } \\
\text { at the same frequency and on the same attenuator as } 201.940 \mathrm{a}- \\
21 \text {, by means of modulated sub-carrier method to obtain greater } \\
\text { accuracy of measurement } \\
\text { Calibration of dial setting versus attenuation difference for indirect- } \\
\text { reading variable attenuator at an initial prescribed attenuation } \\
\text { difference value at a single frequency of the following waveguide } \\
\text { sizes terminated with standard waveguide connectors: }\end{array}$ & $(*)$ \\
\hline $201.940 b-1$ & WR284 (2.60-3.95 GHz) & $(*)$ \\
\hline $201.940 \mathrm{~b}-2$ & WR187 (3.95-5.85 GHz) & $(*)$ \\
\hline $201.940 \mathrm{~b}-3$ & WR137 (5.85-8.20 GHz) & $(*)$ \\
\hline $201.940 \mathrm{~b}-4$ & WR112 (7.05-10.0 GHz) $\ldots$ & $(*)$ \\
\hline $201.940 \mathrm{~b}-5$ & WR90 (8.20-12.4 GHz) _--- & $(*)$ \\
\hline $201.940 b-6$ & WR62 (12.4-18.0 GHz) $\ldots \ldots$ & $(*)$ \\
\hline $201.940 \mathrm{~b}-7$ & WR42 (18.0-26.5 GHz) & $(*)$ \\
\hline $201.940 \mathrm{~b}-8$ & WR28 (26.5-40.0 GHz) $\ldots$ & $(*)$ \\
\hline $201.940 b-9$ & WR430 (1.70-2.60 GHz) & $(*)$ \\
\hline
\end{tabular}

*As fees have not been fixed for these services, charges will be made for actual costs incurred. Upon request, estimates will be furnished for specific tasks which should provide a close approximation of actual costs. 


\begin{tabular}{|c|c|c|}
\hline ITEM & DESCRIPTION & FEE \\
\hline $201.940 \mathrm{~b}-20$ & $\begin{array}{l}\text { Calibration of dial setting versus attenuation difference for indi- } \\
\text { rect-reading variable attenuator at each prescribed attenuation } \\
\text { difference value additional to the initial attenuation difference } \\
\text { value at the same frequency and on the same attenuator as } \\
201.940 \mathrm{~b}-1 \text { to } 201.940 \mathrm{~b}-9\end{array}$ & $(*)$ \\
\hline $201.940 b-21$ & $\begin{array}{l}\text { Measurement of attenuation difference of indirect-reading variable } \\
\text { attenuator at an initial prescribed dial setting at a single fre- } \\
\text { quency as for } 201.940 \mathrm{~b}-5 \text { to } 201.940 \mathrm{~b}-6 \text {, by means of modulated } \\
\text { sub-carrier method to obtain greater accuracy of measurement }\end{array}$ & $(*)$ \\
\hline $201.940 b-22$ & $\begin{array}{l}\text { Measurement of attenuation difference of indirect-reading attenu- } \\
\text { ator at each prescribed dial setting additional to the initial dial } \\
\text { setting at the same frequency and on the same attenuator as } \\
201.940 \mathrm{~b}-20 \text {, by means of modulated sub-carrier method to obtain } \\
\text { greater accuracy of measurement }\end{array}$ & $(*)$ \\
\hline $201.940 \mathrm{z}$ & Special calibrations not included in the above schedule & $(*)$ \\
\hline
\end{tabular}

* As fees have not been fixed for-these services, charges will be made for actual costs incurred. Upon request, estimates will be furnished for specific tasks which should provide a close approximation of actual costs.

201.941 Waveguide fixed attenuators, insertion loss.

(a) Insertion loss measurements are made on fixed two-port attenuators.

(b) Insertion loss measurements are made for insertion loss values from 0 to $50 \mathrm{~dB}$. This range of attenuation values can be extended to $70 \mathrm{~dB}$ in some frequency ranges.

(c) Fixed attenuators should have a VSWR less than 1.1 at each waveguide port.

\begin{tabular}{|c|c|c|}
\hline ITEM & DESCRIPTION & FEE \\
\hline & $\begin{array}{l}\text { Measurement of insertion loss of fixed attenuator at a single fre- } \\
\text { quency of the following waveguide sizes terminated with stand- } \\
\text { ard waveguide connectors: }\end{array}$ & \\
\hline $201.941 \mathrm{a}-1$ & WR284 (2.60-3.95 GHz) & $(*)$ \\
\hline $201.941 \mathrm{a}-2$ & WR187 (3.95-5.85 GHz) & $(*)$ \\
\hline $201.941 a-3$ & WR137 (5.85-8.20 GHz) & $(*)$ \\
\hline $201.941 \mathrm{a}-4$ & WR112 (7.05-10.0 GHz) & $(*)$ \\
\hline $201.941 a-5$ & WR90 (8.20-12.4 GHz) _ & $(*)$ \\
\hline $201.941 \mathrm{a}-6$ & WR62 (12.4-18.0 GHz) & $(*)$ \\
\hline $201.941 \mathrm{a}-7$ & WR42 (18.0-26.5 GHz) & $(*)$ \\
\hline
\end{tabular}

* As fees have not been fixed for these services, charges will be made for actual costs incurred. Upon request, estimates will be furnished for specific tasks which should provide a close approximation of actual costs. 


\begin{tabular}{|c|c|c|}
\hline ITEM & DESCRIPTION & FEE \\
\hline $201.941 \mathrm{a}-8$ & WR28 $(26.5-40.0 \mathrm{GHz})$ & $(*)$ \\
\hline $201.941 a-9$ & WR430 (1.70-2.60 GHz) & $(*)$ \\
\hline $201.941 \mathrm{a}-20$ & $\begin{array}{l}\text { Measurement of insertion loss of additional fixed attenuator at the } \\
\text { same frequency as for } 201.941 \mathrm{a}-1 \text { to } 201.941 \mathrm{a}-9\end{array}$ & $(*)$ \\
\hline $201.941 z$ & Special calibrations not included in the above schedule & $(*)$ \\
\hline
\end{tabular}

* As fees have not been fixed for these services, charges will be made for actual costs incurred. Upon request, estimates will be furnished for specific tasks which should provide a close approximation of actual costs.

\subsection{Waveguide noise sources, effective noise temperature.}

(a) Effective noise temperature measurements are made on waveguide noise sources (usually a gas-discharge tube) under conditions of continuous, unmodulated operation in the range 1000 to $300,000{ }^{\circ} \mathrm{K}$ (excess noise ratio range 3.8 to $30 \mathrm{~dB}$ ).

(b) The direct current required for normal operation of the gas-discharge tube should not exceed $300 \mathrm{~mA}$ but should be sufficient to prevent excessive plasma oscillations.

(c) The waveguide noise source must have an input VSWR no greater than 1.2.

(d) The gas-discharge tube should be secure in the mount, and the output port of the unit should be terminated with a matched load.

\begin{tabular}{|c|c|c|}
\hline ITEM & DESCRIPTION & FEE \\
\hline & $\begin{array}{l}\text { Measurement of effective noise temperature of noise source at a } \\
\text { single frequency of the following waveguide sizes terminated } \\
\text { with standard waveguide connectors: }\end{array}$ & \\
\hline $201.950 a-1$ & WR90 (8.20-12.4 GHz) -- & $(*)$ \\
\hline $201.950 a-2$ & WR62 (12.4-18.0 GHz) & $(*)$ \\
\hline $201.950 \mathrm{a}-20$ & $\begin{array}{l}\text { Measurement of effective noise temperature of each additional noise } \\
\text { source at the same frequency as for } 201.950 \mathrm{a}-1 \text { to } 201.950 \mathrm{a}-2\end{array}$ & $(*)$ \\
\hline $201.950 \mathrm{z}$ & Special calibrations not covered by the above schedule & $(*)$ \\
\hline
\end{tabular}

"As fees have not been fixed for these services, charges will be made for actual costs incurred. Upon request, estimates will be furnished for specific tasks which should provide a close approximation of actual costs. 


\title{
CALIBRATION AND TEST SERVICES OF THE
}

\author{
NATIONAL BUREAU OF STANDARDS
}

Notice of Change to NBS Misc. Publ. 250, 1965 Edition*

\section{Change 14}

Mass and Volume: All schedules under Mass and Volume, namely 202.620 through 202.628, which appear on pages 79-88 of MP 250, are cancelled and should be deleted. The fees for these services, listed on pages 127-128 of MP 250, are also to be deleted. These services have been revised as shown in schedules 202.630 through 202.633, which replace the previous Mass and volume schedules. The text of the new schedules is given in this Insert.

This revision increases the scope of the services provided in the areas of mass and volume measurements. The charges for all services in these measurement areas are computed on the basis of actual cost (i.e., direct labor costs plus established overhead charges).

The following is a list of the schedules whose text is given below:

202.630

202.631

202.632

202.633
General.

Mass and Volume

Reference standards of mass.

Reference standard volumetric apparatus.

Density determinations of liquids and sc ids.

\section{Mass and Volume}

202.630 General.

(a) The Mass and Volume Section provides services to support the segments of the national measurement system which rely directly or indirectly on mass measurements. These services include the calibration of reference standards of mass, of glass and metal volumetric reference standards, and of reference standard hydrometers, also the density determinations of solids and liquids, and are offered only if suitable service is not otherwise available. In order to provide prompt and useful service, the acceptance of items for calibration or test is based on discussions with each user to determine details necessary to meet measurement and delivery requirements, and on inspection of the item at the

\footnotetext{
*Changes should be made immediately in your copy of NBS Misc. Publ. 250, 1965 Edition. Additional copies of the insert are available from NBS Office of Technical Information and Publications.
} 
March 22, 1967

Bureau with reference to its suitability for the usage intended. Sections 202.631, 202.632, and 202.633 apply to the calibration (or test) most frequently requested in each measurement area. The services of the Section, however, are not limited to these specific items. Inquiries are invited concerning other measurement problems in the above areas.

(b) Additional services are available which include the formulation of procedures (1) to establish a quantitative measure of the state of statistical control in the user's laboratory for measurement processes which involve mass, (2) to enable the user to monitor his calibration process, and (3) to assist in coordinated evaluation of the results. The nature of these services is described in NBS Technical Note 288 "Measurement Philosophy of the Pilot Program for Mass Calibration".l

(c) Arrangements for calibration (or test) must be completed before shipping apparatus to the Bureau. While all of the work of the section is on an actual cost basis, subject to a $\$ 25.00$ minimum charge, a mutual agreement on the work to be performed generally results in substantial savings for the user. Detailed packing and shipping instructions are available on request. Items not accepted for calibration or test will be returned, the cost of inspection or the minimum charge being applicable.

(d) The results of a calibration (or test) will be reported either in a National Bureau of Standards Report of Calibration or Test (which in many cases is prepared by a computer program), a continuation report, or a letter report. In each of these, the values reported are accompained by an appropriate estimate of uncertainty (allowance for random and systematic errors) as determined by an analysis of the specific measurement process. A continuation report is used for those items submitted for recalibration on which preliminary tests indicate that no significant changes have occurred since the last calibration. A letter report is usually used to report a test for compliance with a specification which states limits for the departure of the actual value from nominal.

\subsection{Reference Standards of Mass}

(a) The Bureau's calibration af reference standards of mass provides extensions of the mass unit embodied in the NBS standards of mass. A normal calibration consists of establishing a mass value, and the appropriate uncertainty for that value, for each weight which has been designated to be a reference standard. It is desirable, but not necessary, that a weight should meet the adjustment tolerances established for classes $A, B, M$, S, or $S-1$.

(b) Individual weights, or sets of weights, in the range of 30 kilograms to 1 milligram or 50 pounds to 1 micropound in decimal subdivisions, which are designated as reference standards, must be of design, material, and surface finish comparable to but not necessarily limited to present Class A, B, M, S, or S-1 as described in Circulars 3 and 547 in Volume III of NBS Handbook 77.2 Design, material, and surface finish of large mass standards (over $50 \mathrm{lb}$ to $50,000 \mathrm{lb}$ ) must be compatible with the intended usage. For these large mass standards, an adjustment with reference to a nominal or desired value can be included as a part of the calibration procedure.

(1) Available at 30 cents per copy from Superintendent of Documents, U. S. Government Printing Office, Washington, D. C. 20402.

(2) Vol. 111 (Optics, Metrology, and Padiation) of NES Handbook 77 is available at $\$ 7.00$ per copy from Superintendent of Documents, U. S. Government Printing Office, Washington, D. C. 20402. 
(c) The values of true mass (and an apparent mass correction) included in the report will be determined by using computed volumes based either on the manufacturer's statement of density of the material, on the density computed from measured volumes, or, in the absence of this information, on estimated density values. The apparent mass corrections are computed for $20^{\circ} \mathrm{C}$ with réference to Normal Brass (density $8.4 \mathrm{~g} / \mathrm{cm}^{3}$ at $0^{\circ} \mathrm{C}$, volume coefficient of expansion $0.000054 / \mathrm{C}^{\circ}$ in an ideal air density of $1.2 \mathrm{mg} / \mathrm{cm}$. Apparent mass corrections to any other basis can be furnished if requested.

(d) For periodic recalibrations of reference mass standards, the user need only measure differences between weights or groups of weights within a set and compare them with computed differences. As long as the agreement is within allowable limits, the values can be considered constant within the precision of the comparison process. Mass standards which are submitted to the Bureau for recalibration are frequently tested in this manner. If these tests indicate that no significant changes have occurred, a continuation report so stating and referring to the previous NBS Report of Calibration will be issued.

\begin{tabular}{|c|c|c|}
\hline Item & \multicolumn{1}{|c|}{ Description } & Fee \\
\hline 202.6312 & $\begin{array}{l}\text { For calibration of reference mass stan- } \\
\text { dards or supporting services described } \\
\text { in TN288, fees will be computed on a } \\
\text { cost basis. }\end{array}$ & \\
\hline
\end{tabular}

\subsection{Reference Standard Volumetric Apparatus}

(a) The procedure almost universally used for testing glass volumetric apparatus is to weigh the amount of distilled water contained or delivered with reference to the graduations marked on the instrument, the volume being computed from the density of the water (for tables see NBS Circular 19, available on request 4 ). The quality of the markings and the care exercised in reading or setting the liquid level are major factors in test calibration and usage. The Bureau will normally accept instruments for calibration which have volumes in the range of $1 \mathrm{~mm}$ to 1 gallon, and which essentially conform to requirements contained in NBS Circular 602 "Testing of Glass Volumetric Apparatus" 5, Federal Procurement Specifications NNN-B-00789 (Buret, straight, precision), NNN-F-00395a (Pipet, volumetric), NNN-P00350a (Pipet, measuring), or NNN-F-00289a (Flask, volumetric), if such instruments are to be used as reference or transfer standards.

(1) Groups of blood pipets which are used as factory standards for quality control will be accepted for test, and values will be furnished in a letter report.

(3) See footnote 1.

(4) From the Mass and Volume Section, Institute for Basic Standards, National Bureau of Standards. Washington, D. C. 20234.

(5) Available at 20 cents per copy from Superintendent of Documents, U. S. Government Printing Office, Washington, D. C. 20402. 
(2) Suggested test procedures for the verification of the compliance of precision grade glassware with specifications and tolerances are available on request.

(b) The usual calibration procedure for metal volumetric apparatus consists of determining the value "to contain" or "to deliver" by either gravimetric means or by the use of transfer standards. The Bureau will normally accept instruments for calibration which have values in the range of 1 gill to 1000 gallons, which essentially comply with the specifications contained in NBS Monograph 62, "Testing of Volumetric standards" 6, and which are free from dents, bumps or scratches.

(1) While it is preferred that the zero index or the gage scale be adjusted and sealed prior to calibration, these operations can be incorporated into the calibration procedure if requested. Slicker plate type standards should be adjusted by the manufacturer.

\begin{tabular}{|c|l|l|}
\hline Item & \multicolumn{1}{|c|}{ Description } & Fee \\
\hline $202.632 \mathrm{z}$ & $\begin{array}{l}\text { For calibration of reference standard } \\
\text { volumetric apparatus, fees will be } \\
\text { computed on a cost basis. }\end{array}$ & \\
\hline
\end{tabular}

\subsection{Density determinations of liquids and solids}

(a) The usual procedure for determining the density of solids is hydrostatic weighing. At the Bureau liquid densities are usally determined by gravimetric methods. The picnometer can be filled at a specified temperature between $0^{\circ}$ and $70^{\circ} \mathrm{C}$. Other methods are available depending on the requirements. The Bureau will accept requests for density determinations if the need is critical, as in the support of scientific studies or standard sample programs. Limitations on the mass, physical dimensions or volume of the sample are available on request.

(b) Specific gravity hydrometers covering the range of 0.62 to 3 , and proof spirit hydrometers in the range of 0 to 200 proof which are designated reference standard hydrometers (used to test other hydrometers) are normally accepted for calibration. A limited number of other types of reference standard hydrometers will be accepted for multi-point calibration subject to a discussion of detailed request. Instruments accepted must essentially comply with the requirements of NBS Circular 555, "Testing of Iy drometers"?

\begin{tabular}{|c|l|l|}
\hline Item & \multicolumn{1}{|c|}{ Description } & Fee \\
\hline $202.633 \mathrm{z}$ & $\begin{array}{l}\text { For density determination of liquids } \\
\text { or solids or the calibration of ref- } \\
\text { erence standard hyarometers fees will } \\
\text { be computed on a cost basis. }\end{array}$ & \\
\hline
\end{tabular}

(6) Available at 15 cents per copy from Superintendent of Documents, U. S. Government Printing Office, Washington, D. C. 20402.

(7) Available at 10 cents per copy from Superintendent of Documents, U. S. Government Printing Office, Washington, D. C. 20402. 


\section{CALIBRATION AND TEST SERVICES OF THE \\ NATIONAL BUREAU OF STANDARDS}

Notice of Change to NBS Misc. Pub1. 250, 1965 Edition*

Dosimetry in High-Energy Electron Beams: This insert gives the text of a new schedule, 204.503, which describes a measurement service that has been added to the other radiation-physics measurements in Part 204 of MP 250 .

The new schedule is as follows:

204.503 Dosimetry in high-energy electron beams.

(a) The Bureau will prepare and mail dosimeters to users requesting assistance with absorbed-dose measurements in high-energy electron beams. The dosimeters employed will consist of ferrous sulfate (Fricke) solution in radiation-resistant silica-glass spectrophotometer cells. The users will expose all but two of the furnished dosimeters to between 5,000 and 8,000 rads at electron energies between 5 and $50 \mathrm{MeV}$, employing the exposure geometry (field size, phantom, position of dosimeter in phantom) given in the "Protocol for Dosimetry of High-Energy Electrons," Physics in Medicine and Biology 11,505 (1966).

(b) After irradiation, the dosimeters will be returned to the Bureau for spectrophotometric evaluation of the ferric-ion concentration in terms of absorbed dose in the phantom, using the G-value given in the Protocol. The results of this evaluation will be reported to the users.

(c) The Bureau plans to provide this service four times a year starting on or about July 1, 1967, and to offer it quarterly thereafter.

\footnotetext{
*Changes should be made immediately in your copy of NBS Misc. Publ. 250, 1965 Edition. Additional copies of the insert are available from NBS office of Technical Information and Publications.
} 


\begin{tabular}{|c|l|c|}
\hline Item & \multicolumn{1}{|c|}{ Description } & Fee \\
\hline $204.503 \mathrm{a}$ & $\begin{array}{l}\text { Preparing and shipping four Fricke } \\
\text { dosimeters, two as controls, and } \\
\text { two for irradiation; evaluating } \\
\text { the ferric-ion content in terms } \\
\text { of absorbed dose in the phantom; } \\
\text { reporting the test results. }\end{array}$ & $\star \star \$ 250.00$ \\
\hline $204.503 \mathrm{~b}$ & $\begin{array}{l}\text { For an additional fee an addi- } \\
\text { tional Fricke dosimeter may be } \\
\text { supplied and its ferric-ion } \\
\text { content evaluated after irrad- } \\
\text { iation. }\end{array}$ & $\star \star 50.00$ \\
\hline
\end{tabular}

* Through a subsidy provided by the National Center for Radiological Health, Public Health Service, Department of Health, Education, and Welfare, a reduction in fee may become available to all medical users interested in a check of the absorbed dose calibrations employed in high energy electron beam therapy. For details contact the Dosimetry Section, Radiation Physics Division, National Bureau of Standards, Room C-209, Radiation Physics Building, Washington, D. C. 20234.

(This announcement is from the Federal Register, Vol. 32, No. 45-Wednesday, March 8, 1967) . 
U. S. Department of Commerce National Bureau of Standards

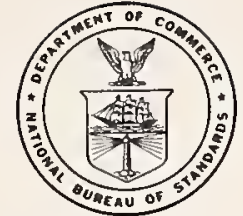

INSERT 8

Apri 1 17, 1967

Page 1 of 1

CALIBRATION AND TEST SERVICES OF THE

NATIONAL BUREAU OF STANDARDS

Notice of Change to NBS Misc. Pub1. 250, 1965 Editinn*

\begin{abstract}
Hath
\end{abstract}
Change 16

Electricity, Microwave Region: Insert 8 describes (See table below) two new calibration services that have been added to section 201.912, "Coaxial bolometer units, continuous wave, low-level power." This sheet should be inserted after page 20 of Insert 5, where the most recent revision of section 201.912 is given.

Both of the new services are for the measurement of effective efficiency of coaxial bolometer units fitted with 14-mm precision coaxial connectors over a continuous frequency range from 4 to 8.5 GHz. Use of $14-m m$ precision coaxial connectors permits greater accuracy of measurement of radio frequencies than with the older type $\mathrm{N}$ connectors. At present the measurements are available at a nominal power of 10 milliwatts and for bolometer units fitted with thermistor-type elements having a nominal operating resistance of 200 ohms.

\begin{tabular}{|c|c|c|}
\hline Item & Description & Fee \\
\hline $201.912 a-2$ & $\begin{array}{l}\text { Determination of effective efficiency of } \\
\text { a coaxial bolometer unit at a single fre- } \\
\text { quency in the range of } 4 \text { to } 8.5 \mathrm{GHz} \text { and } \\
\text { a power level of } 10 \mathrm{mw} \text { Bolometer unit } \\
\text { must be fitted with a } 14 \mathrm{~mm} \text { general pre- } \\
\text { cision connector and a thermistor-type } \\
\text { element for nominal operating resistance } \\
\text { of } 200 \text { ohms. }\end{array}$ & $(* *)$ \\
\hline $201.912 a-21$ & $\begin{array}{l}\text { Determination of effective efficiency of } \\
\text { each additional coaxial bolometer unit } \\
\text { at the same frequency as for } 201.912 \mathrm{a}-2 \text {. }\end{array}$ & $(* *)$ \\
\hline
\end{tabular}

*Changes should be made immediately in your copy of NBS Misc. Pub1. 250, 1965 Edition. Additional copies of the insert are available from NBS office of Technical Information and Publications, Washington, D. C. 20234.

**As fixed prices have not been established for these services, charges will be made for actual costs incurred. Upon request, estimates will be furnished for specific tasks which should provide a close approximation of actual costs.

(1) For measurements on coaxial bolometer units below $4 \mathrm{GHz}$, see section 201.821 (p. 6 of lnsert 5). (2) "Precision Coaxial Connectors," Recommendations of the IEEE I-M Group Subcommittee on Precision Coaxial Connectors, Revised July 10, 1966. This report describes the mechanical, electrical, and environmental requirements for precision coaxial connectors. It is available upon request from: Chairman, IEEE G-1M Technical Committee on High Frequency Instruments and Measurements, The lnstitute of Electronic Engineers, Inc., 345 East 47 th Street, New York, New York 10017.

(This announcement is from the Federal Register, Vol. 32, No. 65-Wednesday, April 5, 1967 ) 


\title{
CALIBRATION AND TEST SERVICES OF THE
}

\author{
NATIONAL BUREAU OF STANDARDS
}

Notice of Change to NBS Misc. Publ. 250, 1965 Edition*

\section{Change 17}

Electricity, High-Frequency Region: Insert 9 gives the text of two new Sections, 201.870 and 201.871, describing a new service for the measurement of phase-angle shift by insertion of coaxial phase shifters (precision air- or dielectric-filled line) and variable-type coaxial phase shifters. The initial service is at a frequency of $30 \mathrm{MHz}$.

This sheet should be inserted after page 20 of Insert 5 which gives the most recent over-all revision of the services provided by the NBS Radio Standards Laboratory.

\subsection{Coaxial phase shifters, precision air- or dielectric-filled line.}

(a) Phase shifters are calibrated by insertion into a 50 -ohm coaxial line. A VSWR of any reasonable magnitude for the phase shifter is acceptable; the measurement uncertainty will be adjusted to the VSWR relation.

(b) The phase shifter must be fitted with Type N or TNC connectors or precisiontype connectors.

\begin{tabular}{|c|l|c|c|}
\hline Item & \multicolumn{1}{|c|}{ Description } & Fee \\
\hline $201.870 \mathrm{a}$ & $\begin{array}{l}\text { Measurement of phase angle shift by insertion of a coaxial } \\
\text { phase shifter (precision air- or dielectric-filled line) in } \\
\text { coaxial line at MHz. }\end{array}$ & $\left(^{* *}\right.$ \\
\hline $201.870 \mathrm{z}$ & \begin{tabular}{l} 
Special calibrations not covered by the above schedule. \\
\hline
\end{tabular}
\end{tabular}

*Changes should be made immediately in your copy of NBS Misc. Publ. 250, 1965 Edition. Additional copies of the insert are available from NBS Office of Technical Information and Publications, Washington, D. C. 20234.

**As fixed prices have not been established for these services, charges will be made for actual costs incurred. Upon request, estimates will be furnished for specific tasks which should provide a close approximation of actual costs. 


\subsection{Coaxial phase shifters, variable type.}

(a) Phase shifters are calibrated by insertion into a 50 -ohm coaxial line. A VSWR of any reasonable magnitude for the phase shifter is acceptable; the measurement uncertainty will be adjusted to the VSWR relation.

(b) Measurements will be performed at any specified phase angle(s).

(c) Phase shifters should have a repeatability of setting better than 0.1 degree.

(d) The phase shifter must be fitted with Type $\mathrm{N}$ or TNC connectors or precisiontype connectors.

\begin{tabular}{|c|l|c|c|}
\hline Item & \multicolumn{1}{|c|}{ Description } & Fee \\
\hline $201.871 \mathrm{a}$ & $\begin{array}{l}\text { Measurement of phase angle shift at initial setting by } \\
\text { insertion of variable-type coaxial phase shifter in coaxial } \\
\text { line at MHz. }\end{array}$ & $\left(^{* *}\right)$ \\
\hline $201.871 \mathrm{~b}$ & $\begin{array}{l}\text { Measurement of phase angle shift at each setting additional } \\
\text { to the initial setting as for 201.87la. }\end{array}$ & $\left(^{* *}\right)$ \\
\hline $201.871 \mathrm{z}$ & $\begin{array}{l}\text { Special calibrations not covered by the above schedule. } \\
{ }^{*}\end{array}$ & $\left.{ }^{* *}\right)$ \\
\hline
\end{tabular}

**As fixed prices have not been established for these services, charges will be made for actual costs incurred. Upon request, estimates will be furnished for specific tasks which should provide a close approximation of actual coss. 


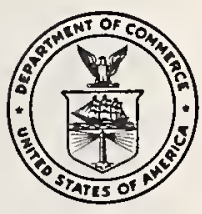

\section{CALIBRATION AND TEST SERVICES OF THE}

\section{NATIONAL BUREAU OF STANDARDS}

Notice of Change to NBS Misc. Publ. 250, 1965 Edition*

$:: 0:: 0:: 0:: 0:: 0:: 0:: 0:: 0:: 0:: 0:: 0:: 0:: 0:: 0:: 0:: 0:: 0:: 0:: 0:: 0:: 0:: 0:: 0:: 0:: 0::$

\section{Change 18}

Electricity, Microwave Region: Insert 10 gives the text of three new items, 201.910a-6, 201.9 $\frac{10 b-6,}{6}$ and $201.910 c-6$, which expand to an additional waveguide size (WR42: 18.0 to $26.5 \mathrm{GHz}$ ) the present service for measuring the effective efficiency and calibration factor of bolometercoupler units.

This sheet should be inserted after page 18 of Insert 5 , which gives the most recent over-all revision of the services provided by the NBS Radio Standards Laboratory.

Section 201.910 Waveguide bolometer units and bolometercoupler units, continuous wave, low-level power.

\begin{tabular}{|c|l|l|}
\hline Item & \multicolumn{1}{|c|}{ Description } & Fee \\
\hline $201.910 a-6$ & $\begin{array}{l}\text { Measurement of effective efficiency of bo- } \\
\text { lometer unit at a single frequency of the } \\
\text { following waveguide size terminated with } \\
\text { standard waveguide connector: WR42 (18.0- } \\
26.5 \text { GHz) }\end{array}$ & $(* *)$ \\
\hline $201.910 \mathrm{~b}-6$ & $\begin{array}{l}\text { Measurement of calibration factor of bo- } \\
\text { lometer unit at a single frequency of the } \\
\text { following waveguide size terminated with } \\
\text { standard waveguide connector: WR42 (18.0- }\end{array}$ & $(* *)$ \\
\hline 26.5 GHz) & $\begin{array}{l}\text { Measurement of calibration factor of bo- } \\
\text { lometer-coupler unit at a single frequen- } \\
\text { cy of the following waveguide size ter- } \\
\text { minated with standard waveguide connec- } \\
\text { tor: WR42 (18.0-26.5 GHz) }\end{array}$ & $(* *)$ \\
\hline
\end{tabular}

*Changes should be made immediately in your copy of NBS Misc. Publ, 250, 1965 Edition. Additional copies of the insert are available from NBS Office of Technical Information and Publications.

**As fixed prices have not been established for these services, charges will be made for actual costs incurred. Upon request, estimates will be furnished for specific tasks which should provide a close approximation of actual costs. 
U. S. Department of Commerce National Bureau of Standards

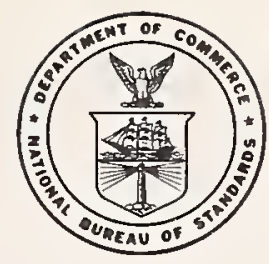

INSERT 11

June 25, 1967

Page 1 of 3

\section{CALIBRATION AND TEST SERVICES OF THE}

NATIONAL BUREAU OF STANDARDS

Notice of Change to NBS Misc. Publ. 250, 1965 Edition*

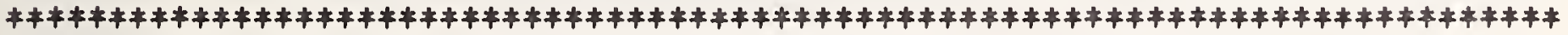

Change 19

Metrology: Insert 11 reports three changes in the schedules of part 202, Metrology:

(1) Section 202.108, Reflectometry, is deleted. The deleted section appeared on pages 55-56 of MP 250 .

(2) Items 202.114a and 202.114h of Section 202.114, Radiometry, are deleted.

(3) The text of Section 202.202 has been revised (see below) and the name of the section has been changed to "Photogrammetry". The title was formerly "Photographic Objectives" and the section appeared on pages 58-61 of MP 250 .

The revised text of Section 202.202, Photogrammetry, is as follows:

\subsection{Photogrammetry.}

The following information is pertinent to the tests a to $i$ in this schedule:

a. and b. This is a test of the definition characteristics of a lens. It is performed photographically. In general, if a lens yields satisfactory results when subjected to this test, it is probable that no additional test for lateral chromatic aberration is necessary.

c. This is a qualifying test for photographic objectives for aerial mapping cameras. It is a photographic test and the determinations are made for the plane of best average definition.

d. and $e$. The $f$-number is the ratio of the equivalent focal length of the lens to the diameter of the effective aperture.

$f$. This is a test of the platen of a precision aerial mapping camera which is the surface against which the film is held during exposure. It is a test to determine conformance to specifications requiring that the platen shall not depart from a true plane by more than \pm 12 microns $( \pm 0.0005$ in.).

*Changes should be made immediately in your copy of NBS Misc. Publ. 250, 1965 Edition. Additional copies of the insert are available from NBS Office of Technical Information and Publications, Washington, D. C. 20234. 
g. This is a test of a photographic objective mounted in a camera. It gives the same information as test $202.202 \mathrm{c}$ except for back-focal distance. It is preferable that these lens characteristics be determined for the lens as mounted in a barrel shutter but occasionally it is desirable to determine these quantities for the lens mounted in a camera. The shutter should be open when the camera is submitted for test.

h. This is a test of a lens-camera combination for photogrammetric mapping. It gives the departure of the principal point of auto-collimation from the center of collimation which is the intersection point of lines joining opposite pairs of collimation index markers. The radial distortion is determined with respect to the calibrated focal length of the lens.

This test cannot be performed on a camera having a detachable magazine which bears the collimation index markers. This is the preliminary test on a precision type camera to determine compliance with specification. If no provision has been made for ready adjustment of the collimation index markers and they are not aligned at $90^{\circ}$, the camera is returned for adjustments. If the $90^{\circ}$ condition is satisfied but no provision has been made for ready adjustment of the principal point with respect to the center of collimation, the camera is returned for adjustments.

i. If the principal point can be properly positioned with respect to the center of collimation by ready adjustment of the lens in a transverse direction or by ready movement of the collimation index markers, this is done in the course of the test. Following adjustment, pins are set to preserve the setting.

When a camera is submitted for test, the drill holes for the pins, a proper sized drill and reamer, and a sufficient number of pins to perform the doweling must accompany the camera. It is desired that roll pins be submitted for this task.

THE TABLE OF INDIVIDUAL ITEMS OF THIS

SCHEDULE IS GIVEN ON THE FOLLOWING PAGE 


\begin{tabular}{|c|c|c|}
\hline Item & Description & Fee \\
\hline $202.202 a$ & $\begin{array}{l}\text { Determination of resolving power at } 5^{\circ} \text { inter- } \\
\text { vals from center to edge of field for colli- } \\
\text { mated light at one aperture. }\end{array}$ & $\$ 97.00$ \\
\hline $202.202 b$ & Fee for each additional aperture. & 50.00 \\
\hline $202.202 c$ & $\begin{array}{l}\text { Determination of back-focal distance, equiva- } \\
\text { lent focal } \\
\text { power at } 5^{\circ} \text { intervals from the center to edge } \\
\text { of the field. } \\
\text { This is the test usually required for lenses } \\
\text { that are to be mounted in precision aerial } \\
\text { cameras. }\end{array}$ & 135.00 \\
\hline $202.202 d$ & $\begin{array}{l}\text { Determination of equivalent focal length and } \\
\text { true geometric f-number for one marked stop. }\end{array}$ & 78.00 \\
\hline $202.202 e$ & Fee for each additional stop. & 19.00 \\
\hline $202.202 f$ & $\begin{array}{l}\text { Determination of compliance of camera platen } \\
\text { with flatness requirements to } \pm 0.0005 \mathrm{in} \text {. }\end{array}$ & 28.00 \\
\hline $202.202 \mathrm{~g}$ & $\begin{array}{l}\text { Determination of calibrated focal length, } \\
\text { radial and tangential distortion, and re- } \\
\text { solving power at } 7.5^{\circ} \text { intervals from center to } \\
\text { edge of field for lens mounted in camera. }\end{array}$ & 185.00 \\
\hline $202.202 h$ & $\begin{array}{l}\text { Location of the principal point of auto- } \\
\text { collimation, check of } 90^{\circ} \text { condition for lens } \\
\text { mounted in camera, and radial distortion. }\end{array}$ & 165.00 \\
\hline $202.202 i$ & $\begin{array}{l}\text { Setting the principal point of auto- } \\
\text { collimation and } 90^{\circ} \text { condition, checking and } \\
\text { doweling for lens mounted in camera. }\end{array}$ & 135.00 \\
\hline $202.202 z$ & $\begin{array}{l}\text { For special tests not covered by the above } \\
\text { schedule, fees charged depend on the nature of } \\
\text { the test. }\end{array}$ & \\
\hline
\end{tabular}


U. S. Department of Commerce National Bureau of Standards

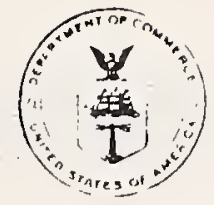

INSERT 12

June 30,1967

Page 1 of 18

\section{CALIBRATION AND TEST SERVICES OF THE}

\section{MATIONAL BUREAU OF STANDARDS}

Notice of Change to NBS Misc. Pub1. 250, 1965 Edition*

\section{$0:: 0:: 0:: 0:: 0:: 0:: 0:: 0:: 0:: 0:: 0:: 0:: 0:: 0:: 0:: 0:: 0:: 0:: 0:: 0:: 0:: 0:: 0:: 0:: 0$}

\section{Change 20}

General policies and procedures: Insert 12 is a revision of the whole of "Part 200 .. 'everal". It restates and expands the statement of policies and procedures relating to various measurement services, including calibrations and tests. The entire text of part 200, which appears on pages 5 through 10 of MP250, 1965 Edition, should be deleted; and this ilisert should be placed after page 4.

The revised text of Part 200 follows:

\section{PART 200 -- GENERAL}

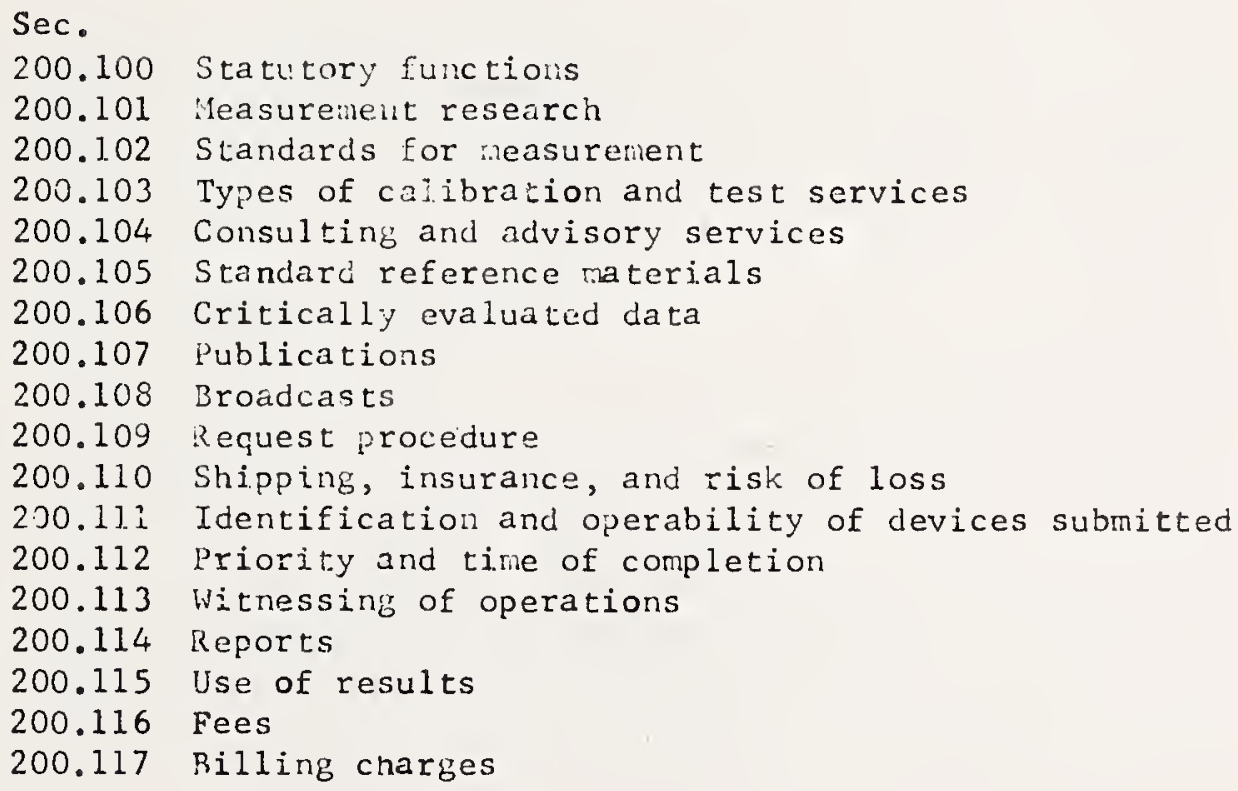

* Changes should be madé immediately in your copy of NBS Misc. Publ. 250, 1965 Edition. Additional copies of the insert are available from IBS Cffice of Techuical Information and Publications. 


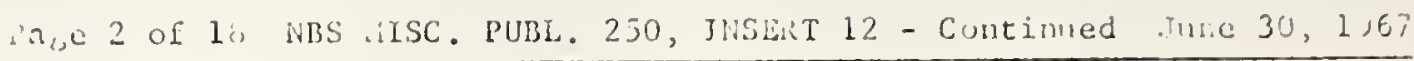

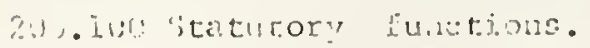

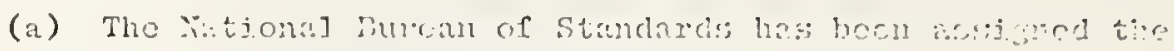
fol] owjug function (15 U. В.C. 27]-?.780):

(1) The cuitociy, mintenance, anci cleveloju:ont of the natirsal

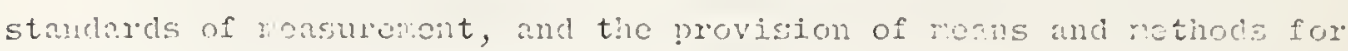

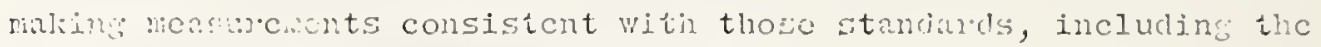

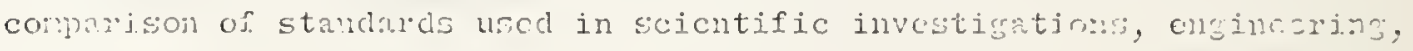

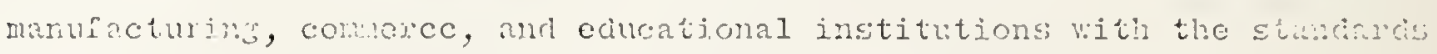
adopticd or recognized by the Goverment.

(2) The cloternination of physical constants and propertica cf Inatcrials wirn suen data axc of gicat importance to seicntific or Hamusciuling intorests and arc not to be obtaired of sufficient accisacy crsowicre.

(3) Tilc devclopront of netlods for icsing materials, mechanjs:is, and structures, and the testing of materials, supplics, and confowent, including itenis purchased for use of Go:crumcnt departronts and independent cstablisinents.

(4) Cooperation with other governiontal agencies and witis privatc organizations in the cstablishment of standari practices, incorporated in codes and specifications.

(5) Advisory service to Goverment agcncies on scicntific and technjical problen!s.

(6) Invention and development of devices to serve special necis of the Goverment.

(b) Thc calibration and testing activitics of the Lurcau stem from the functions in paragraph (a) (1) and (3) of this section. Theso nctivitios arc assigncd primarily to the NIS Institute for Basic Standards. Its progran providcs the central basis witilin the united states for a complete and consistcnt system of physical measurenent; coordinctes that systcu and the mcasurencit system of other nations; and furnishes esscntial services lcading to accurste and uniform phosical measurenents throughout the Tation's scicntific comitunty, industry, and cominerce.

(c) The provision of stanclaxd reference materials for salc to the publec is assigned to the Office of standred Reference Materials 
June 30, 1967 NBS MISC. PUBL. 250, INSERT 12 - Continued Page 3 of 18

200.100 (comtio)

of the Nisi Institute for Materials Rescarch. It evaluates the

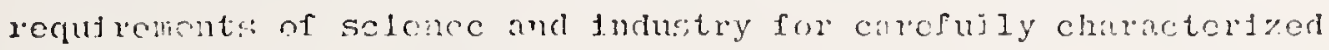

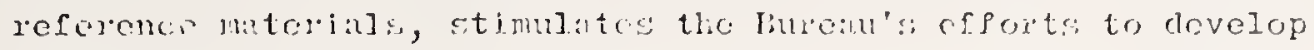
methods for production of nceded reference matexils and djects theix preillation and distribution. Tho itons avajlab]e under this prowam are Iisted ton Subchatier $D$ of this chapter.

(d) l'he provision of tecinical serrices to facilitite technjcil inmovation and indusirial uss of the results of rodern scicnce und techmolo..y is assigncr to the ins Institute for Apllied Tocuolons. The principal olcments of the Institute are

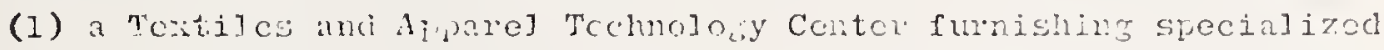
teohrical. scrvices to that industry; (2) tochucil divisions vijo? provide sorices in tosmology of moro genoral. arplicabiljty; (3) the clenringhotio for Fecical Sejentific and lecmical Information which promotes widest effective use by the scientific commity, industry, ancl comerce of current informatinn $1 \mathrm{n}$ all fields of Industrial technoloy; and (1) a Conter for Computer Scionces and Technolosy wich conducts rescarch and provides tochnical services designed to inprove cost effectiveness in the conduct ef agency programs through the use of computers and related techniciues.

200.101 Mensureinent research.

(a) The NBS Inetitute for Basic Standare's carries out the Bureau's function in developing an alcquate national systen of physical riensureront, and $j u$ providing reinted calibration services. Its staff contimal. Iy reviows the advances in scicnce and the trends in techmology, examines the measuronent potentialities of neriy discovered physical phenomena, and uses these to devise and improve standards, mensulug devices, and measurcront techniques. As neri requirements appoar, there are continual shifts of program emphasis to mect the most urgent neels for the mensurerent of additional quantitios, extended ranges, or improved accuracies.

(b) The basic research and developunt activities of the Bureau are primarily funded by diect appropriations, and are aimed 


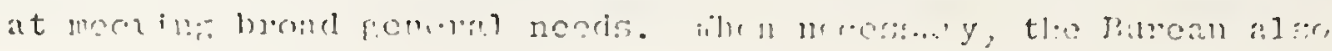

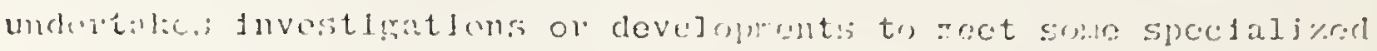

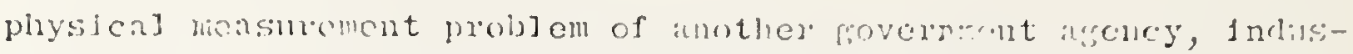

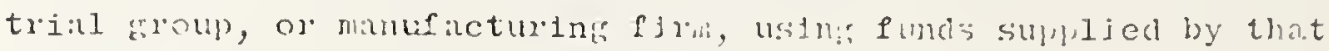
orkranization.

\subsection{Standireds for neasurement.}

(a) An international treaty, the retric Combontion, wis.s signed by 18 comtintes in 1875. In lug: the linited statcs estishlished prototype in. 27 of the 1nternitional lovior bas and prototype No. 20 of the international kilnerin.: as lajted states prototyje Standiads for length and mass. liepresentaives of mny of the 8 r nations now alhering to this treaty meet poriclicaliy, in tho cencrul Conference of livimlin and hensures, to conside" detailed propolinls concernirg international standards for physical ronsurci..ont. The Ilth Conference (1260) redefined the meter in tems of ravelengths of krypton S6 light, and agreed to adopt six linits to serve as a practical base for an Intexmational Syston of Inits (abbreviated SI from the Frencin, Systine Intemational) - kilograr, neter, second, degree kelvin, ampere, and candela. These are arbitraxily chosen but precisely dcfined magnitudes of six quantities of the physical world - rass, length, time, temperature, electric current and luminous intensity, respectively - wich are assigned unitary value in the International System. The units of the English System pound, Inch, second, degree Fahremicit, etc. - and of other systers of units are relatec to the SI units by arrect-upon conversion factors. Consistent units for all other physical quantities needed by science and technology can be derived from, and their numerical values are fixed by; these SI units.

The SI units for the six quantities are defired as follows: (1) In terms of a prototype object:

(1.1) Miss: The kilogran is the mass of a platinim-1ridfun cylinder preserved at the Intermational Bureau of lietglts and ieasures in Sevres, France. Prototype No. 20 is kept at NBS; equivlont prototypes are kept by other countries. 
$200.102(\operatorname{contc})$

(2) In terms of maturi fhenomenu:

(2.I) Ienetis: 'we meter is the leneth of exactly $1,650,763.73$

wavelenetlis of raliation in vacum corresponding to the unporturbed transition between the levels $2 \mathrm{p}_{10}$ and $5 \mathrm{~d}_{5}$ of the atom of krypton 86 , the orance-reil lise.

(2.2) Tine interval: The second ros J bug clefined as $1 / 36400$ of the tine required in an ayerare complete rotntion of the earth on its axis with respect to the sur. This Iod to tic univereal tine scale (UT). Socaus of the slight slowins of the ewh's average rotation rate ( $f r_{0,1} 5$ to 6 ms per year, eacin yeir), and other larger randoril fluctutions, tho universaj scond thus defined is not a constant. The ilth Cunferenco ( 1560 ) ratified the following definition: "the second is the fruction $1 / 31,556,025.9717$ of the troptcul year for Jaruary 0,1900 at $1.20^{\circ} \mathrm{cloch}$ cphemeris time." The lath Conference (1964) authorized the destgnation of an atonic standard of frequency to be used temporarliy for the plysical measurement of time. The standard desigrated is "the trinsition between the hyperfine levels $F=4, M=0$, inul $F=3$, il $=0$ of the ground state ${ }^{2} \mathrm{~S}$ of the cesium 133 atom not perturbed by external fields, and the value 9,192,631,770 hertz is asslgned to the frequency of this transition." Experimental evidence indicates that the two alternative definitions of the second are consistent rithin expected uncertainties.

(2.3) Temerature: The degree kelvin is $1 / 273.16$ of the thermodynamic tcrperature range between the triple point of water and absolute zero.

(2.4) Electric Current: The ampere is that constant current which If maintained in two straight parallel conductors of infinite length, of negligible circular sections, and placed I nieter apart in a vacuum, would froduce between these conductors a force equal to $2 \mathrm{x}$ $10^{-7}$ newton per meter of length.

(2.5) Luminous intensity: The candela is the luminous intensity of $1 / 60$ of one sriare centimeter of projected area of a blackbody radiator at the temperature of freezing platinum. 
$2 \cdot \cdots \cdot .202$ (contd.)

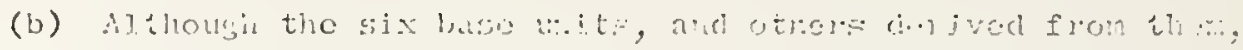

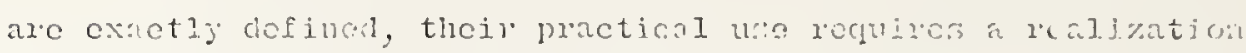
throunh the develonment of accurste neasurenent standarels. Vicasure-

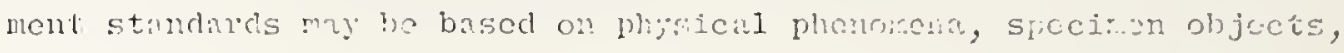

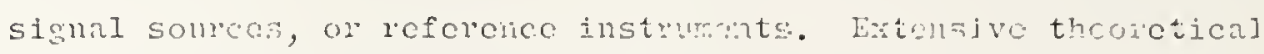

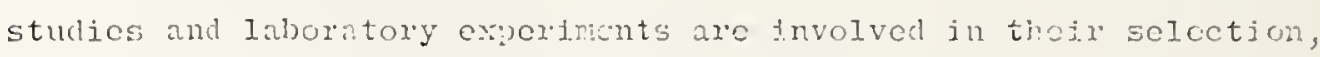
desisn, construction, and operation.

It will be noted that a kilogrut mass stanciarci cilin be calibrated

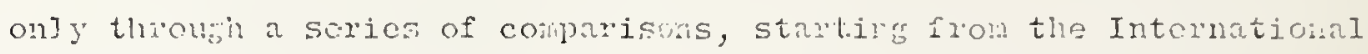
Prototypo. The units for the other five base quantitirs, and ail quantities derived fron ther, aro in princisle independently realizablc in many laboratories. In yuncice, horver, inevitable minor differences among instruments, environments, ancl operators are bound to introcucc smil disciepancifs. Penicric comparisor of standards and the resolution of these discropancics is reculied for compatibility among domestic standards laboratories, as viell as internationally.

Within the United States, ITS consults with the major industrial and goverumental standards laboratories, and cooperates with the Departhent of Defense and the National Conference of Standards Laboratories in concucting moasurenent agrocnent comarisons. Ferioclic inter-comparisons of Burcau standards with tho:e of other countrics are made through the Intemational Buronu of bieights and ressures, through intermational scicntific organizations, or by direct arrargement. The operations of the International Burcau are supcrviscd by tic Gencral Conference of Weights ancl Weasures, to which U. S. dolcerates are appointed by the Departmont of State. Froquency and time comparisons within the lniter states arc made between the vational Bureau of Stardards, the United Statcs Naval Observatory, and manufacturers of frequency stancards. Tric data from rorld-wide astronoulical ohscrvations and fron standaros laboratories in many countrics are coordinated by tire International Bureau of the Hour, which amounces recommencic alproximations for the ratc difference between atoric and universal time, as well as for 
200.102 (contd.)

epoch adfustments.

200.103 Types of calibration and test sorvices.

(a) The Bureau has developed Instrumentation and techniques for realizing stindards for the six hase unjts of the International System of Units, as agrecd upon by the Genoral Conference of lieights and Measures. Reference standirds have been established not only for these six base units, but also for many derived quantities and their muliples anc subnultinles. Such reference standards, or equivaient working staniards, are used to calibrate laboratory and plant standards for other organizations. Accuracy is maintained by stability checks, by comparison with the standards of other national and international laboratories, and by the exploration of alternative technigue as a means of reducing possible systematic errol.

(b) Calibrations for many types of instruients and ranges of physical quantities are described in the itemized schedules of this Subchapter. (Sce also NBS Miscellaneous Publication 250*, "Calibration and Test Services of the National Bureau of Standards"). Charges for many services are based upon established fees, while charges for some services are billed on the basis of actual costs incurred. (See subsequent parts of this Subchapter for description of service items and schedule of fees). Changes in services and fees are published in the Federal Register. Such changes are announced also in supplements to Miscellaneous Publication 250 and in the monthly NBS Technical News Bulletin.*

(c) Consideration will always be given to requests involving unucual physical quantities, upper or lower extremes of range, higher levels of accuracy, fast response speeds, short durations, broader ranges of associated parameters, or special environmental

*For sale by the Superintendent of Documents, U.S. Government Printing Office, Washington, D. C. 20402 
$200.103(\operatorname{conta})$

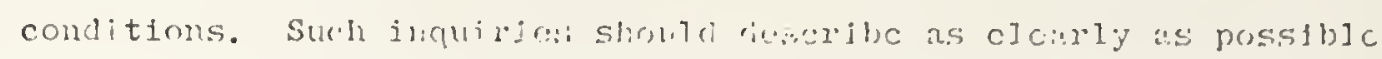
the measurencut desirod and the scicntifin or economic hasts for the requirement to be satisfied.

(d) The Burcau's principal crullasis is on thosc cal1brations and other tests requildng such accuracy as can be obtinned only by diect comprison with its refcrcucc standuds. Hovever, in ordc: io maintain cfficiont utilization of spectalizer cquipment and skilled porsonnel, NTSS will at times undertarc uron request to calibrate devices reiuiring lcsscr accuracy but suitable for roxklug standards in plant or laboretory.

(c) Othcr Ecrvices which may be obtainable include:

(1) Tests of measuring instrumants to detcrmine compliance with spcciflcations or ciains, when the evaluation is crifical in natiomal setoutific or technical operations, and when sutablc facilitics are not available clsewhere.

(2) Refcrec cests in important ciscs when clients arc unable to arree lipon trif riethod of neasurcment, the results of tests, or the intorprctation of these results, but lave agrced in advarce in writing to accest and abide by the findings of the Bureau.

(f) In gcneral, measurement scrvices are not provided for organizations or individuals in foreign countries.

(5) Thc Burcau reserves the right to dccline anj recuest for serviccs if the work would interfcre with other activities deemed by the Lirector to be of greate: importancc.

200.104 Coisulting and advisory services.

(a) In arcas of 1 ts special comptcnce, the Bureau offers consultire and advisory serviccs on physical or mathematical problems related to measurement, e.g. unusual or cxtrcuc conditions, methods of statistical control of the noasurcmont process automated acquisition of laboratory data, and data reduction and analysis by computer. Thc Bureau at its discretion may makc appropilate charges for renderine sueh services; the chares would he based upon actual costs. 
June 30, 1967 NBS MISC. PUBL. 250, INSERT 12 - Cont1nued Page 9 of 18

$200.10 .1($ contd.)

(b) To enhance the competence of standards laboratory personnel, the Bureau concucts annually several group seminars on the prectsion measurement of specific types of phystcal quantities, offering the opportunity of laboratory observation and informal discussion. A 2-week summer course in electromagnetic measurements and standards is conducted biennially by the IBS Radjo Standards Laboratory.

(c) Suggestions will be offered on measurenent techniques and on other sources of assistance on calibration or measurement problems when the Bureau's own equipment and personnel are unable to undertake the work. The National Conference of Standards Laboratories issues a Directory of Standards Laboratories in the inited States (obtainable from NCSi. Secretariat, c/o National Bureau of Standards, Washington, D. C. 20234.) Others are Iisted in the ASTM Directory of Testing Laboratories, Commercial and Institutional. (Directory available from the American Society for Testing and Materials, 1916 Race Street, Phfladelphia, Pa. 19103). Similar listings appear In buyer's guides for comercial products and in technical journals concerned with physical measurement.

200.105 Standard reference materials.

Often the performance of a device or structure can be evaluated at the user's laboratory by comparing its response to unknown values with its response to a standardized specimen or a material of certified composition, properties, or purity. Several types of such specimens are listed in Part 202 of this Subchapter. (See also NBS Miscellaneous Publication 250*). Carefully characterized materials are listed in Part 230 of Subchapter B of Charter II, Title 15 of the Code uf Federal Regulations. (See also iliscellaneous Publication 260*, "Standard Reference Mateilial"). The Office of Standard Reference Materials in the NBS Institute for Naterials Research administers a

*For sale by the Superintendent of Documents, U.S. Government Printing Office, Washington, D. C. 20402 


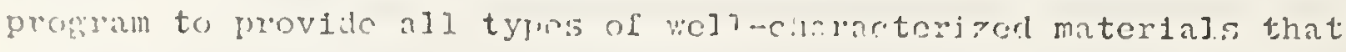
are necled to calibrate a measurement system or to produce scientific data that can be readily refcrued to a common basc.

200.106 Criticaliy craluated data.

Data on the physical propertics of the thousands of well-rlerined substances which are conroreiajly availabje necd to be complled and evaluated to be usciul for refcrence in cugincering design. The Orfice of Standard Reference Data in tle NBS Institutc for Basic Standards provides two-way conunication with a number of governncitul and non-governmental data contcrs throughout the country. Its conpilation and dissenination activities cover scven technical arcas nuclear data, atomic and molccular data, solid statc data, thermodynamic and transport data, chomical kinetics, solloid and surface properties, and mechanical propolties. Monthly accounts of progress appcar in the National Standard Reference Data System News (available upon request from the Offlce of Standard Refcrence Data) and in the Technical News Bulletin.*

200.107 Publications.

The monthly NBS Tcclnical Ners Bulletin * announces changes in. services and fecs, as publishcd in the Federal Register. The Bulletin also describes recent results of Bureau stafî work, lists currently issucd publications, and carries sections giving up-to-date detailed infomation on standards and calibrations, standard reference materials, and the National Standard Reference Data System. A 6-year Index to publications by Bureau authors will be found in a supplement* to Miscellaneous Publication 240, Publications of the National Bureau of Standards, for July 1, 1960 to Junc 30, 1966. The Index covers Mlonographs,* Technical Notes, * and all papers appearing elther in the NBS Journal of Research* or in outside technical journals.

Unclassified research and dovelopmont reports from all government agencies and their contractors are listed in a semi-monthly Government-

*For sale by the Superintendert of Documents, U.S. Govermient Printing Officc, Washington, D. C. 20402 
200.107 (contd.)

wide Index avaliable from the N3S Clearinghouse for Federal Scientific, and Techicical Informtion, Springfield, Va. 22151. Publication series avaliabie from the Clearinghouse include Report Abstracts, Fast Announcenent Service, Package Reviews, and Technical Translations.

200.108 Broadcasts.

The Rafio Standards Laboratory of MBS broadcasts various types of standard frequency and time signals from 4 radio stations: Wirt, WWVH, WMVL, and WrVB. (NBS Miscellaneous Publication 235*, "NBS Standard Frequency and Time Services", contalns information concerning the broadcosts of various types of such signais from these four stations.) Wry is locnted at Maui, Haraij. Hiv, WivL, and WWB are located at Fort Collins, Colorado. (Wiv was relocated in December 1966 from Greenbelt, Naryland.) Notices of precisions, accuracies, and adfustments in NDS clocks and radio emissions are published regularly in the Federal Register. (Such notices are published also in the Time and Frequency Service Bulletin wich is avallable from the Radio Standards Laboratory on request.)

Broadcasts from whr are at nominal frequencies of $2.5,5,10$, 15,20 , and $25 \mathrm{MHz}$, and from wivH at $2.5,5,10,15 \mathrm{NHz}$; the carrier frequencies and time puise rates emitted by both are offset from nominal values in accordance with the Universal Time Coordinated (UTC) system. The frequency is offset by -300 parts in $10^{10}$, and the time pulses occur at intervals slightly longer than one second. As recomended by the International Bureau of the Hour, the phase of the t1re pulses is occasionally adjusted to approximate UT2 within about I00 ms. The UT2 scale is a partiy sroothed version of Universal Time (UT), as determined by astromomical observations and with anuual and semi-annual fluctuations removed. Wiv and wivt also provide standard musical pitch at 440 hertz, weather forecasts, and geophysical alerts. WW broadcasts Universal Time - seconds, minutes, hours, and days of the year - in the code format of the National Aeronautics and Space Administration. For more precise determination of UT2, both WWV and WWH broadcast in International Norse Code appropriate 
PaB 12 of 18 NBS MISC. PUBL. 250, INSERT 12 - Continued June 30, 1967 200.108 (conte.)

corrections basca on astronomical data from the U. S. Naval Obscrvatory, Wash1ngton, D. C.

At WrVl, the modes of broadcast of the carricr and the timing siguals are also in conformity with the UTC system.

Station WivB broacicasts on the standard radio frequency of 60

KHz w1thout offset, cmitting time marker pulses exactly 1 second apart, as detcrmincd by the NBS ceslum clock. The phase of these pulscs is re-sct every few months by $0.2-s$ adfustnonts, as recommended by the International Bureau of the Hour, in order to approximate UT2 within about $0.1 \mathrm{~s}$. Th1s $1 \mathrm{~s}$ a coordinated systcm known as Stepped Atomic TIme (SAT).

The U.S. Naval Obscrvatory aIso broadcasts standard UTC timc and time interval (frequency), using botr astronomical and atomic data. It coordinates a number of Navy and Coast Guard stations around the globe, and also monttors the NBS broadcasts. Both USNO and NBS monitor broadcasts from selected laboratories in forelgn countries, and 1ssue pellodic comparisons of reference signals.

200.109 Request procedure.

(a) A formal purchase order for the callbration or test should be sent prior to or at the time of shipment. This should provide clear 1dentification of the instrument or standard being submitted, and give instructions for bliling. If a client wishes to minimize the time during which his equipment is out of service, he can usually arrange to delay shipment unt1l the test is scheduled to start. Requests from Federal agencles, or from state agencles, for callbrations or tests on material to be used on private or Federal contract work, should be accompanied elther by purchase order or by lotter or dncumert authorlzing the cost of the test to be billed to the agency.

(b) Acceptance of purchase orders does not $1 \mathrm{mply}$ acceptance of any provisions set forth in the order contrary to the policy, practice, or regulations of the NationaI Bureau of Standards or the U.S. 
200.109 (contd.)

Government. (A statement to the effect that the National Bureau of Standards is an agency of the U. S. Governnent should satisfy other Government agencies with regard to compliance with Government regulations and executive orders.)

(c) A test number will be assigned by the Bureau to each item (instrument or group of simflar instruments or standards) wher. accepted for test. This test number should be referred to in all subseciuent communications. If the apparatus submitted has been previously calibrated by the Burcau, reference should be made to the test number previously assigned, so that a continuing record of stability history can be established.

(d) Incluiries related to electrical standards in the radio frequency region (above $30 \mathrm{kllz}$, Part 201, sections 201.701 through 201.950 of this Subchapter), and on all fxequency and time standards should be directed to:

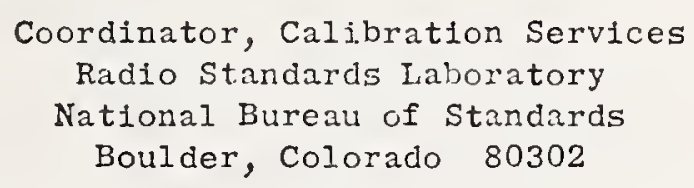

(e) Inquiries for measurement services listed in this subchapter, other than those noted in par. (d) of this section, should be directed to:

Test Administration Unit

National Bureau of Standards Washington, D. C. 20234

200.110 Shipping, insurance, and risk of loss.

(a) Shipment of material to the Bureau for calibration or other test should be made only after the client has accepted the estimate of cost and the tentative scheduling.

(b) Calibrations of electrical standards in the radio frequency region (above $30 \mathrm{kHz}$, part 201, sections 201.701 through 201.950 of this Subchapter) are performed at boulder, Colorado. Shipments should be addressed to:

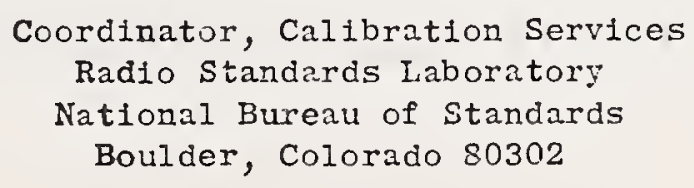


200.110 (contd.)

If apparatus for high frequency is also to be given incidental low-fiequency calfbration, this may he done at Boulder, Colorado, but if a complcte range of low-frequency tests are nceded, the instrument should be sent to:

National Burcau of Standards Route 70 S \& Quince Orchard Rd. Ga1 thersburg, Md.

(c) The cillibrations listed in this subchaptcr, other than thosc notcd in par. (b) of this section, are performed in the Bureau's Iaboratories at elther Ga1thersburg, lid. or liashington, D. C. For shipilcits which are heavy (1n excess of 100 lbs.) or bulky (a combined girth in excess of 27 cublc $f t$.$) , request a shipping address$ from:

\section{Test Administration Unit National Bureau of Standards Washington, D. C. 20234}

Items other than heavy or bulky shipments that are sent by common carier, should be addressed to:

National Bureau of Standards

Route $70 S$ \& Quince Orchard Rd. Gaithersburg, Md.

(d) Equipment sent to the Bureau must be properly packed to minimize likelihood of damage in shipment and handling. Suggestions on packing and shipping are made in some sections of the fee schedule. In every case, the client should consider the nature of the equipment, pack it accordingly, and clearly label shipments containing fragile instruments or materials, such as glass and the like. The use of "security express" should be considcred in shipping delicate instruments.

(e) To minimize damage during shipment resulting from inadequate packing, the use of strong reusable contanners is recomended. As an aid in preventing loss of such contalners, the client's name should be legibly and permanently marked on the outside. In order to prolong the container's use, the notation REUSABLE CONTAINER, DO NOT DESTROY should be markce on the outside.

(f) Shtpping and insurance coverage instructions, in order to 
$200.110($ contd.)

be followed, must be elearly and legibly shown on the purehase order for the calibration or test. As the Bureau will not pay shipping or Insurance eharges and add this eost to the biling involee, return shipnent, when no shipping or insuranee instruetions are furnished, w11 be wade by enmon carier eolieet, but uninsured.

(g) Viren a test number has been assigned prior to shipment to the Burcau, tris number should be elearly marked on the shipping contalner. When a test number has not been assigned, an involee, copy of the purchase order, or letter should be enclosed in the shipment to insure proper identifieation. The original purehase order stovid be forwaried as appropriate to:

\author{
Test Administration lintt \\ National Bureau of Standaris \\ Washington, D. C. 20234 \\ Coordinator, Cailbration Serviees \\ Radio Standards Laboratory \\ National Bureau of Standards \\ Boulder, Colorado 80302
}

(h) NBS will not be responsible for the risk of loss or damage to any item in shipping to or from the Bureau. Any arrangements for insuranee eovering this risk must be made by the client. Return shipment will be made by the Bureau as indicated in par. ( $f$ ) of this seetion. The purehase order should always show the value of the equipment, and if transit insurance is earried by the elient, this faet should be stated.

(1) The risk of loss or damage in handling or testing of any 1 tem by NBS must be assumed by the elient, exeept when it is determined by the Bureau that such loss or damage was occasioned solely by the negligence of Bureau perscunel.

\title{
200.1II Identification and operability of devices submitted.
}

(a) Since the data provided by the Bureau's report is speeifie to the Individual item or pleee of apparatus tested, it is essential that this pleee be identified uniquely by an appropriate number or symbol. In most eases, the manufaeturer's nane and serial numbers 
Page 16 of 18

NAS MISC. PUBL. 250,

200.131 (conta.)

are uscd. When such a number is lacking, an alternative ident1fying mark should bc provided. If nolle is found, the Burcau may apply an appropriate one, usually the Bureau's Test Number, for which an additiunal charisc may be made.

(b) All apparatus submittci for calibration and test must bc in good opcrating condition. Repairs and adjusinonts should be attended to by tho clicnt prior to shipnent. Apparatus not in good condition cinnot be testcd, nor can the Bureau undertake the repair or adjustment of aly cculpment, except by special arrangcment. If $1 \mathrm{t}$ is wident that cquinnent has been abused or has not recelved proper care, il tcst ordinarly w1l rot be conducted. If defects are found at thc Burcau after a test has begun, this fact will be reportcd, the test may be tcrminated, and a report issucd summarizing such information as has been found, and a fee charged in accordance with the amount of work done.

\subsection{Priority and time of completion.}

(a) Except for emergency Government work, calibrations and other tests are in general undertaken in the order in which requcsts are received.

(b) The date at which a test will be completed depends on a number of factors, such as the condition of submitted equipment, setup time, duration of test run, l1mitations on available personnel, occasional large backlogs of work, and grouping of tests of similar devices to lessen costs. Somctimes repetitive runs are needed to determine reliablity of results, or peculiar behavior is noted, requiring unusually careful investigation. Tre Bureau fill cooperate with a client to minimize the out-of-use time for his equipment, and W111 upon requcst inform hin of a probable starting date and give notice of uncxpected delays in completion of the work. Estinates of completion dates are therefore provisional.

\subsection{Witnessing of operations.}

The Bureau velcomes scientists and engineers who may wish to 
Jube 30, 1967 NBS MISC. PUBL. 250, INSERT 12 - Contirued Page 17 of 18

200.113 (contcl.)

visit its laboratorles and discuss its methods, However, visitors ordinarily will not he perintterl to witnoss the actual carrying out of hifhly precise measurenents becalise their presence introduces distraction that may lead to crrors or delays. This policy may be waived In thosc cases where the visitor can be of service in setting up apparatus of a new or unusual naturc, in the case of referec tests, or in other cases in wich the legal validity of the result may require the presence of duly authorized witnesses.

\subsection{Reports.}

Results of calibrations and other tests are 1ssued as reports entitled, "National Bureau of Stanclards Report of Calibration", "National Bureau of Standards Report of Test", or "National Bureau of Standards Report of Analysis", as appropriate. The report form used carries no special significance. Whenever formal certification Is required by law, or to meet special conditions adfudged by the National Bureal of Standards to karrant it, a letter will be provided certifying that the particular 1 tem was received and calibrated or tested, and identffying the report containing the results.

$\underline{200.115 \text { Use of results. }}$

(a) The NBS report of calibration or test contains data which pertain only to the particular device or specimen calibrated or tested. There is no 1mplication tixat other items of the same lot or type will show comparable results. However, on the basis of tests on a sample of instruments or objects dram from a lot of nominaliy identical Items, in accordance with an approved sampling procedure, the Bureau may declare that the entire lot does or does not meet stated requirements for acceptance.

(b) The results given in the NBS report are limited to the condition of the equipment at the time of calibration or test. Clients should not assume that comparable performance will be sustained unless suitable precautions are taken in handling and use.

(c) The Nat1onal Burcau of Standards does not "approve," 
Page 18 of 18 NBS MISC. PUBL. 250, INSERT 12 - Continued June 30, 1967

$200.115\left(\right.$ cn:t $\left.{ }^{2}.\right)$

"recommend," or "endorse" any proprietary product or matorial, e1ther as a single 1tem or as a class or group. Results reported by the Bureau shall not be used in advertising or sales promotion, or to indicate explicit or $1 \mathrm{mplic}$ t endorsement of the product or material by the Dureau.

200.116 Fees.

(a) In accoldance with 15 U. S. C. 271-278e, lees are charged for all calfurations and tests made by the National Bureau of Standards.

(b) Tiris fee schedule is published subject to the abovementioned basic act which authorizes the Secretary of Commerce, from time to time, to make regulations regarding the payilent of fees, the limits of tolerance on standards submitted for verification, and related matters.

\subsection{B1111ng charges.}

The minimum billing charge for any test request accepted by the Bureau is $\$ 10$, unless otherwise indicated in a particular fee schedule. If apparatus is returned ilthout testing, a minimum charge of $\$ 10$ may be made to cover handling. Fees for tests include the cost of preparation of an original report. Additional copies ordinarily are not issued to other than the reciplent of the original, and are not issued unless the client has shown a technical need for them. Copies of reports requested subsequent to the date of tests will be supplied at cost, with a minimum charge of $\$ 5$. All checks should be made payable to NBS, Department of Commerce.

USCOM-NBS-DC 
U. S. Department of Commerce National Bureau of Standards

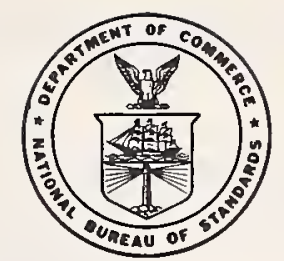

INSERT 13

June 30,1967

Page 1 of 6

\section{CALIBRATION AND TEST SERVICES OF THE}

\section{NATIONAL BUREAU OF STANDARDS}

Notice of Change to NBS Misc. Publ. 250, 1965 Edition*

Change 21

Appendix C: Insert 13 contains a list of all fees that have been established as of June 1967 for services described in Misc. Pub1. 250. Attention is called to changes in fees for Part 201 (Electricity), Part 202 (Metrology), Part 203 (Heat), and Part 206 (Mechanics), many of which have not been noted in previous inserts. The schedule which follows is applicable to the electrical, photometric, dimensional, thermal, radiation, and mechanical measurements, as recently published in Parts 201 (Sections 201.101 through 201.604), 202,203,204, and 206 of the Federal Register CFR 15, Chapter II, Subchapter A. This schedule supersedes in its entirety the Appendix C of the NBS Miscellaneous Publication 250, "Calibration and Test Services of the National Bureau of Standards", 1965 edition, pages 125 through 129. The original pages should be removed and the new schedule inserted in their place.

To meet increasing costs of the Bureau's calibration and test services, it has been found necessary to raise the stated fees rather generally. The following tabulation lists the fees that have been established for measurement services described in the schedules. The items included here are identified in the schedules by a single asterisk (*) in the Fee column.

For further information on NBS policy in regard to fees, see Part 200 , as given in Insert 12 , dated June 30,1967 , especially Sections 200.116 and 200.117 , and the various sections with the title "General" (see Contents of MP 250).

Items carrying the suffix " $z$ " are automatically excluded from the list, since these services, and consequently also the fees for them, vary according to the requirements of the individual case, as agreed upon in advance by the client and the NBS laboratory concerned.

Change 22

Lffective July 1, 1967, calibration charges made to public customers by the Llectronic Calibration Center (ECC) will be increased. Charges which were previously $\$ 20.00$ per hour will be $\$ 40.00$ per hour; charges which were previously $\$ 25.00$ per hour will be $\$ 45.00$ per hour. These charges affect calibration services in the high frequency and microwave regions ( $30 \mathrm{kIlz}$ and up) which are performed by the Radio Standards Laboratory at Boulder, Colorado. The services of the Radio Standards Laboratory are described in Insert 5, dated April 3, 1967; Insert 8, dated April 17, 1967; Insert 9, dated June 15, 1967; and Insert 10, dated June $16,1967$.

*Changes should be made immediately in your copy of NBS Misc. Pub1, 250, 1965 Edition. Additional copies of the insert are available from NBS office of Technical Information and Publications, Washingt on, D. C. 20234. 
Llectricity

\section{I tem}

Precision standard resistors

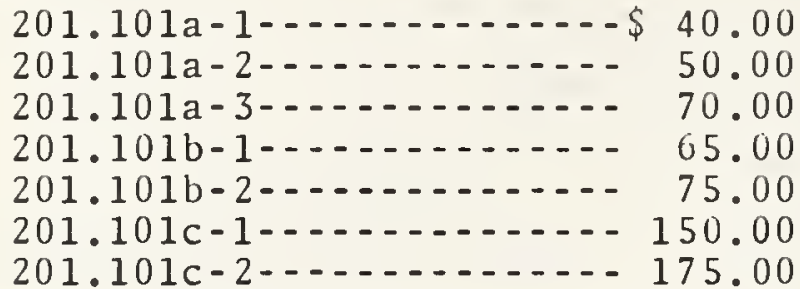

Precision resistance apparatus 201.102 a (1) -.........

(2) - . . . . . .

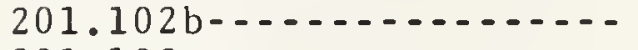

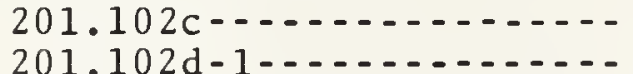

$201.102 \mathrm{~d}-2 \ldots \ldots \ldots \ldots-\ldots$

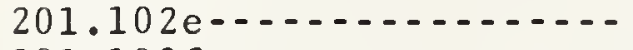

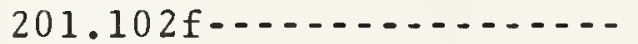

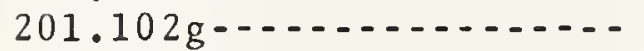

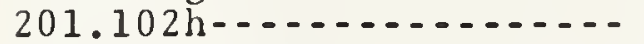

$201.102 i-1-\ldots . .-\ldots . .-1$

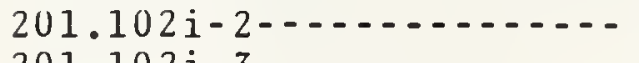

$201.102 i-3-\ldots \ldots-\ldots-\ldots 47$

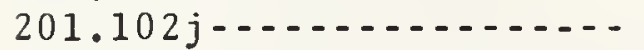

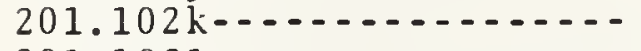

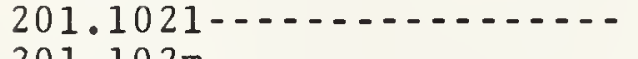

$201.102 \mathrm{~m}-\ldots \ldots \ldots \ldots$

20.00

5.00

195.00

70.00

520.00

705.00

300.00

555.00

215.00

630.00

350.00

435.00

475.00

110.00

110.00

285.00

520.00

Multi-megohm resistance standards

$201.103 a-\ldots . . .-\ldots 60.00$

201.103b-_........ 70.00

$201.103 \mathrm{c}-\ldots \ldots-\ldots 00$

Standard inductors

$201.104 \mathrm{a}-\ldots \ldots+\ldots 00$

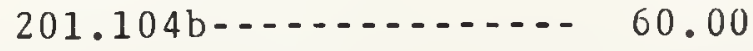

Standard capacitors

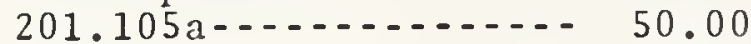

$201.105 b \ldots \ldots 20.00$

Standard cells

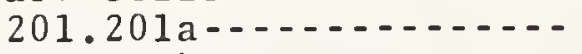

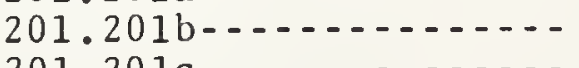

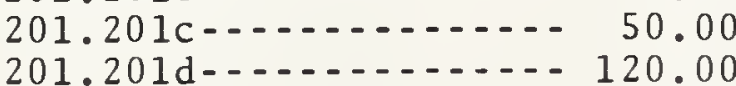

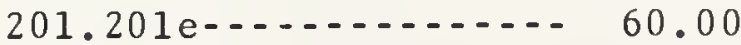

Standard resistors

$201.301 \mathrm{a}-1 \ldots \ldots-10 .-100.00$

$201.301 a-2-\ldots-\ldots-\ldots 160.00$

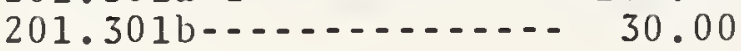

$201.301 \mathrm{c}-\ldots-\ldots-1 .-25.00$

$201.301 d-\ldots-\ldots-160.00$

$201.301 \mathrm{e}-\ldots-\ldots-\cdots \quad 45.00$

$201.301 f-\ldots \ldots+-\ldots 410.00$

I tem

Fee

Volt boxes (fixed ratio voltage dividers)

$201.302 \mathrm{a}-\ldots \ldots \ldots-\ldots-\ldots 150.00$

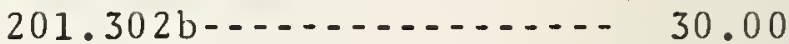

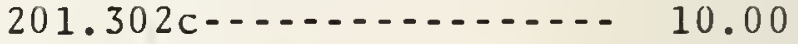

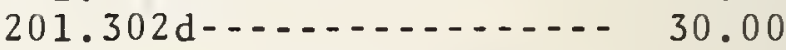

Ac-dc instruments and thermal converters

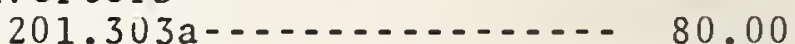

$201.303 \mathrm{~b}-\ldots \ldots . . \ldots 20.00$

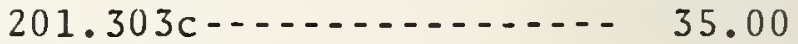

Ac-dc wattmeters, single phase

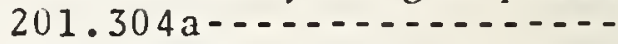
$201.304 \mathrm{~b}-\ldots-\cdots \cdot-\cdot-\cdot-\cdot$

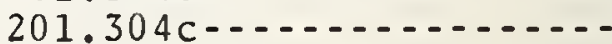

95.00

35.00

15.00

Watthour meters

201.305 a-..............

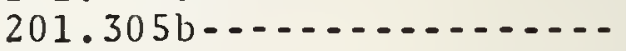

$201.305 \mathrm{c} \ldots \ldots \ldots$

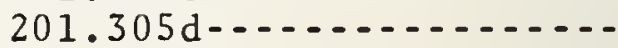

115.00

15.00

60.00

10.00

Current transformers

201.306a-1 ............

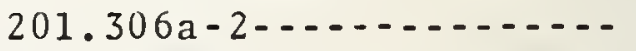

$201.306 \mathrm{~b}-1-\ldots-\ldots-\ldots-\ldots$

$201.306 \mathrm{~b}-2-\ldots-\ldots-\ldots$

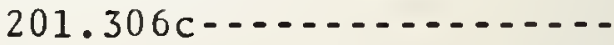

180.00

210.00

30.00

45.00

10.00

Current transformer comparators $201.307 \mathrm{a}-\ldots . .-\ldots . .-\ldots$ $201.307 \mathrm{~b}-\ldots . \ldots \ldots \ldots$

540.00 60.00

Normal induction and hysteresis

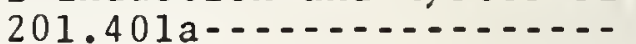

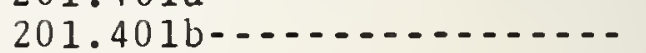

$201.401 \mathrm{c}-\ldots-\ldots-\ldots-\ldots-14$

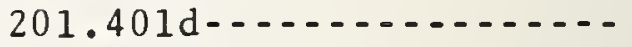

$201.401 \mathrm{e}-$

70.00

80.00

140.00

70.00

(1)

源

$201.401 \mathrm{~g} \ldots \ldots \ldots \ldots$

Magnetic materials: a-c permeability and core loss

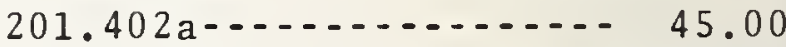

$201.402 \mathrm{~b}-\ldots \ldots \ldots-\ldots-15.00$

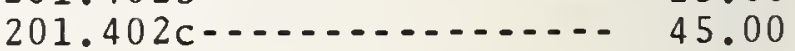

$201.402 \mathrm{~d}-\ldots \ldots 15.00$

Míagnetic testing apparatus

$201.403 \mathrm{a}-\ldots \ldots 35.00$

$201.403 \mathrm{~b}-\ldots . \ldots 20.00$

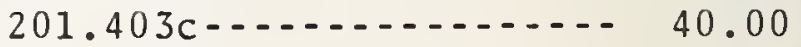

$201.403 \mathrm{~d}-\cdots-\ldots-\cdots-25.00$

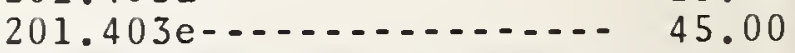

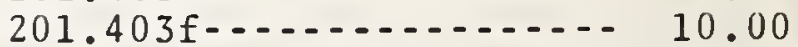

$201.403 \mathrm{~g}-\ldots-\cdots--30.00-70.00$ 
Item

Fee

Voltage dividers

$201.601 \mathrm{a}-\ldots \ldots+\ldots-\ldots 140.00$

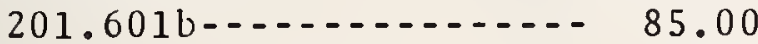

Voltage transformers

$201.602 \mathrm{a}-1 \ldots \ldots \ldots 00$

$201.602 \mathrm{a}-2-\ldots-\cdots-\cdots-165.00$

$201.602 \mathrm{a}-3 \ldots \ldots-\ldots-\cdots 90.00$

$201.602 \mathrm{a}-4 \ldots \ldots \ldots \ldots+\ldots 130.00$

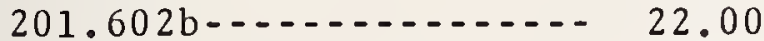

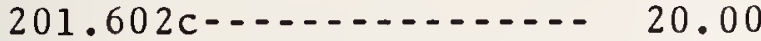

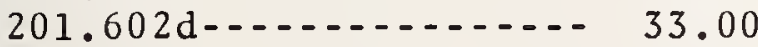

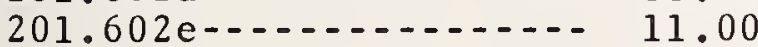

Kilovol tmeters

$201.604 a-\ldots . .-\ldots . .-110.00$

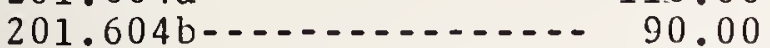

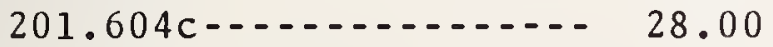

$201.604 \mathrm{~d}-\ldots \ldots \ldots-\ldots$

Metrology

Miscellaneous photometric measurements

$202.103 a \ldots \ldots+\ldots .090$

Incandescent electric lamps

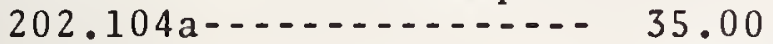

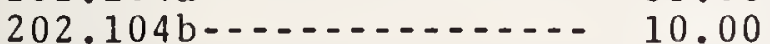

Spectrophotometric standards

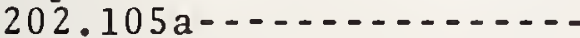
$202.105 \mathrm{~b}=\ldots \ldots \ldots \ldots-\ldots$

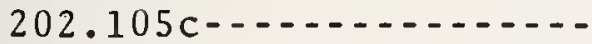
$202.105 \mathrm{~d}-\ldots-\ldots-\ldots-\ldots$

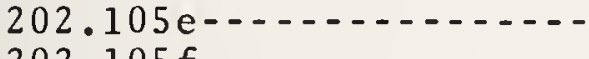
$202.105 \mathrm{f}-\ldots-\ldots-\ldots-\ldots$
$202.105 \mathrm{~g}-\ldots . . . . . . .-$.
$202.105 \mathrm{~h}-\ldots-\ldots-\ldots-.-$.
$202.105 \mathrm{i}-\ldots \ldots \ldots-\ldots$
$202.105 \mathrm{j}-\ldots .-\ldots-\ldots-\ldots$
$202.105 \mathrm{k}-\ldots . .-\ldots . . .-1$
$202.1051-\ldots-\cdots-\cdots-\cdots$
$202.105 \mathrm{~m}-\ldots-\ldots . .-1 .-$.
$202.105 n \ldots \ldots \ldots \ldots 175.00$
160.00
60.00
15.00
80.00
80.00
125.00
140.00
140.00
175.00
175.00
175.00
100.00

Spectrophotometric measurements

$202.106 a-\ldots . . .-\ldots . . .-18$

202.106 b - . . . . . . -

$202.106 \mathrm{c}-\ldots-\ldots$

$202.106 \mathrm{~d}-\ldots . .-\ldots-\ldots$

$202.106 \mathrm{e}-\ldots-\ldots-\ldots$

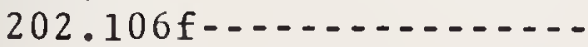

$202.106 \mathrm{~g}-\ldots \ldots-\ldots$

$202.106 \mathrm{~h}-\ldots \ldots-\ldots$

$202.106 \mathrm{i}-\ldots . .-2 .-2 .-.-13$

$202.106 j$

80.00

8.00

8.00

80.00

8.00

8.00

95.00

15.00

130.00

25.00

95.00

15.00
Item

Fee

Spectrophotometric measurements-Continued

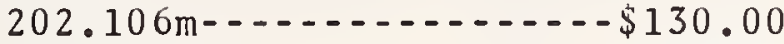

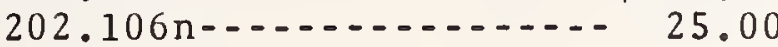

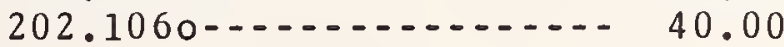

Colorimetry

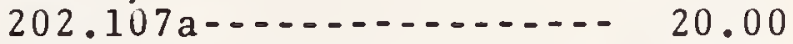

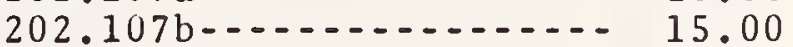

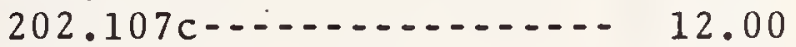

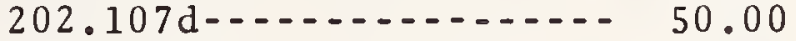

$202.107 \mathrm{e}-\ldots \ldots \ldots-\ldots-\ldots 12.00$

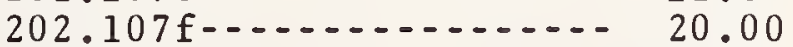

$202.107 \mathrm{~g}-\ldots . . .-\ldots . .-50.00$

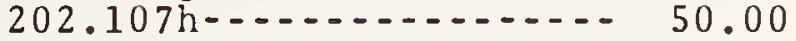

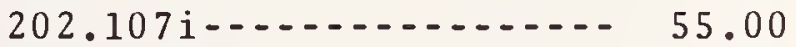

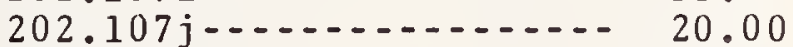

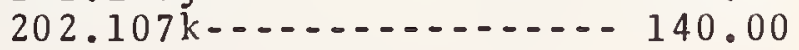

Opacime try

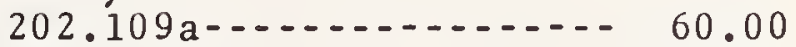

$202.109 \mathrm{~b} \ldots \ldots \ldots \ldots-\ldots 180.00$

Lovibond glasses

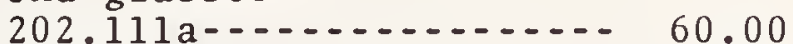

$202.111 b-\ldots \ldots \ldots 25.000$

Signal glass limit glasses and IPL calibrating filters

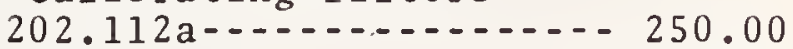

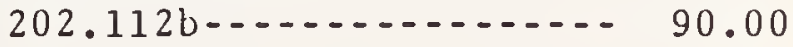

202.112 c............. 15.00

Radiometry

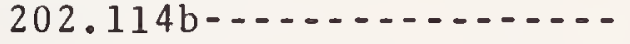

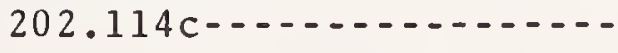

90.00

90.00

Visual measurements of optical characteristics

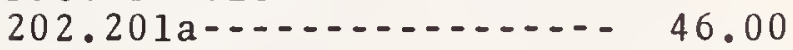

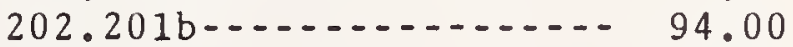

$202.201 \mathrm{c} \ldots \ldots \ldots \ldots+\ldots-\ldots 180.00$

$202.201 \mathrm{~d}-\ldots \ldots \ldots . . .-\ldots 250.00$

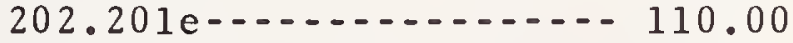

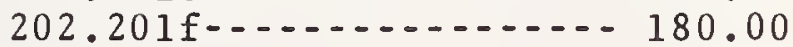

$202.201 \mathrm{~g} \ldots \ldots \ldots \ldots \ldots+275.00$

$202.201 \mathrm{~h}-\ldots \ldots \ldots-\ldots . .-250.00$

$202.201 \mathrm{i}-\ldots-\ldots-\ldots-\ldots-\ldots 110.00$

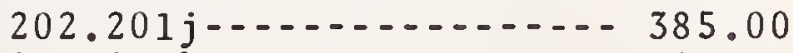

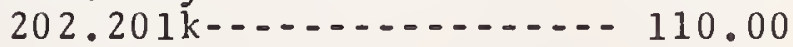

Photogrammetry

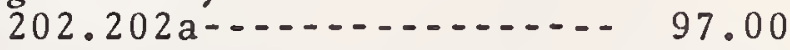

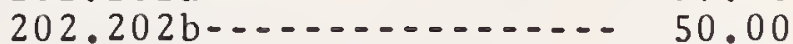

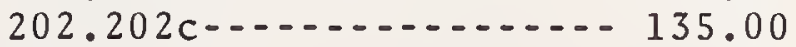

$202.202 \mathrm{~d}-\ldots \ldots \ldots-\ldots . . .-78.00$

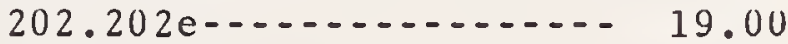

$202.202 \mathrm{f} \ldots \ldots . . . . . . . .28 .00$ 
Item

Photogrammetry--Continued

$202.202 \mathrm{~g}-\ldots-\ldots-\ldots 185.00$

$202.202 \mathrm{~h} \ldots \ldots \ldots \ldots+\ldots 165.00$

$202.202 \mathrm{i} \ldots \ldots \ldots \ldots$

Modulation transfer function measurements of $1 \mathrm{enses}$

$202.207 \mathrm{a}-\ldots \ldots 000$ $202.207 \mathrm{~b} \ldots \ldots \ldots+\ldots$

Photography

$202.311 \mathrm{a}-\ldots \ldots$

$202.311 \mathrm{~b}-\ldots-\ldots-\ldots$

$202.311 \mathrm{c}-\cdots \cdot-\cdot-\cdot-\cdot-\cdot$

$202.311 \mathrm{~d}-\ldots .-\ldots-\ldots$

$202.311 \mathrm{e}-\ldots-\cdots$

$202.311 \mathrm{f} \ldots \ldots \ldots$

33.00

33.00

33.00

11.00

36.00

11.00

Working line standards of length

$202.402 \mathrm{a}-\ldots . .-\ldots 165.00$

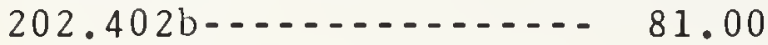

202.402 c . . . . . . 3.00

Steel tapes

$202.404 \mathrm{a}-\ldots-\ldots-\ldots$

$202.404 \mathrm{~b}-\cdots-\cdot-\cdot-\cdot-\cdot-$

$202.404 \mathrm{c} \ldots \ldots . . . . . .-$.

$20.2 .404 \mathrm{~d}-\ldots . .-\ldots-\ldots$

$202.404 \mathrm{e}-\ldots . .-\ldots$

$202.404 \mathrm{f}-\ldots . .-\ldots . . .-. .$.

$202.404 \mathrm{~g}-\ldots . .-\ldots$

$202.404 \mathrm{~h}-\ldots . . .-\ldots$

$202.404 \mathrm{i}-\ldots \ldots$

$202.4041-\ldots \ldots .-\ldots . . .-1$

$202.404 \mathrm{~m}-\ldots . .-\ldots-\ldots$

$202.404 n-\ldots . . .-\ldots$

$202.4040-\ldots-\ldots-\ldots$

$202.404 \mathrm{p}-\ldots \ldots \ldots$

Invar base-line tapes

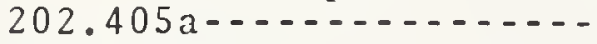

$202.405 b-\ldots . . .-\ldots . .-1$

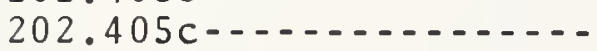

$202.405 d-\ldots-\ldots-\ldots$

$202.405 \mathrm{e}-\ldots . .-1 . .-.$.

$202.405 \mathrm{~g}-\ldots-.-\ldots-.-.-$

202.405 h-...........

$202.405 \mathrm{i}-\ldots . . .-\ldots$

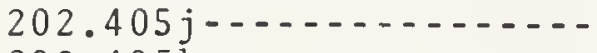

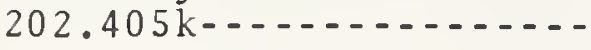

$202.4051 \ldots \ldots-\ldots$

$202.405 \mathrm{~m}-\ldots . . . . . . .$.

36.00

7.00

7.00

7.00

6.00

7.00

7.00

6.00

7.00

10.00

20.00

7.00

20.00

7.00

200.00

52.00

26.00

26.00

295.00

10.00

20.00

7.00

20.00

7.00

60.00

22.00

Surveyors' measuring instruments

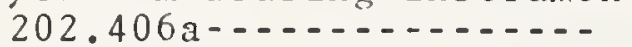

62.00

Sieves

$202.407 a \ldots \ldots \ldots 18.00$
Item

Fec

Hia emacy tometers

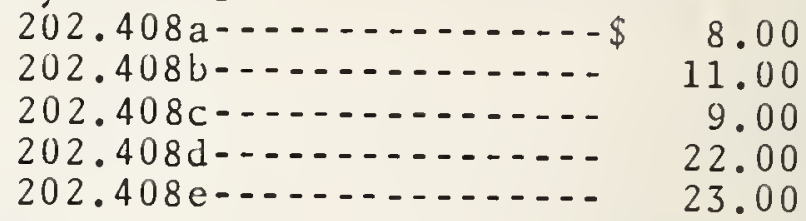

Gage blocks

$202.412 \mathrm{a}-\ldots . \ldots 10.00$

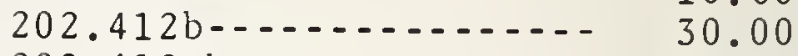

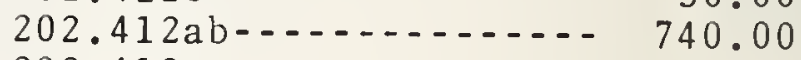

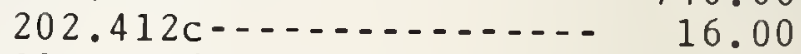

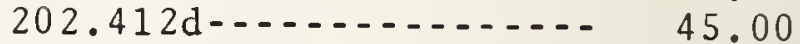

$202.412 \mathrm{~cd}-\ldots-\ldots-\ldots-1,250.00$

$202.412 \mathrm{e}-\ldots \ldots+\ldots-\ldots 12.00$

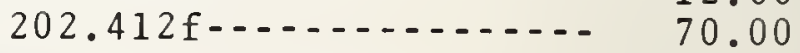

End standards of length

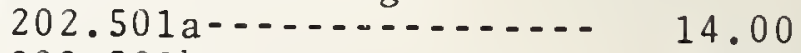

$202.501 \mathrm{~b}-\ldots \ldots \ldots$

$202.501 \mathrm{c}-\ldots-\ldots-\ldots-24.00$

$202.501 \mathrm{~d}-\ldots \ldots \ldots-\ldots . .-28.00$

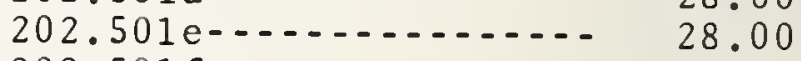

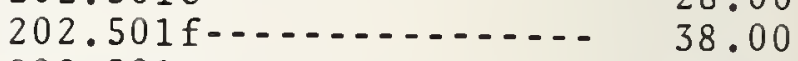

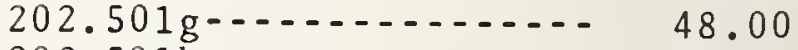

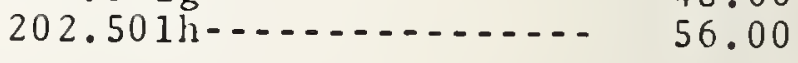

Plain cylindrical plug and ring gages

$202.502 \mathrm{a}-\ldots-\ldots-\ldots-\ldots 14.00$

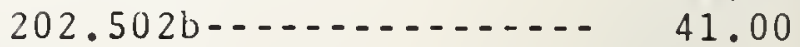

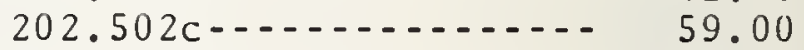

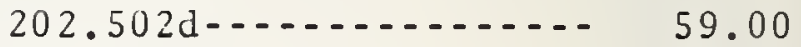

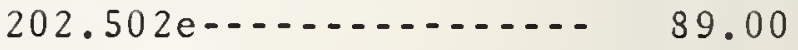

$202.502 \mathrm{f}-\ldots \ldots \ldots-\ldots 115.00$

Thread plug and ring gages

$202.503 \mathrm{a}-\ldots . . . . . . . .$.

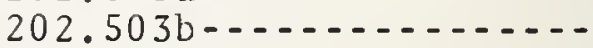

$202.503 \mathrm{c}-\ldots . .-\ldots$

$202.503 \mathrm{~d}-\ldots . .-1 .-.-1$

$202.503 \mathrm{e}$

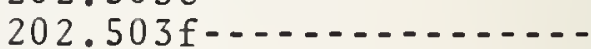

$202.503 \mathrm{~g}$

$202.503 \mathrm{~h}-\ldots . . .-\ldots . . .-$

$202.503 i$

$202.503 \mathrm{j}-\ldots \ldots$

$202.503 \mathrm{k}$

$202.5031-\ldots-\cdots-\cdot-\cdot-\cdot$

$202.503 \mathrm{~m}-$

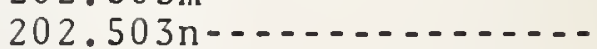

$202.5030-$

$202.503 p-\cdots \cdot-\cdot-\cdot-\cdot-$

$202.503 q$

115.00

36.00

36.00

89.00

115.00

71.00

115.00

130.00

89.00

27.00

36.00

71.00

36.00

59.00

165.00

100.00

125.00

82.00

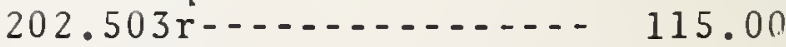

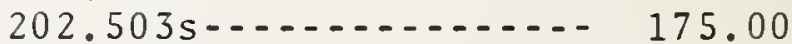

$202.503 \mathrm{t}-\cdots-\cdots-\cdots-175.00$

$202.503 \mathrm{u}-\ldots \ldots \ldots$........... 120.00 
I tem

Fee

Instruments and components

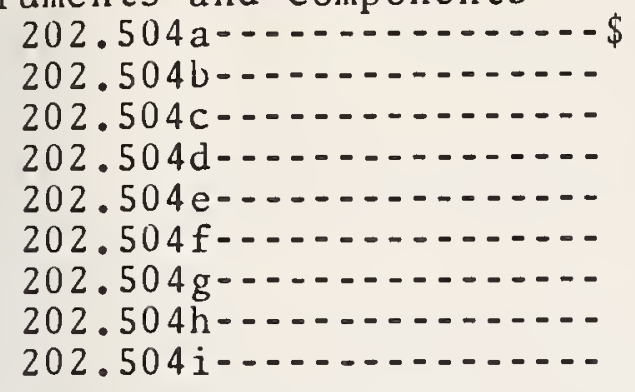

54.00

38.00

6.00

8.00

18.00

5.00

6.00

4.00

27.00

Optical reference planes

$202.505 \mathrm{a}-\ldots-\ldots-\ldots-1 .-1$

$202.505 \mathrm{~b}-\ldots-\ldots-1 .-1-1$

$202.505 c$

82.00

120.00

175.00

Angle blocks

$202.506 a-\ldots \ldots+\ldots .0410 .00$

Polygons

$202.507 \mathrm{a}-$

205.00

$202.507 \mathrm{~b}-\ldots \ldots-\ldots$

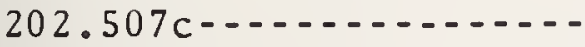

$202.507 \mathrm{~d}-\ldots .-\ldots-\ldots$

202.507 e $-\ldots-\ldots-\ldots$

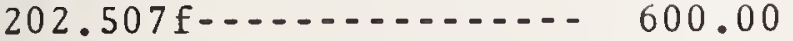

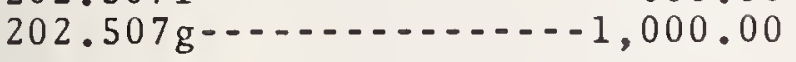

Niaster ba11s

$202.508 \mathrm{a}-\ldots-\ldots-\ldots-\ldots$

$202.508 \mathrm{~b}-\ldots-\ldots-\ldots-.-1$

$202.508 \mathrm{c}-\ldots-\ldots-\cdots$

$202.508 \mathrm{~d}-$

12.00

18.00

29.00

71.00

Gears

$202.509 a(1) \ldots \ldots \ldots$ $202.509 a(2)$

190.00 235.00

Heat

Laboratory thermometers

203.101a-..............

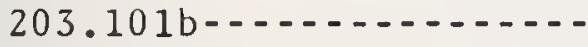

203.101c-............

$203.101 \mathrm{~d}-\ldots . . .-\ldots . . .-$.

$203.101 \mathrm{e}-\ldots . . .-\ldots . .-$.

$203.101 \mathrm{f}-\ldots-\ldots-\ldots$

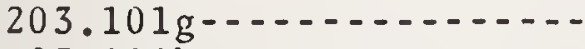

203.101 h-............

$203.101 \mathrm{i}-$

16.00

27.00

45.00

47.00

74.00

100.00

110.00

2.00

4.00

Thermocouples, thermocouple materials, pyrometer indicators

$203.102 \mathrm{a}-\ldots . .-\ldots+\ldots$

$203.102 \mathrm{~b}-\ldots-\ldots-\cdot-\cdot-\cdot-\cdot$

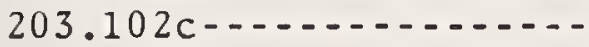

$203.102 \mathrm{~d}-\ldots \ldots \ldots-\ldots$

$203.102 \mathrm{e}-\ldots . .-\ldots-\ldots$

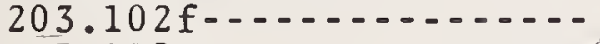

$203.102 \mathrm{~g}-\ldots-\ldots-\ldots$

$203.102 \mathrm{~h}-$
115.00

34.00

100.00

370.00

3.00

45.00

38.00

65.00
I tem

Fee

Thermocouples, thermocouple materials, pyrometer indicators--Continued

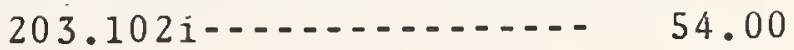

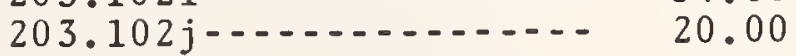

Resistance thermometers
$203.103 a-$
$203.103 \mathrm{~b}-\ldots \ldots \ldots \ldots$
225.00
$203.103 \mathrm{c}-$
300.00
225.00
$203.103 \mathrm{~d}$
590.00
$203.103 \mathrm{e}$
95.00

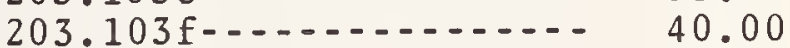

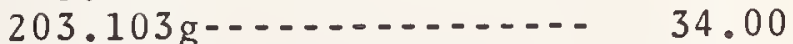
$203.103 \mathrm{~h}+\ldots \ldots-\ldots-15.00$

Optical pyrometers and ribbon

filament lamps

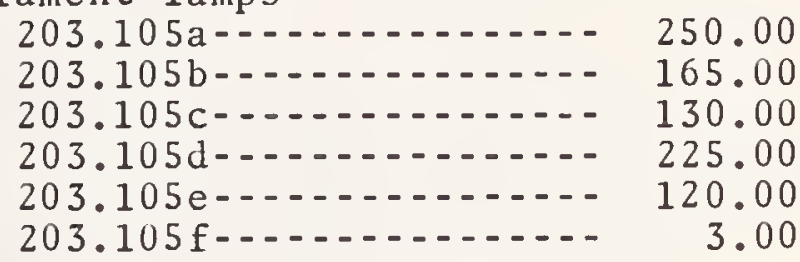

Cryogenic Physics

Capsule-type germanium resistance thermometers

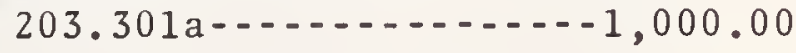

Radiation Physics

Gamma-emitting radioactive samples

$204.201 \mathrm{a}(1)-\ldots-\ldots-\ldots-110.00$

$204.201 \mathrm{a}$ (2) - . . . . - 110.00

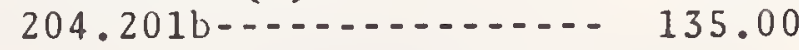

Alpha-emitting radioactive samples $204.202 \mathrm{a}-\ldots . \ldots 8.00$

Beta-emitting radioactive samples

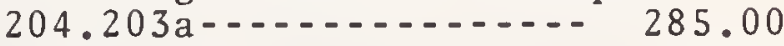

$204.203 \mathrm{~b} \ldots \ldots \ldots \ldots 0 . \ldots 150.00 \ldots$

$X$-ray and gamma-ray instruments

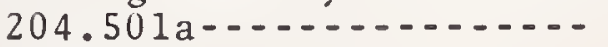

$204.501 \mathrm{~b}-\ldots-\ldots$

$204.501 \mathrm{c}-\ldots-\ldots-\ldots$

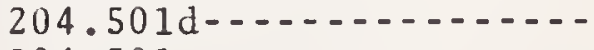

$204.501 \mathrm{e}-\ldots-\ldots-\ldots$

48.00

18.00

60.00

24.00

17.00

Gamma-ray sources

$204.502 \mathrm{a}-\ldots \ldots+\ldots$

$204.502 \mathrm{~b}-\ldots+\ldots 28.00$

204.502 c - . . . - 40.00

Neutron sources

$204.701 \mathrm{a} \ldots \ldots \ldots \ldots 57.00$

Neutron instruments

$204.702 \mathrm{a}$

107.00 
Item Fee

Neutron irradiation of foils

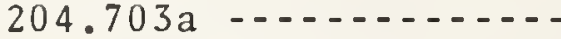

81.00

Mechanics

Acoustic measurements

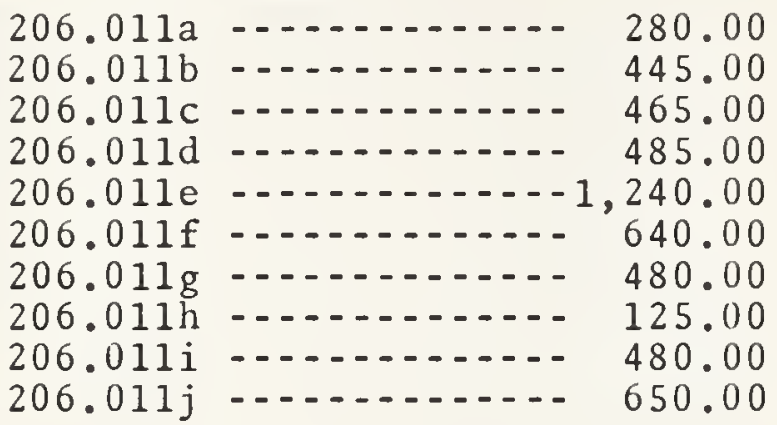

Hardness tests

$206.041 \mathrm{a} \ldots \ldots \ldots+73.00$

Load cells with remote-reading electrical indicators
$206.042 a$
$206.042 \mathrm{~b}$
205.00
$206.042 \mathrm{c}$
$206.042 \mathrm{~d}$
$206.042 \mathrm{e}$
$206.042 \mathrm{f}$
$206.042 \mathrm{~g}$
$206.042 \mathrm{~h}$
$206.042 i$
$206.042 j$
$206.042 \mathrm{k}$

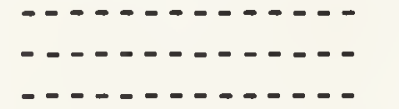
225.00
270.00
230.00
240.00
325.00
425.00
460.00
670.00
590.00
640.00
206.0421
(1)
940.00

Special mechanical tests of devices, materials and structures

$206.043 \mathrm{a}-\ldots .0 .00$

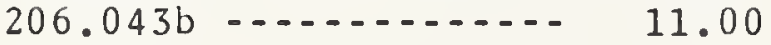

Proving rings

$206.044 \mathrm{a}$

$206.044 \mathrm{~b}$

$206.044 \mathrm{c}$

$206.044 \mathrm{~d}$

$206.044 \mathrm{e}$

$206.044 \mathrm{f}$

$206.044 \mathrm{~g}$

$206.044 \mathrm{~h}$

200.0441

$206.044 j$

$206.044 \mathrm{k}$

206.0441

$206.044 \mathrm{~m}$

$206.044 \mathrm{n}$

206.0440

280.00

445.00

205.00

280.00

400.00

650.00

290.00

455.00

880.00

$1,425.00$

530.00

$206.044 \mathrm{p}$
I tem

Fee

Elastic force measuring devices

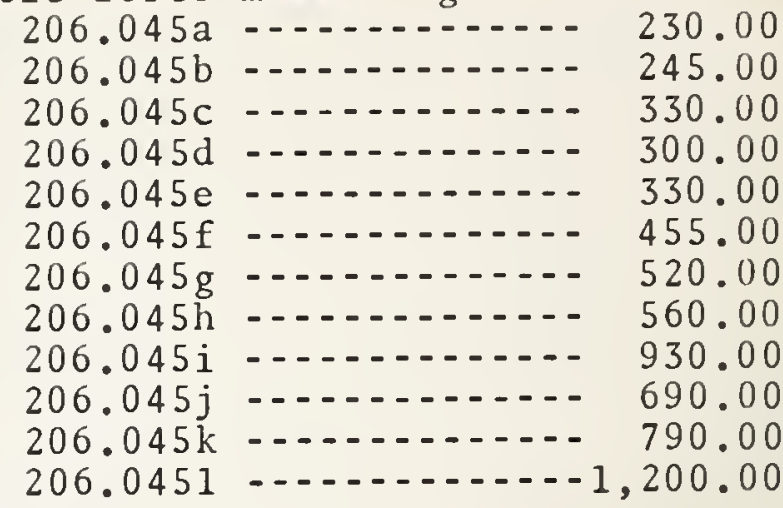

Vibration pickups

$206.231 \mathrm{a}-\ldots .-\ldots-145.00$

$206.231 b$-.......... 200.00

$206.231 \mathrm{c}-\ldots-\ldots-\cdots-580.00$

$206.231 \mathrm{~d}-\ldots-\cdots-\cdots \quad 580.00$

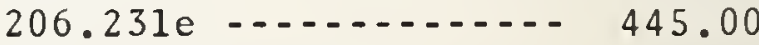

Humidity instruments

$206.241 \mathrm{a}$-............6 660.00

$206.241 \mathrm{~b}-\cdots-\cdots-1,375.00$

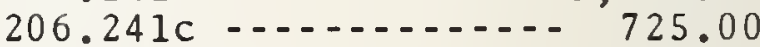

$206.241 \mathrm{~d} \ldots \ldots-\cdots-1,570.00$

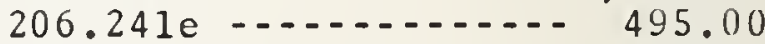

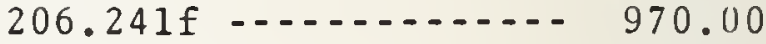

$206.241 \mathrm{~g}-\ldots-\cdots+\cdots 915.00$

$206.241 \mathrm{~h}-\ldots \ldots \ldots-\ldots 1,265.00$

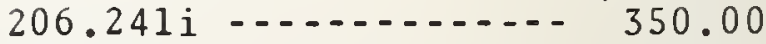

$206.241 \mathrm{j}-\ldots . . .-\ldots . .-165.00$

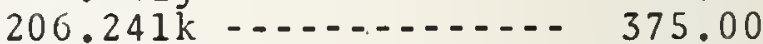

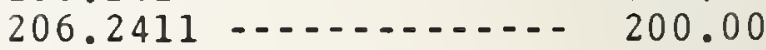

Fluid meters, including gasmeasuring instruments

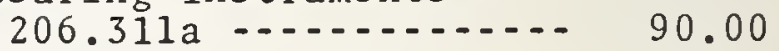

$206.311 b-\cdots-\cdots-\cdots \quad 275.00$

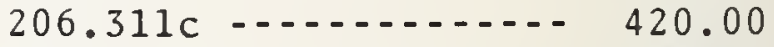

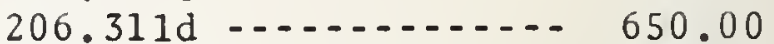

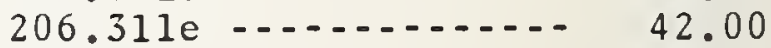

$206.311 \mathrm{f}-\cdots-\cdots+200.00$

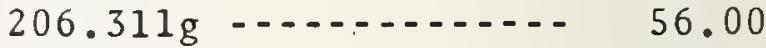

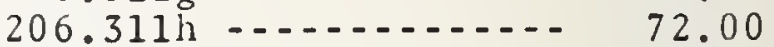

206.311 i - . . . 160.00

$206.311 \mathrm{j}-\ldots-\ldots-\cdots-\cdots \quad 7.00$

$206.311 \mathrm{k} \ldots \ldots \ldots . . \ldots 15.00$

Aerodynamical measurements

206.331 a _............. 170.00

\section{Building Research*}

Thermal conductivity

$210.601 \mathrm{a}$

$210.601 \mathrm{~b} \ldots \ldots \ldots-\ldots 1,750.00$

$210.601 \mathrm{c} \ldots \ldots \ldots \ldots-\ldots 1,225.00$

$210.601 \mathrm{~d} \ldots \ldots \ldots \ldots$

*Changes in the following are still under consideration. 
U. S. Department of Commerce

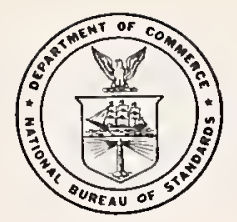

INSERT 14

July 1967

Page 1 of 1

CALILPATION AND TEST SERVICES OF THE

NATIONAL BUREAU OF STANDARLS

Notice of Change to NBS Misc. Pub1. 250, 1965 Edition*

Change 23

Electricity, High-Frequency Region: Insert 14 adds two new iters, $201.822 \mathrm{c}$ and $201.822 \mathrm{~d}$, to Section $201.822--$ Fulse power, peak measurement, coaxial systems. For convenience, the text of the entire section, inciuding the two new items, is given below.

This sheet should be inserted after page 6 of Insert 5 (dated 1 pril 3 , $1267)$, the last over-al1 revision of the services frovided by the NBS Padio Standards Laboratory. The previous version of Section 201.822, on page 7 of Insert 5, should be deleted.

201.822 Pulse power, peak measurement, coaxial systems.

(a) Instruments submitted for calibration should have a nominal impedance of 50 ohms and be fitted with Type $\mathrm{N}, \mathrm{BNC}, \mathrm{HN}$, or precision input connectors. 13

(b) Measurements are made with pulsed rf signals having a rectangular envelope.

\begin{tabular}{|c|c|c|}
\hline ITEM & DESCRIPTION & FEE \\
\hline $201.822 a$ & 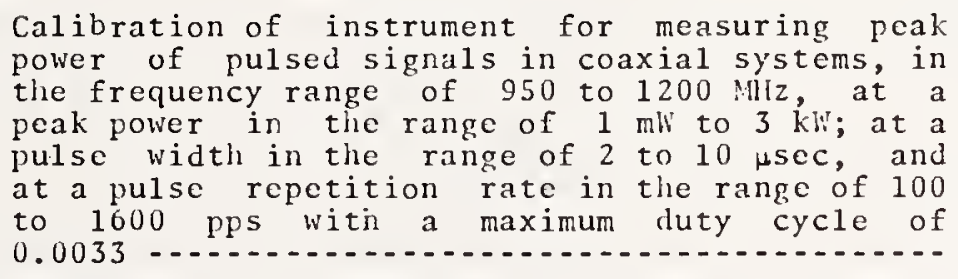 & $(* *)$ \\
\hline $201.822 \mathrm{~b}$ & $\begin{array}{l}\text { Calibration of instrument for measuring peak } \\
\text { power of pulsed signals in coaxial systems at } \\
\text { cach additional peak power level or a different } \\
\text { pulse width or pulse reptition rate, at the } \\
\text { same frequency as for } 201.822 \text { a }\end{array}$ & $(* *)$ \\
\hline $201.822 c$ & $\begin{array}{l}\text { Calibration of instrument for measuring peak } \\
\text { power of pulsed signals in coaxial systems, in } \\
\text { the frequency range of } 300 \text { to } 500 \mathrm{MHz} \text {, at a } \\
\text { peak power in the range of } 1 \text { mli to } 2.5 \mathrm{kll} \text {; at a } \\
\text { pulse width in the range of } 2 \text { to } 10 \mathrm{Hec} \text {, and } \\
\text { at a pulse repetition rate in the range of } 100 \\
\text { to } 1600 \text { pps with a maximum duty factor of } \\
0.0033\end{array}$ & $(* *)$ \\
\hline $201.822 \mathrm{~d}$ & $\begin{array}{l}\text { Calibration of instrument for measuring peak } \\
\text { power of pulsed signals in coaxial systems at } \\
\text { each additional peak power level or a different } \\
\text { pulse width or pulse repetition rate, at the } \\
\text { same frequency as for } 201.822 \text { c }\end{array}$ & $(* *)$ \\
\hline $201.822 z$ & $\begin{array}{l}\text { Special calibrations not covered by the above } \\
\text { schedule }\end{array}$ & $(* *)$ \\
\hline
\end{tabular}

13 see Section 201.800 .

* Changes should be made immediately in your copy of NES Misc. Publ. 250, 1y65 ldition. Additional copies of the insert are available from NBS office of Technical Information and Publications.

**As fixed prices have not been established for these services, charges will be made for actual costs incurred. Upon request, estimates will be furnished for specific tasks which should provide a close approximation of actual costs. Sec also Insert 13, Change 22 . 


\title{
CALIBRATION AND TEST SERVICES OF THE
}

\author{
NATIONAL BUREAU OF STANDARDS
}

Notice of Change to NBS Misc. Pub1. 250, 1965 Edition*

\section{Change 24}

Building kesearch: The services described in Section 210.201, Fire Resistance Tests of Buildinc Haterials, have been discontinued since there is no longer a demand at the National Bureau of Standards for tests of this type. The text of Section 210.201, page 112 of MP 250, 1965 edition, therefore, should be deleted.

\section{Change 25}

Building Research: Section 210.601, Thermal Conductivity, has been revised in two ways: (1) The fee for item $201.601 \mathrm{a}$ is increased from $\$ 150$ to $\$ 160$. The former fee, page 6 of Insert 13 (June 10, 1967) of MP 250, should be deleted and the new fee entered. (2) The fees for the other tests described previously in Section 210.601 are canceled and the text of these items $(210.601 \mathrm{~b}$ through $210.601 \mathrm{~d})$, page 113 of MP 250, 1965 eclition, should be deleted. These tests are now grouped under item $210.601 z$ for which fees are based on the nature of the test and the time required. As vefore, for determination of thermal conductivity of a metal suecimen, the required sample is a cylindrical bar $46.0 \mathrm{~cm}$ long and approximately $2.54 \mathrm{~cm}$ uniform diameter.

Below is given the complete revised text of Part 210, Building Research, which can be inserted after page 112 of MP 250, 1265 edition:

210.601 Thermal Conductivity.

\begin{tabular}{|c|c|c|}
\hline Item & Description & $\mathrm{Fee}$ \\
\hline $210.601 \mathrm{a}$ & 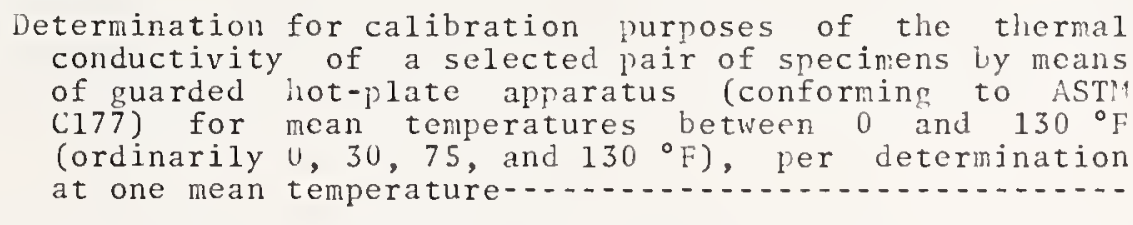 & $\$ 160$ \\
\hline $210.601 z$ & $\begin{array}{l}\text { Determination of thermal conductivity of a metal specimen } \\
\text { for a range of mean temperature from }-150 \text { to } 750{ }^{\circ} \mathrm{C} \text {. } \\
\text { kequired sample is a cylindrical bar } 46.0 \mathrm{~cm} \text { long and } \\
\text { approximately } 2.54 \mathrm{~cm} \text { uniform diameter--... } \\
\text { * Fees have not been fixed for these services. Charges } \\
\text { will ve made for actual costs incurred. Upon request, } \\
\text { estimates will be furnished for specific tasks which } \\
\text { should provide a close approximation of actual cost. }\end{array}$ & $* *$ \\
\hline
\end{tabular}

* Changes should be made immediately in your cony of NBS Misc. Puh1. 250, 1965 Edition. Additional copies of the insert are available from NBS Office of Technical Information and Fublications, Waslington, L. C. 20234. 


\section{Change 26}

lieutron Physics: The fees for the three Neutron physics measurement services have been revised upwards to reflect the increase in cost since 1965 , as follows:

$\begin{array}{cr}\text { Item } & \text { New Fce } \\ 204.701 \mathrm{a} & \$ 560 \\ 204.702 \mathrm{a} & 110 \\ 204.703 \mathrm{a} & 90\end{array}$

The old fees, listed on pages 5 and 6 of MP 250 Insert 13 (June 30, 1967), should be deleted and the new fees entered. 
U. S. Department of Commerce National Bureau of Standards

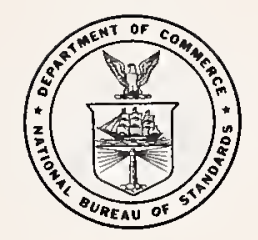

INSERT 16

November 1967

Page 1 of 3

\section{CALIBRATION AND TEST SERVICES OF THE}

National Bureau of Standards

Notice of Change to NBS Misc. Publ. 250, 1965 Edition*

Change 27

Calibration of gamma-, beta-, and alpha-emitting radioactive samples: The revised text of schedules 204.201,204.202, and 204.203 given in this insert supersedes the text of these same schedules as given both in MP 250, pages 93 to 95, and in Insert 4, dated Apri1 3, 1967.

The version of schedules 204.201, 204.202, and 204.203 on pages 93 to 95 of MP 250 therefore should be deleted (if this was not done when Insert 4 was issued); Insert 4 should be discarded; and the present insert should replace Insert 4 after page 92 of MP 250.

Changes also have been made in most of the fees, revising them upward to yield full recovery of the cost of providing the services. The old fees, on page 5 of Insert 13, should be deleted and the new ones written in.

Other changes are: (1) the addition of mercury-197 to the list of samples referred to in items 204.201a(2)iii and 204.202aiii, and (2) the text of the " $z$ " item at the end of each schedule has been reworded.

204.201 Calibration of gamma-emitting radioactive samples.

Calibration of gamma-emitting radioactive samples that conform to the physical, chemical, and activity level specifications for measurement in the National Bureau of Standards' $4 \pi \gamma$-ionization chamber:

\begin{tabular}{|c|c|c|}
\hline Item & Description & Fee \\
\hline $204.201 a$ & 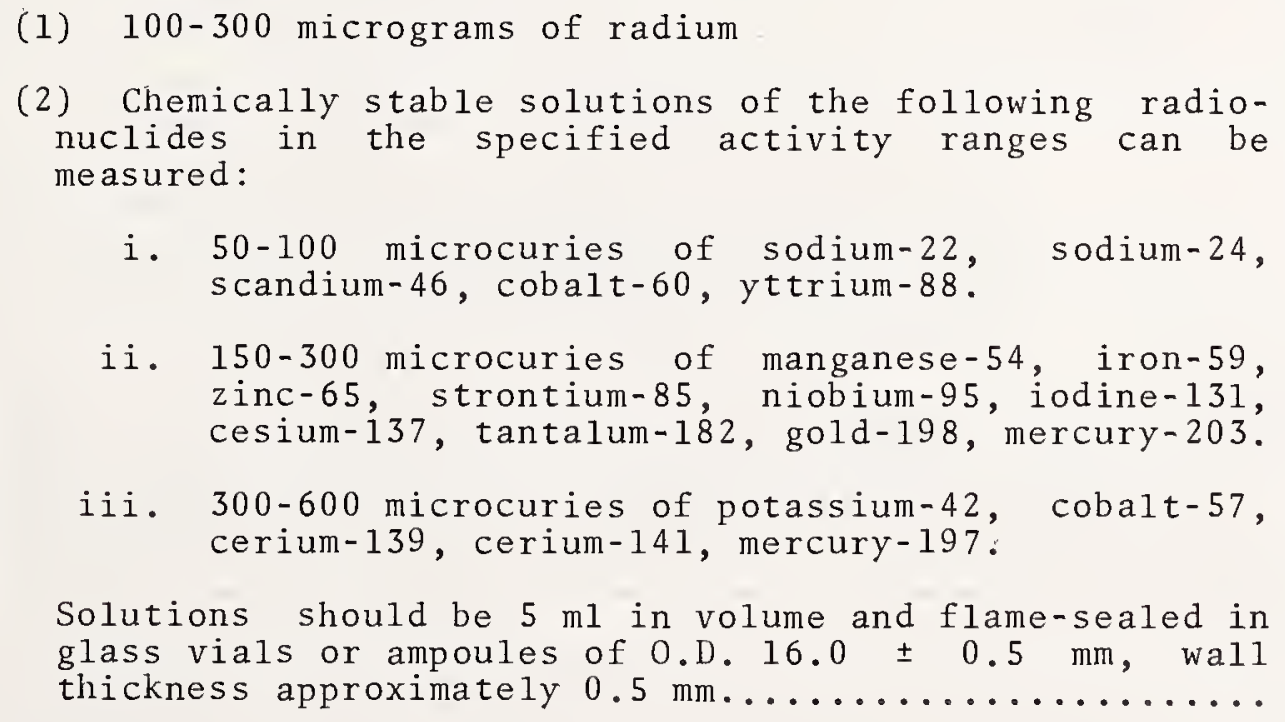 & . \\
\hline
\end{tabular}

* Changes should be made immediately in your copy of NBS Misc. Pub1. 250, 1965 Edition. Additional copies of the insert are available from NBS office of Technical Information and Publications. 


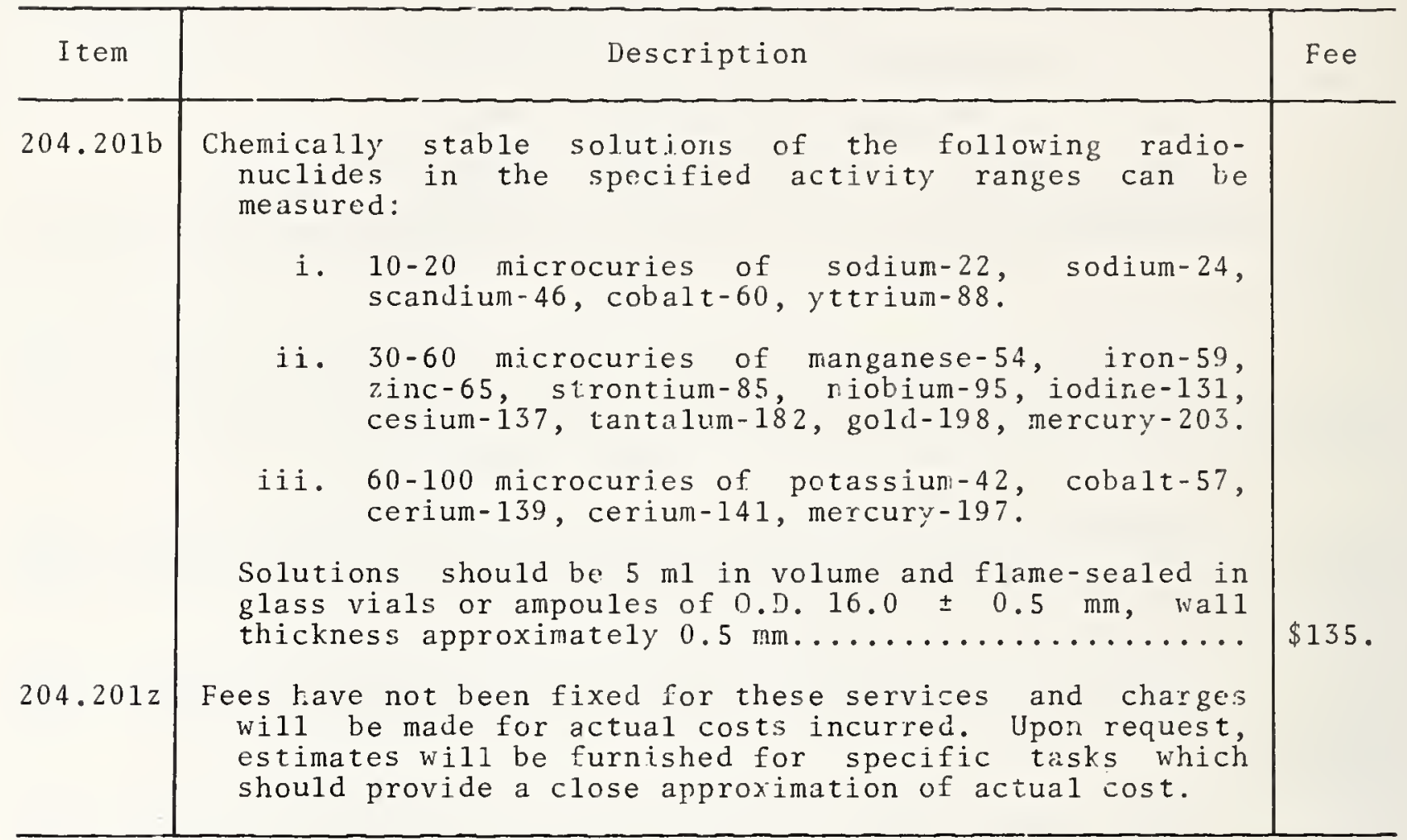

204.202 Calibration of alpha-emission rate of sources.

Calibration of alpha-emitting radioactive sanples that conform to the physical and activity level specifications for measurement in the National Bureau of Standards' $2 \pi \alpha$-proportional counter:

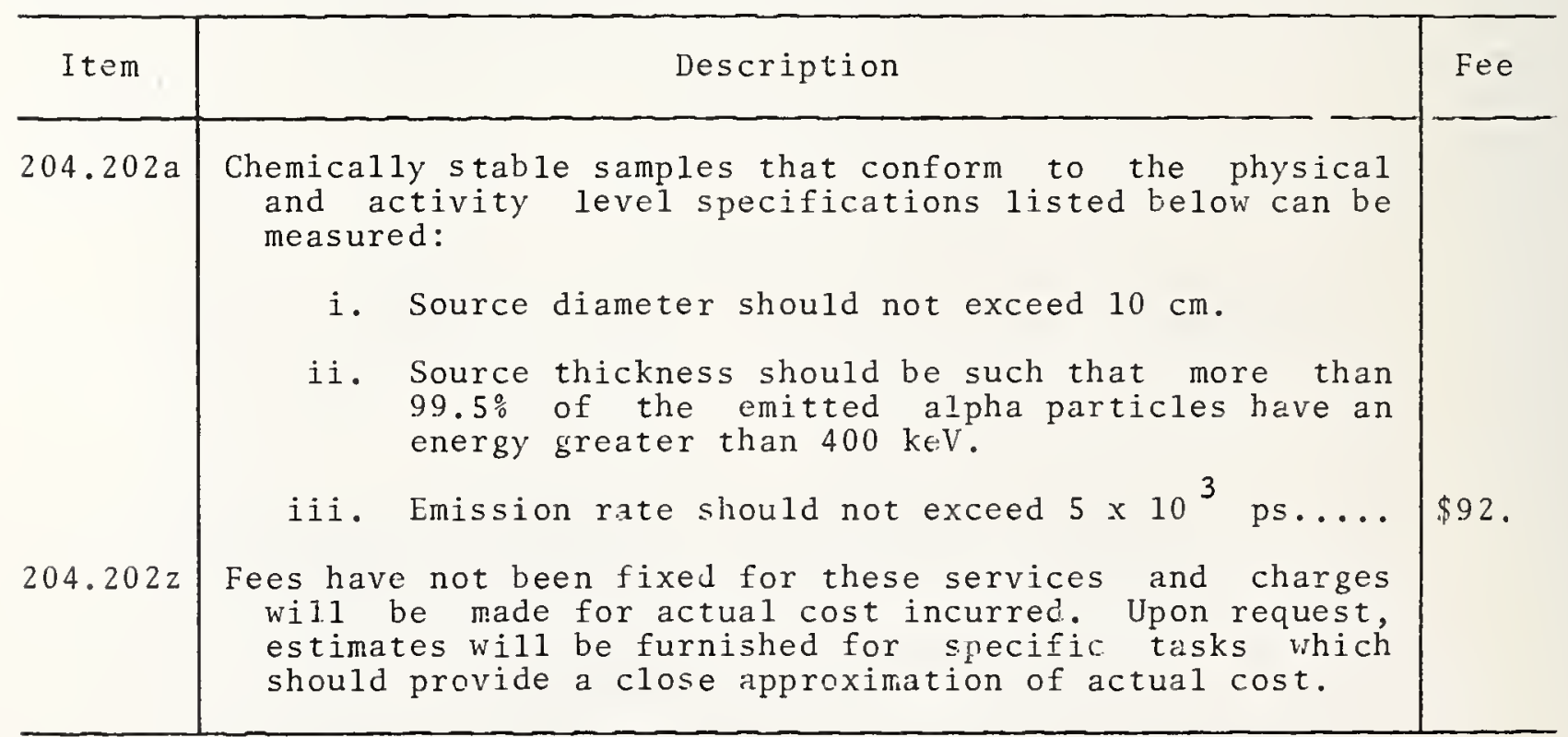


Page 3 of 3 NBS MISC. PUBL. 250, INSERT 16 - Continued November 1967

204.203 Calibration of beta-emitting radioactive samples.

Calibration of beta-emitting radioactive samples that conform to the physical, chemical, and activity level specifications for measurement in either the National Bureau of Standards' $2 \pi \beta$-windowless proportional flow counter or in the Bureau's $2 \pi \beta$ ionization chamber:

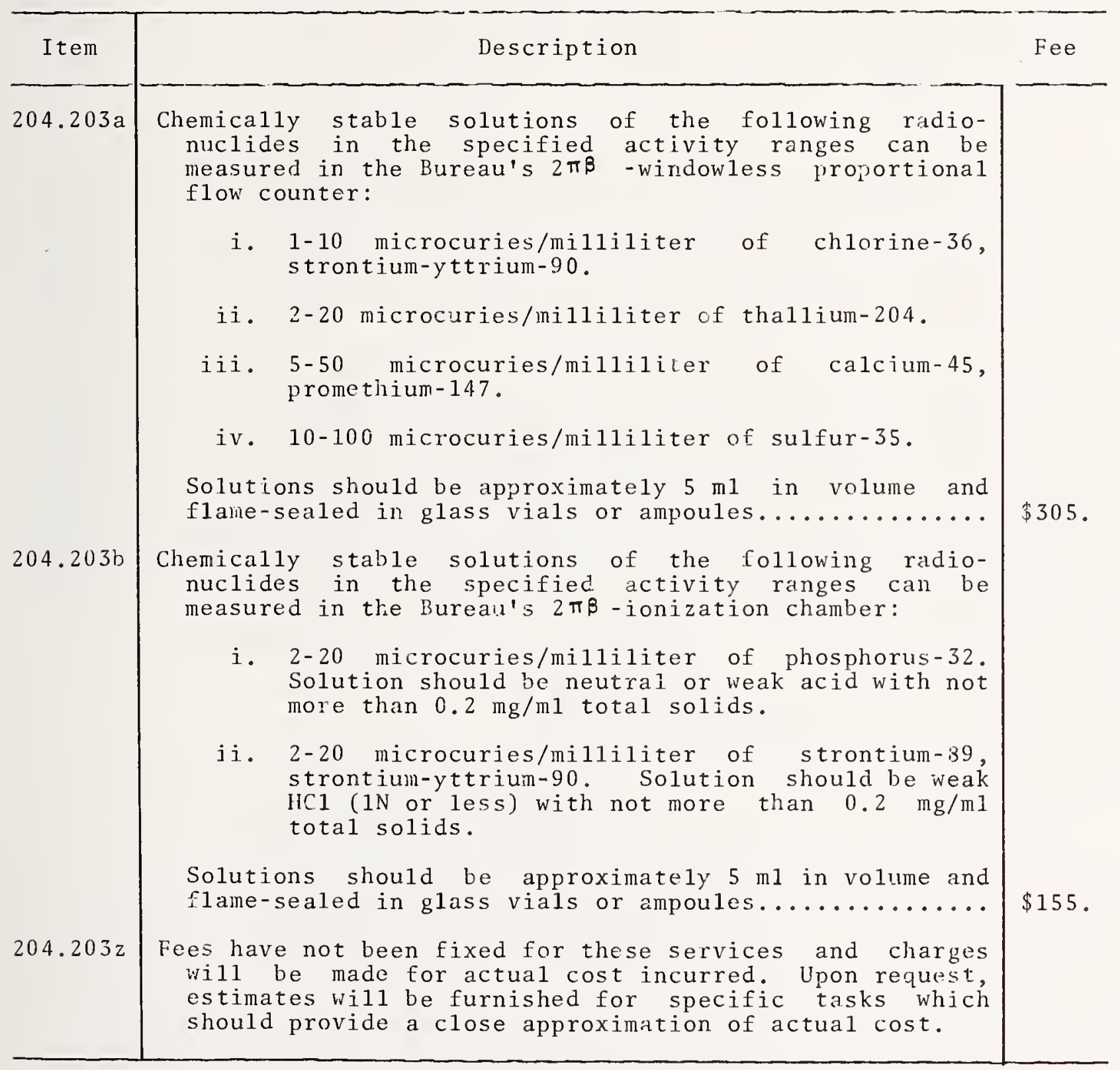




\section{CALIBRATION AND TEST SERVICES OF THE}

NATIONAL BUREAU OF STANDARDS

Notice of Change to NBS Misc. Pub1. 250, 1965 Fdition*

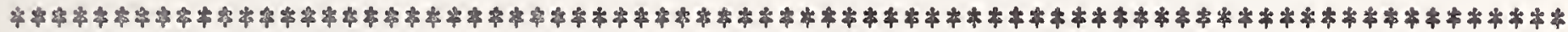

Change 28

Policies, services, procedures, and fees: Insert 17 is a revision of the whole of "Part 200-General," whose title is now changed to "Part 200Policies, Services, Procedures, and Fees." It supersedes Insert 12, dated June 30,1967 , as well as the still earlier version on pages 5 to 10 of MP 250, 1965 Edition. Insert 12 should be discarded and renlaced by the present insert which should be inserted after page 4 of MP 250,1965 Edition.

Attention is called to the first paragraph of the following page and to schedule 200.116 of this insert, which imply that unon publication of this revision of Part 200 in the Federal Register, official announcements concerning the details of NBS measurement services will appear in MP 250 and its supplements (Inserts) rather than in the Federal Register. (In regard to standard reference materials in the program of the NBS Institute for Materials Research, a similar arrangement will be made shortly, with official announcements to be made in :IP 260, "Catalog and Price List of Standard Materials Issued by the National Bureau of Standards.")

The revised text of Part 200 follows:

\section{PART 200-GENERAL}

Sec.

200.100

200.101

200.102

200.103

200.104

200.105

200.106

200.107

200.108

200.109

200.110

200.111

200.112

200.113

200.114

200.115

200.116
Statutory functions.

Measurement research.

Standards for measurement.

Types of calibration and test services.

Consulting and advisory services.

Standard reference materials.

Critically evaluated data.

Publications.

Broadcasts.

Request procedure.

Shipping, insurance, and risk of loss.

Priorities and time of completion.

Witnessing of operations.

Reports.

Use of results or reports.

Fees and bills.

Description of services and list of fees, incorporation by reference.

कChanges should be made immediately in your copy of NBS Misc. Publ. 250 , 1965 Edition. Additional copies of the insert are available from the NBS Office of Technical Information and Publications. 
This revision, effective upon publication in the Federal Register, restates the policies and procedures relating to the National Bureau of Standards' measurement services and incorporates by reference NBS Miscellaneous Publication 250 (MP 250), "Calibration and Test Services of the National Bureau of Standards." MP 250 states NBS policies, describes NBS measurement services in detail, prescribes the procedures for obtaining, such services, and lists the fees charged.

\subsection{Statutory functions.}

(a) The National Bureau of Standards has been assigned the following functions (15 U.S.C. 271-278e):

(1) The custody, maintenance, and development of the national standards of measurement and the provision of means and metlods for making measurements consistent with those standards, including the comparison of standards used in scientific investigations, engineering, manufacturing, commerce, and educational institutions with the standards adopted or recognized by the government.

(2) The determination of physical constants and properties of materials when such data are of great importance to scientific or manufacturing interests and are not to be obtained with sufficient accuracy elsewhere.

(3) The development of methods for testing materials, mechanisms, and structures and the testing of materials, supplies, and equipment, including items purchased for use of government departments and indenendent establishments.

(4) Cooperation with other governmental agencies and with nrivate organizations in the establishment of standard practices, incorporated in codes and specifications.

(5) Advisory service to government agencies on scientific and technical problems.

(6) Invention and development of devices to serve special needs of the Government.

(b) The calibration and testing activities of the Bureau stem from the functions in paragraphs (a)(1) and (3) of this section. These activities are assigned primarily to the NBS Institute for Basic Standards. Its program provides the central basis within the United States for a complete and consistent system of physical measurement; coordinates that system and the measurement systems of other nations; and furnishes essential services leading to accurate and uniform physical measurements throughout the Nation's scientific community, industry, and commerce.

(c) The provision of standard reference materials for sale to the public is assigned to the Office of Standard Reference Materials of the NBS Institute for Materials Research. It evaluates the requirements of science and industry for carefully characterized reference materials, stimulates the Bureau's efforts to develop methods for production of needed reference materials, and directs their production and distribution. For information on standard reference materials, see Subchapter B, Chapter II, Title 15, of the Code of Federal Regulations. 
(d) The provision of technical services to facilitate technical innovation and industrial use of the results of modern science and technology is assigned to the NBS Institute for Applied Technology. The principal elements of the Institute are: (1) a Center for Computer Sciences and Technology which conducts research and provides technical services designed to improve cost effectiveness in the conduct of agency programs through the use of computers and related techniques; technical divisions which provide services in technology of more general applicability; and (3) the Clearinghouse for Federal Scientific and Technical Information which promotes widest effective use by the scientific community, industry, and commerce of current information in all fields of industrial technology.

\subsection{Measurement research.}

(a) The NBS Institute for Basic Standards carries out the Bureau's functions in developing an adequate national system of physical measurement and in providing related calibration services. Its staff continually reviews the advances in science and the trends in technology, examines the measurement potentialities of newly discovered physical phenomena, and uses these to devise and improve standards, measuring devices, and measurement techniques. As new requirements appear, there are continual shifts of program emphasis to meet the most urgent needs for the measurement of additional quantities, extended ranges, or improved accuracies.

(b) The basic research and development activities of NBS are funded primarily by direct appropriations and are aimed at meeting broad general needs. Nlso the Bureau may undertake investigations or developments to meet some specialized physical measurement problem of another government agency, industrial group, or manufacturing firm, using funds supplied by the requesting organization.

\subsection{Standards for measurement.}

(a) An international treaty, the Metric Convention, was signed by 18 countries in 1875. In 1893 the United States established prototyne No. 27 of the international meter bar and prototype No. 20 of the international kilogram as United States Prototype Standards for length and mass. Representatives of many of the 40 nations now adhering to this treaty meet periodically, in the General Conference of Weights and Measures, to consider detailed proposals concerning international standards for physical measurement. Successive Conferences now have agreed to adopt six units to serve as a practical base for an International system of Units (Système International d'Unités, abbreviated SI)-kilogram, meter, second, kelvin, ampere, and candela. These are arbitrarily chosen but precisely defined magnitudes of six physical quantities-mass, length, time, temperature, electric current, and luminous intensity, respectively-which are assigned unitary value in the International System. Because the system is coherent, the expressions for the other quantities of science and technology derived from these six through the equations of physics will have unitary coefficients also. The units of the English system-pound, inch, second, degree Fahrenheit, etc. - and of other systems of units are related to the SI units by agreed-upon conversion factors. 
(b) The SI units for the six quantities are defined as follows:

(1) In terms of a prototype object:

(i) Mass: The kilogram is the mass of a platinum-iridium cylinder preserved at the International Bureau of Weights and Measures in Sèves, France. Prototype No. 20 is kept at NBS; equivalent prototypes are kept by other countries.

\section{(2) In terms of natural phenomena:}

(i) Length: The meter is the length of exactly $1,650,763.73$ wavelengths of radiation in vacuum corresponding to the unperturbed transition between the levels $2 \mathrm{p}_{10}$ and $5 \mathrm{~d}_{5}$ of the atom of krypton 86 , the orange-red line.

(ii) Time interval: The second was long defined as $1 / 86400$ of the time required for an average complete rotation of the earth on its axis with respect to the sun. This, with daily corrections from zenith transits of a star, is the basis for a universal time scale (UT). With further correction for polar motion, it becomes UTl, and with further correction for annual seasonal variations, UT2. Also, the earth's average daily rotation rate has been decreasing, thereby increasing the length of each year by about $6 \mathrm{~ms}$ over the length of the preceding year. Because of this, and other larger random fluctuations, the universal second thus defined is not a constant. Consequently, the 11th Conference (1960) ratified the definition of a second based on ephemeris time (ET): "the fraction $1 / 31,556,925.9747$ of the tropical year for January 0, 1900 at 12 o'clock. ephmeris time." The 12th Conference (1964) authorized the designation of a cesium atom transition as a standard of frequency to be used temporarily for the physical measurement of time. The 13 th Conference (1967) abrogated the 1960 action and decided that: The unit of time of the International System of Units is the second, defined in the following terms: "The second is the duration of $9,192,631,770$ periods of the radiation corresponding to the transition hetween the two hyperfine levels of the fundamental state of the atom of cesium 133."

(iii) Temperature: The kelvin, the unit of thermodynamic temperature, is the fraction $1 / 273.16$ of the thermodynamic temperature of the triple point of water. It was decided by the 13 th Conference that the same name, kelvin, and the symbol $k$ should be used for expressing temperature intervals, dropping the former convention which expressed a temperature interval in degrees Kelvin or as abbreviated, deg $K$. However, the old designations are acceptable temporarily as alternatives to the new ones. One may also express temperature intervals in degrees Celsius.

(iv) Electric current: The ampere is that constant current which if maintained in two straight parallel conductors of infinite length, of negligible circular sections, and placed 1 meter apart in a vacuum, would produce between these conductors a force equal to $2 \times 10^{-7}$ newton per meter of length.

(v) Luminous intensity: The candela is the luminous intensity, in the direction of the normal, of a blackbody surface $1 / 600,000$ square meter in area, at the temperature of solidification of platinum under a pressure of 101,325 newtons per square meter. 
(c) Although the six base units, and others derived from them, are exactly defined, their practical use requires a realization through the development of accurate measurement standards. Measurement standards may be based on physical phenomena, specimen objects, signal sources, or reference instruments. Extensive theoretical studics and laboratory experiments are involved in their sclection, design, construction, and operation.

(d) It will be noted that a kilogram mass standard can be calibrated only through a series of comparisons, starting from the International Prototype. The units for the other five base quantities, and all quantities derived from them, are in principle independently realizable in many laboratories. In practice, however, inevitable minor differences among instruments, environments, and operators are bound to introduce small discrepancies. Periodic comparison of standards and the resolution of these discrepancies is required for compatibility among domestic standards laboratories, as well as internationally.

(e) Within the United States, NBS consults with the major industrial and governmental standards laboratories and cooperates with the Department of Defense and the National Conference of Standards Laboratories in conducting measurement agrement comparisons. Periodic intercomparisons of NBS standards with those of other countries are made through the International Bureau of Weights and licasures, through international scientific organizations, or by direct arrargement. The operations of the International Bureau are supervised by the General Conference of Weights and Measures to which U.S. delegates are appointed by the Department of State.

(f) Frequency and time comparisons within the United States are made by the National Bureau of Standards, the United States Naval Obscrvatory, and other organizations which have an interest in precise time and frequency standards. The data from world-ride astronomical observations and from standards laboratories in many countries arc coordinated by the International Bureau of the Hour, which announces recommended approximations for the rate difference between atomic and universal time, as well as for epoch adjustments.

\subsection{Types of calibration and test services.}

(a) NBS has developed instrumentation and techniques for realizing standards for the six base units of the Intcrnational System of Units as agreed on by the General Conference of Weights and leasures. Reference standards have been established not only for these six base units but also for many derived quantities and their multiples and submultiples. Such reference standards, or equivalent working stankiards, are used to calibrate laboratory and plant standards for other organizations. Accuracy is maintained by stability checks, by comparison with the stardards of other national and international laboratories, and by the exploration of alternative techniques as a means of reducing possible systematic error.

(b) Calibrations for many types of instruments and ranges of physical quantities are described in the itemized service schedules of $M P$ 250. On those services for which fees have been established, the fees also are listed in MP 250. In cases where fees have not been fixed, services will be billed on the basis of actual costs incurred. (See Section 200.116 below for details relating to the description of service items and listing of fees.) Changes in services and fees are announced in supplements to MP 250 and in the monthly NBS Technical News Bulletin.*

For sale by the Superintendent of Documents, U. S. Covernment Printing office, Washington, D.C. 20402 . 
(c) Upon request, special measurements not listed in MP 250 may be made. These might involve unusual physical quantities, upper or lower extremes of range, higher levels of accuracy, fast response specds, short durations, broader ranges of associated parameters, or special environmental conditions. Such inquiries should describe clearly the measurement desired. Indication of the scientific or economic basis for the requirement to be satisfied will be helpful in determining future NBS programs. recs for wor? accepted will lic hased or actual costs incurrei.

(d) The principal emphasis of the National Bureau of Standards is on those calibrations and other tests requiring such accuracy as can be obtained only by direct comparison with its standards. However, in order to maintain efficient utilization of specialized equinment and skilled personnel, when workload permits NBS may calibrate devices requiring lesser accuracy but suitable for working standards in plant or laboratory.

(e) Other services which may be obtainable include:

(1) Tests of measuring instruments to determine compliance with specifications or claims when the evaluation is critical in national scientific or technical operations and when suitable facilities are not available elsewhere.

(2) Referce tests in important cases when clients are unable to agree upon the method of measurement, the results of tests, or the interpretation of these results, but have agreed in advance in writing to accept and abide by the findings of NBS.

(f) NBS reserves the right to decline any request for services if the work would interfere with other activities deemed by the Director to be of greater importance. In general, measurement services are not provided when widely available from commercial laboratories or for organizations or individuals in foreign countries.

(g) Suggestions will be offered on measurement techniques and on other sources of assistance on calibration or measurement problems when the Bureau's own equipment and personnel are unable to undertake the work. The National Conference of Standards Laboratories issues a Directory of Standards Laboratories in the United States which perform calibration work (obtainable from NCSI Secretariat, c/o National Bureau of Standards, Washington, D. C. 20234). Those which perform testing are listed in the ASTM Directory of Testing Laboratories, Commercial and Institutional. (Directory available from the American Society for Testing and Materials, 1916 Race Street, Philadelphia, Pennsylvania 19103.) Similar listings appear in buyer's guides for commercial products and in technical journals concerned with physical measurement.

\subsection{Consulting and advisory services.}

(a) In areas of its special competence, the National Bureau of Standards offers consulting and advisory services on various problems related to measurement, e.g. details of design and construction, operational aspects, unusual or extreme conditions, methods of statistical control of the measurement process, automated acquisition of laboratory data, and data reduction and analysis by computer. Brief consultation may be obtained at no charge; the fee for extended effort will be based on actual costs incurred.

(b) To enhance the competence of standards laboratory personnel, NBS at irregular intervals conducts several group seminars on the precision measurement of specific types of physical quantities, offering the opportunity of laboratory observation and information discussion. $\Lambda$ summer course in electromagnetic measurements and standards is conducted periodically by the NBS Radio Standards Laboratory at Boulder, Colorado. 


\subsection{Standard reference materials.}

Often the performance of a device or structure can be evaluated at the user's laboratory by comparing its response to unknown materials with its response to a standardized specimen or a substance of certified composition, properties, or purity. Types of such specimens are listed in several of the detailed fee schedules in MP 260.* For information regarding carefully characterized materials, see Subchapter $B$ of Chapter II, 15 CFR. The Office of Standard Reference Materials in the NBS Institute for Materials Research administers a program to provide many types of well-characterized materials that are needed to calibrate a measurement system or to produce scientific data that can be readily referred to a common base.

\subsection{Critically evaluated data.}

Data on the physical properties of the thousands of well-defined substances which are commercially available need to be compiled and evaluated to be useful for reference in engineering design. The office of Standard Reference Data in the NBS Institute for Basic Standards provides two-way communication with a number of governmental and non-governmental data centers throughout the country. Its present compilation and dissemination activitics cover seven technical areas-nuclear data, atomic and molecular data, solid state dato, thermodynamic and transport data, chemical kinetics, colloid and surface properties, and mechanical properties. Accounts of progress apnear in the National Standard Reference Data System News (available upon request from the office of Standard Reference Data) and in the monthly NBS Technical News Bulletin.*

\subsection{Publications.}

Changes in services and fees, as published in the supplements to MP 250, appear also in the monthly NBS Technical News Bulletin.* The Bulletin also describes recent results of Bureau staff work, lists currently issued publications and carries sections giving up-to-date detailed information on standards and calibrations, standard reference materials, seminar announcements, conference summaries, and the National Standard Reference Data System. An index to publications by the Bureau authors will be found in Supplements to Miscellaneous Publication 240, Publications of the National Bureau of Standards.* This index covers the publication series of Monographs* and Technical Notes* and includes all papers appearing either in the NBS Journal of Research* or in outside technical journals.

U. S. Government Research and Development Reports, a semi-monthly announcement journal covering over 1000 new documents per issue, is sold by the NBS Clearinghouse for Federal Scientific and Teclinical Information, Springfield, Virginia 22151. Other CFSTI series available on subscription include the USGRDR Index and a Fast Announcement Service which highlights in 57 categories those USGRDR items of particular technological and industrial significance. Any individual item announced is available as photostat or microfiche. 


\subsection{Broadcasts.}

(a) The NBS Radio Standards Laboratory broadcasts various types of standard frequency and time signals as a service from three radio stations: HIVV, WWVH, and WWVB. A fourth station, WWVL, is engaged in an experimental program to evaluate precise time synchronization techniques. NBS Miscellaneous Publication 236, "NBS Standard Frequency and Time Services,"* contains information concerning the broadcasts of such signals from these four stations. WVH is located at Maui, Hawail. MWV, WNVL, and MVD are located at Fort Collins, Colorado. Notices of precisions, accuracies, and adjustments in NBS clocks and radio emissions are published in the Federal Register. Such notices are published also in the Time and Frequency Service Bulletin which is available on request from the NBS Radio Standards Laboratory, Boulder, Colorado 80302.

(b) Broadcasts from Wh are at nominal frequencies of $2.5,5,10$, 15, 20, and $25 \mathrm{MHz}$ and from WHVH at 2.5, 5, 10, and $15 \mathrm{NHH}$. Time pulses superimposed on these carrier frequencies occasionally are adjusted in phase and also as to emission rate (by offsetting the carrier frequency from nominal) in accordance with the Universal Time Coordinated (UTC) system,** as recommended by the Bureau International de 1'Heure (BIH). The carrier offset currently is minus 300 parts in 1010 , giving pulses which occur at intervals slightly longer than one second. With phase adjustment the result approximates UT2 within about $100 \mathrm{~ms}$ and therefore is useful in furnishing information about the earth's position on its axis as used to determine the observer's longitude. WWV and WWII also provide standard musical pitch at 440 hertz, ionosnheric propagation condition forecasts, and geophysical alerts. WWV broadcasts Greenwich Mean Time-seconds, minutes, hours, and days of the year-in the code format of the National Aeronautics and Space Administration. For more precise determination of UT2, both WWV and WWVII broadcast in International Morse Code appropriate corrections based on astronomical data from the U. S. Naval observatory, Washington, D. C.

(c) At MVVL a carrier frequency of $20 \mathrm{kIlz}$ is provided and timeshared with others near $20 \mathrm{kHz}$. Also these carrier frequencies are offset from nominal, hence timing information derived from their nhase is also in conformity with the UTC system. Station WivB broadcasts on the standard radio frequency of $60 \mathrm{l} / \mathrm{Hz}$ without offset, emitting time marker pluses one second apart, as determined by the NBS cesium clock. The phase of these pulses is re-set every few months by $200 \mathrm{~ms}$ adjustments as recommended by the Bureau International de I'Heure in order to approximate UT2 within about $100 \mathrm{~ms}$. This is the coordinated system known as Stepped Atomic Time (SAT) .

(d) The U. S. Naval Observatory (USNO) also broadcasts standard UTC time and time interval (frequency), using both astronomical and atomic data. It coordinates a number of Navy and Coast Guard stations around the globe and also monitors the NBS broadcasts. Both USNO and NBS monitor broadcasts from selected laboratories in foreign countries and issue periodic comparisons of reference signals.

FFor sale by the Superintendent of Documents, U. S. Government Printing office, Washington, D. C. 20402.

**See G. E. Hudson, Some Characteristics of Commonly Used Time Scales, Proceedings, Institute of Electrical and Electronic Engineers, Vo1. 55, No. 6 , pp. $815-821$, June 1967 . 


\subsection{Request procedure.}

(a) A formal purchase order for the calibration or test should be sent before or at the time the instrument or standard is shipped. This should provide clear identification of the apparatus being sulmitted and give separate instructions for return shipment, mailing of renort, and billing. If a customer wishes to minimize the time during which his equipment is out of service, usually he can arrange to delay shipment until the test is scheduled to start (see Section 200.111 below). Requests from Federal agencies, or from state agencies, for calibrations or tests on material to be used on private or Federal contract work, should be accompanied either by purchase order or by letter or document authorizing the cost of the work to be billed to the agency.

(b) The subinission of a purchase order for measurement services under this Subchapter shall be understood as constituting an agreement on the part of the customer to be bound hy the restrictions on the use of results as set forth in Section 200.114 below. Accentance of nurchase orders does not imply acceptance of any provisions set forth in the order contrary to the policy, practice, or regulations of the National Bureau of Standards or the U. S. Covernment. ( 1 statement to the effect $t$ l. nt tie iational iureau of Standards is an agency of the U. S. Government should satisfy other government agencies with regard to compliance with government regulations and executive orders.)

(c) A test number will be assigned by the Bureau to each instrument or group of similar instruments or standards when the order is accepted. This test number should be referred to in all sulisequent communications. Also, each instrument in a group must be uniquely identified, usually by the manufacturer's name and instrument serial number. When the serial number is lacking, an alternative identifying mark should be provided. If none is found, the Burcau will mark the nicce with an NBS identification number. If the apparatus submitted has been calibrated previously by the Bureau, the serial number or identifying mark should be given on the nev: order so that a continuing record of stability history can be established.

(d) Inquiries for measurement services related to electrical standards in the radio-frequency region (above $30 \mathrm{kHz}$ ) or to frequency and time standards should be directed to:

\section{Coordinator, Calibration Services \\ Radio Standards laboratory \\ National Bureau of Standards Boulder, Colorado 80302}

(e) Inquiries for measurement services other than those noted in paragraph (d) of this Section should be directed to the following:

Test Administration Unit

National Bureau of Standards

Washington, D. C. 20234 


\subsection{Shipping, insurance, and risk of loss.}

(a) Shipment of apparatus to NBS for calibration or other test should be made only after the customer has accented the estimate of cost and the tentative scheduling. Repairs and aljustments on apparatus submitted should be attended to by the owner since NBS will not undertake them except by special arrangement. Apparatus not in good condition will not be calibrated. If defects are found after calibration has begun, the effort may be terminated, a report issued summarizing sucl information as has been found, and a fee charged in accordance with the amount of work: done.

(b) The customer should pack apparatus sent to NBS so as to minimize the likelihood of damage in shipment and handling. Suggestions on racking and shipping are made in some sections of $M p 250$. In every case, the sender should consider the nature of the apparatus, pack it accordingly, and clearly label shipments containing fragile instruments or materials such as glass. The use of "security express" should be considered in shipping delicate instruments.

(c) To minimize damage during shipment resulting from inadequare packing, the use of strong reusable containers is recommended. As an aid in preventing loss of such containers, the customer's name should be legibly and permanently marked on the outside. In order to prolong the container's use, the notation REUSABLE CONTAINER, NO NOT DESTROY should be marked on the outside.

(d) Shipping and insurarice coverage instructions should be clearly and legibly shown on the purcilase order for the calibration or test. The customer must pay shipping charges to and from NBS; shipments from NBS will be made collect. The method of return transportation should be stated, and it is recommended that return shipments be insured, since NBS will not assume liability for their loss or damage. For long-distance shipping it is found that air express and air freight provide an advantage in reduction of time in transit. If return shipment by parcel post is requested or is a suitable mode of transportation, shipments will be prepaid by NBS, but without covering insurance. When no shipping or insurance instructions are furnished, return shipment will be made by common carrier collect and uninsured.

(e) NBS will not be responsible for the risk of loss or damage to any item during shipment to or from the Bureau. Any arrangements for insurance covering this risk must be made by the customer. Return shipment will be made by the Bureau as indicated in paragraph (d) of this section. The purchase order should always show the value of the equipment and if transit insurance is carried by the customer this fact should be stated.

(f) The risk of loss or damage in handling or testing of any item by NBS must be assumed by the customer, except when it is determined by the Bureau that such loss or damage was occasioned solely by the negligence of Bureau personnel.

(g) When a test number has been assigned prior to shipment to NBS, this number should be clearly marked on the shipping container. When a test number has not been assigned, an invoice, copy of the purchase order, or letter should be enclosed in the shipment to insure proper identification. The original purchase order should be forwarded as appropriate to: 


\author{
Test Administration Unit \\ National Bureau of Standards \\ Washington, D. C. 20234 \\ or to \\ Coordinator, Calibration Services \\ Radio Standards Laboratory \\ National Bureau of Standards \\ Boulder, Colorado 80302
}

(h) The calibrations listed in $M P$ 250 are performed at these locations: Boulder, Colorado; Gaithersburg, Maryland; and Washington, D.C.

(1) Calibrations of electrical standards and materials in the radio-frequency region (above $30 \mathrm{kHz}$ ) and all frequency and time calibrations are performed at Boulder, Colorado and shipments should be addressed to:

\title{
Coordinator, Calibration Services \\ Radio Standards Laboratory \\ National Bureau of Standards \\ Boulder, Colorado 80302
}

If apparatus for radio frequency is to be given incidental low-frequency calibration also (below $30 \mathrm{kHz}$ ), this may be done at Boulder but if a complete range of low-frequency calibrations are needed, the instrument should be sent to:

National Bureau of Standards

Route $70 \mathrm{~S}$ and Quince Orchard Road

Gaithersburg, Maryland 20760

(2) Calibrations listed in MP 250 other than those noted in paragraph (1) above, of this Section, are performed in the Bureau's laboratories at either Githersburg, Maryland or Washington, D.C. For shipments which are heavy (in excess of 100 lbs.) or bulky (a combined girth in excess of $27 \mathrm{cu}$. $\mathrm{ft.}$ ), request a shipping address from:

\footnotetext{
Test $\Lambda$ dministration Unit

National Bureau of Standards

Washington, I. C. 20234
}

Itens other than heavy or bulky shipments that are sent by common carrier should be addressed to:

National Burcau of Standards

Route $70 S$ and Quince Orchard Road

Gaithersburg, Maryland 20760 


\subsection{Priorities and time of completion.}

Scheduled work assignments for calibrations and other tests generally will be made in the order in which confirmed requests are received. However, government work may be given priority. On the regular services, the workload usually is such that the turn-around interval, between the date a customer's apparatus is received and the date it is prepared for return shipment, will be not more than 45 days. Some types of instruments may require considerably longer, particularly if their abnormal behavior requires re-runs to check reliability. Others can be calibrated and returned within 10 days. Special tests, such as the " $z$ " items 1 isted in "1p 250 require individual scheduling. The customer who can spare his instrument for only a short time usually can arrange by letter or phone call for shipping it to the Bureau just as his assigned starting date approaches. A notice will be sent acknowledging receint of the customer's standard and/or purchase order. If both a confirmed purchase order (or equivalent) and the apparatus have been received, estimates of a completion date and a calibration fee will be sent upon request.

\subsection{Witnessing of operations.}

The Bureau welcomes scientists and engineers who may wish to visit its laboratories and discuss its methods. Ordinarily visitors will not be permitted to witness the actual carrying out of highly precise measurements because their presence introduces distraction that may lead to errors or delays. This policy may be waived in those cases where the visitor can be of service in setting up apparatus of a new or unusual nature, in the case of referee tests, or in other cases in which the legal validity of the result may require the presence of duly authorized witnesses.

\subsection{Reports。}

(a) Results of calibrations and other tests are issued to the customer as formal reports entitled, "National Bureau of Standards Report of Calibration," "National Bureau of Standards Report of Test," or "National Bureau of Standards Report of Analysis," as appropriate. Copies are not supplied to other parties. Whenever formal certification is required by law, or to meet special conditions adjudged by the National Bureau of Standards to warrant it, a letter will be provided certifying. that the particular item was received and calibrated or tested, and identifying the report containing the results.

(b) NBS reports of calibration generally include in sentence form a statement of the uncertainty attached to the numerical values reported. Limits of uncertainty usually comprise (1) an estimate of systematic error, plus (2) a value of imprecision.

(1) Often the systematic error estimate is based on experience or judgment. Sometimes it is an explicit combination of a number of elemental systematic errors. Sometimes the value can be clecked by using two completely different physical phenomena, types of standard, or measurement tecliniques.

(2) Imprecision is preferably expressed as three times the standard deviation of a single determination or three times the standard error of the arithmetic mean of $n$ determinations, either being a canonical value for the measurement process based on considerable recent experience. When extended experience is lacking, the tcrms "computed standard deviation" or "computed standard error" should be used. 
(3) A laboratory using NBS results to estimate the uncertainty attached to its own work may equate its own systematic error to the NBS quoted limit of uncertainty, as a minimum. The imprecision of its own work is best evaluated by calibration records extended over considerable periods of time, with repetition of its specified calibration procedure and assurance that its measurement process is in statistical control. For further information see:

(i) Youden, W. J., Uncertainties in Calibration. IRE Trans., Vol. I-11, Nos. 3 and 4, p. 133 (Dec. 1962).

(ii) Eisenhart, Churchill, Realistic Evaluation of the Precision and Accuracy of Instrument Calibration Systems. NBS $\mathrm{J}$. Res., Vol. 67C, No. 2, p. 161 (April-June 1962).

(iii) Natrella, M. G., Experimental Statistics. NBS llandbook 91 , Ch. 23 (Aug. 1, 1963).

(iv) Wildhack, W. A.; Mlason, H. J..; and Powell, R. C.; Accuracy in Neasurements and Calibrations, 1965. NBS Technical Note No. 262. (Shows the general status of NBS accuracy limits as of June 1965.)

(v) Wildhack, W. A.; Mason, H. L.; and Powers, R. S., Jr.; Accuracy Charts for RF Measurements. Proc. IEEE, Vol. 55, No.6, pp. 1056-1063 (June 1967).

(vi) Eisenhart, Churchill and $\mathrm{Ku}, \mathrm{H}, \mathrm{H}$, , Expression of the Uncertainty of Final Results and a Tabular Guide to Commonly Used Terms and Expressions. In press.

\subsection{Use of results or reports.}

(a) As the national standards laboratory of the United States, NBS maintains and establishes the primary standards from which measurements in science and industry ultimately derive. It is sometimes desirable therefore for manufacturers or users of measurement standards to make appropriate reference to the relationship of their calibrations to NBS calibrations. The following considerations must be borne in mind and shall be understood as constituting an agreement on the part of the NBS customer to be bound thereby in making reference to NBS calibration and test reports.

(b) The results of calibrations and tests performed by NBS are intended solely for the use of the organization requesting them and only apply to a particular device or specimen at the time of its test. The results shall not be used to indicate or imply that they are apnlicable to other similar items. In addition, such results must not be used to indicate or imply that NBS approves, recommends, or endorses the manufacturer, the supplier, or the user of such devices or specimens, or that NBS in any way "guarantees" the later performance of items after calibration or test.

(c) NBS declares it to be in the national interest that the Bureau maintain an impartial position with respect to any commercial product. Advertising the findings on a single instrument could be misinterpreted as an indication of performance of other instruments of identical or similar type. There vill be no objection, however, to a statement by a manufacturer that his primary standards have been periodically calibrated by NBS, if actually this is the case, or that his customer might arrange to have NBS calibrate the item purchased from him. 
(d) NBS does not approve, recommend, or endorse any pronrietary product or proprietary material. No reference shall be made to the Bureau or to reports or results furnished by NBS in any advertising or sales promotion which would indicate or imply that NBS approve's, recommends, or endorses any proprietary product or proprietary material, or which has as its purpose an intent to cause directly or indirectly the advertised product to be used or purchased because of NBS test reports or results.

In its own activities as a scientific institution, the NBS uses many different materials, equipments, and services. This does not imply that it has given them a preferential position or a formal endorsement. Therefore, NBS discourages references, either in advertising or in the scientific litcrature, which identify it as a user of any proprietary product, material, or service. Occasionally, effective communication of results by NBS to the scientific community requires that a proprietary instrument, product, or material be identified in an NDS publication. Such reference to a proprietary item does not constitute endorsement and should not be used in any way apart from the context of the NBS publication without the express written consent of the Bureau.

\subsection{Fees and bills.}

(a) In accordance with 15 U.S.C. 271-278e, fees are charged for al1 measurement services performed by the National Bureau of Standards unless waived by the Director when deemed to be in the interest of the government. The above-mentioned statutes authorize the Secretary of Commerce to make appropriate regulations from time to time regarding the payment of fees, the limits of tolerance on standards submitted for verification, and related matters. See Section 200.116 below for information as to fees.

(b) The minimum fee for any service request accented by the Bureau is $\$ 10$, unless otherwise indicated in MP 250. If an apparatus is returned without testing, a minimum charge of $\$ 10$ may be made to cover handing. Charges commensurate with the work performed will be assessed for calibrations which cannot be completed because of faulty operation of the customer's device. Fees for calibrations or tests include the cost of preparation of an NBS report. All checks should be made payable to $\because B S$, Department of Commerce.

\section{reference. \\ 200.116 Description of services and list of fees, incorporation by}

(a) NBS Miscellaneous Publication 250, "Calibration and Test Services of the National Bureau of Standards," is hereby incorporated by reference, pursuant to 5 U.S.C. 552 (a)(1) and 1 CFP. Part 20 . 1T 250 states the authority under which NBS performs various types of measurement services, including caliurations and tests, and charges fees therefor, states the general conditions under which the public may secure such services, describes these services in considerable detail, lists the fees to be charged, and sets out the instructions for requesting them.

(b) MP 250 is available at the following places:

Superintendent of Documents, Government Printing Office, Washington, D. C. 20402.

(2) Office of Technical Information and Publications, National Bureau of Standards, Washington, D. C. 20234. 
December 1967 NBS MISC. PUBL. 250, INSERT 17 - Continued Page 15 of 15

(3) Field offices of the Office of Field Services, Nepartment of Commerce.

(4) Federal Depository Libraries.

(c) Revisions, amendments, revocations, deletions, recodifications, redesignations, and corrections to MP 250 will be issued from time to time by the National Bureau of Standards, Washington, D.C. in the form of replacement pages or insert sheets; a postcard is provided in MP 250 for requesting copies. NBS will maintain an official historic file of MP 250 and of replacement pages and insert sheets.

(d) Further information concerning policies, procedures, services, and fees may be obtained by writing the Office of Technical Information and Publications, National Bureau of Standards, Washington, D.C. 20234. 
U. S. Department of Commerce

National Bureau of Standards

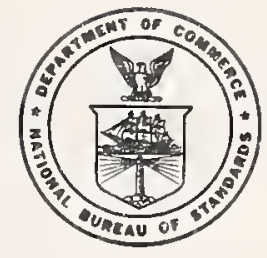

INSERT 18

January 1968

Page 1 of 5

CALIBRATION AND TEST SERVICES OF THE

NATIONAL BUREAU OF STANDARDS

Notice of Change to NBS Misc. Pub1. 250, 1965 Edition*

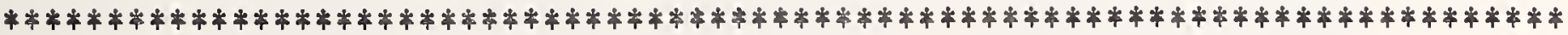

Change 29

$X$ - and gamma-ray instruments: This insert contains revised versions of Schedules 204.501 and 204.502. The old text, appearing on pages 95-99 of MP 250, 1965 edition, should be deleted and the present insert placed after page 94.

Fees have been revised upward to yield full recovery of the cost of providing the services. The old fees, which appear on page 5 of Insert 13 (June 30, 1967), should be deleted and the new fees written in beside them. The other principal changes are the following:

204.501e: The calibration range has been extended upward to 100 roentgens.

204.501g: This is a new item, providing for calibration of guard-ring type chambers.

204.502: The wording of items in this schedule have been modified for greater clarity.

The revised text of Schedules 204.501 and 204.502 follows:

(roentgens).

$204.501 \mathrm{X}$ - and gamma-ray measuring instruments in exposure units

X-ray exposure-indicating instruments are calibrated to within \pm 2 percent by a substitution method in an $x$-ray beam at a point where the exposure rate (R/min) has been determined by means of a standard free-air ionization chamber. In order to provide instrument calibration over a wide spectrum of $x$-ray energies, many combinations of kilovoltage and filtration are available. These are given in the tables below. The calibration technique chosen should be appropriate to the particular instrument submitted. 
Lightly filtered $x$ rays

\begin{tabular}{|c|c|c|c|c|c|c|c|c|c|c|}
\hline \multirow[t]{2}{*}{ Technique } & \multirow[t]{2}{*}{ kvep } & \multirow{2}{*}{$\begin{array}{l}\text { Approx, } \\
\text { inherent } \\
\text { filter }\end{array}$} & \multirow{2}{*}{$\begin{array}{l}\text { Added } \\
\text { filter }\end{array}$} & \multirow{2}{*}{$\begin{array}{l}\text { Dis- } \\
\text { tance }\end{array}$} & \multirow{2}{*}{$\begin{array}{l}\text { Approx. } \\
\text { first half- } \\
\text { value } \\
\text { layer }\end{array}$} & \multirow{2}{*}{$\begin{array}{c}\text { Homogeneity } \\
\text { coefficient } \\
\text { (1st HVL/2d HVL) }\end{array}$} & \multicolumn{2}{|c|}{$\begin{array}{l}\text { Instrument } \\
\text { range from } \\
\text { zero }\end{array}$} & \multicolumn{2}{|c|}{$\underset{\text { rate }}{\text { Exposure }}$} \\
\hline & & & & & & & $\min$. & $\max$. & $\min$ & $\max$. \\
\hline LFB & 10 & $m m B e$ & $m m A l$ & ${ }_{25}$ & $m m A l$ & 0.75 & $\begin{array}{l}R \\
50\end{array}$ & $\begin{array}{c}R \\
500\end{array}$ & $R / \min$ & $R / \min$ \\
\hline LFC $\ldots$ & 15 & 1. 00 & 0 & 25 & 0.035 & 0.62 & 100 & 1000 & 25 & 250 \\
\hline LFD _._ 50 & 20 & 0.25 & 0 & 50 & 0.06 & 0.42 & 100 & 500 & 50 & 200 \\
\hline LFD _._ 70 & 20 & 0.25 & 0 & 70 & 0.07 & $\ldots$ & 50 & 100 & 20 & 80 \\
\hline LFD_._ 100 & 20 & 0.25 & 0 & 100 & 0.08 & -..... & 25 & 50 & 7 & 30 \\
\hline $\mathrm{LFE}_{\ldots} \ldots$ & 20 & 0.25 & 0.5 & 50 & 0.20 & 0.68 & 10 & 100 & 2 & 8 \\
\hline LFG & 30 & 0.25 & 0.5 & 50 & 0.33 & 0.67 & 25 & 250 & 5 & 20 \\
\hline LFI _. & 50 & 0.25 & 1.0 & 50 & $0.9 n$ & 0.68 & 25 & 250 & 6 & 25 \\
\hline LFK & 75 & 0.25 & 1.5 & 50 & 1.6 & 0.66 & 25 & 250 & 10 & 22 \\
\hline LFM & 100 & 0.25 & 2. 0 & 50 & 2.5 & 0.63 & 25 & 250 & 14 & 25 \\
\hline
\end{tabular}

Moderately filtered $x$ rays

\begin{tabular}{|c|c|c|c|c|c|c|c|c|c|c|c|}
\hline \multirow[t]{2}{*}{ Technique } & \multirow[t]{2}{*}{ kvep } & \multirow{2}{*}{$\begin{array}{l}\text { Approx. } \\
\text { inherent } \\
\text { filter }\end{array}$} & \multicolumn{2}{|c|}{ Added filter } & \multicolumn{2}{|c|}{$\begin{array}{l}\text { Approx. first } \\
\text { half-value } \\
\text { layer }\end{array}$} & \multirow{2}{*}{$\begin{array}{c}\text { Homogeneity } \\
\text { coefficient } \\
\text { (1st HVL/2d HVL) }\end{array}$} & \multicolumn{2}{|c|}{$\begin{array}{l}\text { Instrument } \\
\text { range from } \\
\text { zero }\end{array}$} & \multicolumn{2}{|c|}{$\begin{array}{l}\text { Exposure } \\
\text { rate }\end{array}$} \\
\hline & & & $\mathrm{Cu}$ & Al & $\mathrm{Cu}$ & Al & & $\min$. & $\max$. & $\min$. & $\max$ \\
\hline & & $m m A l$ & $m m$ & $m m$ & $m m$ & $m m$ & & $R$ & $R$ & $R / \min$ & $R / \min$ \\
\hline $\mathrm{MFB}_{\ldots} \ldots$ & 60 & 1.5 & 0 & 0 & $\ldots-\ldots$ & 1. 64 & 0.67 & 5 & 100 & 0.4 & 3. 0 \\
\hline $\mathrm{MFC}_{\ldots} \ldots$ & 60 & 1.5 & 0 . & 2. 5 & 0.09 & 2. 7 & 0.77 & 5 & 100 & 0.4 & 2. 5 \\
\hline MFE_...- & 75 & 1.5 & 0 & 2. 5 & 0.11 & 3. $4_{1}$ & $\ldots .73$ & 5 & 100 & 0.4 & 4. 0 \\
\hline $\mathrm{MFG}_{\ldots \ldots}$ & 100 & 1.5 & 0 & 3. 5 & 0.20 & 5. $0_{s}$ & 0.73 & 5 & 100 & 0.9 & 6. 0 \\
\hline MFI _. _.. & 150 & 1.5 & 0.25 & 3. 5 & 0.66 & 10.1 & 0.87 & 5 & 100 & 1. 0 & 8. 0 \\
\hline MFK_.... & 200 & 1.5 & 0.5 & 3. 5 & 1. 2 。 & 13. 2 & 0.92 & 10 & 250 & 2.0 & 13. 0 \\
\hline $\mathrm{MFM}_{----}$ & 250 & 1.5 & 1. 0 & 3.5 & 2. $1_{7}$ & 16. 2 & -0.94 & 10 & 250 & 2.5 & 17. 0 \\
\hline $\mathrm{MFO}_{\ldots} \ldots$ & 250 & 1.5 & 3. 2 & 3. 5 & 3. 20 & 18. 4 & 0.98 & 10 & 250 & 1. 3 & 10.0 \\
\hline
\end{tabular}

Heavily filtered $x$ rays *

\begin{tabular}{|c|c|c|c|c|c|c|c|c|c|c|c|c|c|}
\hline \multirow{3}{*}{$\begin{array}{l}\text { Tech- } \\
\text { nique }\end{array}$} & \multirow{3}{*}{ kvep } & \multirow{3}{*}{$\begin{array}{l}\text { Approx. } \\
\text { inherent } \\
\text { filter }\end{array}$} & \multicolumn{4}{|c|}{ Added filter } & \multicolumn{3}{|c|}{ Approximate } & \multirow{2}{*}{\multicolumn{2}{|c|}{$\begin{array}{l}\text { Instrument } \\
\text { range from } \\
\text { zero }\end{array}$}} & \multirow{2}{*}{\multicolumn{2}{|c|}{$\begin{array}{c}\text { Exposure } \\
\text { rate }\end{array}$}} \\
\hline & & & $\mathrm{Pb}$ & Sn & $\mathrm{Cu}_{3}$ & Al & & HVI & HVI & & & & \\
\hline & & & & & & & & & & $\min$. & $\max$. & min. & $\max$. \\
\hline & & $m m \mathrm{Al}$ & $m m$ & $m m$ & $m m$ & $m m$ & kev & $m m \mathrm{Cu}$ & $m m \mathrm{Al}$ & $R$ & $R$ & $R / \min$ & $R / \min$ \\
\hline HFC . . & 50 & 1. 5 & 0.12 & 0 & 0 & 2. 5 & 40 & 0.16 & 4. 4 & 0.1 & 1 & 0.02 & 0.09 \\
\hline $\mathrm{HFE}_{--}$ & 100 & 1.5 & 0.53 & 0 & 0 & 2.5 & 70 & 0. 72 & 11. 2 & 0.1 & 5 & 0.05 & 0.27 \\
\hline $\mathrm{HFG}_{--}$ & 150 & 1. 5 & 0 & 1. 5 & 4. 0 & 2. 5 & 120 & 2.4 & 16. 8 & 0.1 & 5 & 0.04 & 0.22 \\
\hline HFl.... & 200 & 1. 5 & 0.7 & 4. 0 & 0.6 & 2. 5 & 170 & 4. 1 & 19.5 & C. 1 & 5 & 0.03 & 0.21 \\
\hline HFK & 250 & 1. 5 & 2.7 & 1. 0 & 0.6 & 2.5 & 215 & 5.4 & 21. 5 & 0.1 & 5 & 0.03 & 0.21 \\
\hline
\end{tabular}


204.501a Calibration of one x-ray exposure or exposure-rate indicating instrument of one range for each technique or setup listed under "LIGHTLY FILTERED $X$ RAYS" or "MODERATELY FILTERED X RAYS" ......................

$\$ 68$.

204.501b Calibration of each additional x-ray exposure or exposure-rate indicating instrument of the same range by the same technique as selected under $204.501 \mathrm{a}$ and

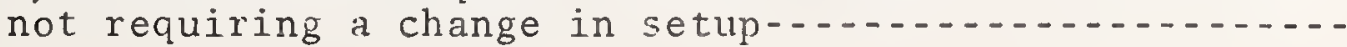

26.

204.501c Calibration of one $x$-ray exposure or exposure-rate indicating instrument for each technique listed under "HEAVILY FILTERED X RAYS" ...........................

87.

204.501d Calibration of each additional x-ray exposure or exposure-rate indicating instrument of the same range by the same technique as selected under 204.501c, not

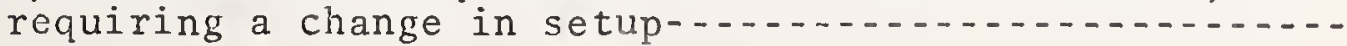

Instrument calibrations for cobalt 60 and cesium 137 gamma radiation are performed by exposure of the instrument to the garma rays at points in the collimated beams which have been calibrated to within about \pm 2 percent by means of carbon wall cavity ionization chambers. The exposure rates at the time of the measurements are computed from the original calibration data and appropriate decay corrections. Ionization chambers submitted for calibration should have sufficient wall thickness for electronic equilibrium for the gamma-ray energy selected.

204.501e Calibration of one instrument for gamma rays when no ster effect is considered:

(1) Exposure-rate indicating instrument for each exposure-rate between 0.01 and $15 \mathrm{R} / \mathrm{min}$; or

(2) Exposure-indicating instruments with full scale

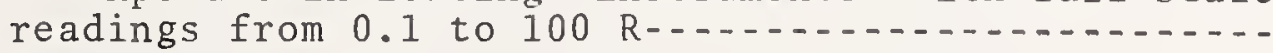

When the chamber must be calibrated with the stem exposed and protected, the fee will be the sum of fees for $204.501 \mathrm{e}$ and $\mathrm{f}$.

204.501f Calibration of each additional instrument having the same exposure or exposure-rate range as under 204.501 e, when the instruments are submitted at the same time, and

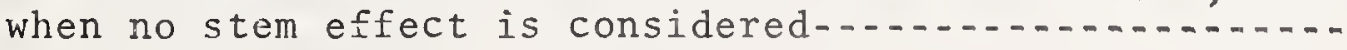

When the chamber must be calibrated with the stem exposed and protected the fee will be the sum of fees for $204.501 e$ and $f$.

Guard-ring type cavity ionization chambers independent of electrometers may be calibrated for $x$ and gamma rays in terms of amperes per roentgen per minute, Calibrations are performed for both positive and negative collection 
potentials. The ratio of ionization currents for fulland half-voltage collection potentials and the exposure rate used in the calibration will be stated.

204.501g Calibration of one guard-ring-type cavity ionization chamber for each x-ray technique or gamma-ray energy

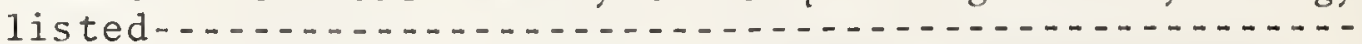

204.501z Calibration of one $x$ - or gamma-ray exposure or exposurerate indicating instrument:

(1) Calibrations of higher accuracy or greater range than that routinely furnished; or

(2) Calibrations on $x$ rays of energies other than those listed under $204.501 \mathrm{a}, \mathrm{c}$, or e; or

(3) Calibrations requiring a special setup or special procedure.

Only a limited number of special calibrations can be undertaken and requests for such should be submitted with full details for consideration. For these and other special measurements not covered by the above schedule, fees have not been fixed and charges will be made for actual costs incurred. Upon request, estimates will be furnished for specific tasks which should provide a close approximation of actual cost.

\subsection{Gamma-ray sources.}

Radioactive preparations submitted to the Bureau for test are subject to the following conditions:

(a) Financial responsibility: The Bureau assumes no responsibility for loss or damage to radioactive preparations while in its possession. The risk should be covered by insurance.

(b) Period of measurement: Approximately 10 days are required for measurement of these radioactive preparations.

(c) Preparation of specimens: Radioactive preparations submitted for test must be sealed carefully so that there can be no escape of any radioactive material, including any gaseous decay products. The preparations, shielding, and packaging must be free of contamination. Contaminated or leaking preparations cannot be measured and may cause considerable loss of time and damage to laboratory facilities. Preparations must have been sealed for a sufficient time to be substantially in radioactive equilibrium with their decay products when these contribute to the gamma emission (at least 30 days for radium).

(d) Packaging for shipment: Regulations of the Interstate Commerce Commission regarding the shipment of radioactive substances by rail must be complied with. These regulations are enforceable by law and prospective shippers of these substances need to be familiar with them. Copies of the regulations can be obtained from the Interstate Commerce Commission, Washington, DC 20423.

(e) Possession of licensed material: In submitting specimens of cobalt 60 or other licensed source material (except radium, which is not 
licensed) for calibration, it will be necessary for the submitter to certify that he is duly authorized to possess the material under license by the USAEC, except in the case of individuals residing in a State which has entered into agreement with the USAEC, in which case State regulations are applicable. This certification may be by letter, by a suitable statement on the purchase order covering the calibration fee, or by a clear copy of the submitter's Possession License for the source material.

\section{(f) Type of measurements:}

(1) Radium is calibrated in terms of milligrams of equivalent radium content measured relative to the National Radium Standard through comparison of the gamma radiation from the specimen and the standard. Where the details of encapsulation of the specimen are known, corrections can be made to obtain milligrams of radium content. Cobalt 60 is calibrated in terms of exposure rate, milliroentgens per hour at one meter, based on comparison with derived standards of cobalt 60 .

(2) Postal regulations prohibit mailing radioactive materials which require a caution label under ICC regulations. This effectively prohibits placing radioactive preparations in the mail.

204.502a Gamma-ray measurement of one radioactive preparation: 0.5 to $15 \mathrm{mg}$ radium or encapsulated cobalt 60 having exposure rates from 0.5 to $15 \mathrm{mRhm}$ (milliroentgens per hour at one meter). Measurement to \pm 0.7 percent for radium and to \pm 3 percent for cobalt $60 \ldots \ldots$

204.502b Gamma-ray measurement of one radioactive preparation: $15+$ to $100 \mathrm{mg}$ radium or encapsulated cobalt 60 having exposure rates from $15+$ to $100 \mathrm{mRhm}$ (milliroentgens per hour at one meter). Measurement to \pm 0.7 percent for radium and to \pm 3 percent for cobalt $60 \ldots$

amma-ray measurement of one radioactive preparation: $100+$ to $250 \mathrm{mg}$ radium or encapsulated cobalt 60 having exposure rates from $100+$ to $200 \mathrm{mRhm}$ (milliroentgens per hour at one meter). Measurement to \pm 0.7 percent for radium and to \pm 3 percent for cobalt $60 \ldots$

$204.502 \mathrm{~d}$ For measurements in groups not exceeding 10 preparations, double the fee for preparations of same content as the total content of the group.

204.502e For handling and examination of a shipment containing contaminated or leaking preparations, the fee will be the same as for measurements of a preparation having a content equal to the total nominal radioactive content of the shipment.

$204.502 z$ For special measurements not covered by the above schedule, fees have not been fixed and charges will be made for actual costs incurred. As only a limited number of special tests can be carried out, prior arrangements must be made, including submission of full details concerning the required test. Upon request, estimates will be furnished for specific tasks which should provide a close approximation of actual cost. 


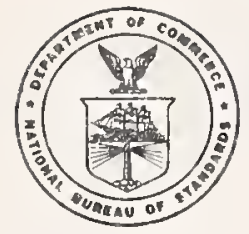

CALIBRATION AND TEST SERVICES OF THE

NATIONAL BUREAU OF STANDARDS

Notice of Change to NBS Misc. Publ. 250, 1965 Edition

Change 30

Electricity, Microwave Region: Several new services, all pertaining to waveguide WR284 (2.60-3.95 GIz), are now offered:

Item 201.920a-6 is added to Section 201.920--Waveguide reflectors (mismatches), reflection coefficient magnitude. The most recent version of this section appear 3 on page 20 of Insert 5 (Apr. 3, 1957), and the following line shonld be written in the space between itens 201.9208-5 and 201.920z-20 of the table there given:

$$
\begin{array}{|l|l|l|l|l}
\hline 201.920 a-6 & \text { WR 284 (2.60-3.95 Giz) } \\
\hline
\end{array}
$$

Three new items are added to Section 201.910, as shown in the rable below. To enter these chanies, the present sheet should be inserted just ahead of page 19 of Insert 5 (Apr. 3, 1967).

Section 201.910 Continuous-wave, low-1evel power measurements of waveguide bolometer units and bolometer-coupler. units.

\begin{tabular}{|c|c|c|}
\hline Item & Description & Fee \\
\hline $201 \cdot 910 a-7$ & $\begin{array}{l}\text { Deteruination of effective efficiency of bolometer unit, } \\
\text { at a single frequency, of the following waveguide size } \\
\text { terninated with a standard waveguide connector: } \\
\text { UR284 (2.60-3.95 Giz)- }\end{array}$ & $(* *)$ \\
\hline $201.910 b-7$ & 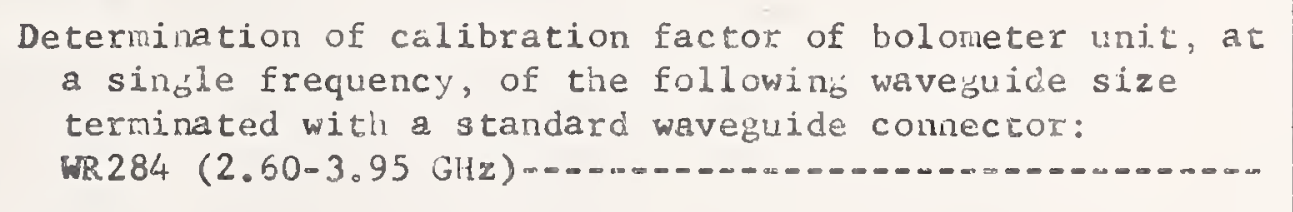 & $(* * *)$ \\
\hline $201.910 c-7$ & $\begin{array}{l}\text { Determination of calibration factor of bolometer-coupler } \\
\text { unit, at a single frequency, of the following wavesuide } \\
\text { size terilinated with a standard waveguide connector: } \\
\text { WR } 284(2.60-3.95 \text { GHa) }\end{array}$ & $(+4)$ \\
\hline
\end{tabular}

* Changes should be made immedistely in your copy of NBS Misc. Publ. 250, 1965 Edition. Additional copies of the inbert are available from office of Technical Information and Publications, National Bureau of Standards, Washington, D. C。20234。 


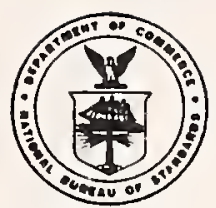

INSET 20

Pebruary 1968

Page 1 of 1

CALIBRATION AND TEST SFRVICES OF TIIE

NATIONAL BUREAU OF STANDARDS

Notice of Change to NBS Misc. Publ. 250, 1965 Edition*

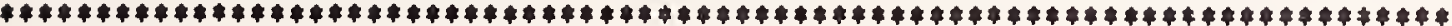

Change 31

Blectrlcity, Mcrowave Region: A series of services for nonreflecting waveguide ports has been added, as described in the new Section 201.921, the complete text of which is given below. To enter this change, the present sheet (Insert 20) should be inserted just ahead of page 21 of Insert 5 (Afc 3, 1.967).

Section 201.921 Nonreflecting waveguide ports (including matched loads), with reflection coefficient magnitude of nearly zero.

(a) Evaluations are made on nonreflecting waveguide ports, including matched loads.

(b) Nonreflecting waveguide ports must be fitted with a standard type of waveguide flange. The face of the flange should be machined flat and smooth and should not contain protusions or indentations. The connecting holes of the flange should be symetrically and accurately aligned to the rectangular waveguide opening. The back of the flange which makes contact with the connecting bolts should be nominally flat and free of soft materials, including paint.

\begin{tabular}{|c|c|c|}
\hline Item & Description & Pee \\
\hline & $\begin{array}{l}\text { Evaluation of nonreflecting waveguide port at a } \\
\text { single frequency of the following waveguide sizes }\end{array}$ & \\
\hline $201.921 a-1$ & WR $90(8.20-12.4 \mathrm{GHz})$ & $(\star \star)$ \\
\hline $201.921 a-2$ & WR62 $(12.4-18.0 \mathrm{GHz})$ & $(\star *)$ \\
\hline $201.921 a-3$ & WR137 (5.85-8.20 GHz) & $(\star \star)$ \\
\hline $201.921 a-4$ & WR112(7.05-10.0 GHz) & $(* \star)$ \\
\hline $201.921 a-5$ & WR187 (3.95-5.85 GHz) & $(* *)$ \\
\hline $201.921 a-6$ & WR284 (2.60-3.95 GHz) & $(* \star)$ \\
\hline $201.9218-20$ & $\begin{array}{l}\text { Evaluation of each additional nonreflecting wave- } \\
\text { guide port at the same frequency as for } \\
201.921 a-1 \text { to } 201.921 a-6\end{array}$ & $(* *)$ \\
\hline \multicolumn{3}{|c|}{$\begin{array}{l}\text { ( } \star *) \text { As fixed prices have not been established for these services, } \\
\text { charges will be made for actual costs incurred. Upon request, estimates } \\
\text { will be furnished for specific tasks which should provide a close approx- } \\
\text { imation of actual costs. }\end{array}$} \\
\hline
\end{tabular}

-Changes should be made immediately in your copy of NBS Misc. Publ. 250, 1965 Edition. Additional copies of the insert are available from NBS office of Technical Information and Publications, Washington, D. C. 20234. 
